\title{
Strategies to activate brown adipose tissue in humans
}

Citation for published version (APA):

Vosselman, M. J. (2015). Strategies to activate brown adipose tissue in humans. [Doctoral Thesis, Maastricht University]. Datawyse / Universitaire Pers Maastricht. https://doi.org/10.26481/dis.20150109mv

Document status and date:

Published: 01/01/2015

DOI:

10.26481/dis.20150109mv

Document Version:

Publisher's PDF, also known as Version of record

\section{Please check the document version of this publication:}

- A submitted manuscript is the version of the article upon submission and before peer-review. There can be important differences between the submitted version and the official published version of record.

People interested in the research are advised to contact the author for the final version of the publication, or visit the DOI to the publisher's website.

- The final author version and the galley proof are versions of the publication after peer review.

- The final published version features the final layout of the paper including the volume, issue and page numbers.

Link to publication

\footnotetext{
General rights rights.

- You may freely distribute the URL identifying the publication in the public portal. please follow below link for the End User Agreement:

www.umlib.nl/taverne-license

Take down policy

If you believe that this document breaches copyright please contact us at:

repository@maastrichtuniversity.nl

providing details and we will investigate your claim.
}

Copyright and moral rights for the publications made accessible in the public portal are retained by the authors and/or other copyright owners and it is a condition of accessing publications that users recognise and abide by the legal requirements associated with these

- Users may download and print one copy of any publication from the public portal for the purpose of private study or research.

- You may not further distribute the material or use it for any profit-making activity or commercial gain

If the publication is distributed under the terms of Article $25 \mathrm{fa}$ of the Dutch Copyright Act, indicated by the "Taverne" license above, 


\section{Strategies to Activate Brown Adipose Tissue in Humans}

MAARTEN VOSSELMAN
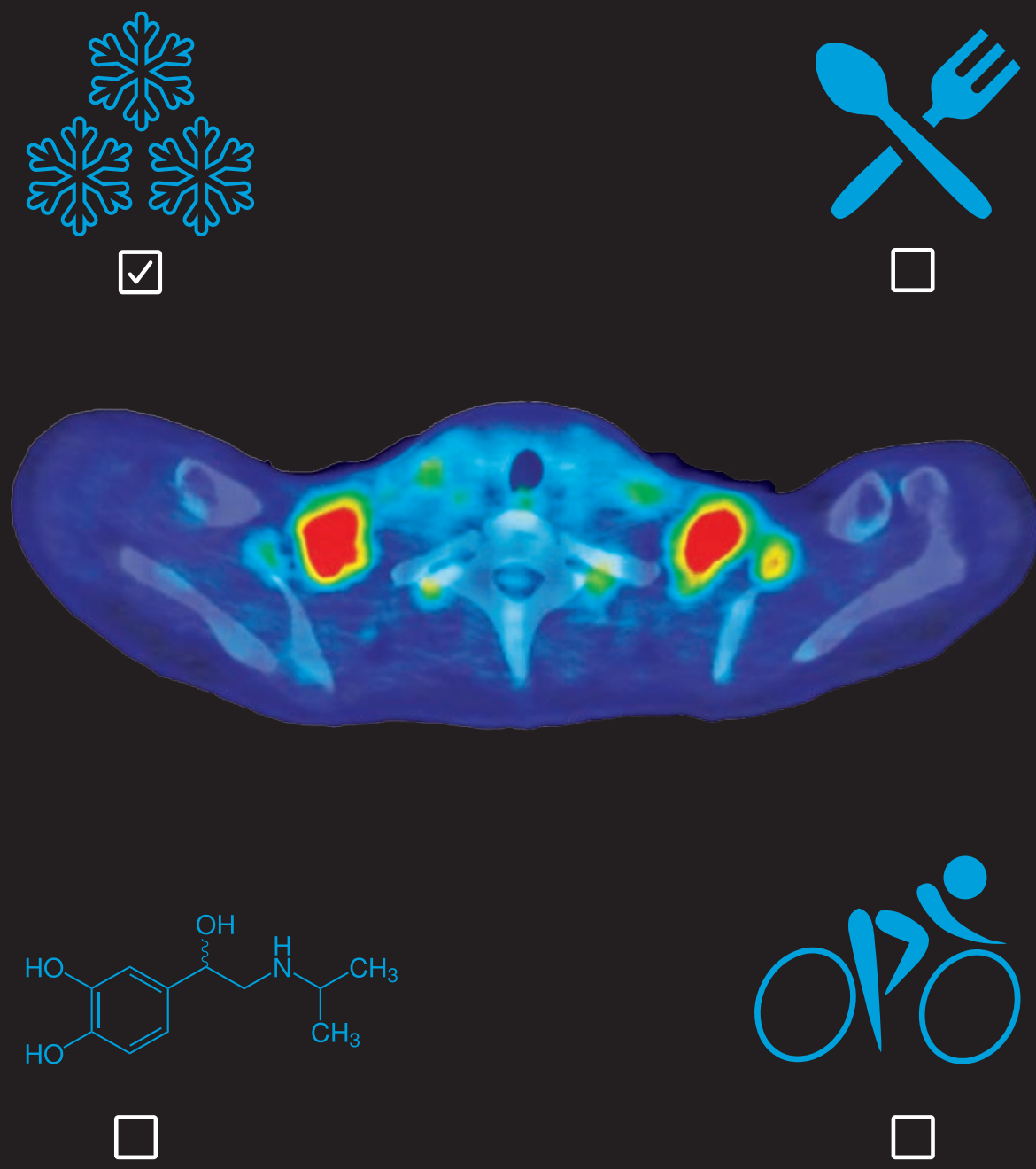


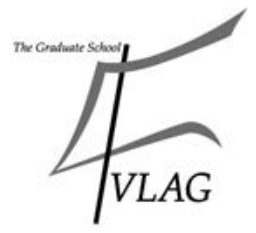

The research presented in this thesis was performed within NUTRIM School for Nutrition, Toxicology and Metabolism which participates in the Graduate School VLAG (Food, Technology, Agrobiotechnology, Nutrition and Health Sciences), accredited by the Royal Netherlands Academy of Arts and Sciences.

Financial support by Perimed $A B$ for the publication of this thesis is gratefully acknowledged.

\section{PERIMED}

(C) Maarten Vosselman, Maastricht 2014

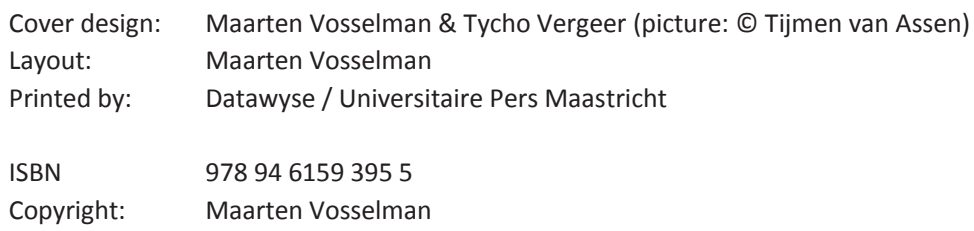




\title{
Strategies to activate brown adipose tissue in humans
}

\author{
PROEFSCHRIFT \\ ter verkrijging van de graad van doctor aan de Universiteit Maastricht, \\ op gezag van de Rector Magnificus, Prof. dr. L.L.G. Soete, \\ volgens het besluit van het College der Decanen, \\ in het openbaar te verdedigen \\ op vrijdag 9 januari 2015 om 10:00 uur \\ door \\ Maarten Johannes Vosselman
}

Geboren op 6 december 1983 te Epe, Nederland

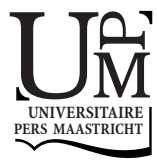




\section{Promotores}

Prof. dr. W.D. van Marken Lichtenbelt

Prof. dr. L.P.A.J. Schrauwen

\section{Beoordelingscommissie}

Prof. dr. M.K.C. Hesselink (voorzitter)

Dr. G. Goossens

Prof. dr. J. Nedergaard (Stockholm University, Zweden)

Prof. dr. P.C.N. Rensen (Leids Universitair Medisch Centrum)

Prof. dr. N.C. Schaper 


\section{Table of Contents}

$\begin{array}{lll}\text { Chapter } 1 & \text { General Introduction } & 7\end{array}$

Chapter 2 Energy dissipation in brown adipose tissue: from mice to men 19

$\begin{array}{lll}\text { Chapter } 3 \text { Brown adipose tissue activity after a high caloric meal in humans } & 37\end{array}$

Chapter 4 Systemic $\beta$-adrenergic stimulation of thermogenesis is not 53 accompanied by brown adipose tissue activity in humans

Chapter 5 Reduced brown adipose tissue activity in endurance trained 73 compared to lean sedentary men

Chapter 6 Frequent extreme cold exposure and brown fat and cold-induced 93 thermogenesis: a study in a monozygotic twin

$\begin{array}{lll}\text { Chapter } 7 & \text { General Discussion } & 111\end{array}$

$\begin{array}{lr}\text { Summary - Samenvatting } & 127\end{array}$

$\begin{array}{ll}\text { Valorisation } & 135\end{array}$

$\begin{array}{ll}\text { Dankwoord } & 141\end{array}$

$\begin{array}{ll}\text { Curriculum Vitae } & 147\end{array}$

$\begin{array}{ll}\text { List of publications } & 151\end{array}$ 

CHAPTER 1

General Introduction 


\section{Obesity}

Obesity prevalence has nearly doubled since 1980, and in 2008 more than 1.4 billion adults were overweight of whom 200 million men and 300 million women were obese. Strikingly, more than 40 million children under the age of five are obese (1). Furthermore, obesity is associated with metabolically related diseases such as type 2 diabetes, cardiovascular diseases, and certain forms of cancer. Therefore, strategies are warranted to counteract this global epidemic. Obesity develops as a consequence of a positive energy balance in which energy intake exceeds energy expenditure. Increasing energy expenditure would thus be beneficial in restoring this energy balance, by inducing weight loss and weight maintenance. One potential way to increase energy expenditure is by activating and recruiting brown adipose tissue (BAT). This type of adipose tissue has the capacity to generate heat, thereby wasting energy instead of storing it like in white adipose tissue (WAT).

\section{History and function of brown adipose tissue}

The first report on BAT already dates from 1551 when the Swiss naturalist Conrad Gessner discovered BAT in marmots and called it "neither fat nor flesh" (2). At the end of the nineteenth and beginning of the twentieth century, BAT was found in many mammals (around 55 species) including humans. During that time, BAT was given several names, such as the 'primitive fat organ', 'fat gland', 'hibernating gland', 'interscapular gland', 'gland-like fat tissue', and for the first time as 'brown fat' by Hammar in 1895 (3). These names already indicated its distinct morphological features compared to WAT.

During the early 1900's, the function of BAT was not known, although it was believed that it was different from WAT given its distinct morphological features. Cramer (1920) hypothesized that BAT was likely an important secreting gland due to its gland like anatomical structure with high vascularization, and connection with the thyroid and adrenal gland (3). Interestingly, Cramer thought that BAT might also be important in maintaining adequate levels of certain vitamins since the fat and lipid content of BAT were exhausted in animals that died due to vitamin free diets. However, it took until the 1960's before the true physiological function of this type of fat tissue became clear: heat production (4).

Since all true hibernators possess BAT it was thought that this organ could be involved in maintaining a stable body temperature and arousal during hibernation. In 1964, Smith \& Roberts showed in rats that BAT activity increased upon cold acclimation (4). Cold acclimation led to increased total BAT mass and concurrent increments in oxygen consumption measured in vitro. From then onwards research in 
the 1960s and 1970s contributed greatly to the understanding of BAT anatomy and physiology and its role in nonshivering thermogenesis (NST), which is the regulated heat production during cold exposure without shivering. However, it took until 1978 when the full thermogenic potential of BAT was realized (5), and the protein responsible for the energy dissipation in the mitochondrion was discovered, called uncoupling protein1 (UCP1) (6). Interestingly, one year later it was demonstrated that BAT might play an important role in diet-induced thermogenesis (DIT), releasing excess energy intake as heat due to an unbalanced diet (7). These findings regained the interest in the role of BAT in humans (Figure 1).

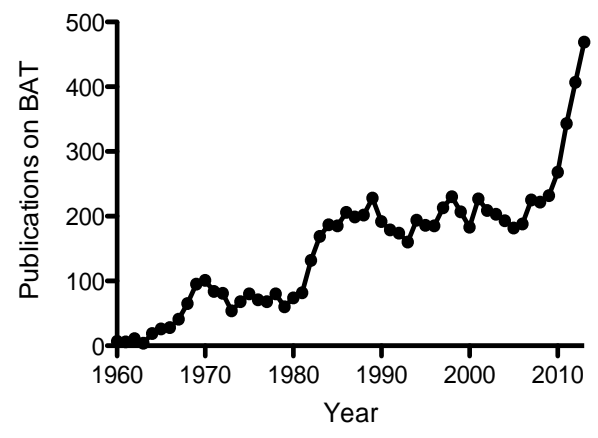

Figure 1. Total publications in PubMed each year on search term: 'brown adipose tissue'. BAT = brown adipose tissue.

\section{Brown adipose tissue in humans}

The observation that humans possess BAT was already done in the late $19^{\text {th }}$ century (8). Anatomical studies in human infants showed that this highly vascularized BAT was located in subpleural tissue, in the axilla, around the kidneys, and between the scapulae, the latter being regarded as a separate anatomical organ ('the interscapular gland'). In adults BAT was mainly found in the neck region, around the clavicle bone, surrounding the trachea and large blood vessels (3). Bonnot (1908) described BAT from a human subject as: "it is pink in colour and lobulated, presenting much the appearance of a fresh pancreas" (8). Furthermore, It was also evident that the amount of BAT diminished soon after birth in humans, whereas this was not true for BAT in rodents and hibernating animals (3).

A more detailed anatomical distribution of BAT was shown in the 1960s and 1970s in infants (9) and adults (10). It was found that the largest sites of BAT were located in the axillary-deep cervical and perirenal depots. Moreover, it was observed that the prominent kite-shaped interscapular site in infants was quantitatively unimportant in human adults. It was also suggested that human BAT had thermogenic capacities based on the histological features of BAT from infants (9) and adult humans (11). Histological analysis showed that BAT cytoplasm was densely packed with 
mitochondria and was highly vascularized, just as in rodents. Interestingly, the Finnish post-mortem survey by Huttunen et al. demonstrated that outdoor workers, exposed to cold, contained BAT whereas indoor workers did not (11). Finally it was shown that mitochondria from human BAT contained UCP1 with comparable biochemical characteristics as from animals (12). However studies that tried to determine the functional capacity of human BAT were somewhat disappointing. Astrup et al. (1985) measured the contribution of perirenal BAT activity during ephedrine administration. BAT thermogenesis was estimated by measuring both temperature, via thermocouples placed deeply in perirenal adipose tissues, and blood flow in perirenal BAT (13). The estimated contribution of BAT to ephedrine-induced thermogenesis was low, and a more important role was given to skeletal muscle. Furthermore, Cunningham et al. (1985) confirmed this minor role by in vitro measurements with human perirenal adipose tissue determining the oxygen uptake capacity. These findings dampened the scientific interest in human BAT.

Twenty years later the role of BAT in human energy metabolism has become a hot topic again. This revived interested was initiated by Nedergaard et al. (14) in 2007, who reviewed several radiology papers that suggested the presence of BAT in cancer patients. These reports showed the uptake of $\left[{ }^{18} \mathrm{~F}\right]$ fluorodeoxyglucose (FDG) in adipose tissue from cancer patients who underwent a clinical positron emission tomography (PET)/computed tomography (CT)-scan. Subsequently, in 2009, three dedicated human studies using $\left[{ }^{18}\right]$ FDG-PET/CT imaging demonstrated that cold exposure increased glucose uptake in fat tissue located in supraclavicular and neck region (15-17). Adipose biopsies from the neck region where $\left[{ }^{18}\right]$ FDG-uptake was found showed the presence of UCP-1, confirming that the tissue was BAT indeed $(16,18)$.

In rodents, brown adipocytes are present in typical BAT depots, such as the interscapular depot, and these cells are known as 'classical' brown adipocytes. However, brown-like fat cells can also appear in typical WAT depots (e.g. inguinal region) upon cold or pharmacological treatment, a process called 'browning'. These cells are named brite (BRown-in-whITE) (19) or beige (20) adipocytes. Gene expression profiling demonstrated that these adipocytes likely originate from a different cell lineage as the classical brown adipocytes (20), although browning of WAT might also occur via transdifferentiation of white adipocytes (21). Both classical brown adipocytes as beige adipocytes have recently been identified in humans by means of gene expression profiling $(22,23)$. Results thus far point towards human BAT having a more 'beige' phenotype $(20,24)$.

This rediscovery of functional human BAT in 2009 has put the tissue on the scientific agenda again as illustrated in Figure 1. Interestingly, several studies have found that BAT activity is inversely correlated with body fat percentage and body mass index suggesting that BAT might be involved in obesity development $(15,17,25,26)$. Given its high metabolic capacity, BAT is seen as a potential target to increase energy 
expenditure and thus as a therapeutic for obesity and its secondary metabolic complications such as type 2 diabetes.

\section{BAT physiology}

The BAT mediated heat production, or thermogenesis, takes place in the mitochondria of the brown adipocyte. The function of the mitochondrion is to convert energy from carbohydrates, fat and proteins into adenosine triphosphate (ATP), which is the energy carrier molecule that can be utilized by all energy requiring processes in the cell. To form ATP, ATP synthase (complex $V$ of the electron transport chain) uses the proton gradient created over the inner mitochondrial membrane by the electron transport chain to generate energy necessary to couple a phosphate to ADP to form ATP. The UCP1 molecule, located in the inner mitochondrial membrane, is capable of uncoupling this process by facilitating the flow of protons back into the mitochondrial matrix thereby preventing ATP production leading to heat production (Figure 2) (27).

The UCP-1 induced thermogenesis (e.g. during cold exposure) is under control of the hypothalamus $(28,29)$. The peripheral signals coming from cold receptors in the skin and core are integrated by the hypothalamus. When thermogenesis is needed, the brain exerts its actions via the sympathetic nervous system (SNS). The SNS stimulates thermogenesis by releasing the neurotransmitter norepinephrine (NE) at the postsynaptic nerve endings triggering the adrenergic receptors $\left(\alpha_{1^{-}}, \alpha_{2^{-}} \beta_{1^{-}}, \beta_{2^{-}}, \beta_{3^{-}}\right.$-ARs $)$ (Figure 2). Furthermore, it stimulates the adrenal medulla to release both epinephrine and NE as hormones. (27). A role for the SNS in regulating BAT activity in humans has been shown in two patients with the Horner's syndrome. In this case study, unilateral sympathetic denervation led to unilateral ${ }^{123}$ I-metaiodobenzylguanidine (MIBG) uptake (30), which reflects the sympathetic activity of the tissue, and unilateral $\left[{ }^{18} \mathrm{~F}\right] \mathrm{FDG}$ uptake (31) in the neck demonstrating that the SNS is involved in mediating BAT glucose uptake. Moreover, human fat biopsies from the neck showed dense SNS innervation (18) and $\beta_{3}-A R$ mRNA (16) in UCP-1 positive cells. In addition, pheochromocytoma patients, who have elevated levels of NE due to a catecholaminesecreting tumour in the adrenal gland, have high rates of $\left[{ }^{18} \mathrm{~F}\right] \mathrm{FDG}$ uptake in BAT in the basal state (32-35), which disappears after tumour resection $(32,35)$. These findings underline the important role for the SNS and the adrenergic receptors in mediating BAT thermogenesis. 


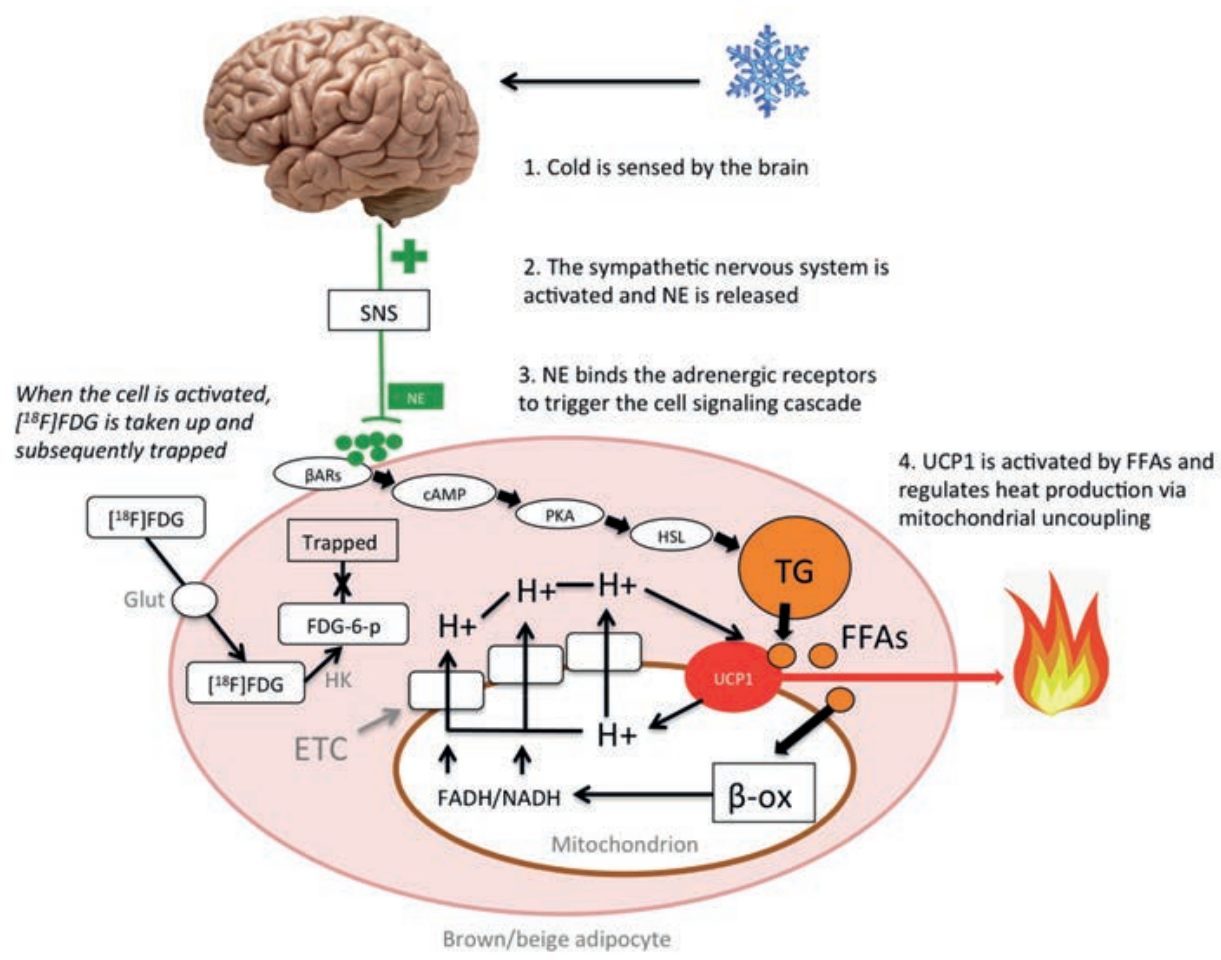

Figure 2. Schematic overview of sympathetic activation of brown/beige adipocytes. Cold exposure is sensed by the cold receptors in the skin and body core, which send the information to the hypothalamus via the sensory nerves. If the stimulus is sufficient, the sympathetic nervous system (SNS) is activated and releases norepinephrine (NE) at the synaptic clefts. Subsequently, NE binds to the adrenergic receptors and activate cyclic adenosine monophosphate (cAMP), which next stimulates protein kinase A (PKA) thereby activating hormone sensitive lipase (HSL). HSL hydrolyzes triglycerides (TG) thereby releasing free fatty acids (FFA) that activate uncoupling protein 1 (UCP1) and also enter the mitochondrion for beta-oxidation ( $\beta$-ox). The NADH and FADH is used for protons $(\mathrm{H}+)$, which are pumped through the protein complexes (white boxes) of the electron transport chain (ETC) thereby forming a proton-motive force that drives the protons back in to the mitochondrion via UCP1. The energy stored in the proton motive force is then released as heat (27). Furthermore, when the cell is activated by the SNS, glucose transporters (glut) take up the glucose tracer $\left[{ }^{18} \mathrm{~F}\right]$ FDG. The tracer is then phosphorylated by hexokinase (HK) to glucose-6-phosphate, which is not further metabolized and trapped in the cell. This is can be detected by the PET-scanner. ARs = adrenergic receptors, $\mathrm{NE}=$ norepinephrine, $\mathrm{SNS}=$ sympathetic nervous system .

\section{The role of BAT in facultative thermogenesis}

It is well established in rodents that BAT plays an important role in NST, as ablation of BAT leads to cold intolerance in these animals (27). In humans, several studies have indicated a relationship between BAT activity and NST $(26,36-38)$. However, the quantitative contribution of BAT to NST is not known. Tracer studies show conflicting results $(36,39)$. Little is known about the role of BAT in DIT. DIT can be divided in an 
obligatory and a facultative part. The obligatory part of energy expenditure is due to the intake and processing of the food (40), whereas the remaining part of DIT is facultative, which likely involves mitochondrial uncoupling, futile cycles and/or ion shuttling across membranes (41). Rothwell \& Stock in 1978 demonstrated that overfeeding rodents with nutrient-poor diets for periods of weeks did lead to less than expected weight gain based on their caloric intake (7). This low metabolic efficiency was accompanied with increased BAT activity. In addition to this adaptive form of DIT, several studies in rats have shown that BAT is activated upon a single meal as well (42$45)$, indicating that it might burn off excessive caloric intake in the postprandial phase. This active role for BAT in DIT and weight regulation is not generally accepted, since in several genetic models of thermogenesis no clear evidence was found for diet-driven thermogenesis (as reviewed in (46)). However, Feldmann et al. did show that UCP1 $1^{-/}$ mice held during thermoneutral conditions developed obesity due to abolished DIT (47).

Overfeeding studies in humans demonstrated a large variation in weight gain (48). For example, the classical paper by Bouchard et al (49) showed that excess energy intake of $353 \mathrm{MJ}$ in 100 days induced a weight gain of 4.3 to $13.3 \mathrm{~kg}$. The energy intake was standardized which suggests that the variation was, in addition to differences in physical activity, was caused by variation in DIT. In 1999, Stock did a reanalysis of twelve human overfeeding studies and showed that overfeeding low protein diets resulted in a lower metabolic efficiency and hypothesized that this was a result of increased DIT (50). Finally, Wijers et al (2007) demonstrated that cold-induced thermogenesis was related to DIT, suggesting comparable underlying mechanisms (51). Whether BAT is involved deserves further investigation.

Altogether these findings suggest that BAT might be relevant in both NST and DIT, with a crucial role for the SNS in mediating these processes. The SNS can be studied by mimicking its activity through stimulation of the adrenergic receptors. Studies in rodents indeed revealed $\beta$-adrenergic stimulated BAT thermogenesis (52). In humans, it has been shown that $\beta$-adrenergic stimulation increases thermogenesis (53), however whether BAT is involved is unknown. In addition to targeting BAT via the SNS, alternative routes have also been demonstrated in rodents. Several endogenous hormones have been demonstrated to stimulate both classical as beige adipocytes (54, 55). One such hormone is irisin. This myokine is released upon endurance exercise and was shown to increase browning in rodents (56). Thus, both targeting the SNS and these alternative routes might increase the metabolic capacity of BAT and thereby increasing energy expenditure in humans. 


\section{Outline of the thesis}

This thesis starts by reviewing the anatomy and physiology of BAT from rodents with humans in chapter 2. In addition, the current known effective and potential BAT simulators in humans are addressed. In chapter $\mathbf{3}$ we studied the role of BAT in DIT by measuring energy expenditure and BAT activity in young adult males upon the intake of a high-calorie, carbohydrate-rich meal. The results were compared with cold, fasting, and thermoneutral conditions. In chapter $\mathbf{4}$ we examined the role of the SNS and the adrenergic receptors in regulating BAT thermogenesis in humans. This was studied in young adult men by measuring energy expenditure and BAT activity during systemic infusion of the non-selective $\beta$-AR-agonist isoprenaline. We compared this to cold-induced BAT activity in the same subjects. Studies in mice have demonstrated that endurance exercise could stimulate BAT and recruit brown/beige adipocytes in WAT via the myokine irisin. We tested this in humans by comparing BAT activity and browning of subcutaneous abdominal WAT of endurance trained athletes and sedentary males (chapter $\mathbf{5}$ ). In chapter $\mathbf{6}$, the effects of chronic exposure to extreme cold on NST and BAT activity was measured in the Dutch 'Iceman', who holds multiple records involving exposure to extreme cold. As a control, we measured his nonacclimatized monozygotic twin brother. In chapter 7, the main findings of this thesis are discussed and are put in a broader perspective. Finally, recommendations for future research on human BAT are addressed as well as the potential of stimulating BAT in humans.

\section{References}

1. Nguyen T, and Lau DC. The obesity epidemic and its impact on hypertension. Can J Cardiol. 2012;28(3):326-33.

2. K. G. Conradi Gesneri medici Tigurine Historiae Animalium Lib. I de Quadripedibus uiuiparis. 1551:842.

3. Cramer W. On Glandular Adipose Tissue, and its Relation to other Endocrine Organs and to the Vitamine Problem. Br J Exp Pathol. 1920;1(4):184-96.

4. Smith RE, and Roberts JC. Thermogenesis of brown adipose tissue in cold-acclimated rats. Am J Physiol. 1964;206(1):143-8.

5. Foster DO, and Frydman ML. Nonshivering thermogenesis in the rat. II. Measurements of blood flow with microspheres point to brown adipose tissue as the dominant site of the calorigenesis induced by noradrenaline. Can J Physiol Pharmacol. 1978;56(1):110-22.

6. Nicholls DG, Bernson VS, and Heaton GM. The identification of the component in the inner membrane of brown adipose tissue mitochondria responsible for regulating energy dissipation. Experientia Suppl. 1978;32:89-93.

7. Rothwell NJ, and Stock MJ. A role for brown adipose tissue in diet-induced thermogenesis. Nature. 1979;281(5726):31-5.

8. Bonnot E. The Interscapular Gland. J Anat Physiol. 1908;43(Pt 1):43-58.

9. Aherne W, and Hull D. Brown adipose tissue and heat production in the newborn infant. J Pathol Bacteriol. 1966;91(1):223-34. 
10. Heaton J. The distribution of brown adipose tissue in the human. J Anat. 1972;112(Pt 1):35-9.

11. Huttunen P, Hirvonen J, and Kinnula V. The occurrence of brown adipose tissue in outdoor workers. Eur J Appl Physiol Occup Physiol. 1981;46(4):339-45.

12. Lean $M E$, James $W P$, Jennings $G$, and Trayhurn P. Brown adipose tissue uncoupling protein content in human infants, children and adults. Clin Sci (Lond). 1986;71(3):291-7.

13. Astrup A, Bulow J, Madsen J, and Christensen NJ. Contribution of BAT and skeletal muscle to thermogenesis induced by ephedrine in man. Am J Physiol. 1985;248(5 Pt 1):E507-15.

14. Nedergaard J, Bengtsson T, and Cannon B. Unexpected evidence for active brown adipose tissue in adult humans. Am J Physiol Endocrinol Metab. 2007;293(2):E444-52.

15. van Marken Lichtenbelt WD, Vanhommerig JW, Smulders NM, Drossaerts JM, Kemerink GJ, Bouvy ND, Schrauwen $\mathrm{P}$, and Teule GJ. Cold-activated brown adipose tissue in healthy men. $N$ Engl J Med. 2009;360(15):1500-8.

16. Virtanen KA, Lidell ME, Orava J, Heglind M, Westergren R, Niemi T, Taittonen M, Laine J, Savisto NJ, Enerback S, et al. Functional brown adipose tissue in healthy adults. N Engl J Med. 2009;360(15):151825.

17. Saito M, Okamatsu-Ogura Y, Matsushita M, Watanabe K, Yoneshiro T, Nio-Kobayashi J, Iwanaga T, Miyagawa M, Kameya T, Nakada K, et al. High incidence of metabolically active brown adipose tissue in healthy adult humans: effects of cold exposure and adiposity. Diabetes. 2009;58(7):1526-31.

18. Zingaretti MC, Crosta F, Vitali A, Guerrieri M, Frontini A, Cannon B, Nedergaard J, and Cinti S. The presence of UCP1 demonstrates that metabolically active adipose tissue in the neck of adult humans truly represents brown adipose tissue. Faseb J. 2009;23(9):3113-20.

19. Petrovic N, Walden TB, Shabalina IG, Timmons JA, Cannon B, and Nedergaard J. Chronic peroxisome proliferator-activated receptor gamma (PPARgamma) activation of epididymally derived white adipocyte cultures reveals a population of thermogenically competent, UCP1-containing adipocytes molecularly distinct from classic brown adipocytes. J Biol Chem. 2010;285(10):7153-64.

20. Wu J, Bostrom P, Sparks LM, Ye L, Choi JH, Giang AH, Khandekar M, Virtanen KA, Nuutila P, Schaart G, et al. Beige adipocytes are a distinct type of thermogenic fat cell in mouse and human. Cell. 2012;150(2):366-76.

21. Cinti S. Adipocyte differentiation and transdifferentiation: plasticity of the adipose organ. J Endocrinol invest. 2002;25(10):823-35.

22. Cypess AM, White AP, Vernochet C, Schulz TJ, Xue R, Sass CA, Huang TL, Roberts-Toler C, Weiner LS, Sze $C$, et al. Anatomical localization, gene expression profiling and functional characterization of adult human neck brown fat. Nat Med. 2013;19(5):635-9.

23. Lidell ME, Betz MJ, Dahlqvist Leinhard O, Heglind M, Elander L, Slawik M, Mussack T, Nilsson D, Romu T, Nuutila P, et al. Evidence for two types of brown adipose tissue in humans. Nat Med. 2013;19(5):631-4.

24. Sharp L, Shinoda K, Ohno H, Scheel D, Tomoda E, Ruiz L, Hu H, Wang L, Pavlova Z, Gilsanz V, et al. Human BAT Possesses Molecular Signatures That Resemble Beige/Brite Cells. PLoS One. 2012;7(11).

25. Cypess AM, Lehman S, Williams G, Tal I, Rodman D, Goldfine AB, Kuo FC, Palmer EL, Tseng YH, Doria A, et al. Identification and importance of brown adipose tissue in adult humans. $N$ Engl J Med. 2009;360(15):1509-17.

26. Vijgen GH, Bouvy ND, Teule GJ, Brans B, Schrauwen P, and van Marken Lichtenbelt WD. Brown adipose tissue in morbidly obese subjects. PLoS One. 2011;6(2):e17247.

27. Cannon B, and Nedergaard J. Brown adipose tissue: function and physiological significance. Physiol Rev. 2004;84(1):277-359.

28. Bartness TJ, Vaughan $\mathrm{CH}$, and Song CK. Sympathetic and sensory innervation of brown adipose tissue. Int J Obes (Lond). 2010;34 Suppl 1(S36-42.

29. Morrison SF, Madden CJ, and Tupone D. Central control of brown adipose tissue thermogenesis. Front Endocrinol (Lausanne). 2012;3(5).

30. Gelfand M. 123I-MIBG uptake in the neck and shoulders of a neuroblastoma patient: damage to sympathetic innervation blocks uptake in brown adipose tissue. Pediatric radiology. 2004;34(7):577-9. 


\section{GENERAL INTRODUCTION}

31. Lebron L, Chou A, and Carrasquillo J. Interesting image. Unilateral F-18 FDG uptake in the neck, in patients with sympathetic denervation. Clin Nucl Med. 2010;35(11):899-901.

32. Hadi M, Chen C, Whatley M, Pacak K, and Carrasquillo J. Brown fat imaging with (18)F-6-fluorodopamine PET/CT, (18)F-FDG PET/CT, and (123)I-MIBG SPECT: a study of patients being evaluated for pheochromocytoma. J Nucl Med. 2007;48(7):1077-83.

33. Joshi $P$, and Lele V. Unexpected Visitor on FDG PET/CT-Brown Adipose Tissue (BAT) in Mesentery in a Case of Retroperitoneal Extra-Adrenal Pheochromocytoma: Is the BAT Activation Secondary to Catecholamine-Secreting Pheochromocytoma? Clin Nucl Med. 2012;37(5):20.

34. Kuji I, Imabayashi E, Minagawa A, Matsuda H, and Miyauchi T. Brown adipose tissue demonstrating intense FDG uptake in a patient with mediastinal pheochromocytoma. Ann Nucl Med. 2008;22(3):231-5.

35. Yamaga L, Thom A, Wagner J, Baroni R, Hidal J, and Funari M. The effect of catecholamines on the glucose uptake in brown adipose tissue demonstrated by (18)F-FDG PET/CT in a patient with adrenal pheochromocytoma. Eur J Nucl Med Mol Imaging. 2008;35(2):446-7.

36. Ouellet V, Labbe SM, Blondin DP, Phoenix S, Guerin B, Haman F, Turcotte EE, Richard D, and Carpentier AC. Brown adipose tissue oxidative metabolism contributes to energy expenditure during acute cold exposure in humans. J Clin Invest. 2012;122(2):545-52.

37. Orava J, Nuutila P, Lidell ME, Oikonen V, Noponen T, Viljanen T, Scheinin M, Taittonen M, Niemi T, Enerback $S$, et al. Different metabolic responses of human brown adipose tissue to activation by cold and insulin. Cell Metab. 2011;14(2):272-9.

38. Yoneshiro T, Aita S, Matsushita M, Kameya T, Nakada K, Kawai Y, and Saito M. Brown adipose tissue, whole-body energy expenditure, and thermogenesis in healthy adult men. Obesity (Silver Spring). 2011;19(1):13-6.

39. Muzik O, Mangner TJ, and Granneman JG. Assessment of oxidative metabolism in brown fat using PET imaging. Front Endocrinol (Lausanne). 2012;3:15.

40. van Baak MA. Meal-induced activation of the sympathetic nervous system and its cardiovascular and thermogenic effects in man. Physiol Behav. 2008;94(2):178-86.

41. Sims EA, and Danforth E, Jr. Expenditure and storage of energy in man. J Clin Invest. 1987;79(4):1019-25.

42. Glick Z, Teague RJ, and Bray GA. Brown adipose tissue: thermic response increased by a single low protein, high carbohydrate meal. Science. 1981;213(4512):1125-7.

43. Glick Z, Teague RJ, Bray GA, and Lee M. Compositional and metabolic changes in brown adipose tissue following a single test meal. Metabolism. 1983;32(12):1146-50.

44. Glick Z, Bray GA, and Teague RJ. Effect of prandial glucose on brown fat thermogenesis in rats: possible implications for dietary obesity. J Nutr. 1984;114(2):286-91.

45. Glick Z, Wickler SJ, Stern JS, and Horwitz BA. Regional blood flow in rats after a single low-protein, highcarbohydrate test meal. Am J Physiol. 1984;247(1 Pt 2):R160-6.

46. Kozak LP. Brown fat and the myth of diet-induced thermogenesis. Cell Metab. 2010;11(4):263-7.

47. Feldmann HM, Golozoubova V, Cannon B, and Nedergaard J. UCP1 ablation induces obesity and abolishes diet-induced thermogenesis in mice exempt from thermal stress by living at thermoneutrality. Cell Metab. 2009;9(2):203-9.

48. Wijers SL, Saris WH, and van Marken Lichtenbelt WD. Recent advances in adaptive thermogenesis: potential implications for the treatment of obesity. Obes Rev. 2009;10(2):218-26.

49. Bouchard C, Tremblay A, Despres JP, Nadeau A, Lupien PJ, Theriault G, Dussault J, Moorjani S, Pinault S, and Fournier G. The response to long-term overfeeding in identical twins. $N$ Engl J Med. 1990;322(21):1477-82.

50. Stock MJ. Gluttony and thermogenesis revisited. Int J Obes Relat Metab Disord. 1999;23(11):1105-17.

51. Wijers SL, Saris WH, and van Marken Lichtenbelt WD. Individual thermogenic responses to mild cold and overfeeding are closely related. J Clin Endocrinol Metab. 2007;92(11):4299-305.

52. Collins S. beta-Adrenoceptor Signaling Networks in Adipocytes for Recruiting Stored Fat and Energy Expenditure. Front Endocrinol (Lausanne). 2011;2:102.

53. Schiffelers SL, Saris WH, Boomsma F, and van Baak MA. beta(1)- and beta(2)-Adrenoceptor-mediated thermogenesis and lipid utilization in obese and lean men. J Clin Endocrinol Metab. 2001;86(5):2191-9. 
54. Whittle A. Searching for ways to switch on brown fat: are we getting warmer? J Mol Endocrinol. 2012;49(2):87.

55. Broeders E, Bouvy N, and van Marken Lichtenbelt W. Endogenous ways to stimulate brown adipose tissue in humans. Ann Med. 2014.

56. Boström P, Wu J, Jedrychowski M, Korde A, Ye L, Lo J, Rasbach K, Boström E, Choi J, Long J, et al. A PGC1$\alpha$-dependent myokine that drives brown-fat-like development of white fat and thermogenesis. Nature. 2012;481(7382):463-8. 



\section{CHAPTER 2}

\section{Energy dissipation in brown adipose tissue: From mice to men}

The contents of this chapter are published in Maarten J. Vosselman, Wouter D. van Marken Lichtenbelt, Patrick Schrauwen. Energy dissipation in brown adipose tissue: From mice to men. Molecular and Cellular Endocrinology 379:43-50, 2013. 


\begin{abstract}
In rodents, brown adipose tissue (BAT) is a metabolic organ that produces heat in response to cold and dietary intake through mitochondrial uncoupling. For long time, BAT was considered to be solely important in small mammals and infants, however recent studies have shown that BAT is also functional in adult humans. Interestingly, the presence and/or functionality of this thermogenic tissue is diminished in obese people, suggesting a link between human BAT and body weight regulation. In the last years, evidence has also emerged for the existence of adipocytes that may have an intermediate thermogenic phenotype between white and brown adipocytes, so called brite or beige adipocytes. Together, these findings have resulted in a renewed interested in (human) brown adipose tissue and pathways to increase the activity and recruitment of these thermogenic cells. Stimulating BAT hypertrophy and hyperplasia in humans could be a potential strategy to target obesity. Here we will review suggested pathways leading to BAT activation in humans, and discuss novel putative BAT activators in rodents into human perspective.
\end{abstract}




\section{Introduction}

Brown adipose tissue (BAT) is a crucial organ in facultative thermogenesis (acute response) and has a great plasticity to respond to long-term changes (e.g. cold acclimation), known as adaptive thermogenesis. In addition to its important role in maintaining thermal homeostasis, BAT is likely to be involved in energy homeostasis as well, since ablation of the essential protein for heat production in BAT, uncoupling protein-1 (UCP-1), leads to an obese phenotype in mice housed at a thermoneutral temperature (1). Furthermore, it has been shown in mice that BAT is involved in plasma triglyceride clearance (2) and glucose homeostasis $(3,4)$. This implies the important role of BAT in rodents to combat obesity and its related metabolic diseases, such as diabetes and cardiovascular disease. Interestingly, prospective studies have now demonstrated BAT to be present and functional in most (prevalence varying from 40 to $100 \%$ ) young lean human adults by exposing them to cold (5-11). Importantly, an inverse relationship has been shown between adiposity and BAT activity, indicating a relationship between BAT and obesity $(8,12-14)$. In addition, there is evidence that BAT contributes to nonshivering thermogenesis $(6-8,10,11)$, although this relationship has not always been found $(9,14)$. It has been estimated that fully activated BAT in humans can contribute to $5 \%$ of the basal metabolic rate (15). This means that stimulation of BAT can have an impact on long-term energy balance and thus body weight, however only when other factors (e.g. food intake) remain stable (16). Maybe more important, stimulation of BAT could be supportive in body weight maintenance. Therefore, finding strategies to increase BAT activity and recruitment in humans could be important to combat obesity and its related chronic metabolic diseases. Currently, much effort is being put in finding ways to increase BAT thermogenesis and the recruitment of brown adipocytes in rodents. The recent discovery of the so-called brown-in-white (brite) or beige adipocytes has further increased the interest in BAT. Increased "browning" of WAT could be an attractive way to induce weight loss. It is therefore important to find strategies to increase the thermogenic machinery of BAT and brown-like tissues in humans. This review will provide an overview of the most promising pathways to increase BAT activity and recruitment in humans.

\section{Brown, beige and white adipose tissue}

\section{Brown versus white adipose tissue}

In rodents, brown adipose tissue is clearly distinguishable from white adipose tissue, since it is richly innervated by the sympathetic nervous system (SNS), is highly vascularized, and contains brown adipocytes with several small lipid vacuoles and many large mitochondria (17). Unique for the brown adipocyte is the protein UCP-1 located in the inner mitochondrial membrane, which allows protons in the 
intermembrane space to re-enter the mitochondrial matrix without generating ATP, ultimately resulting in heat production.

White and brown adipose tissue in mice can be found in distinctive or classical (i.e. pure white or pure brown) depots (Figure 1A). All these depots have been characterized by genetic markers, and have a distinct genetic profile that probably determines its function (18). Note that these adipose tissue depots sometimes are also viewed as one organ, known as the adipose organ (19).

The largest BAT depot found in mice, iBAT, is predominantly found in human neonates and infants, and then gradually disappears after childhood (20) and is rarely seen in human adults (Figure 1B). In adult humans, BAT ([ ${ }^{18}$ F $]$ FDG-uptake) is often found in the neck, the mediastinum (para-aortic), and above the kidney (suprarenal), which is comparable to some BAT depots (cBAT, mBAT, prBAT) in mice. Furthermore, BAT in humans is located along the spinal cord, in the axillary and abdominal region (suprarenal and perihepatic), and sometimes in areas such as the abdominal wall and acromial-clavicular area. The most prominent and most reported BAT depot in humans is supraclavicular BAT, which has not been found as a distinct depot in mice.
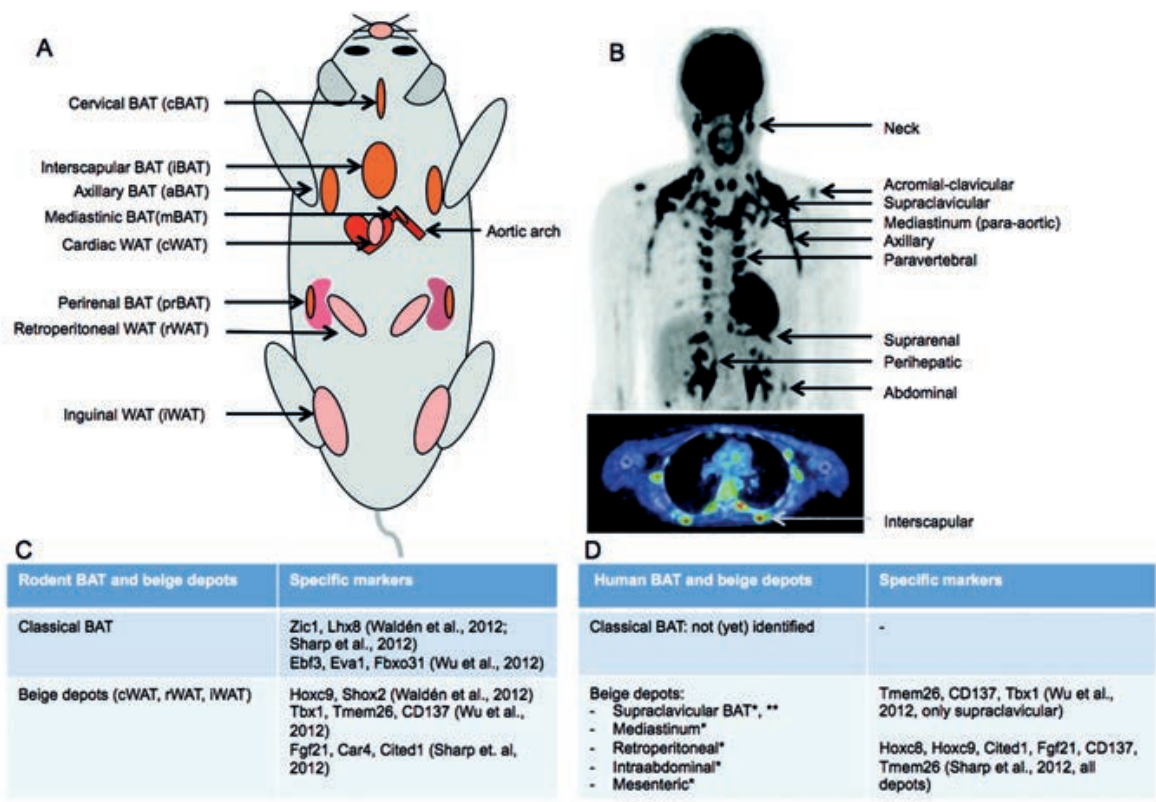

Figure 1. Overview of brown adipose tissue and beige adipose depots in rodents and humans. (A) Image of a mouse demonstrating classical BAT depots and WAT depots that are susceptible to browning (beige depots). (B) The upper part shows a PET image of a lean human adult demonstrating 18F-FDG-uptake in BAT locations during cold exposure and the lower image a transversal PET/CT fusion slice, which demonstrates a rare example of interscapular BAT in a lean human adult. (C) Overview of depot specific markers for both BAT and beige depots in mice. (D) Overview of depot specific markers determined in human BAT based on marker found in beige depots from mice. BAT = Brown adipose tissue, WAT $=$ White adipose tissue. ${ }^{*}$ Measured in children (21), **Measured in human adults (22). 


\section{Brown like cells in white adipose tissue}

In addition to classical BAT, a distinct type of adipocytes has been found within WAT depots, the so-called brite (23) or beige adipocytes (22). However, this is still under dispute as white fat cells may differentiate into brown fat cells (24). At present, no consensus on the terminology of these brown-like white adipocytes has been reached, and is urgently awaited. However, for sake of clarity we will refer to these cells as beige adipocytes in the remainder of this review. These beige adipocytes can appear within WAT depots after long-term adrenergic stimulation and cold exposure, and especially appear in the inguinal depot. In the basal state, these beige cells resemble the unilocular white adipocytes, whereas upon stimulation these cells obtain a more brown like phenotype. Furthermore, these cells do not express the myogenic markers nor the brown adipocyte specific markers Zic1, Lhx8, Meox2, and PRDM16 (23), but express specific markers as well (e.g. Hoxc9) (18). Interestingly, Wu et al. (22) were able to isolate brown-like cells from the subcutaneous (inguinal) adipose depot and found a distinct pool of progenitors giving rise to these so-called beige cell lines. Linkage of the expressed genes after microarray analysis in these cell lines revealed that beige adipocytes are identical, but not similar, to classical brown adipocytes. These beige adipocytes were characterized by unique genetic markers, such as CD137, Tmem26, and Tbx1, and did not contain unique BAT markers such as Ebf3, Eva1 and Fbxo31 (Figure 1C). Furthermore, they found that unstimulated beige cells resemble white adipocytes since they have similar low expression of the brown adipocyte markers UCP-1, Cidea, and Cox7a1. However, upon CAMP stimulation absolute levels of UCP-1 mRNA and respiratory capacity were comparable to classical brown adipocytes. In coherence with this, Petrovic et al. (23) showed beige cell recruitment in the inguinal depot, and that even the purest WAT depot (epididymal) contains preadicpocytes that can be induced to functional beige adipocytes. Again, a low basal UCP-1 expression was found during baseline conditions, however, after rosiglitazone (PPARY activator) treatment beige cells increased UCP-1 expression and demonstrated many features of the classical brown adipocytes. Moreover, oxygen consumption increased after treating these cells with norepinephrine. In conclusion, it is clear that beige adipocytes are molecular and developmentally different from classical brown adipocytes, however, after stimulation these cells show comparable thermogenic potential.

\section{Type of brown adipocytes in humans}

Do humans have brown, beige or both types of adipocytes? Studies measuring BAT via FDG-PET/CT cannot determine the type of BAT, as it merely measures glucose uptake. However, biopsies from the supraclavicular region (25) and the perithyroid region (26) have already demonstrated a mixture of both white and brown adipocytes, and showed that brown adipocytes occur as islands within WAT. The clearly brown colored depots as found in mice, have not (yet) been found in humans. Interestingly, a recent 
study has examined several adipose depots in 13 post-mortem children (aged between 3 days and 18 years) and also found the brown like cells dispersed within WAT (21). These brown adipocyte islands were located in the subcutaneous supraclavicular areas, posterior mediastinum, retroperitoneal, intra-abdominal, and mesenteric depots.

In the study by Wu et al. (22), human adipose tissue biopsies (both WAT and BAT) from the supraclavicular area were analyzed for gene expression. Interestingly, we found increased mRNA expression of the genes that were characteristic for beige cells (CD137, Tmem26, Tbx1) and not classical murine BAT (Ebf3, Eva1, Fbxo31) (Figure 1D). In addition, we also performed immunohistochemistry to identify the beige marker proteins (CD137 and Tmem26), and found positive staining for both proteins in the UCP-1 positive cells. Thus, human BAT from the supraclavicular area in adults has beige characteristics. In the study by Sharp et al. (21), total RNA was isolated from the BAT depots from post-mortem children, and interestingly, all BAT depots expressed beigecell selective genes and no classical brown fat-selective genes (Figure 1D). They found that these BAT depots correlated well with the expression of brown fat genes such as PGC1 $\alpha$ and PRDM16, and with beige-cell genes (e.g. Cited1), however not with classical BAT genes (e.g. Zic1) (21). These findings thus indicate that human BAT may be composed of mainly beige adipocytes.

\section{BAT physiology}

Crucial in activating BAT thermogenesis is the sympathetic nervous system (SNS). Furthermore, the thermogenic capacity of BAT is dependent on the thyroid hormone axis as well. After sympathetic stimulation, norepinephrine (NE) is released at the nerve endings activating the adrenergic receptors on the brown adipocytes. This leads to increased cAMP levels activating protein kinase A (PKA), which has both acute and chronic effects on BAT. The acute response of PKA is to increase lipolysis leading to increased cytosolic FFA levels. These FFA's are essential for mitochondrial energy dissipation, as they are both used as substrates and to activate UCP-1 in the inner mitochondrial membrane. This acute effect increases UCP-1 activity within seconds. On the other hand, prolonged stimulation of BAT for hours and days will result in increased amounts of UCP-1 protein, mitochondrial biogenesis, and both hyperplasia and hypertrophy of BAT (27). The thyroid hormone works synergistic with NE and is required to generate the full thermogenic response (28). Crucial is the enzyme type II iodothyronine deiodinase (D2, which can transform the inactive prohormone thyroxine (T4) into the bioactive hormone triiodothyronine (T3).

In contrast to the extensive knowledge in rodents, the regulation and activation of human BAT is still fairly unknown. However, both the SNS and the thyroid axis are thought to be crucial in activation of BAT in humans too. For instance, patients with 
pheochromocytoma, who have elevated plasma catecholamine levels due to a catecholamine-secreting tumor in de adrenal gland, had high rates of $\left[{ }^{18}\right.$ F]FDG-uptake in BAT in the basal state (29-32), which disappeared after resection of the tumor (29, 32). Thus, high systemic levels of NE can activate human BAT, indicating a role for the adrenergic part of the SNS. In support, inhibition of $\beta$-adrenergic receptors with propranolol diminished $\left[{ }^{18} \mathrm{~F}\right] \mathrm{FDG}$-uptake in the supraclavicular BAT during room temperature $(33,34)$. In 2009, anatomical evidence for the SNS involvement in BAT was found, as BAT biopsies from the perithyroid (26) and supraclavicular region (25) demonstrated sympathetic innervation and mRNA expression of the $\beta_{3}$-adrenergic receptor respectively. Finally, disruption of the sympathetic fibers completely abolished $\left[{ }^{18} \mathrm{~F}\right] \mathrm{FDG}$-uptake in BAT in a patient with the Horner Syndrome (deficiency of sympathetic activity) (35). With respect to the thyroid hormone axis, it is known from patients that thyroid hormone replacement has significant effects on resting energy expenditure (36). It has also been shown that elevated levels of thyroid hormones are able to increase mitochondrial uncoupling in skeletal muscle $(37,38)$. Although these results may suggest that thyroid hormone also plays a role in activation of BAT, evidence for such a role in humans has so far not been demonstrated.

\section{Known BAT activators in humans}

Since the discovery of functional BAT in adult humans, some studies have examined possible routes to activate BAT in humans, which will be discussed here.

\section{Cold exposure and acclimatization}

Currently, the strategy for which most evidence has been gathered to activate BAT in humans is cold exposure. In our cold exposure experiments we applied a personalized cooling protocol in which we decreased ambient temperature until shivering occurred $\left(16-17{ }^{\circ} \mathrm{C}\right)$ and then increased temperature slightly again. At these mild cold temperatures, cold-induced thermogenesis levels in young lean male adults were observed between $5 \%$ and $30 \%(9,14)$. Brown adipose tissue was present in all individuals, however the activity level of BAT did not correlate to cold-induced thermogenesis. Other studies did find a relationship between BAT presence and/or activity and cold-induced thermogenesis $(6-8,11,39)$. Cold exposure likely increased BAT activity via the SNS as shown by increased plasma NE levels during cold exposure $(6,9)$.

It is well known from animal studies that long-term cold exposure leads to BAT recruitment in both BAT and WAT depots (40). A cold acclimation study in humans in 1961 demonstrated that long-term cold exposure was effective to increase coldinduced thermogenesis in man, with a decrease in shivering, indicating a potential role for BAT (41). Preliminary results from our lab confirm this adaptive response to cold 
acclimation as both cold-induced (non-shivering) thermogenesis and BAT activity increase (unpublished results).

\section{Isoprenaline and ephedrine}

Rodent studies have clearly demonstrated that BAT can be activated (acute) and recruited (chronic) upon adrenergic receptor agonist treatment. Recently, three studies measured the effect of adrenergic stimulation on BAT activity in human adults. We measured BAT activity in lean human adults during infusion of the non-selective $\beta$ adrenergic agonist isoprenaline, and compared this to cold exposure (9). Isoprenaline infusion increased energy expenditure with $20 \%$ comparable to levels during cold exposure (17\%). Surprisingly, nine out of ten subjects showed no BAT activity during isoprenaline infusion, whereas cold exposure increased BAT activity in all subjects. Cypess et al. (5) studied the effects of ephedrine (1 $\mathrm{mg} / \mathrm{kg})$, which is a sympathomimetic drug activating $\beta$-adrenergic receptors directly and indirectly by enhancing NE release from the sympathetic terminals, on BAT activity and compared this with cold exposure and placebo. In coherence with our results (9), ephedrine did not result in BAT activity measured by FDG-PET/CT measurements, whereas cold exposure activated BAT in all subjects (5). However, a recent study using higher dosages of ephedrine $(2.5 \mathrm{mg} / \mathrm{kg})$ did find increased BAT activity in six out of nine lean human adults, however not in obese subjects (42). This is the first study that showed that pharmacological treatment of BAT in humans is possible. The activity level of BAT was still 4-fold lower than observed during cold exposure. The explanation for the lack of effect of systemic adrenergic stimulation on BAT activation is likely that the concentrations of $\mathrm{NE}$ reached at the brown adipocyte cell surface during central stimulation (e.g. cold exposure) are higher than systemically reached by the sympathomimetics used in these studies. Thus, pharmacological stimulation of BAT is possible, however high dosages are required. A major burden of very high levels of sympathomimetic drugs is the cardiovascular load induced by adrenergic agonists. All three studies observed increased blood pressure and heart rate levels, with the highest increase in systolic blood pressure $(45 \mathrm{mmHg})$ measured in the study by Carey et al. (42).

\section{Capsinoids}

Another route to activate BAT via the SNS is via ingestion of certain food components. One such component are the capsinoids (non-pungent capsaicin analogs), the active compound found in chili pepper, which is known to increase BAT activity in rodents (43), and RMR in humans (44), although this has not been consistenly shown (among others: (45)). A recent study showed that capsinoids could be effective in activating BAT in humans (10), without inducing unwanted side-effects. Although they did not directly measure the effect of capsinoid intake on BAT activity, they found that subjects with BAT (based on cold PET-CT) showed a higher increase in energy 
expenditure upon capsinoid intake compared to subjects without BAT. The proposed mechanism is that capsinoids activate the transient receptor potential channel 1 (TRPV1) located in the upper digestive tract leading to increased sympathetic nerve activity to BAT, as demonstrated in interscapular BAT in rats (46). Direct evidence for the effect of capsinoids on BAT in humans is needed to draw definite conclusions. Furthermore, whether long-term administration of these bioactive compounds can induce weight loss via BAT remains to be studied.

\section{Insulin}

Another way to induce glucose uptake in BAT is via insulin (6). In this study, insulin infusion (hyperinsulinemic euglycemia) was compared with cold exposure on BAT glucose uptake and perfusion. They showed that insulin increased $\left[{ }^{18} \mathrm{~F}\right]$ FDG-uptake in BAT to similar levels as in skeletal muscle, and much higher than in WAT. This was most likely due to the high expression of GLUT4 in BAT compared to WAT. However, the increased $\left[{ }^{18}\right.$ F]FDG-uptake in BAT was not accompanied by increased perfusion, suggesting that glucose is solely transported in BAT without concomitant thermogenesis taking place. Since insulin leads to high glucose uptake in BAT, it would be interesting to measure whether BAT is involved in glucose uptake, and possibly thermogenesis, in the postprandial state as well. It is known from rodent studies that single meals can activate BAT, which could be due to insulin release (47).

\section{Novel putative BAT activators}

Next to the known activators of BAT as described above, novel findings in mainly rodent studies hint towards other potentially important activators of BAT. The focus of this paragraph will be on the hormones irisin (released by muscle) and the natriuretic peptides (released by heart). We have chosen for these hormones as they are released under physiological conditions (exercise and cardiac stress), and because there is already indirect evidence of these activators in humans. For information on the other potential BAT activators we would like to refer to other reviews $(48,49)$.

\section{Exercise and brown adipose tissue: irisin}

Exercise is well known for its beneficial effects on systemic metabolism. In the past decades, several animal studies have investigated whether exercise has beneficial effects on BAT activity and recruitment. It was hypothesized that exercise could affect BAT function via the SNS, as exercise is known to increase general SNS activity (50). However, most studies did not find any stimulatory effect of exercise on BAT activity (50-53), except for studies using swimming exercise protocols (54-56), which probably induced BAT activity to compensate for the heat loss to the water. 
However, recent studies in rodents did observe stimulating effects of exercise on brown and beige adipocytes (57-60). A study in rats demonstrated that a low level of exercise training is beneficial for the metabolic response upon cold exposure in classical BAT (58). It was shown that exercise in combination with cold exposure led to an increase in UCP-1 expression in BAT, whereas cold exposure $\left(12^{\circ} \mathrm{C}\right)$ alone did not, suggesting that physical activity is required for an optimal heat producing BAT machinery. Xu et al. (60) found that exercise in mice led to increased recruitment of adipogenic progenitor cells in interscapular BAT and increased UCP-1 expression ( $\sim$ twofold). Interestingly, in addition to these stimulating effects of exercise on classical BAT, they found an increased expression of the thermogenic gene program in epidydimal (visceral) adipose tissue, including increased UCP-1 levels ( $\sim$ twofold). Another study showed the occurrence of beige cells within the retroperitoneal depot (visceral) of rats already after one week of exercise (61). Quantification of UCP-1 positive adipocytes within the retriperitoneal WAT showed a 8-fold increase in the number of brown cells in the exercise group versus controls.

Interestingly, a recent study demonstrated that endurance exercise predominantly results in browning of subcutaneous WAT (57). In this study, Boström et al. found that mice overexpressing the transcriptional coactivator PGC1- $\alpha$ showed increased browning in inguinal WAT. Since exercise also increases PGC1- $\alpha$, they examined the effect of endurance exercise on markers of browning and observed similar effects. In further studies, they identified a new hormone called irisin, which is released by skeletal muscle after proteolysis of the membrane protein FNDC5. Boström et al. found that the irisin precursor FNDC5 induced browning in primary subcutaneous white adipocytes demonstrated by increased UCP1 mRNA (7-500-fold) and the upregulation of thermogenic genes (Ucp1, Elovl3, Cox7a1 and Otop1). Adenoviral-mediated overexpression of FNDC5 in mouse liver resulted in plasma irisin levels to be increased 3-4-fold, which increased UCP1 mRNA 13-fold in subcutaneous WAT. Furthermore, the same technique was used in C557BL/6 mice, which are prone to diet-induced obesity and diabetes, and increased irisin levels leading to improved glucose tolerance, decreased fasting insulin, increased oxygen consumption and reduced body weight. Together these results demonstrate the possible beneficial effects of endurance exercise on the recruitment of beige cells within subcutaneous white adipose tissue, and moreover, the potential of irisin to induce a more healthy metabolic phenotype.

Are these stimulating effects of exercise on the recruitment of beige cells translatable to humans? Importantly, the authors showed that irisin in mice and humans are $100 \%$ identical and that plasma irisin levels were increased twofold after 10 weeks of endurance training in human subjects (57). Interestingly, a study in patients with heart failure demonstrated increased FNDC5 expression in skeletal muscle in the patient group with a better aerobic performance (62). Conversely, a recent study by Timmons et al. (63) demonstrated that the stimulating effect of 
exercise on FNDC5 is limited. They analyzed FNDC5 induction by means of gene expression arrays in muscle biopsies from $\sim 200$ subjects from different exercise programs (both endurance and resistance straining) from earlier published studies. They found that endurance exercise ( 6 weeks of endurance cycling) in young adults as well as resistance training in 20-80 year old men did not increase FNDC5 mRNA. However, only highly active elderly subjects did show increased (30\%) FNDC5 compared to sedentary controls. The authors therefore conclude that the stimulatory effect of exercise on irisin production is limited and that irisin probably has little contribution to the overall broad benefits of exercise on metabolic status.

Another recent paper on irisin presented data from cross-sectional and interventional studies on the physiological role of irisin in humans looking at correlations with anthropometric, metabolic, and hormonal parameters (64). The presence of FNDC5 in human tissues, in skeletal muscle but also in the pericardium, intracranial artery, and rectum (cardiac and smooth muscles) was confirmed and muscle mass was found to be the primary predictor of circulating irisin in humans. However no support for a beneficial role for irisin in metabolic regulation in a cross sectional study of 117 middle-aged women (BMI range $20-47.7 \mathrm{~kg} / \mathrm{m}^{2}$ ) was found. Interestingly, acute anaerobic exercise (sprint exercise) in young healthy subjects increased irisin levels, whereas chronic exercise of 8 weeks (three times sprint exercise per week) did not. It is important to note that this study solely looked at anaerobic exercise; it is known that aerobic exercise increases PGC1 $\alpha$ to a greater extent than anaerobic exercise (65), and this (aerobic) type of exercise would thus be more effective in irisin production.

These first human studies question the potential beneficial effects of irisin on metabolic status. However, prospective studies that measure the direct effects of exercise on browning are required, and prospective studies should focus on aerobic exercise protocols. In addition to the physiological release of irisin by exercise, the therapeutic use of irisin in human clinical trials should be investigated.

\section{Natriuretic peptides and brown adipose tissue}

A recent study showed that the cardiac natriuretic peptides (NPs) are capable of browning white adipocytes from mice and humans (66). The cardiac peptides, atrial NP (ANP) and the ventricular form (BNP), are predominantly known for their role in the homeostatic control of blood pressure, by promoting vasodilatation, natriuresis and diuresis, and inhibiting renin and aldosterone release (67). Later, these hormones were also found to regulate lipolysis as demonstrated both in vitro as in vivo (68). Natriuretic peptides mediate these lipolytic effects predominantly via the NP receptor A (NPRA), whereas the clearance receptor (NPRC) removes the peptides from the circulation. Binding of the NPs to the guanylyl cyclase receptor NPRA leads to increased cellular cGMP, which stimulates lipolysis by acting on HSL (69). These lipolytic effects of the NPs were only observed in human WAT, and were thought to be primate specific due 
to the high expression of clearance receptors and a low expression of "biologically active" receptors in other species (68).

This was confirmed in the study by Bordicchia et al. (66), in which primary adipocyte cultures from wildtype mice showed no lipolytic response upon ANP infusion. However, in NPRC knockout mice they did find increased lipolysis in these adipocytes, indicating the inhibitory effects of this clearance receptor. Interestingly, these knockout mice had reduced adipose tissue mass and a more brownish adipose tissue phenotype. In support, brown adipocyte marker genes, such as PRDM16, were elevated in both BAT and WAT (inguinal and epididymal). These results indicated the browning effects on WAT via the NPs. It was then shown that exposing mice to cold $\left(4^{\circ}\right.$ for $6 \mathrm{~h}$ ) significantly increased plasma BNP levels, and ANP and BNP mRNA expression in the heart. Furthermore, BNP infusion in mice increased UCP-1 and PGC-1 $\alpha$ mRNA expression in both WAT and BAT (66). Altogether, these data demonstrate that the NPs have the capacity to enhance BAT activity and recruitment in mice in vitro and in vivo.

Do these NPs exert similar effects in humans? Administering ANP systemically and via a microdialysis probe increased lipolysis in healthy men (70). One functional role for the lipolytic effects of NPs could be substrate supply of fatty acids to the heart and muscle during aerobic exercise (71). In addition, it is thought that the NPs are important regulators in postprandial fatty acid oxidation in humans (72). Interestingly, it is known in humans that low NP levels are associated with hypertension, obesity, insulin resistance and diabetes $(73,74)$. Furthermore, weight loss in obese subjects by lifestyle intervention (75-78) showed that BNP levels are increased after weight loss. Interestingly patients with heart failure who suffer from severe weight loss (cachexia) have increased levels of both forms of NPs $(79,80)$, and elevated energy expenditure levels, and it could be suggested that elevated NP levels increase brown adipocyte recruitment and activity leading to elevated EE. Birkenfeld et al. $(70,72)$ showed that ANP infusion increased postprandial energy expenditure, however energy expenditure in the fasted state was not affected. The dosage $(25 \mathrm{ng} / \mathrm{kg} / \mathrm{min})$ of ANP used by Birkenfeld et al. (72) increased plasma ANP concentrations fourfold (approximately $300 \mathrm{pg} / \mathrm{mL}$ ), which is lower than found in heart failure patients (>500 pg/mL). This relative low dose already affected lipid mobilization and postprandial thermogenesis (and possibly BAT) without causing any adverse effects. Currently, therapeutic use of NPs (carperitide and nesiritide) in patients with acute heart failure and acutely decompensated heart failure is only possible by means of infusion and not orally (81).

The potential effect of NPs on browning in humans has been demonstrated in the study of Bordicchia et al., where they tested whether NPs could induce a thermogenic gene program in differentiated human multipotent adipose-derived stem (hMADS) cells and subcutaneous adipocytes. Interestingly, both ANP and BNP activated PGC-1 $\alpha$ and UCP-1 expression, induced mitochondrial biogenesis, and increased uncoupled and total respiration. These findings imply the potential role of the NPs in increasing 
acute thermogenesis and brown adipocyte recruitment in humans. They demonstrated that the mechanism of action of the NP's share a common downstream target with the adrenergic pathway, namely p38 MAPK. Activation of the p38 MAPK pathway ultimately leads to increased transcription of UCP-1 and PGC-1 $\alpha$ (66). Moreover, it was shown that ANP treatment of hMADS led to a similar increase in UCP-1, PGC-1 $\alpha$, and cytochrome c protein levels as shown during $\beta$-adrenergic treatment. The authors also found that both the adrenergic and NP's signaling pathways work additive at very low (physiological) concentrations. The activation pathway of the NPs could therefore play a prominent role in addition to the well-known adrenergic pathway in inducing both short-term as long-term effects on BAT. Currently, this is the only direct evidence of browning effects via NPs in humans and future studies are warranted.

\section{Conclusions and perspectives}

The current global obesity problem is affecting more than 1.4 billion adults of 20 years and older, and strikingly, more than 40 million children under the age of five were overweight in 2010 (WHO). Obesity goes along with increased risk on developing diseases such as type 2 diabetes and cardiovascular diseases. Finding strategies to induce weight loss are therefore necessary. Currently, brown adipose tissue is regarded as a potential tissue to tackle obesity due to its great capacity to increase energy expenditure and thereby stimulating weight loss. The rediscovery of functional BAT in humans has resulted in an explosion of BAT studies, especially in rodents, to find potential molecules that could lead to BAT hypertrophy and hyperplasia. It is now clear that a third type of adipocyte exists, the beige adipocyte, which can be recruited within WAT after cold acclimation and long-term adrenergic receptor stimulation. This distinct type of adipocyte has shown to arise from a different lineage as the other two types, although functionally and metabolically seen it is similar to the brown adipocyte. Current evidence shows that human BAT is likely composed of mainly beige adipocytes.

Prospective studies in humans are scarce, mostly because of the difficulties associated with the technique to measure BAT activity (PET-CT). Nevertheless, current studies have shown that cold exposure is the most effective in stimulating BAT in humans. Adjusting ambient temperature in public buildings to the lower range of our thermoneutral zone could therefore be a sensible and physiological way to increase thermogenesis by increasing the thermogenic potential of BAT. Adrenergic agonists (isoprenaline and ephedrine) have not shown to be effective in BAT activation as high dosages are required. This indicates that pharmacological activation of BAT via the adrenergic part of the SNS is difficult. Furthermore, a major drawback of adrenergic agonists and sympathomimetics is the associated cardiovascular stress. Sympathetic activation via capsinoids could be a way to increase energy expenditure and possibly 


\section{ENERGY DISSIPATION IN BROWN ADIPOSE TISSUE}

weight loss (with low risks of adverse events), and the indirect evidence of BAT being a mediator is promising. Insulin has been shown to induce glucose uptake in BAT to higher levels than WAT, and comparable to skeletal muscle. However, since perfusion of BAT was absent, it remains unclear whether actual thermogenesis takes place after insulin stimulation.

Interestingly, studies in rodents have shown additional pathways to activate BAT and recruit beige adipocytes. Two of them - irisin and NPs - have recently attracted much attention, but definitive answers in humans are so far lacking. Therefore, the coming years are crucial in finding and testing novel activators of BAT in human clinical trials, but most of all to test the hypothesis that activation of BAT may indeed be of importance in the treatment of human obesity. Furthermore, future studies should also reveal if continuous activation of mitochondrial uncoupling in BAT could lead to hyperthermia, as has previously been shown to occur when dinitrophenol was used in humans to obtain weight loss.

\section{References}

1. Feldmann HM, Golozoubova V, Cannon B, and Nedergaard J. UCP1 ablation induces obesity and abolishes diet-induced thermogenesis in mice exempt from thermal stress by living at thermoneutrality. Cell Metab. 2009;9(2):203-9.

2. Bartelt A, Bruns OT, Reimer R, Hohenberg H, Ittrich H, Peldschus K, Kaul MG, Tromsdorf UI, Weller H, Waurisch $\mathrm{C}$, et al. Brown adipose tissue activity controls triglyceride clearance. Nat Med. 2011;17(2):200-5.

3. Guerra C, Navarro P, Valverde A, Arribas M, Brüning J, Kozak L, Kahn C, and Benito M. Brown adipose tissue-specific insulin receptor knockout shows diabetic phenotype without insulin resistance. J Clin Invest. 2001;108(8):1205-13.

4. Gunawardana SC, and Piston DW. Reversal of type 1 diabetes in mice by brown adipose tissue transplant. Diabetes. 2012;61(3):674-82.

5. Cypess AM, Chen YC, Sze C, Wang K, English J, Chan O, Holman AR, Tal I, Palmer MR, Kolodny GM, et al. Cold but not sympathomimetics activates human brown adipose tissue in vivo. Proc Natl Acad Sci U S A. 2012;109(25):10001-5.

6. Orava J, Nuutila P, Lidell ME, Oikonen V, Noponen T, Viljanen T, Scheinin M, Taittonen M, Niemi T, Enerback $S$, et al. Different metabolic responses of human brown adipose tissue to activation by cold and insulin. Cell Metab. 2011;14(2):272-9.

7. Ouellet V, Labbe SM, Blondin DP, Phoenix S, Guerin B, Haman F, Turcotte EE, Richard D, and Carpentier AC. Brown adipose tissue oxidative metabolism contributes to energy expenditure during acute cold exposure in humans. J Clin Invest. 2012;122(2):545-52.

8. Vijgen GH, Bouvy ND, Teule GJ, Brans B, Schrauwen P, and van Marken Lichtenbelt WD. Brown adipose tissue in morbidly obese subjects. PLoS One. 2011;6(2):e17247.

9. Vosselman MJ, van der Lans AA, Brans B, Wierts R, van Baak MA, Schrauwen P, and van Marken Lichtenbelt WD. Systemic beta-adrenergic stimulation of thermogenesis is not accompanied by brown adipose tissue activity in humans. Diabetes. 2012;61(12):3106-13.

10. Yoneshiro T, Aita S, Kawai Y, Iwanaga T, and Saito M. Nonpungent capsaicin analogs (capsinoids) increase energy expenditure through the activation of brown adipose tissue in humans. Am J Clin Nutr. 2012;95(4):845-50. 
11. Yoneshiro T, Aita S, Matsushita M, Kameya T, Nakada K, Kawai Y, and Saito M. Brown adipose tissue, whole-body energy expenditure, and thermogenesis in healthy adult men. Obesity (Silver Spring). 2011;19(1):13-6.

12. Cypess AM, Lehman S, Williams G, Tal I, Rodman D, Goldfine AB, Kuo FC, Palmer EL, Tseng YH, Doria A, et al. Identification and importance of brown adipose tissue in adult humans. $N$ Engl J Med. 2009;360(15):1509-17.

13. Saito M, Okamatsu-Ogura $Y$, Matsushita $M$, Watanabe $K$, Yoneshiro $T$, Nio-Kobayashi J, Iwanaga $T$, Miyagawa M, Kameya T, Nakada K, et al. High incidence of metabolically active brown adipose tissue in healthy adult humans: effects of cold exposure and adiposity. Diabetes. 2009;58(7):1526-31.

14. van Marken Lichtenbelt WD, Vanhommerig JW, Smulders NM, Drossaerts JM, Kemerink GJ, Bouvy ND, Schrauwen $\mathrm{P}$, and Teule GJ. Cold-activated brown adipose tissue in healthy men. $N$ Engl J Med. 2009;360(15):1500-8.

15. van Marken Lichtenbelt WD, and Schrauwen P. Implications of nonshivering thermogenesis for energy balance regulation in humans. Am J Physiol Regul Integr Comp Physiol. 2011;301(2):R285-96.

16. Christiansen E, and Garby L. Prediction of body weight changes caused by changes in energy balance. Eur J Clin Invest. 2002;32(11):826-30.

17. Frontini A, and Cinti S. Distribution and development of brown adipocytes in the murine and human adipose organ. Cell Metab. 2010;11(4):253-6.

18. Waldén T, Hansen I, Timmons J, Cannon B, and Nedergaard J. Recruited vs. nonrecruited molecular signatures of brown, "brite," and white adipose tissues. Am J Physiol Endocrinol Metab. 2012;302(1):31.

19. Cinti S. The adipose organ: morphological perspectives of adipose tissues. Proc Nutr Soc. 2001;60(3):319-28.

20. Heaton J. The distribution of brown adipose tissue in the human. J Anat. 1972;112(Pt 1):35-9.

21. Sharp L, Shinoda K, Ohno H, Scheel D, Tomoda E, Ruiz L, Hu H, Wang L, Pavlova Z, Gilsanz V, et al. Human BAT Possesses Molecular Signatures That Resemble Beige/Brite Cells. PLoS One. 2012;7(11).

22. Wu J, Bostrom P, Sparks LM, Ye L, Choi JH, Giang AH, Khandekar M, Virtanen KA, Nuutila P, Schaart G, et al. Beige adipocytes are a distinct type of thermogenic fat cell in mouse and human. Cell. 2012;150(2):366-76.

23. Petrovic N, Walden TB, Shabalina IG, Timmons JA, Cannon B, and Nedergaard J. Chronic peroxisome proliferator-activated receptor gamma (PPARgamma) activation of epididymally derived white adipocyte cultures reveals a population of thermogenically competent, UCP1-containing adipocytes molecularly distinct from classic brown adipocytes. J Biol Chem. 2010;285(10):7153-64.

24. Cinti S. Adipocyte differentiation and transdifferentiation: plasticity of the adipose organ. J Endocrinol Invest. 2002;25(10):823-35.

25. Virtanen KA, Lidell ME, Orava J, Heglind M, Westergren R, Niemi T, Taittonen M, Laine J, Savisto NJ, Enerback S, et al. Functional brown adipose tissue in healthy adults. N Engl J Med. 2009;360(15):151825.

26. Zingaretti MC, Crosta F, Vitali A, Guerrieri M, Frontini A, Cannon B, Nedergaard J, and Cinti S. The presence of UCP1 demonstrates that metabolically active adipose tissue in the neck of adult humans truly represents brown adipose tissue. Faseb J. 2009;23(9):3113-20.

27. Lowell BB, and Spiegelman BM. Towards a molecular understanding of adaptive thermogenesis. Nature. 2000;404(6778):652-60.

28. Silva J. Thermogenic mechanisms and their hormonal regulation. Physiol Rev. 2006;86(2):435-64.

29. Hadi M, Chen C, Whatley M, Pacak K, and Carrasquillo J. Brown fat imaging with (18)F-6-fluorodopamine PET/CT, (18)F-FDG PET/CT, and (123)I-MIBG SPECT: a study of patients being evaluated for pheochromocytoma. J Nucl Med. 2007;48(7):1077-83.

30. Joshi $P$, and Lele V. Unexpected Visitor on FDG PET/CT-Brown Adipose Tissue (BAT) in Mesentery in a Case of Retroperitoneal Extra-Adrenal Pheochromocytoma: Is the BAT Activation Secondary to Catecholamine-Secreting Pheochromocytoma? Clin Nucl Med. 2012;37(5):20.

31. Kuji I, Imabayashi E, Minagawa A, Matsuda H, and Miyauchi T. Brown adipose tissue demonstrating intense FDG uptake in a patient with mediastinal pheochromocytoma. Ann Nucl Med. 2008;22(3):231-5. 


\section{ENERGY DISSIPATION IN BROWN ADIPOSE TISSUE}

32. Yamaga L, Thom A, Wagner J, Baroni R, Hidal J, and Funari M. The effect of catecholamines on the glucose uptake in brown adipose tissue demonstrated by (18)F-FDG PET/CT in a patient with adrenal pheochromocytoma. Eur J Nucl Med Mol Imaging. 2008;35(2):446-7.

33. Parysow O, Mollerach AM, Jager V, Racioppi S, San Roman J, and Gerbaudo VH. Low-dose oral propranolol could reduce brown adipose tissue F-18 FDG uptake in patients undergoing PET scans. Clin Nucl Med. 2007;32(5):351-7.

34. Soderlund V, Larsson SA, and Jacobsson H. Reduction of FDG uptake in brown adipose tissue in clinical patients by a single dose of propranolol. Eur J Nucl Med Mol Imaging. 2007;34(7):1018-22.

35. Lebron L, Chou A, and Carrasquillo J. Interesting image. Unilateral F-18 FDG uptake in the neck, in patients with sympathetic denervation. Clin Nucl Med. 2010;35(11):899-901.

36. Al-Adsani H, Hoffer LJ, Silva JE. Resting Energy Expenditure is Sensitive to Small Dose Changes in Patients on Chronic Thyroid Hormone Replacement. J Clin Endocrinol Metab. 1997;82(4):1118-25.

37. Lebon V, Dufour S, Petersen KF, Ren J, Jucker BM, Slezak LA, Cline GW, Rothman DL, Shulman GI. Effect of triiodothyronine on mitochondrial energy coupling in human skeletal muscle. J Clin Invest. 2001;108(5):733-7.

38. Mitchell C, Savage D, Dufour S, Schoenmakers N, Murgatroyd P, Befroy D, Halsall D, Northcott S, Raymond-Barker $\mathrm{P}$, Curran $\mathrm{S}$, et al. Resistance to thyroid hormone is associated with raised energy expenditure, muscle mitochondrial uncoupling, and hyperphagia. J Clin Invest. 2010;120(4):1345-54.

39. Vijgen G, Bouvy N, Teule GJ, Brans B, Hoeks J, Schrauwen P, and van Marken Lichtenbelt W. Increase in Brown Adipose Tissue Activity after Weight Loss in Morbidly Obese Subjects. J Clin Endocrinol Metab. 2012;97(7):E1229-33.

40. Young $\mathrm{P}$, Arch J, and Ashwell M. Brown adipose tissue in the parametrial fat pad of the mouse. FEBS letters. 1984;167(1):10-4.

41. Davis T. Chamber cold acclimatization in man. J Appl Physiol. 1961;16(1011-5.

42. Carey AL, Formosa MF, Van Every B, Bertovic D, Eikelis N, Lambert GW, Kalff V, Duffy SJ, Cherk MH, and Kingwell BA. Ephedrine activates brown adipose tissue in lean but not obese humans. Diabetologia. 2013;56(1):147-55.

43. Kawabata F, Inoue N, Masamoto Y, Matsumura S, Kimura W, Kadowaki M, Higashi T, Tominaga M, Inoue $\mathrm{K}$, and Fushiki T. Non-pungent capsaicin analogs (capsinoids) increase metabolic rate and enhance thermogenesis via gastrointestinal TRPV1 in mice. Biosci Biotechnol Biochem. 2009;73(12):2690-7.

44. Whiting S, Derbyshire E, and Tiwari B. Capsaicinoids and capsinoids. A potential role for weight management? A systematic review of the evidence. Appetite. 2012;59(2):341-8.

45. Galgani JE, and Ravussin E. Effect of dihydrocapsiate on resting metabolic rate in humans. Am J Clin Nutr. 2010;92(5):1089-93.

46. Ono K, Tsukamoto-Yasui M, Hara-Kimura Y, Inoue N, Nogusa Y, Okabe Y, Nagashima K, and Kato F. Intragastric administration of capsiate, a transient receptor potential channel agonist, triggers thermogenic sympathetic responses. J App/ Physiol. 2011;110(3):789-98.

47. Cannon B, and Nedergaard J. Brown adipose tissue: function and physiological significance. Physiol Rev. 2004;84(1):277-359.

48. Whittle A. Searching for ways to switch on brown fat: are we getting warmer? J Mol Endocrinol. 2012;49(2):87.

49. Whittle A, and Vidal-Puig A. NPs -- heart hormones that regulate brown fat? J Clin Invest. 2012;122(3):804-7.

50. Wickler SJ, Stern JS, Glick Z, and Horwitz BA. Thermogenic capacity and brown fat in rats exercise-trained by running. Metabolism. 1987;36(1):76-81.

51. Scarpace PJ, Yenice S, and Tumer N. Influence of exercise training and age on uncoupling protein mRNA expression in brown adipose tissue. Pharmacol Biochem Behav. 1994;49(4):1057-9.

52. Segawa M, Oh-Ishi S, Kizaki T, Ookawara T, Sakurai T, Izawa T, Nagasawa J, Kawada T, Fushiki T, and Ohno H. Effect of running training on brown adipose tissue activity in rats: a reevaluation. Res Commun Mol Pathol Pharmacol. 1998;100(1):77-82. 
53. Shibata $\mathrm{H}$, and Nagasaka $\mathrm{T}$. The effect of forced running on heat production in brown adipose tissue in rats. Physiol Behav. 1987;39(3):377-80.

54. Hirata K. Enhanced calorigenesis in brown adipose tissue in physically trained rats. Jpn J Physiol. 1982;32(4):647-53.

55. Hirata K. Blood flow to brown adipose tissue and norepinephrine- induced calorigenesis in physically trained rats. Jpn J Physiol. 1982;32(2):279-91.

56. Oh-ishi S, Kizaki T, Toshinai K, Haga S, Fukuda K, Nagata N, and Ohno H. Swimming training improves brown-adipose-tissue activity in young and old mice. Mech Ageing Dev. 1996;89(2):67-78.

57. Boström P, Wu J, Jedrychowski M, Korde A, Ye L, Lo J, Rasbach K, Boström E, Choi J, Long J, et al. A PGC1$\alpha$-dependent myokine that drives brown-fat-like development of white fat and thermogenesis. Nature. 2012;481(7382):463-8.

58. Seebacher F, and Glanville EJ. Low levels of physical activity increase metabolic responsiveness to cold in a rat (Rattus fuscipes). PLoS One. 2010;5(9):e13022.

59. Slocum N, Durrant JR, Bailey D, Yoon L, Jordan H, Barton J, Brown RH, Clifton L, Milliken T, Harrington W, et al. Responses of brown adipose tissue to diet-induced obesity, exercise, dietary restriction and ephedrine treatment. Exp Toxicol Pathol. 2013;65(5):549-57.

60. Xu X, Ying Z, Cai M, Xu Z, Li Y, Jiang SY, Tzan K, Wang A, Parthasarathy S, He G, et al. Exercise ameliorates high-fat diet-induced metabolic and vascular dysfunction, and increases adipocyte progenitor cell population in brown adipose tissue. Am J Physiol Regul Integr Comp Physiol. 2011;300(5):R1115-25.

61. De Matteis R, Lucertini F, Guescini M, Polidori E, Zeppa S, Stocchi V, Cinti S, and Cuppini R. Exercise as a new physiological stimulus for brown adipose tissue activity. Nutr Metab Cardiovasc Dis. 2012;23(6):582-90

62. Lecker S, Zavin A, Cao P, Arena R, Allsup K, Daniels K, Joseph J, Schulze P, and Forman D. Expression of the Irisin Precursor FNDC5 in Skeletal Muscle Correlates with Aerobic Exercise Performance in Patients with Heart Failure. Circ Heart Fail. 2012;5(6):812-8

63. Timmons JA, Baar K, Davidsen PK, and Atherton PJ. Is irisin a human exercise gene? Nature. 2012;488(7413):E9-10; discussion E-1.

64. Huh JY, Panagiotou G, Mougios V, Brinkoetter M, Vamvini MT, Schneider BE, and Mantzoros CS. FNDC5 and irisin in humans: I. Predictors of circulating concentrations in serum and plasma and II. mRNA expression and circulating concentrations in response to weight loss and exercise. Metabolism. 2012;61(12):1725-38.

65. Handschin C, and Spiegelman B. The role of exercise and PGC1alpha in inflammation and chronic disease. Nature. 2008;454(7203):463-9.

66. Bordicchia M, Liu D, Amri EZ, Ailhaud G, Dessi-Fulgheri P, Zhang C, Takahashi N, Sarzani R, and Collins S. Cardiac natriuretic peptides act via p38 MAPK to induce the brown fat thermogenic program in mouse and human adipocytes. J Clin Invest. 2012;122(3):1022-36.

67. Levin E, Gardner D, and Samson W. Natriuretic peptides. N Engl J Med. 1998;339(5):321-8.

68. Sengenès C, Zakaroff-Girard A, Moulin A, Berlan M, Bouloumié A, Lafontan M, and Galitzky J. Natriuretic peptide-dependent lipolysis in fat cells is a primate specificity. Am J Physiol Regul Integr Comp Physiol. 2002;283(1):65.

69. Sengenès C, Berlan M, De Glisezinski I, Lafontan M, and Galitzky J. Natriuretic peptides: a new lipolytic pathway in human adipocytes. Faseb J. 2000;14(10):1345-51.

70. Birkenfeld AL, Boschmann M, Moro C, Adams F, Heusser K, Franke G, Berlan M, Luft FC, Lafontan M, and Jordan J. Lipid mobilization with physiological atrial natriuretic peptide concentrations in humans. $J$ Clin Endocrinol Metab. 2005;90(6):3622-8.

71. Moro C, Polak J, Hejnova J, Klimcakova E, Crampes F, Stich V, Lafontan M, and Berlan M. Atrial natriuretic peptide stimulates lipid mobilization during repeated bouts of endurance exercise. Am J Physiol Endocrinol Metab. 2006;290(5):9.

72. Birkenfeld AL, Budziarek P, Boschmann M, Moro C, Adams F, Franke G, Berlan M, Marques MA, Sweep FC, Luft FC, et al. Atrial natriuretic peptide induces postprandial lipid oxidation in humans. Diabetes. 2008;57(12):3199-204. 


\section{ENERGY DISSIPATION IN BROWN ADIPOSE TISSUE}

73. Khan A, Cheng S, Magnusson M, Larson M, Newton-Cheh C, McCabe E, Coviello A, Florez J, Fox C, Levy D, et al. Cardiac natriuretic peptides, obesity, and insulin resistance: evidence from two community-based studies. J Clin Endocrinol Metab. 2011;96(10):3242-9.

74. Magnusson M, Jujic A, Hedblad B, Engström G, Persson M, Struck J, Morgenthaler N, Nilsson P, NewtonCheh $\mathrm{C}$, Wang $\mathrm{T}$, et al. Low plasma level of atrial natriuretic peptide predicts development of diabetes: the prospective Malmo Diet and Cancer study. J Clin Endocrinol Metab. 2012;97(2):638-45.

75. Chainani-Wu N, Weidner G, Purnell D, Frenda S, Merritt-Worden T, Kemp C, Kersh E, and Ornish D. Relation of B-type natriuretic peptide levels to body mass index after comprehensive lifestyle changes. Am J Cardiol. 2010;105(11):1570-6.

76. Changchien E, Ahmed S, Betti F, Higa J, Kiely K, Hernandez-Boussard T, and Morton J. B-type natriuretic peptide increases after gastric bypass surgery and correlates with weight loss. Surg Endosc. 2011;25(7):2338-43.

77. Chen-Tournoux A, Khan A, Baggish A, Castro V, Semigran M, McCabe E, Moukarbel G, Reingold J, Durrani $\mathrm{S}$, Lewis $\mathrm{G}$, et al. Effect of weight loss after weight loss surgery on plasma N-terminal pro-B-type natriuretic peptide levels. Am J Cardiol. 2010;106(10):1450-5.

78. St Peter J, Hartley G, Murakami M, and Apple F. B-type natriuretic peptide (BNP) and N-terminal proBNP in obese patients without heart failure: relationship to body mass index and gastric bypass surgery. Clin Chem. 2006;52(4):680-5.

79. de Lemos J, McGuire D, and Drazner M. B-type natriuretic peptide in cardiovascular disease. Lancet. 2003;362(9380):316-22.

80. Tikkanen I, Fyhrquist F, Metsärinne K, and Leidenius R. Plasma atrial natriuretic peptide in cardiac disease and during infusion in healthy volunteers. Lancet. 1985;2(8446):66-9.

81. Saito Y. Roles of atrial natriuretic peptide and its therapeutic use. J Cardiol. 2010;56(3):262-70. 


\section{CHAPTER 3}

\section{Brown adipose tissue activity after a high-calorie meal in humans}

This content was published in Maarten J. Vosselman, Boudewijn Brans, Anouk A.J.J. van der Lans, Roel Wierts, Marleen A. van Baak, Felix M. Mottaghy, Patrick Schrauwen, and Wouter D. van Marken Lichtenbelt. Brown adipose tissue activity after a highcalorie meal in humans. American Journal of Clinical Nutrition 98:57-64, 2013. 


\section{Abstract}

Background: Studies in rodents have shown that brown adipose tissue (BAT) is activated upon food intake, thereby reducing metabolic efficiency.

Objective: The present study investigated whether a single high-calorie, carbohydraterich meal activates BAT in lean human adults.

Design: BAT activity was studied in eleven lean adult men (age: $23.6 \pm 2.1$ years; BMI: $22.4 \pm 2.1 \mathrm{~kg} / \mathrm{m}^{2}$ ) after consumption of a high-calorie, carbohydrate-rich meal (1622 \pm $222 \mathrm{kcal} ; 78 \% \mathrm{CHO}, 12 \% \mathrm{P}, 10 \% \mathrm{~F})$. BAT activity during 2 hours of mild cold exposure served as a positive control experiment. BAT activity was assessed by $\left[{ }^{18} \mathrm{~F}\right]$ fluorodeoxyglucose-positron emission-tomography-computed tomography ( $\left[{ }^{18}\right.$ F]FDG-PET-CT). Energy expenditure was measured by indirect calorimetry.

Results: Postprandial $\left[{ }^{18} \mathrm{~F}\right] F D G-u p t a k e$ in BAT $\left(1.65 \pm 0.99\right.$ SUV $\left._{\text {mean }}\right)$ was significantly higher than in subcutaneous $\left(0.35 \pm 0.15\right.$ SUV $\left._{\text {mean }}, P<0.05\right)$ and visceral $(0.49 \pm 0.24$ SUV $\left._{\text {mean }} P<0.05\right)$ WAT, and liver $\left(0.95 \pm 0.28\right.$ SUV $\left._{\text {mean }}, P<0.05\right)$. Postprandial BAT activity was lower compared to cold-induced BAT activity (7.19 \pm 2.09 SUV $\left._{\text {mean }}\right)$. However, postprandial BAT activity may have been underestimated due to high postprandial $\left[{ }^{18} \mathrm{~F}\right] \mathrm{FDG}$-uptake in skeletal muscle compared to cold (1.36 \pm 0.31 vs. 0.59 \pm 0.07 SUV $\left._{\text {mean }} P<0.05\right)$, reducing $\left[{ }^{18}\right.$ F]FDG bioavailability for BAT and other tissues. There was no direct relationship between BAT and diet-induced thermogenesis (DIT).

Conclusions: Glucose uptake in BAT is increased after a meal in humans indicating a role for BAT in reducing metabolic efficiency. However, the quantitative contribution of BAT to DIT, relative to other tissues such as skeletal muscle remains to be investigated. 


\section{Introduction}

Brown adipose tissue (BAT) is currently considered as a potential preventive and therapeutic target for the combat against obesity and its related metabolic diseases due to its high metabolic capacity. It is now well established that BAT is functional in human adults $(1,2)$ and that it could contribute to cold-induced thermogenesis (CIT) (3-6). Indeed, BAT is well known for its role in maintaining thermal homeostasis in small rodents and infants during cold challenges (7). However, in addition to its thermoregulatory function, BAT may also be involved in maintaining energy balance. Interestingly, it has been shown that cold-induced BAT activity is lower in obese people $(1,6,8)$.

It was originally believed that deletion of uncoupling protein-1 (UCP-1), which is crucial for heat production, did not induce obesity in mice spontaneously. However, a recent study showed that these mice do develop obesity during thermoneutral conditions (9). UCP-1-ablated mice are more susceptible to obesity during overfeeding due to a high metabolic efficiency, indicating that a greater fraction of the ingested energy is saved in body energy stores (9). In contrast, wild type rodents have a lower metabolic efficiency because BAT wastes excessive caloric intake, as demonstrated by increased BAT recruitment and enhanced norepinephrine-induced thermogenesis during high fat feeding and voluntary overeating $(9,10)$. It was believed that this decrease in metabolic efficiency during overfeeding was due to nutrient-deficient or unbalanced diets. In 1999, Stock explored this theory in humans, and in his reanalysis of twelve overfeeding studies he showed that overfeeding low-protein diets resulted in a lower weight gain than expected based on the caloric intake, and hypothesized that this was due to increased thermogenesis, and thus possibly via BAT activation (11). The role of BAT in maintaining energy balance is however not generally supported (12).

In addition to this adaptive response of BAT upon long-term overfeeding nutrient deficient diets, single meals are also known to induce an increase in thermogenesis, known as diet-induced thermogenesis (DIT), and is comprised of an obligatory and a facultative part (13). The obligatory component of DIT includes the required energy needed for digestion, absorption, distribution and storage of the nutrients, whereas the facultative part wastes a fraction of the ingested energy as heat (14). Several rodent studies have demonstrated that a single meal leads to BAT activation (15-20), and moreover that cold-acclimated animals have increased DIT (21). Therefore, these rodent data suggest that even after a single meal, BAT can be activated to waste a part of the energy intake as heat. Again, such evidence is lacking in humans. Here we set out to investigate if a single meal is able to activate BAT in humans. Since it is thought that the sympathetic nervous system (SNS) plays an important role in facultative DIT, and because it is known from human studies that of all macronutrients carbohydrates are the most potent SNS stimulators (14), we tested the effects of a high-calorie, high- 
carbohydrate meal on BAT activity in humans, and compared this to cold-activated BAT activity as a positive control.

\section{Subjects and methods}

\section{Subjects}

Eleven healthy lean men (age: $23.6 \pm 2.1$ years; BMI: $22.4 \pm 2.1 \mathrm{~kg} / \mathrm{m}^{2}$ ) were recruited by advertising in the Maastricht University Medical Centre+. All subjects signed a written informed consent and underwent a standard medical examination. The local medical ethical committee approved the study protocol and all subjects were treated according to declaration of Helsinki of 1975, as revised in 1983.

\section{Study design and measurements}

Brown adipose tissue activity was determined during two experimental conditions, after the intake of a high-calorie meal and during mild cold exposure. The mild cold experiment was conducted in 6 out of 11 subjects and served as a positive control. The experiments were conducted in Maastricht (The Netherlands) during the months September till December, with outside temperatures varying between 0 and $20^{\circ} \mathrm{C}$. Subjects arrived in the morning after an overnight fast and were asked to refrain from heavy exercise on the previous day. After arrival, subjects ingested a telemetric pill (CoreTemp, HT150002, USA) for core temperature measurement and a cannula was inserted in the antecubital vein for blood sampling. Subsequently, subjects were equipped with wireless temperature sensors (iButtons, Maxim integrated, USA) at the 14 sites prescribed by ISO-standard 9886:2004 (Ergonomics - Evaluation of thermal strain by physiological measurements, International Standards Organization, Geneva, Switzerland), a heart rate monitor across the chest (Polar T31, USA) and a blood pressure cuff on the left upper arm (Cresta, Taiwan) in order to measure skin temperatures, heart rate, and blood pressure respectively. Laser Doppler probes were attached for skin perfusion measurements at the ventral side of the hand at the base of the thumb, at the ventral side of the hallux (Perimed PF4000, Sweden), at the ventral side of the forearm halfway between the elbow and the wrist, and at the abdomen halfway between the umbilicus and the left lateral side of the body (Perimed PF5000, Sweden). Subjects were measured in a specially equipped air-permeable tent (Colorado altitude training, USA), in which ambient temperature could be tightly controlled. During the measurements, subjects wore standardized clothing (0.49 clo).

The meal intake experiment started with a baseline measurement of 45 minutes (Figure 1) after which each subject ingested a high-calorie (average: $1622 \pm 222 \mathrm{kcal}$ ), carbohydrate-rich ( $78 \% \mathrm{CHO}, 10 \% \mathrm{~F}, 12 \% \mathrm{P}$ ) meal consisting of $50 \%$ of their daily required energy intake. Subject's total daily required energy intake was based on the basal metabolic rate determined by the Harris \& Benedict formula (22) multiplied by 
the physical activity level (PAL), which was based on the Baecke Questionnaire (23). The meal was served by the researcher in a liquid form (Nutriprotein and Nutrical, Nutricia, the Netherlands), in order to obtain maximal uptake rate in the gastrointestinal tract. After the subjects finished the meal (within 15 minutes), energy expenditure was measured for two hours. The $\left[{ }^{18} \mathrm{~F}\right] \mathrm{FDG}$-tracer $(50 \mathrm{MBq}, 1.35 \mathrm{mCi}$ ) was injected 75 minutes after the completion of the meal, as pilot studies $(n=6)$ in our laboratory showed the highest peak in postprandial energy expenditure at this timepoint, assuming maximal BAT activity. For the analysis of postprandial energy expenditure a stable period of 20 minutes after the tracer injection was averaged. Diet-induced thermogenesis was measured as the increase (in percentage) of energy expenditure during these 20 minutes compared to baseline. This period was chosen to relate DIT to BAT activity, as the latter is determined in the post-tracer period as well. Blood samples were drawn during baseline, 30 minutes, 60 minutes and 120 minutes after the meal. Subjects were transferred to the positron emission PET-CT scanner (Gemini TF PET-CT, Philips, The Netherlands) one hour after the tracer injection in both experiments in order to measure BAT activity. Although we are aware that $\left[{ }^{18} \mathrm{~F}\right] \mathrm{FDG}$ uptake measures glucose uptake, and not directly BAT oxidative metabolism and thermogenesis, we use BAT activity and $\left[{ }^{18} \mathrm{~F}\right]$ FDG-uptake as reciprocal terms.

The mild cold experiment consisted of a baseline measurement of 45 minutes, followed by two hours of mild cold exposure in which we used a personalized cooling protocol (24) in order to obtain maximal non-shivering thermogenesis. We used the same post-tracer period as in the meal experiment for cold-induced energy expenditure analysis. Cold-induced thermogenesis was defined as the percentual increase in energy expenditure during this period compared to baseline. The $\left[{ }^{18} \mathrm{~F}\right] \mathrm{FDG}$ tracer was injected one hour after the onset of cold exposure. Blood samples were drawn during baseline and after one hour of cold exposure. 


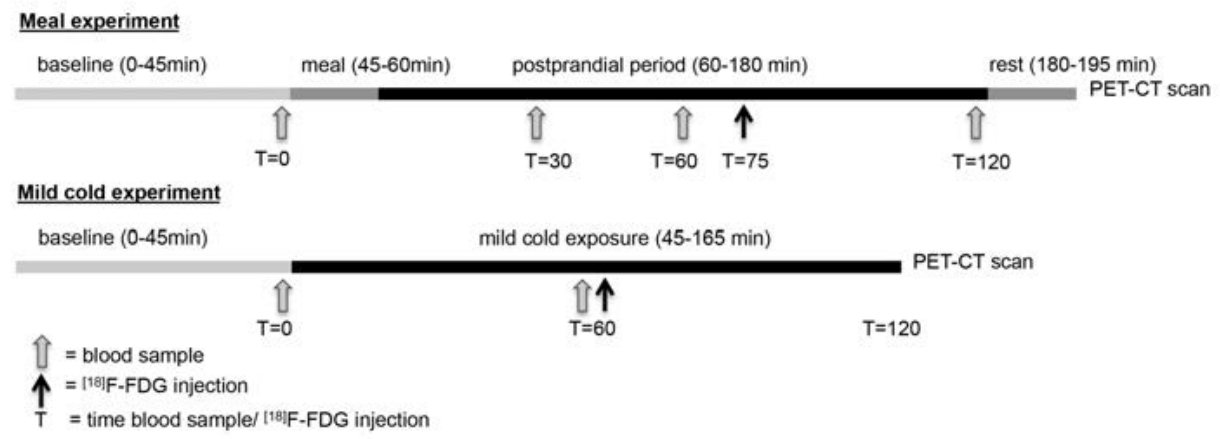

Figure 1. Study protocol. Both experiments started with a baseline period of 45 minutes during $25{ }^{\circ} \mathrm{C}$ degrees. A blood sample was taken at the end of this period. In the meal experiment, subjects were asked to ingest the meal within 15 minutes. The postprandial period lasted for 120 minutes. One hour and 15 minutes after the meal, the ${ }^{[18]}$ F-FDG tracer ( $t=75 \mathrm{~min}$ ) was injected followed by the PET-CT scan one hour later. The rest period of 15 minutes was held to standardize the time between injection and PET-CT scan (one hour). Blood samples were taken 30, 60 and 120 minutes after the meal. The mild cold exposure lasted for 120 minutes, and one hour after the onset of the cold exposure a blood sample was taken and the ${ }^{[18]}$ F-FDG tracer was injected. The PET-CT scan was conducted one hour after the ${ }^{[18]}$ F-FDG injection ( $\left.t=120\right)$.

\section{PET protocol and analysis}

The PET-CT scanning protocol and analysis were similar to our previous studies using static imaging (24), in which a low-dose CT scan (120 kV, $30 \mathrm{mAs})$ preceded the PET scan. The PET scan was used to determine the FDG-uptake and the CT image was used for attenuation and scatter correction of the PET scan. We used PMOD software, version 3.0 (PMOD Technologies) for the analysis of BAT activity. The PET-images were checked for remaining radioactivity at the injection site, and these concentrations were all below $1 \%$ of the total activity of $\left[{ }^{18}\right.$ F]FDG present in the body at the time of scanning.

Together, the researcher and a nuclear-medicine physician (BB) analyzed the PET$\mathrm{CT}$ images. We analyzed the average SUV $\left(\mathrm{SUV}_{\text {mean }}\right)$ in the cold and meal experiment in supraclavicular BAT, subcutaneous WAT and visceral WAT, skeletal muscle, liver, and brain. The SUV $V_{\text {mean }}$ of each tissue was calculated by selecting cubes as volume of interests on the relevant tissues. The same anatomical locations were used in the analysis of both experiments. The SUV $\mathrm{V}_{\text {mean }}$ of BAT was measured in the supraclavicular fat area (total volume $2.67 \mathrm{~cm}^{3}$ ). To determine the average $\left[{ }^{18} \mathrm{~F}\right]$ FDG-uptake in the deltoid muscle and the triceps and biceps brachii muscle, we analyzed the middle (thickest) part of these muscles in both arms. The uptake in the erector spinae muscle was measured in the cervical (C-7), thoracic (T-8), and lumbal (L-3) part of the muscle (total volume in muscle $32 \mathrm{~cm}^{3}$ ). The subcutaneous WAT was measured in the dorsolumbar region near vertebrae L-3 and L-4 $\left(8 \mathrm{~cm}^{3}\right)$, whereas the visceral WAT was measured behind the xiphoid $\left(0.14 \mathrm{~cm}^{3}\right)$. The middle part of liver was chosen for analysis and we avoided uptake in large blood vessels by carefully distinguishing 
between the liver segments $\left(4 \mathrm{~cm}^{3}\right)$. Brain activity was measured in the right and left cerebellum $\left(8 \mathrm{~cm}^{3}\right)$. Adipose tissue was distinguished from muscle tissue by means of Hounsfield Units (CT scan), in which adipose tissue was considered to lie within -10 to $180 \mathrm{HU}$ and skeletal muscle between +15 and $+100 \mathrm{HU}$.

\section{Blood analysis}

Blood was collected from the antecubital vein to determine several blood parameters. Plasma concentrations of free fatty acids (NEFA-HR set, Wako Chemicals, Neuss, Germany), free glycerol (Glycerol kit, R-Biopharm, Darmstadt, Germany) total glycerol ( $A B X$ Triglyceriden $C P$, Radiometer, Horiba ABX, Montpellier, France) and glucose (ABX Glucose HK CP, Radiometer, Horiba ABX, Montpellier, France) were determined on a COBAS FARA centrifugal spectrophotometer (Roche Diagnostica, Basel, Switzerland). Plasma triglyceride concentrations were calculated by subtracting free glycerol from the total glycerol concentrations, and serum insulin was analyzed on a Gamma Counter (2470 Automatic Gamma Counter Wizard ${ }^{2}$ Wallac, Perkin Elmer, USA) with a Human Insulin specific RIA kit (Milipore, USA). Plasma norepinephrine and epinephrine were analyzed using reagents from Recipe (Recipe Chemicals and Instruments, Munich, Germany) on a HPLC through electrochemical detection.

\section{Statistical analysis}

Statistical analysis was performed with IBM SPSS Statistics18.0 for Mac. Reported data are expressed as means \pm SD. The differences between baseline and cold exposure have been compared by Wilcoxon's test $(n=6)$. Paired sample t-tests were used to compare the difference between baseline and dietary intake $(n=11)$. The SUV $V_{\text {mean }}$ values for the various tissues in the cold and meal experiment were compared by Wilcoxon's test $(n=6)$. Blood parameters within the meal experiment were analyzed by one-way ANOVA with Bonferroni correction for post hoc analysis. Spearman rank correlation $(n=6)$ and Pearson correlation $(n=11)$ were performed in order to identify relationships between variables. $P$ values of less than 0.05 were considered as statistically significant.

\section{Results}

\section{Cold -and diet-induced thermogenesis}

Energy expenditure significantly increased in the postprandial phase compared to baseline $(P<0.001$; Figure 2A), with an average DIT of $19.9 \%$ (range $6.9-31.3 \%$ ). During cold exposure, energy expenditure significantly increased compared to baseline as well $(P=0.028$; Figure $2 \mathrm{~A}$ ), with an average $\mathrm{CIT}$ of $13.1 \%$ (range $7-17.1 \%$ ). There was no relationship between CIT and DIT $(n=6)$. As expected, the respiratory quotient significantly increased after the meal $(P<0.001$; Figure 2B). Furthermore, 


\section{BROWN ADIPOSE TISSUE ACTIVITY AFTER DIETARY INTAKE}

carbohydrate oxidation increased after the meal ( $P<0.001$; Figure $2 \mathrm{C}$ ), whereas fat oxidation decreased $(P=0.027$; Figure 2D). During cold exposure, there was a preference for the use of fat as a substrate as shown by the decrease in respiratory quotient $(P=0.041)$ and increase in fat oxidation $(P=0.028)$. The oxidation of carbohydrates decreased during cold exposure $(P=0.046)$. The effects of both interventions on heart rate, blood pressure, and body temperatures are summarized in Table 1.

Table 1. The effect of the meal and cold exposure on metabolic, cardiovascular, and thermoregulatory parameters

\begin{tabular}{|c|c|c|c|c|}
\hline \multirow[b]{2}{*}{ Parameter } & \multicolumn{2}{|c|}{ Meal $(n=11)$} & \multicolumn{2}{|c|}{ Cold $(n=6)$} \\
\hline & Baseline & Meal & Baseline & Cold \\
\hline Heart rate (beats/min) & $61 \pm 7.9$ & $74 \pm 10.2 * *$ & $55 \pm 3.5$ & $52 \pm 3.2 *$ \\
\hline Systolic blood pressure (mmHg) & $119 \pm 6$ & $126 \pm 6.8 * *$ & $120 \pm 9.2$ & $133 \pm 8.9 *$ \\
\hline Diastolic blood pressure $(\mathrm{mmHg})$ & $70 \pm 6.1$ & $71 \pm 6.8$ & $73 \pm 3.2$ & $82 \pm 6.2 *$ \\
\hline Mean Skin Temperature $\left({ }^{\circ} \mathrm{C}\right)$ & $33.2 \pm 0.4$ & $33.5 \pm 0.4 * *$ & $32.7 \pm 0.3$ & $28.8 \pm 0.5 *$ \\
\hline Core Temperature $\left({ }^{\circ} \mathrm{C}\right)$ & $36.9 \pm 0.1$ & $36.8 \pm 0.3 *$ & $36.9 \pm 0.2$ & $36.9 \pm 0.2$ \\
\hline Proximal Temperature $\left({ }^{\circ} \mathrm{C}\right)$ & $34.2 \pm 0.3$ & $35.0 \pm 0.4 * *$ & $33.3 \pm 0.6$ & $30.8 \pm 1.2 *$ \\
\hline Distal Temperature $\left({ }^{\circ} \mathrm{C}\right)$ & $31.2 \pm 1.8$ & $31.1 \pm 2.1$ & $30.8 \pm 1.2$ & $22.6 \pm 1.1 *$ \\
\hline Gradient proximal, distal $\left({ }^{\circ} \mathrm{C}\right)$ & $3.0 \pm 1.8$ & $3.9 \pm 2.5 *$ & $2.5 \pm 1.9$ & $8.2 \pm 2.0 *$ \\
\hline
\end{tabular}

All values are means \pm SDs. Paired sample t-test was used to analyze differences between meal and baseline and Wilcoxon test to analyze differences between cold and baseline. $* P<0.05, * * P<0.001$ 
A
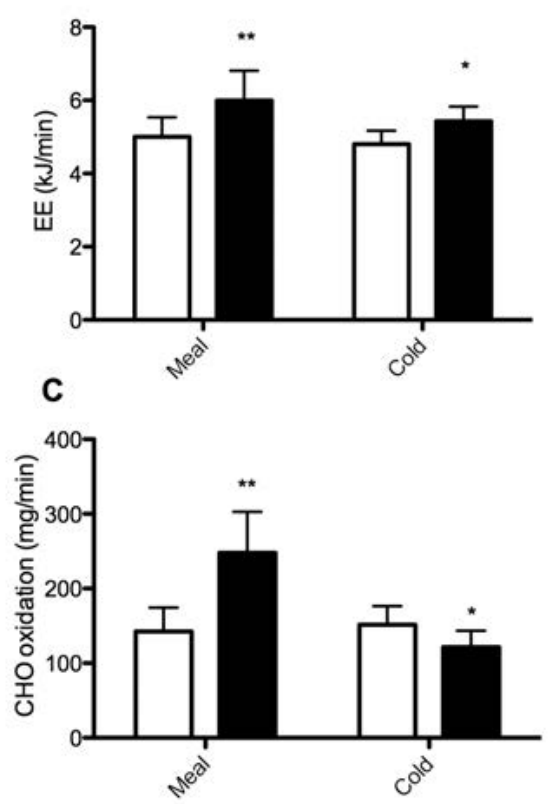

B
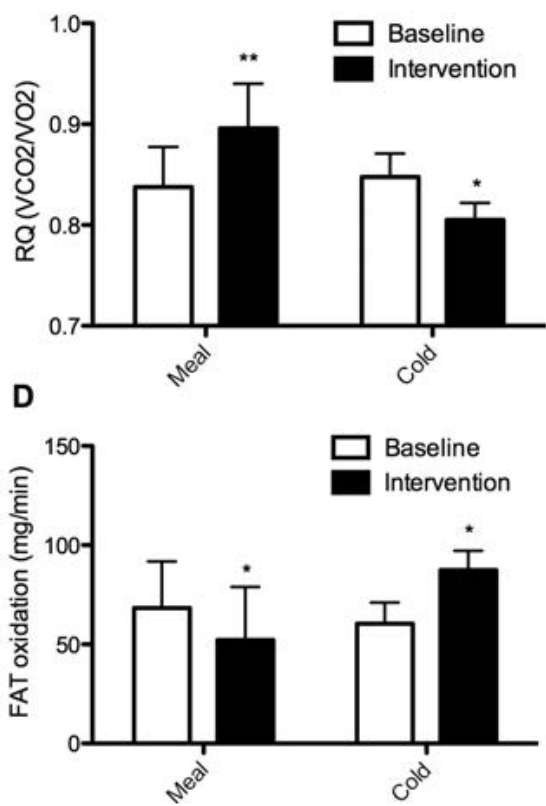

Figure 2. Mean $( \pm S D$ ) energy expenditure and substrate oxidation after meal intake and cold exposure. (A) Energy expenditure, (B) respiratory quotient, (C) carbohydrate oxidation, (D) fat oxidation during baseline (white bars) and intervention (black bars) in the postprandial state $(n=11)$ and during cold exposure $(n=6)$ measured during the post-tracer period. Wilcoxon signed-rank tests were used to measure the difference between both experiments. ${ }^{*}$ Significantly different from baseline, $P<0.05$. ${ }^{*}$ Significantly different from baseline, $P<0.001$. $\mathrm{CHO}$, carbohydrate; $\mathrm{EE}$, energy expenditure; $\mathrm{RQ}$, respiratory quotient.

\section{Glucose uptake in brown adipose tissue and additional tissues}

The $\left[{ }^{18} \mathrm{~F}\right] \mathrm{FDG}$-uptake in the upper body is depicted in Figure 3A, 3B. Interestingly, average postprandial $\left[{ }^{18} \mathrm{~F}\right] \mathrm{FDG}$-uptake in BAT $\left(1.65 \pm 0.99 \mathrm{SUV}_{\text {mean }}\right)$ was markedly higher than in subcutaneous $\left(0.35 \pm 0.15 \mathrm{SUV}_{\text {mean }}, P<0.001\right)$ and visceral $(0.49 \pm 0.24$ SUV $\left._{\text {mean }}, P<0.001\right)$ WAT, and in the liver $\left(0.95 \pm 0.28\right.$ SUV $\left._{\text {mean }}, P=0.042\right)$ (Figure 3C). The average $\left[{ }^{18} \mathrm{~F}\right] \mathrm{FDG}$-uptake trended to be higher compared to skeletal muscle $(1.36 \pm$ $\left.0.31 \mathrm{SUV}_{\text {mean }}\right)$, although this difference was not statistically significant. The activity in BAT was comparable to the brain $\left(1.81 \pm 0.42 \mathrm{SUV}_{\text {mean }}, N S\right)$.

Cold exposure activated BAT as demonstrated by $\left[{ }^{18} \mathrm{~F}\right] \mathrm{FDG}$-uptake in the neck, supraclavicular, paraspinal, para-aortic, axillary, mediastinal, and perirenal regions in all subjects (Figure 3A, 3B). Also during cold exposure, the $\left[{ }^{18} \mathrm{~F}\right]$ FDG-uptake was similar in BAT (7.19 $\pm 2.09 \mathrm{SUV}_{\text {mean }}$ ) and brain (7.19 $\pm 0.74 \mathrm{SUV}_{\text {mean }}$ ) (Figure 3D). Uptake of $\left[{ }^{18} \mathrm{~F}\right] \mathrm{FDG}$ in BAT was significantly higher than in skeletal muscle $\left(0.59 \pm 0.07 \mathrm{SUV}_{\text {mean },} P=\right.$ $0.028)$, subcutaneous WAT $\left(0.18 \pm 0.05 \mathrm{SUV}_{\text {mean }} P=0.028\right)$, visceral WAT $(0.51 \pm 0.23$ $\left.\operatorname{SUV}_{\text {mean, }} P=0.028\right)$, and the liver $\left(1.83 \pm 0.28 \mathrm{SUV}_{\text {mean }} P=0.028\right)$. 
Comparing meal with cold exposure demonstrated that the $\left[{ }^{18} \mathrm{~F}\right] \mathrm{FDG}$-uptake in BAT $(P=0.028)$, liver $(P=0.028)$ and brain $(P=0.043)$ were significantly lower during the meal experiment compared to cold exposure (Figure $3 \mathrm{E}$ ), whereas skeletal muscle uptake was significantly higher during the meal experiment $(P=0.028)$. This reflects the well-known role of skeletal muscle in postprandial glucose homeostasis. The $\left[{ }^{18}\right.$ F]FDG-uptake in WAT was not significantly different between cold and meal, although a trend was observed for higher uptake after meal in subcutaneous WAT ( $P=$ 0.075).

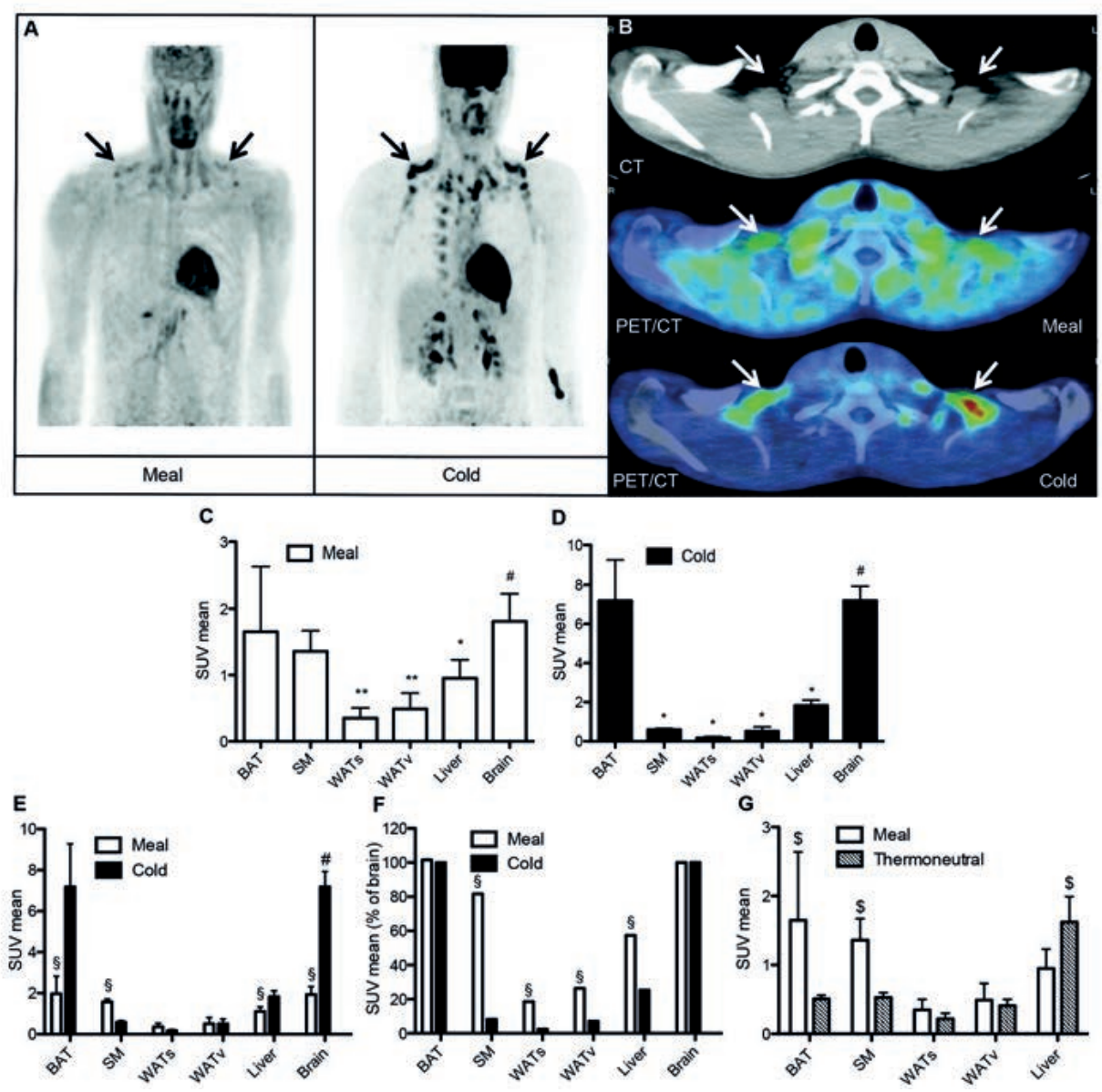

Figure 3. Mean ( \pm SD) uptake of $\left[{ }^{18} \mathrm{~F}\right] F D G$ in BAT and other tissues during cold exposure and the postprandial state. (A) $\left[{ }^{18}\right.$ F]FDG PET images of one subject demonstrating BAT activity (black arrows) after the meal (left) and during cold exposure (right). (B) Transversal CT (top) and PET/CT fusion slices of the supraclavicular region demonstrating BAT activity (white arrows) after the meal (middle) and during cold exposure (bottom). (C) Comparison (paired sample t-tests) of $\left[{ }^{18} \mathrm{~F}\right] \mathrm{FDG}$-uptake in BAT with several tissues after the meal $(\mathrm{n}=11$, \# $n=8)$. (D) Comparison (Wilcoxon signed-rank tests) of $\left[{ }^{18} \mathrm{~F}\right]$ FDG-uptake in BAT with several tissues during cold exposure $(n=6, \# n=5)$. (E) Comparison (Wilcoxon signed-rank tests) of the $\left[{ }^{18} F\right]$ FDG-uptake after the meal 
with cold exposure ( $n=6, \# n=5)$. (F) Illustration of the $\left.{ }^{18} \mathrm{~F}\right] \mathrm{FDG}$-uptake in all tissues relative to the brain (cerebellum) to indicate tracer competition. The $\left[{ }^{18} \mathrm{~F}\right] \mathrm{FDG}$-uptake in the cerebellum was set at $100 \%$, as brain glucose uptake was expected to be constant during both interventions. Wilcoxon signed-rank tests were used to determine the differences in $\left[{ }^{18} F\right] F D G$-uptake between the cold and meal experiment $(n=6, \# n=5)$. (G) Comparison (Mann-Whitney $\mathrm{U}$ test) of the postprandial $\left[{ }^{18} \mathrm{~F}\right] \mathrm{FDG}$-uptake (current study) with the uptake in the fasted state during thermoneutral conditions measured in a previous study $(\mathrm{n}=3)(1) .{ }^{*} P<0.05,{ }^{* *} P$ $<0.001$ significantly different from BAT. $\S P<0.05$ cold exposure significantly different from the postprandial state. $\$ P<0.05$ postprandial state significantly different from fasted thermoneutral conditions. BAT, brown adipose tissue; CT, computed tomography; PET, positron emission tomography; SM, skeletal muscle; SUV, standard uptake value; WATs, subcutaneous white adipose tissue; WATv, visceral white adipose tissue.

The high postprandial $\left[{ }^{18} \mathrm{~F}\right]$ FDG-uptake in skeletal muscle, combined with the fact that total mass of skeletal muscle is much larger than any other organ in the human body, resulted in a marked change in $\left[{ }^{18}\right.$ F]FDG distribution volume and a large fraction of the $\left[{ }^{18} \mathrm{~F}\right]$ FDG tracer to be directed to muscle. This high $\left[{ }^{18} \mathrm{~F}\right] \mathrm{FDG}$-uptake in skeletal muscle might have reduced the availability of $\left[{ }^{18} \mathrm{~F}\right] \mathrm{FDG}$ for other tissues, which is clearly visible in the cerebellum (Figure 3A). Normally, glucose uptake/metabolism is held fairly constant in the brain, since glucose is the brain's major fuel. We therefore hypothesized that this tracer competition might have underestimated true glucose uptake in BAT. In order to correct for this, we also expressed the SUV $\mathrm{V}_{\text {mean }}$ in the tissues as percentages of total $\left[{ }^{18}\right.$ F]FDG-uptake in the cerebellum (Figure 3F) (25). We chose the cerebellum as a representative brain region because it has been shown previously that cold exposure does not affect metabolism in the cerebellum (26), and furthermore that the cerebellum is the most reliable reference area in the brain during mild hyperglycemic conditions (25). Figure $\mathbf{3 F}$ illustrates the possible underestimation of $\left[{ }^{18} \mathrm{~F}\right] \mathrm{FDG}$-uptake in BAT (and the other tissues) during postprandial conditions, and indicates that glucose uptake in BAT in the postprandial state may be comparable to the cold-stimulated condition.

In addition, we compared the postprandial $\left[{ }^{18} \mathrm{~F}\right] \mathrm{FDG}$-uptake with the uptake in the fasted state measured during thermoneutral conditions in a previous study $(n=3)(1)$. The $\left[{ }^{18} \mathrm{~F}\right] F D G-u p t a k e$ in BAT was significantly higher during the postprandial state compared to fasted thermoneutral (FTN) conditions (meal: $1.65 \pm 0.99$ versus FTN: $0.51 \pm 0.05$ SUV $_{\text {mean }} P=0.024$, Figure $3 G$ ), confirming increased postprandial BAT glucose uptake. Furthermore, postprandial $\left[{ }^{18} \mathrm{~F}\right] \mathrm{FDG}$-uptake in skeletal muscle was higher (meal: $1.36 \pm 0.31$ SUV $_{\text {mean }}$ versus FTN: $0.54 \pm 0.07$ SUV $_{\text {mean }}, P=0.01$ ), whereas the uptake in the liver was lower (meal: $0.95 \pm 0.28$ SUV $_{\text {mean }}$ versus FTN: $1.62 \pm 0.36$ SUV $_{\text {mean }}, P=0.024$ ) compared to FTN conditions. Unfortunately, we could not obtain the $\left[{ }^{18} \mathrm{~F}\right]$ FDG-uptake values in the brain during the FTN conditions.

We also analyzed the relationships between BAT and energy expenditure in both experiments. Interestingly, there was a significant relation between CIT and coldinduced BAT activity $(r=0.83, P=0.042 ; n=6)$. However, there was no association between postprandial BAT activity and DIT ( $r=0.11, N S ; n=11)$. Finally, we did not find 
a relationship between cold-induced BAT activity and postprandial BAT activity $(r=-$ $0.49, N S ; \mathrm{n}=6)$.

\section{Hormones, metabolites, and cold acclimatization}

As expected, the intake of the carbohydrate-rich meal significantly suppressed lipolysis already after 30 minutes as demonstrated by decreased plasma free fatty acids (FFA's) $(P<0.001)$ and free glycerol $(P=0.031)$ concentrations, and remained significantly suppressed during the entire experiment. The meal significantly increased plasma glucose concentrations at all time points $(P<0.001)$, as well as plasma insulin concentrations ( $\mathrm{t}=30, P=0.004 ; \mathrm{t}=60$ and $\mathrm{t}=120, \mathrm{p}<0.001)$. Norepinephrine (NE) concentrations tended to increase after the meal $(P=0.10)$. In contrast, cold exposure increased lipolysis as shown by increased FFA $(P=0.028)$ and free glycerol concentrations (Table 2). Furthermore, plasma norepinephrine concentration was significantly increased during cold exposure $(P=0.028)$ suggesting increased sympathetic norepinephrine spill over. We found no correlation between postprandial NE concentrations and both BAT activity and DIT. In addition no correlation was found between NE and cold-induced BAT activity and thermogenesis. We found a relationship between plasma insulin concentrations (AUC) and BAT activity $(r=0.61, P$ $=0.045)$, whereas no relationship was present between plasma glucose concentrations (AUC) and BAT activity $(r=-0.08, P=0.812)$.

Interestingly we observed a negative relationship between the average outdoor temperatures during the two weeks previous to the experiment (obtained from local weather station) and postprandial $\left[{ }^{18} \mathrm{~F}\right] \mathrm{FDG}$-uptake in BAT $(r=-0.72, P=0.012$, Figure 4A), subcutaneous WAT ( $r=-0.60, P=0.046$, Figure 4B), and visceral WAT $(r=-0.83, P$ $=0.002$, Figure $4 \mathrm{C}$ ).

Table 2. Hormone and metabolite concentrations in the postprandial state and during cold exposure

\begin{tabular}{llllllll}
\hline & \multicolumn{3}{l}{ Meal $(\mathrm{n}=11)$} & & \multicolumn{2}{c}{ Cold $(\mathrm{n}=6)$} \\
\cline { 2 - 4 } \cline { 7 - 8 } Parameter & Baseline & Diet $30 \mathrm{~min}$ & Diet $60 \mathrm{~min}$ & Diet $120 \mathrm{~min}$ & & Baseline & Cold $60 \mathrm{~min}$ \\
\hline FFA $(\mu \mathrm{mol} / \mathrm{L})$ & $378 \pm 64$ & $201 \pm 63 * *$ & $98.2 \pm 26.8 * *$ & $68.2 \pm 10.4 * *$ & $401 \pm 93$ & $756 \pm 154 *$ \\
Glyc free $(\mu \mathrm{mol} / \mathrm{L})$ & $51.8 \pm 12.5$ & $39.8 \pm 9.8 *$ & $32.7 \pm 15.4 *$ & $28.6 \pm 15.3 * *$ & $55.9 \pm 10.8$ & $123 \pm 36^{*}$ \\
TG $(\mu \mathrm{mol} / \mathrm{L})$ & $750 \pm 253$ & $926 \pm 417$ & $934 \pm 422$ & $815 \pm 307$ & & $776 \pm 234$ & $811 \pm 273$ \\
Glucose $(\mathrm{mmol} / \mathrm{L})$ & $5.1 \pm 0.2$ & $7.9 \pm 1.3 * *$ & $7.2 \pm 1.3 * *$ & $6.6 \pm 0.8 * *$ & & $5.1 \pm 0.2$ & $5.0 \pm 0.2$ \\
Insulin $(\mathrm{mU} / \mathrm{mL})$ & $12.5 \pm 3.3$ & $155 \pm 99 *$ & $120 \pm 33 * *$ & $124 \pm 59 * *$ & & $12.3 \pm 2.1$ & $12.7 \pm 1.7$ \\
NE $(\mathrm{ng} / \mathrm{L})$ & $318 \pm 148$ & $429 \pm 253$ & $385 \pm 175$ & $369 \pm 152$ & & $239 \pm 101$ & $641 \pm 140 *$ \\
Epi $(\mathrm{ng} / \mathrm{L})$ & $32.0 \pm 10.6$ & $26.3 \pm 9.3$ & $28.6 \pm 12.6$ & $32.0 \pm 12.6$ & & $29.6 \pm 9.1$ & $26.2 \pm 11.8$ \\
\hline
\end{tabular}

All values are means \pm SDs. ANOVA with Bonferroni correction was used to analyze differences between the meal and baseline and Wilcoxon test to analyze differences between cold and baseline. $* P<0.05, * * P<$ 0.001. Epi, epinephrine; Glyc, glycerol; FFA, free fatty acids; NE, norepinephrine TG, triglycerides. 

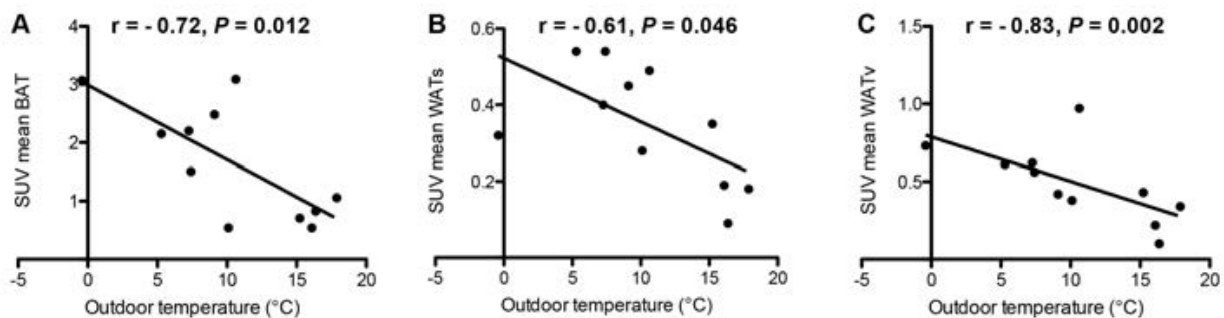

Figure 4. Relationship between postprandial $\left[{ }^{18}\right.$ F]FDG-uptake in BAT (A), WATs (B), and WATv (C) with the mean outdoor temperature over 2 weeks previous to the meal experiment. BAT, brown adipose tissue; FDG, fluorodeoxyglucose; $r$, Pearson correlation coefficient; WATs, subcutaneous white adipose tissue, WATv, visceral white adipose tissue.

\section{Discussion}

We here show postprandial glucose uptake in BAT in lean young adult men. We found that the average $\left[{ }^{18}\right.$ F]FDG-uptake in BAT after a high-calorie, carbohydrate-rich meal was higher compared to WAT and the liver. In fact, $\left[{ }^{18} \mathrm{~F}\right]$ FDG-uptake in BAT tended to be higher compared to skeletal muscle, which is well-known for its role in postprandial glucose homeostasis, and comparable to the brain. Furthermore, $\left[{ }^{18} \mathrm{~F}\right] \mathrm{FDG}$-uptake in BAT during the postprandial state was significantly higher compared to the fasted state (during thermoneutral conditions) measured in a previous study (1). These results indicate that a single meal may be able to activate human brown adipose tissue.

The absolute magnitude of postprandial BAT activity was lower compared to coldinduced BAT activity, which is in agreement with findings in rodent studies (7). However, postprandial BAT activity may have been underestimated due to the high tracer uptake in skeletal muscle, thereby diminishing tracer bioavailability for other tissues. This was clearly illustrated by a decrease in $\left[{ }^{18} \mathrm{~F}\right] \mathrm{FDG}$-uptake in the cerebellum, which glucose uptake/metabolism was expected to be constant during both experimental conditions. This unexpected decrease of $\left[{ }^{18} \mathrm{~F}\right] \mathrm{FDG}$-uptake has been observed previously during postprandial mild hyperglycemic conditions (110-160 $\mathrm{mg} / \mathrm{dL} \approx 6.2-8.9 \mathrm{mmol} / \mathrm{L}$ ) (25). Adjusting for this "stealing effect", by expressing $\left[{ }^{18}\right.$ F]FDG-uptake relative to the cerebellum, suggests that postprandial glucose uptake in BAT is comparable to cold-induced BAT activation. It should be noted that this adjustment assumes that glucose uptake in the cerebellum is unaffected by meal consumption. In addition to the stealing phenomenon, the $\left[{ }^{18}\right.$ F]FDG-uptake in the brain could also be reduced due to increased saturation of the glucose transporters by glucose originating from the meal (27). Nevertheless, postprandial $\left[{ }^{18}\right.$ F]FDG-uptake was highest in BAT of all peripheral tissues studied.

So far, an effect of meal consumption on BAT activity in humans has not been studied directly. A recent study in humans examined the effects of a high fat meal on 
BAT activity, however these measurements were combined with cold exposure (28). $\left[{ }^{18}\right.$ F]FDG-uptake in BAT upon cold exposure was higher when subjects were in the fasted state compared to the (high-fat) fed state. Although these results seem contrary to our findings, they are also confounded by the high glucose uptake in skeletal muscle after the high-fat meal, which precludes separation of the effects of cold from the effect of meal on BAT activity. In fact, the authors also concluded that the lower uptake in BAT was likely due to tracer dilution by skeletal muscle. They did not measure uptake in the brain, although the PET-image depicted in their paper indicates reduced postprandial brain $\left[{ }^{18} \mathrm{~F}\right] \mathrm{FDG}$-uptake compared to cold exposure. The advantage of our study is that we did not combine the postprandial study with coldexposure in one single experimental test, which allows us to directly test the effect of a single meal on BAT activity.

Another human study investigated the effects of insulin infusion (hyperinsulinemic euglycemic clamp) on glucose uptake in BAT (in a warm environment) and found that the uptake rate was higher compared to WAT and comparable to skeletal muscle, indicating BAT to be an insulin sensitive tissue (5). In contrast to cold exposure, they did not find increased BAT perfusion, which shows that insulin by itself does not induce BAT thermogenesis, for which BAT perfusion is an indirect measure. Furthermore, they did not find increased plasma NE concentrations, suggesting no sympathetic stimulation by insulin. Whether in the present study BAT glucose uptake reflects BAT thermogenesis or solely insulin mediated glucose uptake without concomitant heat production cannot be determined. Interestingly, we did find a relationship between plasma insulin concentrations and BAT activity, indicating a likely role for insulin in mediating BAT glucose uptake and possibly thermogenesis.

In rodents, experiments have repeatedly shown BAT activation after single meals. It has been demonstrated that a single meal increases mitochondrial uncoupling (15) and blood flow (18) in BAT, as well as oxygen consumption measured in vitro $(19,20)$. This is likely regulated via the SNS, since NE concentrations and turnover also increased after a single meal (17). In the present study NE concentrations tended to increase after the meal suggesting postprandial sympathetic stimulation. We however did not find a relationship between postprandial $\left[{ }^{18} \mathrm{~F}\right] \mathrm{FDG}$-uptake in BAT and plasma NE. The increased sympathetic drive after a single meal found in rodents is possibly regulated via elevated concentrations of glucose and insulin activity sensed by the hypothalamus (7). This might be true for insulin in humans as well as demonstrated by its relationship with $\left[{ }^{18} \mathrm{~F}\right] \mathrm{FDG}$-uptake in BAT in the present study.

Although $\left[{ }^{18} \mathrm{~F}\right]$ FDG-PET/CT scanning merely measures glucose uptake, it would be tempting to suggest that the meal induced BAT thermogenesis. However, we did not find a relation between BAT activity and DIT. It should be noted that the potential contribution of BAT to the facultative part of DIT is difficult to detect via whole body energy expenditure (29). Unfortunately, we were not able to distinguish between the facultative and obligatory part of DIT in the current experiment. With respect to cold 
exposure, we did find a correlation between BAT activity and CIT, which has been shown previously $(3,5,6)$, although not consistently $(1,24)$.

Interestingly, we found a relationship between postprandial BAT activity and the outdoor temperature averaged over two weeks previous to the experiment. This is likely due to an adaptation of BAT to long-term cold exposure (i.e. cold acclimatization). This could suggest that the contribution of BAT to postprandial thermogenesis may be enhanced by cold-acclimatization, which has been shown in rats (21). It could thus be speculated that BAT most likely contributes to postprandial glucose uptake and possibly thermogenesis during cold seasons.

In conclusion, glucose uptake in BAT increases after a single meal in humans indicating a role for BAT in reducing metabolic efficiency. However, we did not find a direct relation between BAT activity and DIT. The quantitative contribution of BAT to DIT, as well as its role in energy balance regulation, remains to be investigated in future research. It would also be important to determine whether postprandial BAT activity is reduced in overweight and obese subjects.

\section{References}

1. van Marken Lichtenbelt WD, Vanhommerig JW, Smulders NM, Drossaerts JM, Kemerink GJ, Bouvy ND, Schrauwen P, and Teule GJ. Cold-activated brown adipose tissue in healthy men. $N$ Engl J Med. 2009;360(15):1500-8.

2. Virtanen KA, Lidell ME, Orava J, Heglind M, Westergren R, Niemi T, Taittonen M, Laine J, Savisto NJ, Enerback S, et al. Functional brown adipose tissue in healthy adults. N Engl J Med. 2009;360(15):151825.

3. Yoneshiro T, Aita S, Matsushita M, Kameya T, Nakada K, Kawai Y, and Saito M. Brown adipose tissue, whole-body energy expenditure, and thermogenesis in healthy adult men. Obesity (Silver Spring). 2011;19(1):13-6.

4. Ouellet V, Labbe SM, Blondin DP, Phoenix S, Guerin B, Haman F, Turcotte EE, Richard D, and Carpentier AC. Brown adipose tissue oxidative metabolism contributes to energy expenditure during acute cold exposure in humans. J Clin Invest. 2012;122(2):545-52.

5. Orava J, Nuutila P, Lidell ME, Oikonen V, Noponen T, Viljanen T, Scheinin M, Taittonen M, Niemi T, Enerback $S$, et al. Different metabolic responses of human brown adipose tissue to activation by cold and insulin. Cell Metab. 2011;14(2):272-9.

6. Vijgen GH, Bouvy ND, Teule GJ, Brans B, Schrauwen P, and van Marken Lichtenbelt WD. Brown adipose tissue in morbidly obese subjects. PLoS One. 2011;6(2):e17247.

7. Cannon B, and Nedergaard J. Brown adipose tissue: function and physiological significance. Physiol Rev. 2004;84(1):277-359.

8. Saito $M$, Okamatsu-Ogura $Y$, Matsushita M, Watanabe K, Yoneshiro T, Nio-Kobayashi J, Iwanaga T, Miyagawa M, Kameya T, Nakada K, et al. High incidence of metabolically active brown adipose tissue in healthy adult humans: effects of cold exposure and adiposity. Diabetes. 2009;58(7):1526-31.

9. Feldmann HM, Golozoubova V, Cannon B, and Nedergaard J. UCP1 ablation induces obesity and abolishes diet-induced thermogenesis in mice exempt from thermal stress by living at thermoneutrality. Cell Metab. 2009;9(2):203-9.

10. Rothwell NJ, and Stock MJ. A role for brown adipose tissue in diet-induced thermogenesis. Nature. 1979;281(5726):31-5. 


\section{BROWN ADIPOSE TISSUE ACTIVITY AFTER DIETARY INTAKE}

11. Stock MJ. Gluttony and thermogenesis revisited. Int J Obes Relat Metab Disord. 1999;23(11):1105-17.

12. Kozak LP. Brown fat and the myth of diet-induced thermogenesis. Cell Metab. 2010;11(4):263-7.

13. van Marken Lichtenbelt WD, and Schrauwen P. Implications of nonshivering thermogenesis for energy balance regulation in humans. Am J Physiol Regul Integr Comp Physiol. 2011;301(2):R285-96.

14. van Baak MA. Meal-induced activation of the sympathetic nervous system and its cardiovascular and thermogenic effects in man. Physiol Behav. 2008;94(2):178-86.

15. Lupien JR, Glick Z, Saito M, and Bray GA. Guanosine diphosphate binding to brown adipose tissue mitochondria is increased after single meal. Am J Physiol. 1985;249(6 Pt 2):R694-8.

16. Glick Z, Wu SY, Lupien J, Reggio R, Bray GA, and Fisher DA. Meal-induced brown fat thermogenesis and thyroid hormone metabolism in rats. Am J Physiol. 1985;249(5 Pt 1):E519-24.

17. Glick Z, and Raum WJ. Norepinephrine turnover in brown adipose tissue is stimulated by a single meal. Am J Physiol. 1986;251(1 Pt 2):R13-7.

18. Glick Z, Wickler SJ, Stern JS, and Horwitz BA. Regional blood flow in rats after a single low-protein, highcarbohydrate test meal. Am J Physiol. 1984;247(1 Pt 2):R160-6.

19. Glick Z, Teague RJ, Bray GA, and Lee M. Compositional and metabolic changes in brown adipose tissue following a single test meal. Metabolism. 1983;32(12):1146-50.

20. Glick Z, Teague RJ, and Bray GA. Brown adipose tissue: thermic response increased by a single low protein, high carbohydrate meal. Science. 1981;213(4512):1125-7.

21. Allard $\mathrm{M}$, and Leblanc J. Effects of cold acclimation, cold exposure, and palatability on postprandial thermogenesis in rats. Int J Obes. 1988;12(2):169-78.

22. Harris JA, and Benedict FG. A Biometric Study of Human Basal Metabolism. Proc Natl Acad Sci U S A. 1918;4(12):370-3.

23. Baecke JA, Burema J, and Frijters JE. A short questionnaire for the measurement of habitual physical activity in epidemiological studies. Am J Clin Nutr. 1982;36(5):936-42.

24. Vosselman MJ, van der Lans AA, Brans B, Wierts $R$, van Baak MA, Schrauwen $P$, and van Marken Lichtenbelt WD. Systemic beta-adrenergic stimulation of thermogenesis is not accompanied by brown adipose tissue activity in humans. Diabetes. 2012;61(12):3106-13.

25. Kawasaki K, Ishii K, Saito Y, Oda K, Kimura Y, and Ishiwata K. Influence of mild hyperglycemia on cerebral FDG distribution patterns calculated by statistical parametric mapping. Ann Nucl Med. 2008;22(3):191200.

26. Craig AD, Chen K, Bandy D, and Reiman EM. Thermosensory activation of insular cortex. Nat Neurosci. 2000;3(2):184-90.

27. Wong KP, Sha W, Zhang X, and Huang SC. Effects of administration route, dietary condition, and blood glucose level on kinetics and uptake of 18F-FDG in mice. J Nucl Med. 2011;52(5):800-7.

28. Vrieze A, Schopman JE, Admiraal WM, Soeters MR, Nieuwdorp M, Verberne HJ, and Holleman F. Fasting and postprandial activity of brown adipose tissue in healthy men. $J$ Nucl Med. 2012;53(9):1407-10.

29. Weststrate J. Resting metabolic rate and diet-induced thermogenesis: a methodological reappraisal. $A m$ J Clin Nutr. 1993;58(5):592-601. 


\section{CHAPTER 4}

\section{Systemic beta-adrenergic stimulation of thermogenesis is not accompanied by brown adipose tissue activity in humans}

This content was published in Maarten J. Vosselman, Anouk A.J.J. van der Lans, Boudewijn Brans, Roel Wierts, Marleen A. van Baak, Patrick Schrauwen, and Wouter D. van Marken Lichtenbelt. Systemic beta-adrenergic stimulation of thermogenesis is not accompanied by brown adipose tissue activity in Humans. Diabetes 61:3106-3113, 2012. 


\section{Abstract}

Brown adipose tissue (BAT) is currently considered as a target to combat obesity and diabetes in humans. BAT is densely innervated by the sympathetic nervous system (SNS) and can be stimulated by beta-adrenergic agonists, at least in animals. However, the exact role of the beta-adrenergic part of the SNS in BAT activation in humans is not known yet. Here we measured BAT activity by $\left[{ }^{18} \mathrm{~F}\right]$ fluorodeoxyglucose ([ $\left.{ }^{18} \mathrm{~F}\right] \mathrm{FDG}$ ) $\mathrm{PET} / \mathrm{CT}$ imaging in 10 lean men during systemic infusion of the non-selective betaagonist isoprenaline (ISO) and compared this with cold activated BAT activity. ISO successfully mimicked sympathetic stimulation as shown by increased cardiovascular and metabolic activity. Energy expenditure increased to similar levels as during cold exposure. Surprisingly, BAT was not activated during beta-adrenergic stimulation. We next examined whether the high plasma free fatty acids (FFA) levels induced by ISO competed with glucose ( $\left.\left[{ }^{18} \mathrm{~F}\right] \mathrm{FDG}\right)$-uptake in BAT locations by blocking lipolysis with acipimox $(\mathrm{ACl})$. ACl successfully lowered plasma FFA, but did not increase $\left[{ }^{18} \mathrm{~F}\right] \mathrm{FDG}$ uptake in BAT. We therefore conclude that systemic non-selective beta-adrenergic stimulation by ISO at concentrations that increase energy expenditure to the same extent as cold exposure does not activate BAT in humans, indicating that other tissues are responsible for the increased beta-adrenergic thermogenesis. 


\section{Introduction}

Brown adipose tissue (BAT) is present and functional in human adults, as was shown recently (1-3). Due to its high metabolic capacity, this organ is of great interest in the current worldwide obesity problem and its related metabolic diseases such as type 2 diabetes. In support, several studies in humans have shown that adiposity is negatively correlated with BAT presence and activity $(1,2,4,5)$. Moreover, a study by Bartelt et al. (6) showed in mice that BAT is involved in triglyceride clearance and thus could improve blood lipid profile. Furthermore, transplantation of BAT in streptozotocin (STZ)-diabetic mice improved glucose homeostasis and reversed type 1 diabetes (7). In humans, it has been shown that glucose uptake in BAT can increase 12-fold during cold exposure (8). A recent study demonstrated cold-induced fatty acid oxidation in BAT (9). This study also showed that oxidative metabolism in BAT contributed to whole body energy expenditure during acute cold exposure. Therefore, BAT is currently regarded as an organ with preventive and therapeutic potential for diseases related to the metabolic syndrome.

From animal studies it is clear that BAT is under hypothalamic control and is densely innervated by the sympathetic nervous system (SNS) (10). When thermogenesis is needed (e.g. in the cold), postganglionic sympathetic neurons release norepinephrine (NE) acting on (mainly) the beta-adrenergic receptors present on the cell surface, leading to the activation of uncoupling protein-1 (UCP-1). This protein is located in the inner mitochondrial membrane, and is responsible for the generation of heat by uncoupling respiration from ATP-synthesis (11).

In humans several studies indicate the role of the sympathetic nervous system in cold- induced thermogenesis and BAT activation. Cold-induced thermogenesis in humans correlates significantly with fasting norepinephrine plasma concentrations (12). In support, Zingaretti et al. (13) showed that human brown adipocytes are innervated by the SNS, and Virtanen et al. (3) demonstrated the presence of the $\beta_{3}$ adrenergic receptor ( $\left.\beta_{3}-A R\right)$ mRNA in these cells. Finally, blocking the $\beta_{1}$ - and $\beta_{2}-A R$ receptor through oral administration of propranolol decreased $\left[{ }^{18}\right.$ F]FDG uptake in BAT in cancer patients at room temperature $(14,15)$, indicating a role for these receptors in activating BAT under these conditions. Although the role of B-AR stimulation on BAT has not been directly examined in humans, its role in stimulating thermogenesis in humans is well established (16), making it likely that ß-AR receptor stimulation could be an alternative way to activate BAT.

Here we use the non-selective ß-AR agonist ISO to mimic ß-adrenergic SNS activity and investigate its effect on BAT activity, and performed cold exposure as a positive control. We show that ISO stimulated thermogenesis to similar levels as cold exposure; however, BAT was not involved in the thermogenic effect of ISO. 


\section{Research design and methods}

The ethics committee of Maastricht University Medical Centre (MUMC+) approved the study protocol. All study participants provided written informed consent and all procedures conformed the standards of the Declaration of Helsinki.

\section{Subjects}

A total of 10 healthy male subjects (age $22.5 \pm 2.5$ years, BMI $21.6 \pm 1.6 \mathrm{~kg} / \mathrm{m}^{2}$, fat percentage $15.6 \pm 2.9 \%$ ) were enrolled in the study. All subjects were screened for medical history and status. Cardiovascular status was screened by means of an electrocardiogram (ECG) and blood pressure measurement. All subjects had normal blood glucose levels. Body composition was determined by means of dual $x$-ray absorptiometry (DXA, Hologic, type Discovery A, USA).

\section{Study design}

First, the subjects underwent a mild cold experiment in order to define BAT presence and activity, followed by the ISO experiment. Subsequently five out of ten subjects underwent a second ISO experiment in combination with $\mathrm{ACl}$. A minimal washout period of 5 days was taken between the experiments.

Subjects were measured in the morning after overnight fasting and were asked to refrain from heavy exercise 24 hours before the measurements. After arrival, subjects swallowed a telemetric pill (CoreTemp HT150002, USA) for core temperature measurement and iButtons (Maxim integrated, USA) were placed on 14 ISO-defined sites to measure skin temperature (17). A chest strap (Polar T31, USA) and a pressure cuff (Cresta, Taiwan) were attached to measure heart rate and blood pressure, respectively. Laser Doppler probes were attached for skin perfusion measurements at the ventral side of the hand at the base of the thumb, at the ventral side of the hallux (Perimed PF4000, Sweden) at the ventral side of the forearm halfway between the elbow and the wrist, and at the abdomen halfway between the umbilicus and the left lateral side of the body (Perimed PF5000, Sweden). Finally, a canula was inserted in the left antecubital vein for blood sampling during cold exposure. During the ISO experiments a second canula in the antecubital vein of the contralateral arm was placed for ISO infusion. The measurements were performed in a specially equipped airpermeable tent (Colorado altitude training, USA), in which ambient temperature could be tightly controlled. Subjects were measured in semi-supine position in a nephrodialysis chair in order to lie comfortably. During the measurements, subjects wore standardized clothing (0.49 clo).

\section{Mild cold experiment}

The protocol started with a baseline period of 45 minutes in thermoneutral conditions (24-25 $\mathrm{o}$ ), followed by two hours of mild cold exposure in which an individualized 
protocol was used. Each subject was cooled down until shivering occurred. After this, air temperature was slightly increased until shivering stopped. Mild cold was applied by means of air-conditioning. After one hour of cold exposure the $\left[{ }^{18} \mathrm{~F}\right] \mathrm{FDG}$ tracer was injected intravenously. Subjects were asked to lie still during the experiment in order to prevent artifact by muscle activity. Shivering was detected visually and subjects were asked to report shivering on a self-created Visual Analog Scale (VAS) every ten minutes. The cooling protocol has been validated previously (5). After the cooling protocol, subjects were transferred to the positron emission tomography (PET) and computed tomography (CT) scanner (Gemini TF PET-CT, Philips, The Netherlands).

\section{ISO experiment}

After the baseline period of 45 minutes, ISO (ISO sulfate) was infused intravenously in the antecubital vein in incremental dosages $\left(6,12\right.$ and $24 \mathrm{ng}$ ( $\mathrm{kg}$ fat-free mass ${ }^{-1} \mathrm{~min}^{-1}$ ) for 30 minutes (dose 1 and 2) and 55 minutes (dose 3). A previous study has shown that it takes about 8 minutes for each ISO dose to reach a steady state concentration in the body (18). The extended duration of each dose was necessary to obtain a stable period for energy expenditure. The $\left[{ }^{18} \mathrm{~F}\right] \mathrm{FDG}$ tracer was injected intravenously ten minutes after the start of dose 3. Venous blood samples were taken during baseline and at the end of each dose. Cardiovascular function was continuously monitored by means of electrocardiography (Cardiolife TEC 7100K, Nihon Kohden, Japan) and blood pressure.

\section{ISO experiment in combination with $\mathrm{ACI}$}

Subsequently, five subjects underwent a second ISO experiment, in which two times 250-mg of $\mathrm{ACl}$ was given orally (2 hours before- and at the start of baseline) to lower circulating fatty acids. $\mathrm{ACl}$ is a nicotinic acid derivative and blocks lipolyis in fat tissue by decreasing cyclic AMP, and therefore decreasing the lipolytic effects of hormone sensitive lipase (19). The experimental protocol was similar to the ISO experiment as explained before. One subject did not ingest the second capsule due to adverse effects. However, plasma FFA levels during the tracer injection were still lower compared to ISO (ISO+ACl $\mathrm{dose}$ : 171 versus ISO $\left._{\text {dose3 }}: 631 \mu \mathrm{mol} / \mathrm{I}\right)$.

\section{PET scanning protocol}

One hour before the PET-CT scan, subjects were intravenously injected with $50 \mathrm{MBq}$ $(1.35 \mathrm{mCi})$ of $\left[{ }^{18} \mathrm{~F}\right] \mathrm{FDG}$. Imaging started with a low-dose CT scan (120 kV, $\left.30 \mathrm{mAs}\right)$, immediately followed by a PET scan. A total of 6 to 7 bed positions ( 6 minutes per bed position) were necessary to cover the area where BAT is usually found (i.e. abdominal-, thoracic- and neck region). The PET image was used to determine the $\left[{ }^{18}\right.$ F]FDG-uptake and the $\mathrm{CT}$ image was used for PET attenuation correction and localization of the $\left[{ }^{18}\right.$ F]FDG-uptake sites. The voxel size of both reconstructed image sets was $4 \times 4 \times 4$ $\mathrm{mm}^{3}$. 


\section{PET analysis}

We used PMOD software, version 3.0 (PMOD Technologies) for the analysis of BAT activity. Both the researcher and a nuclear-medicine physician interpreted the PET-CT image. The regions of interest were manually outlined in each slice $(4 \mathrm{~mm})$ in the fusion (PET and CT) image. We handled two criteria to qualify [ $\left.{ }^{18} \mathrm{~F}\right]$ FDG-uptake as BAT activity in these regions. First, the region drawn should be localized in fat tissue as determined by the CT scan (Hounsfield Units: -10 to -180 ). Second, the SUV value in each region should be at least 1.5 (approximately 6 times higher than in WAT). BAT activity of each region is determined by the average SUV uptake (SUV mean) times the volume of the region $\left(\mathrm{cm}^{3}\right)$, expressed as SUV total. To compare SUV mean in BAT, WAT, skeletal muscle, we drew regions of interest in the supraclavicular BAT region, subcutaneous abdominal adipose tissue, and in both arms on the deltoid muscle. In order to locate the supraclavicular BAT region during the two ISO experiments, we used the PET-CT fusion image during cold exposure as a reference.

\section{Statistical analysis}

Statistical analysis was performed with PASW Statistics 18.0 for Mac. Reported data are expressed as means \pm SD. Paired sample t-tests were used to compare findings between baseline and cold, and one-way ANOVA for repeated measurements with post hoc analysis, including Bonferroni correction, to compare baseline with the three ISO doses. Wilcoxon's test was used measure differences within the ISO and $\mathrm{ACI}$ experiment and between ISO and the ISO and $\mathrm{ACl}$ experiment. Two-way ANOVA for repeated measurements was used to compare cold exposure with $\mathrm{ISO}_{\text {dose3. }}$. Both study phase (baseline versus intervention) and study type (cold versus $\mathrm{ISO}_{\text {dose3 }}$ ) were taken as independent variables in the model and the interaction effect between these two variables were analyzed. Spearman rank correlation was used to identify correlations between variables. $P$ values of less than 0.05 were considered as statistically significant.

\section{Blood analysis}

Venous blood was collected for analysis of several blood parameters. The supernatant (plasma) was used for analysis of free fatty acids (NEFA-HR set, Wako Chemicals, Neuss, Germany) free glycerol (Glycerol kit, R-Biopharm, Darmstadt, Germany), total glycerol ( $A B X$ Triglyceriden $C P$, Radiometer, Horiba $A B X$, Montpellier, France) and glucose ( $A B X$ Glucose HK CP, Radiometer, Horiba ABX, Montpellier, France) on a COBAS FARA centrifugal spectrophotometer (Roche Diagnostica, Basel, Switzerland). Triglycerides levels were calculated by using the difference in total and free glycerol. Serum insulin was analyzed with a Human Insulin specific RIA kit (Milipore, USA) on a Gamma Counter (2470 Automatic Gamma Counter Wizard ${ }^{2}$ "Wallac, Perkin Elmer, USA). Thyroid related hormones were determined from the supernatant of the serum.

Plasma thyroid stimulating hormone (TSH) was measured by an


electrochemiluminescence immunoassay (ECLIA) kit on a COBAS 6000 system (Roche Diagnostica, Basel, Switzerland). Total thyroxine (T4) was determined by a solid-phase, competitive chemiluminescent enzyme immunoassay on an Immulite 2000 system (Siemens, New York, USA). Free thyroxine (FT4) was analyzed by a solid phase timeresolved fluoroimmunoassay FT4 kit on an AutoDELFIA system (PerkinElmer, Inc., Massachusetts, USA).

\section{Results}

\section{ISO and cold-induced thermogenesis}

We first examined the effect of increasing doses of ISO in lean healthy subjects on thermogenesis. ISO significantly increased energy expenditure ( $p<0.001$, one-way ANOVA), with the highest increase of $19.7 \pm 7.2 \%$ during $24 \mathrm{ng} / \mathrm{kg}$ fat-free mass ${ }^{-1} \mathrm{~min}^{-}$

${ }^{1}$ (Figure 1A). We then compared this increase in energy expenditure with the increase observed during cold exposure. Cold exposure increased energy expenditure to similar levels (baseline: $1.17 \pm 0.10$; mild cold: $1.37 \pm 0.13 \mathrm{kcal} / \mathrm{min} ; \mathrm{p}<0.001$ ), with an average cold induced thermogenesis of $16.9 \pm 7.8 \%$ (Figure 1B). There was no interaction effect between cold exposure and ISO on energy expenditure ( $p>0.05$, two-way ANOVA), confirming a similar increase in energy expenditure. Both cold exposure and ISO significantly decreased the respiratory exchange ratio (Table 1 ). There was no difference between cold exposure and ISO ( $p>0.05$, two-way ANOVA). 
A

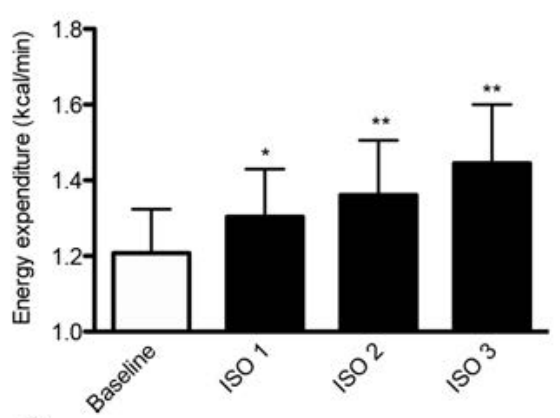

C

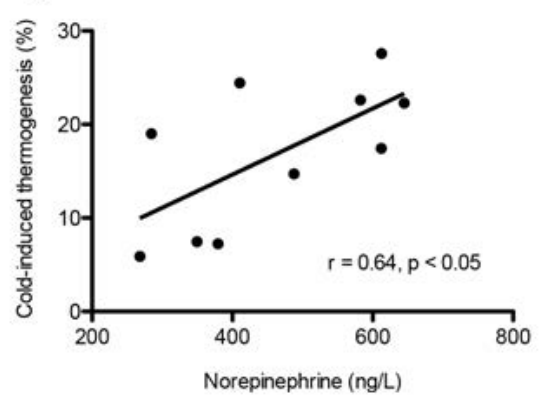

B

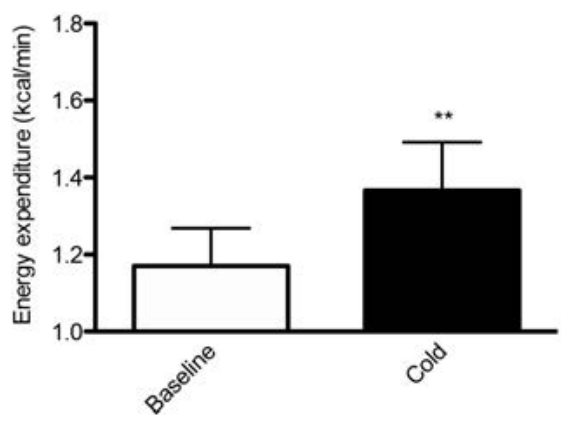

Figure 1. Isoprenaline- and cold-induced thermogenesis (A) energy expenditure during baseline and the three ISO doses. (B) Energy expenditure during baseline and cold exposure. (C) Relationship between the plasma norepinephrine level and cold-induced thermogenesis. Values are expressed as means \pm SD. ${ }^{*} P<$ $0.05, * * P<0.001$, ISO $(n=10)$ and cold exposure $(n=10)$.

Stimulation of the $ß-A R$ receptors leads to an increase in heart rate (mainly $ß-1$ ) and vasodilatation of blood vessels (16). We found that ISO increased heart rate (baseline $60 \pm 5 \mathrm{bpm}$ versus $\mathrm{ISO}_{\text {dose3 }}: 84 \pm 10 \mathrm{bpm}, \mathrm{p}<0.001$ ) and systolic blood pressure (baseline $121 \pm 9 \mathrm{mmHg}$ versus ISO $_{\text {dose3: }} 148 \pm 14 \mathrm{mmHg}, \mathrm{p}<0.001$ ) (Table1), due to its inotropic and chronotropic effects on the heart. Diastolic blood pressure was unchanged during ISO.

With respect to body temperatures (Table 1), ISO significantly increased skin temperature in the proximal area, whereas it dropped in the distal areas. Skin perfusion corresponded to these temperature changes, demonstrating decreased perfusion in the hand and increased perfusion in the abdominal region. Cold exposure increased both systolic and diastolic blood pressure, whereas it decreased heart rate. As expected, cold exposure decreased skin temperatures and skin perfusion in the hand, but slightly increased core temperature. The effects during ISO dose 1 and dose 2 are presented in Table $\mathbf{S 1}$ (supplemental data).

We measured several blood metabolites and hormones as demonstrated in Table S2 and S3 (supplemental data). Plasma norepinephrine levels were increased during 
cold exposure ( $244 \pm 72 \mathrm{ng} / \mathrm{L}$ versus $463 \pm 143 \mathrm{ng} / \mathrm{L}, \mathrm{p}<0.001$ ), as shown previously (8, $12)$, however not during ISO. A significant relation was found between norepinephrine levels and cold-induced thermogenesis $(R=.64, p<0.05)$ (Figure $1 C$ ), however not with BAT activity during cold $(R=-.09, p=0.80)$. Cold exposure significantly increased plasma FFA (baseline: $324 \pm 84 \mu \mathrm{mol} / \mathrm{L}$ versus cold: $637 \pm 398 \mu \mathrm{mol} / \mathrm{L}, \mathrm{p}<0.05$ ), free glycerol (baseline: $56.6 \pm 14.4 \mu \mathrm{mol} / \mathrm{L}$ versus cold: $106.7 \pm 59.6 \mu \mathrm{mol} / \mathrm{L}, \mathrm{p}<0.05$ ), and triglycerides (baseline: $638 \pm 171 \mu \mathrm{mol} / \mathrm{L}$ versus cold: $685 \pm 200 \mu \mathrm{mol} / \mathrm{L}, \mathrm{p}<0.05$ ), whereas plasma glucose decreased (baseline: $4.9 \pm 0.4 \mathrm{mmol} / \mathrm{L}$ versus cold: $4.7 \pm 0.4$ $\mathrm{mmol} / \mathrm{L}, \mathrm{p}<0.05)$. As expected, serum insulin levels were significantly increased by ISO.

Table 1. Cardiovascular effects, skin perfusion, and body temperatures during cold exposure and ISO.

\begin{tabular}{|c|c|c|c|c|}
\hline \multirow[b]{2}{*}{ Parameter } & \multicolumn{2}{|l|}{ Cold } & \multicolumn{2}{|l|}{ ISO } \\
\hline & Baseline & Cold & Baseline & Dose 3 \\
\hline $\mathrm{EE}$ (kcal/min) & $1.17 \pm 0.10$ & $1.37 \pm 0.13 * *$ & $1.21 \pm 0.12$ & $1.45 \pm 0.15 * *$ \\
\hline RER (VCO2/VO2) & $0.87 \pm 0.05$ & $0.81 \pm 0.05 * *$ & $0.85 \pm 0.03$ & $0.80 \pm 0.02 * *$ \\
\hline Heart rate (bpm) & $57 \pm 7.2$ & $54 \pm 4.7 *$ & $59.8 \pm 4.8$ & $84 \pm 10.2 * *$ \\
\hline Systolic BP (mmHg) & $119 \pm 9.2^{\dagger}$ & $123 \pm 6.9 *^{+}$ & $121 \pm 9.1$ & $148 \pm 13.8 * *$ \\
\hline Diastolic BP (mmHg) & $64 \pm 3.1^{\dagger}$ & $73 \pm 3.9 * *^{\dagger}$ & $66 \pm 4.3$ & $63 \pm 8.7$ \\
\hline SP hand (\%) & 100 & $11 \pm 8 * *$ & 100 & $30 \pm 13 * *$ \\
\hline SP abdomen (\%) & 100 & $129 \pm 71$ & 100 & $196 \pm 57 * *$ \\
\hline Tcore $\left({ }^{\circ} \mathrm{C}\right)$ & $36.8 \pm 0.25$ & $37.0 \pm 0.2 *$ & $36.8 \pm 0.2$ & $36.7 \pm 0.2$ \\
\hline Tmean skin $\left({ }^{\circ} \mathrm{C}\right)$ & $32.7 \pm 0.6$ & $29.0 \pm 0.5 * *$ & $33.1 \pm 0.4$ & $33.6 \pm 0.3 * *$ \\
\hline Tproximal $\left({ }^{\circ} \mathrm{C}\right)$ & $33.3 \pm 0.9$ & $31.2 \pm 1.3 * *$ & $34.0 \pm 0.5$ & $35.1 \pm 0.4 * *$ \\
\hline Tdistal $\left({ }^{\circ} \mathrm{C}\right)$ & $31.1 \pm 1.4$ & $22.9 \pm 1.4 * *$ & $31.8 \pm 1.5$ & $30.0 \pm 1.7 * *$ \\
\hline Tgradient prox/dis $\left({ }^{\circ} \mathrm{C}\right)$ & $2.3 \pm 1.4$ & $8.3 \pm 2.2 * *$ & $2.3 \pm 1.7$ & $5.2 \pm 2.0 * *$ \\
\hline
\end{tabular}

The ISO dose 3 is $24 \mathrm{ng}$ ( $\mathrm{kg}$ fat-free mass $(\mathrm{FFM})^{-1} \mathrm{~min}^{-1}$ ). Results are expressed as means $\pm \mathrm{SD}$. The difference between intervention and baseline was used for statistical analysis. ${ }^{*} P<0.05,{ }^{* *} P<0.001$, ISO $(n=10)$, cold exposure $(n=10),{ }^{\dagger} n=9$. See also Table $S 1$. EE, energy expenditure; RER, respiratory exchange ratio; BP, blood pressure; $\mathrm{SP}$, skin perfusion; $\mathrm{T}$, temperature.

\section{BAT activity during ISO and cold exposure}

We next studied if ISO activates BAT at a dose that increases thermogenesis to a similar extent as cold exposure. As expected, cold exposure led to substantial $\left[{ }^{18} \mathrm{~F}\right] \mathrm{FDG}$ uptake in the neck, supraclavicular, paraspinal, para-aortic, axillary, mediastinal, and perirenal regions ( $891 \pm 1027$ SUV total, Figure 2B, 2E). The anatomical location of BAT was comparable to previous findings, with the largest depot in the supraclavicular region (Figure 2E). Surprisingly, after ISO in 9 out of 10 subjects, no detectable $\left[{ }^{18} \mathrm{~F}\right]$ FDG-uptake in BAT locations could be observed (Figure 2C, 2F), despite the 
thermogenic effect of ISO. In only one subject BAT activity was observed (SUV total = 838).

In addition to BAT, other tissues may contribute to cold- or ISO induced thermogenesis. Therefore, we examined the average uptake of $\left[{ }^{18}\right.$ F]FDG into skeletal muscle and WAT (Figure $\mathbf{2 H}$ ). Interestingly, the average SUV uptake (SUV mean) in skeletal muscle was similar during ISO and cold exposure (ISO: $0.53 \pm 0.07$ versus cold: $0.50 \pm 0.08$ SUV mean, $p=0.26)$. Similarly, $\left[{ }^{18} \mathrm{~F}\right]$ FDG-uptake in WAT was also comparable during ISO and during cold exposure (ISO: $0.28 \pm 0.10$ versus cold: $0.27 \pm$ 0.07 SUV mean, $p=0.90$ ).
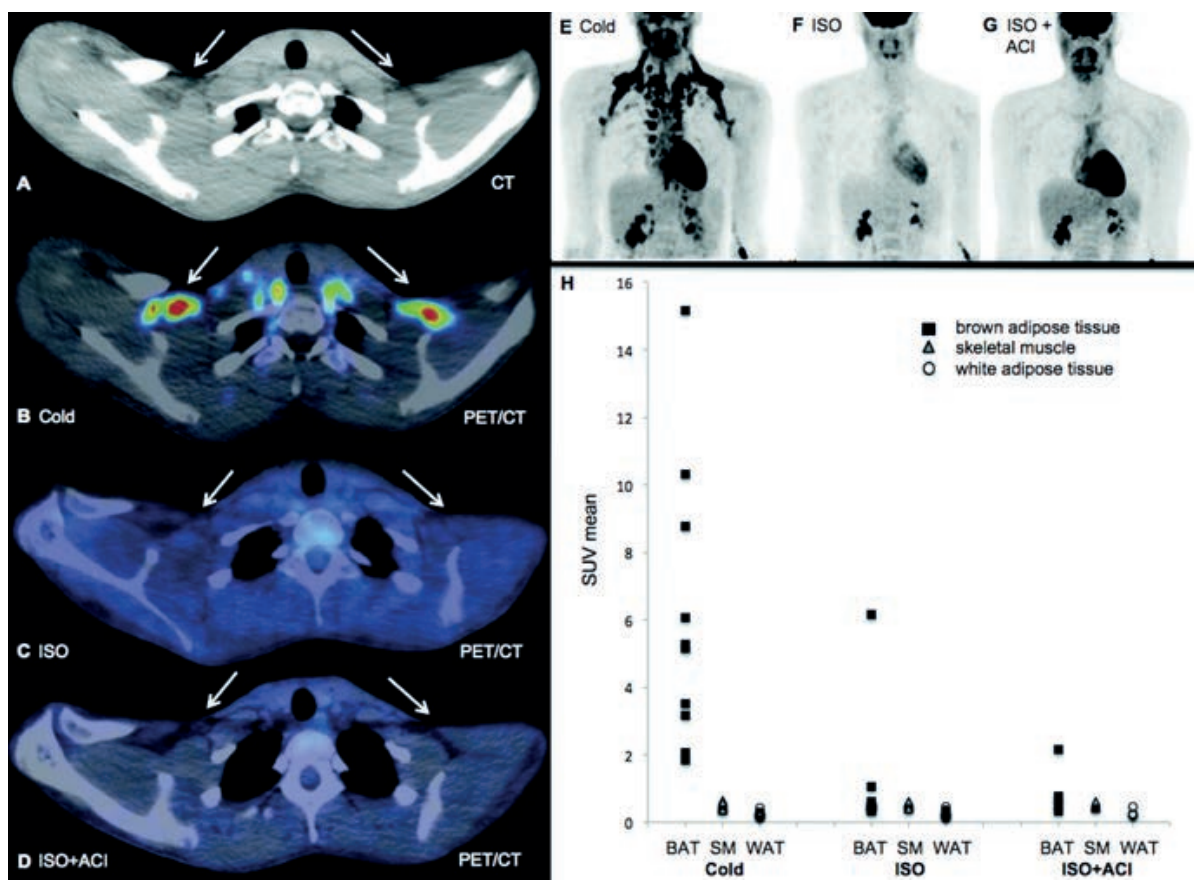

Figure 2. BAT activity during ISO infusion and cold exposure. (A) CT image of the supraclavicular area. (B) Cold exposure $\left[{ }^{18} \mathrm{~F}\right] \mathrm{FDG}-\mathrm{PET} / \mathrm{CT}$ image showing cold-activated BAT. (C) ISO $\left[{ }^{18} \mathrm{~F}\right] \mathrm{FDG}-\mathrm{PET} / \mathrm{CT}$ image showing no BAT activity during ISO. (D) ISO + $\mathrm{ACI}\left[{ }^{18} \mathrm{~F}\right] \mathrm{FDG}-\mathrm{PET} / \mathrm{CT}$ image showing no effect on $\left[{ }^{18} \mathrm{~F}\right] \mathrm{FDG}$-uptake in supraclavicular BAT. (E) Cold exposure $\left[{ }^{18} \mathrm{~F}\right] \mathrm{FDG}-\mathrm{PET} / \mathrm{CT}$ image of the upper body showing BAT activity in the neck, supraclavicular, paraspinal, para-aortic, axillary, mediastinal, and perirenal regions. (F) ISO [ ${ }^{18}$ F]FDG$\mathrm{PET} / \mathrm{CT}$ image of showing no BAT activity during ISO. (G) ISO + $\mathrm{ACI}\left[{ }^{18} \mathrm{~F}\right] \mathrm{FDG}-\mathrm{PET} / \mathrm{CT}$ image showing no effect on $\left[{ }^{18} \mathrm{~F}\right] F D G$-uptake in BAT locations. (H) SUV mean values for BAT, SM, and WAT during cold exposure, ISO, and ISO $+\mathrm{ACl}$; ISO $(\mathrm{n}=10)$, ISO $+\mathrm{ACl}(\mathrm{n}=5)$.

\section{ISO and $\mathrm{ACl}$}

The current method to detect BAT activity is by measuring radiolabeled glucose uptake ( $\left.\left[{ }^{18} \mathrm{~F}\right] \mathrm{FDG}\right)$. It is known that ISO stimulates lipolysis in white adipose tissue and that high fatty acid levels may compete with glucose for uptake in multiple tissues (20). We therefore next examined if the ISO-induced increase in plasma FFA might compete 
with glucose for uptake into BAT. Indeed, ISO led to an increase in plasma concentration of FFA to very high levels (Figure 3A, Table S2). The nicotinic acid derivative $\mathrm{ACl}$ was used to block lipolysis in WAT (19). Indeed, ACl significantly reduced the concentration of FFA by $\sim 78 \%$ in the plasma (ISO: $934 \pm 276$ versus ISO+ACl: $207 \pm$ $140 \mu \mathrm{mol} / \mathrm{l}, \mathrm{p}<0.05$ ) (Table S2) and resulted in an increased whole-body glucose oxidation as demonstrated by the increase in the respiratory exchange ratio (ISO: 0.81 \pm 0.02 versus $\mathrm{ISO}+\mathrm{ACl}: 0.92 \pm 0.04, \mathrm{p}<0.001$ ) (Figure $3 \mathrm{~B}$ ). Lowering circulating plasma FFA levels by $\mathrm{ACl}$ very clearly increased the uptake of $\left[{ }^{18} \mathrm{~F}\right] \mathrm{FDG}$ into the heart; indeed demonstrating that substrate competition can affect $\left[{ }^{18} \mathrm{~F}\right] \mathrm{FDG}$-uptake (Figure 3D). Next, we examined if ISO would lead to $\left[{ }^{18}\right.$ F]FDG-uptake in BAT when plasma FFA were reduced by $\mathrm{ACl}$. The reduction of plasma FFA levels did not lead to enhanced $\left[{ }^{18} \mathrm{~F}\right] \mathrm{FDG}$ uptake in BAT in 4 out of 5 subjects. One person showed a slight increase in BAT activity, however this BAT activity was minimal compared to the activity during mild cold exposure (ISO+ACI: 27 versus cold: 3132 SUV total). Furthermore, ACl did not lead to enhanced $\left[{ }^{18} \mathrm{~F}\right] \mathrm{FDG}$-uptake in skeletal muscle. The combination of ISO with $\mathrm{ACl}$ significantly increased energy expenditure by $12.8 \%(p<0.05)$. This was, however, significantly lower compared to ISO infusion alone $(p<0.05)$ (Figure $3 C)$. The effects of $\mathrm{ACl}$ in combination with ISO on cardiovascular effects, skin perfusion, and body temperatures are presented in Table $\mathbf{S 1}$ (supplemental data). 

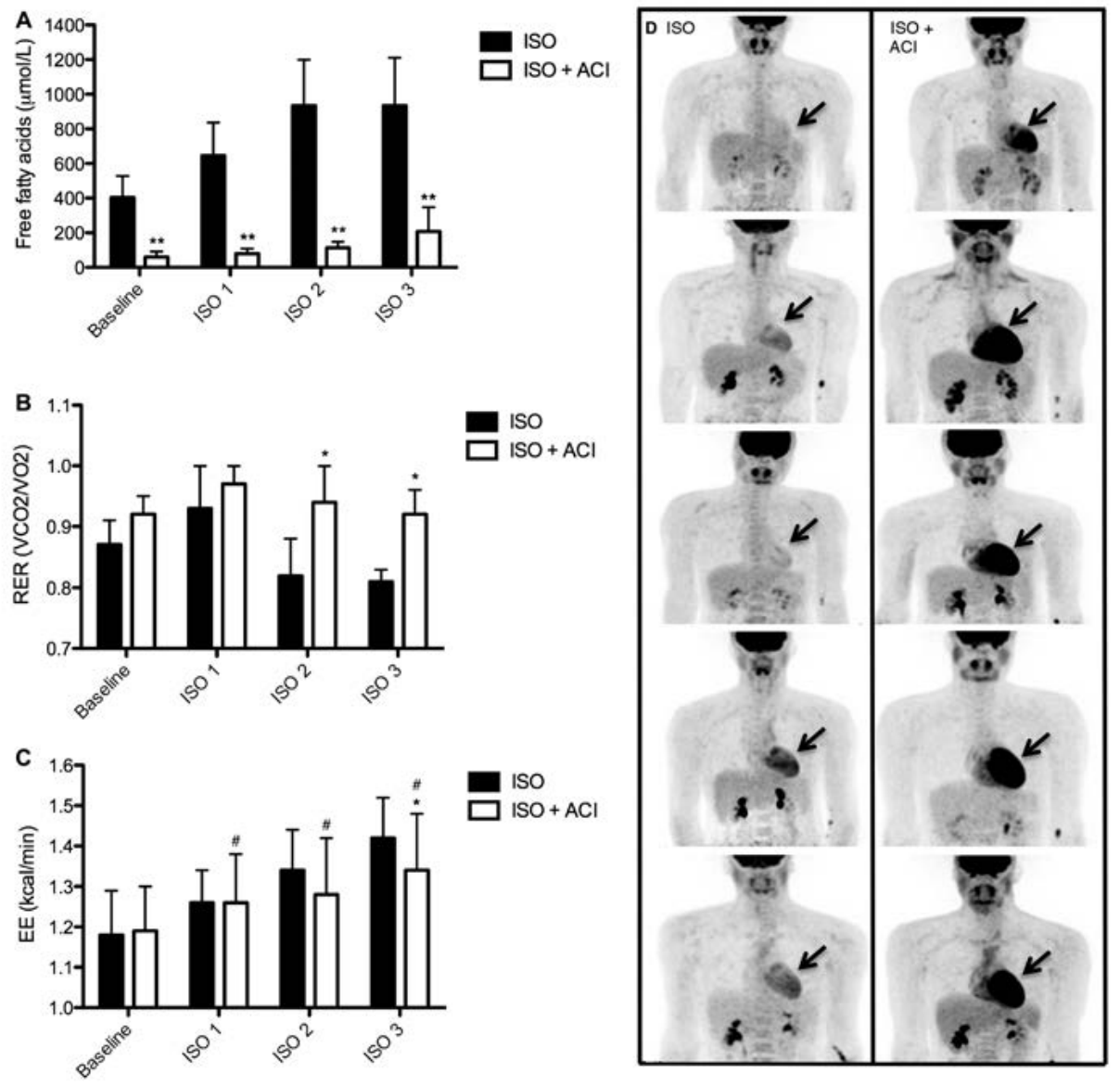

Figure 3. The effects of $\mathrm{ACl}$ on FFA levels, substrate use, energy expenditure, and $\left[{ }^{18} \mathrm{~F}\right] \mathrm{FDG}$-uptake. (A) Plasma FFA levels during ISO and ISO $+\mathrm{ACI}$. (B) Respiratory exchange ratio during ISO and ISO $+\mathrm{ACl}$. (C) Energy expenditure during ISO and ISO $+\mathrm{ACI}$. (D) The left panel shows the 3D-reconstructed PET-images in five subjects during ISO infusion indicating no brown fat activity and a low $\left[{ }^{18}\right.$ F]FDG-uptake in the heart. The right panel shows the same individuals during ISO in combination with $\mathrm{ACl}$. $\mathrm{ACl}$ increases $\left[{ }^{18} \mathrm{~F}\right] \mathrm{FDG}$-uptake in the heart as indicated by the black arrows, however not in BAT locations. Values are expressed as means \pm SD. *significant difference between ISO and ISO + ACI $(P<0.05), * * P<0.001$, " significant difference $(p<$ $0.05)$ between ISO $+\mathrm{ACI}$ dose and baseline, ISO $(n=10)$ ISO $+\mathrm{ACI}(n=5)$.

\section{Discussion}

There is compelling evidence that BAT in animals is under sympathetic control and can be activated through B-AR stimulation (11). However, the exact role of the SNS in activating BAT in humans is less clear. The main objective of this study was to examine whether non-selective B-AR stimulation through ISO activates BAT in humans. Contrary 
to our expectations, the results show that ISO does not activate BAT in humans, despite the observed increase in thermogenesis.

Cold exposure increased energy expenditure by $\sim 17 \%$, comparable to coldinduced thermogenesis levels reported earlier (1). This increased thermogenesis upon cold exposure was accompanied by increased BAT activity in anatomical locations comparable to previous findings, with the largest depot in the supraclavicular region. Interestingly, cold exposure increased plasma triglycerides in the present study, which seems to be in contrast to the triglyceride clearance by BAT occurring in mice during cold exposure (6). However, it has already been previously shown by Vallerand et al. (21) that the FFA's needed for enhanced lipid oxidation during cold exposure do not originate from plasma triglycerides, but rather from intracellular lipolysis. More research is needed to investigate if BAT can affect triglyceride clearance in humans.

Furthermore, we confirm that short-term cold exposure increased plasma norepinephrine levels as previously found by Orava et al. (8), and that these levels were related to cold-induced thermogenesis. Based on these results and evidence obtained from rodent BAT studies, we hypothesized that mimicking ß-adrenergic SNS activation by infusion of the $B-A R$ agonist ISO would activate BAT in humans.

ISO indeed mimicked ß-adrenergic sympathetic activity as shown by the increased heart rate and whole body energy expenditure. The increase of $\sim 20 \%$ in energy expenditure during ISO was comparable to that during previous studies with similar dosages (22-24). Contrary to our expectations, however, ISO did not activate BAT in 9 out of 10 subjects. In rodents, brown adipose tissue has been shown to have a dense B-AR receptor population. Both in vitro $(25,26)$ and in vivo $(27,28)$ experiments in animals have shown that stimulating these receptors leads to BAT activation. Also in humans the $B-A R$ receptor family is likely to be involved in BAT thermogenesis, as demonstrated by the presence of $\beta_{3}-A R$ mRNA in human supraclavicular BAT (3), and the inhibition of BAT activity by ß-AR receptor antagonism $(14,15)$. Moreover, a recent study by Mattson et al. (27) showed the presence of mRNA of all B-AR subtypes in human multipotent adipocyte derived stem (MADS) cells differentiated into brown adipocytes. Stimulating these cells by ISO and CL-316243 ( $\beta_{3}-A R$ agonist) led to increased UCP-1 mRNA and protein levels, indicating ß-AR receptor involvement in cell activation. We were therefore surprised not to find BAT activity upon B-AR stimulation.

In the present study we measured BAT activity in humans by means of radioactive $\left[{ }^{18}\right.$ F]FDG-uptake. Theoretically, however, high plasma FA levels may compete with glucose for cellular uptake, thereby underestimating true BAT activity. Therefore, due to the lipolytic effects of ISO, we hypothesized that the high plasma FFA levels might have competed with glucose $\left(\left[{ }^{18} \mathrm{~F}\right] \mathrm{FDG}\right)$ uptake. We showed that the simultaneous administration of ISO and $\mathrm{ACl}$, which inhibits lipolysis, was able to lower fatty acids and that this resulted in elevated glucose uptake in the heart, illustrating that indeed substrate competition may be a factor determining $\left[{ }^{18}\right.$ F]FDG-uptake. However, lowering circulating fatty acid levels did not lead to increased tracer uptake in BAT 
locations. One could argue that BAT thermogenesis was blunted by $\mathrm{ACl}$ through the inhibition of lipolysis by lowering CAMP levels as seen in white adipose tissue. However, two animal studies showed no effect of nicotinic acid $(\mathrm{ACl}$ is a derivative of nicotinic acid) on FFA and CAMP levels in BAT $(29,30)$, which demonstrates no inhibiting effects of $\mathrm{ACl}$ on $\mathrm{BAT}$ activation. The fact that the increase in energy expenditure upon ISO with $\mathrm{ACl}$ was $8 \%$ lower compared to ISO alone can most likely be explained by the reduction in plasma FFA levels, as previously shown (31).

Based on these findings we can conclude that systemic non-selective ß-AR stimulation, at concentrations that increase energy expenditure to the same extent as cold exposure, does not activate BAT in humans. It is surprising that blocking the $\beta_{1}$ and $\beta_{2}$-receptors by propranolol decreases BAT activity $(14,15)$, whereas stimulating these receptors by ISO does not activate human BAT. A plausible explanation is that the systemic concentration of ISO was not sufficient to trigger the ß-receptors on brown adipocytes. The concentrations of norepinephrine that occur at the postsynaptic areas are high ( 100 nM) during central sympathetic stimulation (e.g. cold), which cannot be reached in plasma during physiological conditions (25). We cannot exclude the possibility that higher doses of ISO are able to stimulate BAT in humans. However, these high doses would lead to unwanted side effects such as tachycardia, arrhythmias and pronounced systolic blood pressure elevations. Central stimulation therefore remains an interesting option for future studies, although achieving such in human studies will be difficult.

Interestingly, these findings thus show that metabolic processes in tissues other than BAT cause the ISO induced thermogenesis. B-AR receptors are expressed in various tissues, such as the heart, skeletal muscle, adipose tissue, liver, bronchi, blood vessels, and the pancreas (16). A small part of the increased thermogenesis can be explained by the energy cost of cardiac and respiratory work upon sympathetic stimulation (32). However, skeletal muscle likely explains a major part. The contribution of skeletal muscle to epinephrine-induced thermogenesis has been estimated at $40 \%$ (33). Moreover, a study by Astrup et al. (34) showed that ephedrineinduced thermogenesis is located for $50 \%$ in skeletal muscle. In our study, the average tracer uptake in skeletal muscle was similar during ISO and cold exposure, indicating similar activity in both situations. However, additional studies focused on skeletal muscle are needed to measure its contribution during cold induced and adrenergic thermogenesis.

The mechanisms behind skeletal muscle thermogenesis are not fully known. Interestingly, Wijers et al. (35) demonstrated, with high-resolution respirometry in permeabilized human skeletal muscle biopsies, that skeletal muscle mitochondrial uncoupling correlated significantly to the increase in whole body energy expenditure after 3 days of cold exposure. This finding indicates that mitochondrial uncoupling could be such a mechanism. Other possible mechanisms involved are futile calcium cycling, protein turnover and substrate cycling (36). 
It should be noted that although $\left[{ }^{18} \mathrm{~F}\right] \mathrm{FDG}$-uptake shows whether BAT is active, it provides limited information on the actual thermogenic activity of the tissues as fatty acids are an important substrate during cold and ISO infusion. Furthermore, the uptake of $\left[{ }^{18} \mathrm{~F}\right] \mathrm{FDG}$ in BAT can occur without simultaneous increased blood perfusion as shown during insulin infusion (8). This could imply that BAT glucose uptake takes place without concurrent thermogenesis. However, due to practical limitations we were not able to use these techniques in the present study.

From the present results it can be concluded that systemic non-selective ß-AR stimulation increased thermogenesis without concomitant BAT activation, indicating that other tissues are involved.

\section{References}

1. van Marken Lichtenbelt WD, Vanhommerig JW, Smulders NM, Drossaerts JM, Kemerink GJ, Bouvy ND, Schrauwen P, and Teule GJ. Cold-activated brown adipose tissue in healthy men. $N$ Engl J Med. 2009;360(15):1500-8.

2. Saito M, Okamatsu-Ogura $Y$, Matsushita M, Watanabe K, Yoneshiro T, Nio-Kobayashi J, Iwanaga T, Miyagawa M, Kameya T, Nakada K, et al. High incidence of metabolically active brown adipose tissue in healthy adult humans: effects of cold exposure and adiposity. Diabetes. 2009;58(7):1526-31.

3. Virtanen KA, Lidell ME, Orava J, Heglind M, Westergren R, Niemi T, Taittonen M, Laine J, Savisto NJ, Enerback S, et al. Functional brown adipose tissue in healthy adults. N Engl J Med. 2009;360(15):151825.

4. Cypess AM, Lehman S, Williams G, Tal I, Rodman D, Goldfine AB, Kuo FC, Palmer EL, Tseng YH, Doria A, et al. Identification and importance of brown adipose tissue in adult humans. $N$ Engl J Med. 2009;360(15):1509-17.

5. Vijgen GH, Bouvy ND, Teule GJ, Brans B, Schrauwen P, and van Marken Lichtenbelt WD. Brown adipose tissue in morbidly obese subjects. PLoS One. 2011;6(2):e17247.

6. Bartelt A, Bruns OT, Reimer R, Hohenberg H, Ittrich H, Peldschus K, Kaul MG, Tromsdorf UI, Weller H, Waurisch $\mathrm{C}$, et al. Brown adipose tissue activity controls triglyceride clearance. Nat Med. 2011;17(2):200-5.

7. Gunawardana SC, and Piston DW. Reversal of type 1 diabetes in mice by brown adipose tissue transplant. Diabetes. 2012;61(3):674-82.

8. Orava J, Nuutila P, Lidell ME, Oikonen V, Noponen T, Viljanen T, Scheinin M, Taittonen M, Niemi T, Enerback $S$, et al. Different metabolic responses of human brown adipose tissue to activation by cold and insulin. Cell Metab. 2011;14(2):272-9.

9. Ouellet V, Labbe SM, Blondin DP, Phoenix S, Guerin B, Haman F, Turcotte EE, Richard D, and Carpentier AC. Brown adipose tissue oxidative metabolism contributes to energy expenditure during acute cold exposure in humans. J Clin Invest. 2012;122(2):545-52.

10. Nakamura K, and Morrison SF. Central efferent pathways mediating skin cooling-evoked sympathetic thermogenesis in brown adipose tissue. Am J Physiol Regul Integr Comp Physiol. 2007;292(1):R127-36.

11. Cannon B, and Nedergaard J. Brown adipose tissue: function and physiological significance. Physiol Rev. 2004;84(1):277-359.

12. Wijers SL, Saris WH, and van Marken Lichtenbelt WD. Individual thermogenic responses to mild cold and overfeeding are closely related. J Clin Endocrinol Metab. 2007;92(11):4299-305.

13. Zingaretti MC, Crosta F, Vitali A, Guerrieri M, Frontini A, Cannon B, Nedergaard J, and Cinti S. The presence of UCP1 demonstrates that metabolically active adipose tissue in the neck of adult humans truly represents brown adipose tissue. Faseb J. 2009;23(9):3113-20. 


\section{BETA-ADRENERGIC STIMULATION OF BROWN ADIPOSE TISSUE}

14. Parysow O, Mollerach AM, Jager V, Racioppi S, San Roman J, and Gerbaudo VH. Low-dose oral propranolol could reduce brown adipose tissue F-18 FDG uptake in patients undergoing PET scans. Clin Nucl Med. 2007;32(5):351-7.

15. Soderlund V, Larsson SA, and Jacobsson H. Reduction of FDG uptake in brown adipose tissue in clinical patients by a single dose of propranolol. Eur J Nucl Med Mol Imaging. 2007;34(7):1018-22.

16. van Baak MA. The peripheral sympathetic nervous system in human obesity. Obes Rev. 2001;2(1):3-14.

17. van Marken Lichtenbelt WD, Daanen HA, Wouters L, Fronczek R, Raymann RJ, Severens NM, and Van Someren EJ. Evaluation of wireless determination of skin temperature using iButtons. Physiol Behav. 2006;88(4-5):489-97.

18. Martinsson A, Lindvall K, Melcher A, and Hjemdahl P. Beta-adrenergic receptor responsiveness to isoprenaline in humans: concentration-effect, as compared with dose-effect evaluation and influence of autonomic reflexes. Br J Clin Pharmacol. 1989;28(1):83-94.

19. Christie AW, McCormick DK, Emmison N, Kraemer FB, Alberti KG, and Yeaman SJ. Mechanism of antilipolytic action of acipimox in isolated rat adipocytes. Diabetologia. 1996;39(1):45-53.

20. Randle PJ, Garland PB, Hales CN, and Newsholme EA. The glucose fatty-acid cycle. Its role in insulin sensitivity and the metabolic disturbances of diabetes mellitus. Lancet. 1963;1(7285):785-9.

21. Vallerand AL, and Jacobs I. Energy metabolism during cold exposure. Int J Sports Med. 1992;13(Suppl 1):S191-3.

22. Bell C, Stob NR, and Seals DR. Thermogenic responsiveness to beta-adrenergic stimulation is augmented in exercising versus sedentary adults: role of oxidative stress. J Physiol. 2006;570(Pt 3):629-35.

23. Schiffelers SL, Blaak EE, Baarends EM, Van Baak MA, Saris WH, Wouters EF, and Schols AM. betaAdrenoceptor-mediated thermogenesis and lipolysis in patients with chronic obstructive pulmonary disease. Am J Physiol Endocrinol Metab. 2001;280(2):E357-64.

24. Stob NR, Seals DR, Jorgen J, van Baak MA, Steig AJ, Lindstrom RC, Bikman BT, and Bell C. Increased thermogenic responsiveness to intravenous beta-adrenergic stimulation in habitually exercising humans is not related to skeletal muscle beta2-adrenergic receptor density. Exp Physiol. 2007;92(5):823-30.

25. Atgie C, D'Allaire F, and Bukowiecki LJ. Role of beta1- and beta3-adrenoceptors in the regulation of lipolysis and thermogenesis in rat brown adipocytes. Am J Physiol. 1997;273(4 Pt 1):C1136-42.

26. Mohell N, Nedergaard J, and Cannon B. Quantitative differentiation of alpha- and beta-adrenergic respiratory responses in isolated hamster brown fat cells: evidence for the presence of an alpha 1adrenergic component. Eur J Pharmacol. 1983;93(3-4):183-93.

27. Mattsson CL, Csikasz RI, Chernogubova E, Yamamoto DL, Hogberg HT, Amri EZ, Hutchinson DS, and Bengtsson T. beta(1)-Adrenergic receptors increase UCP1 in human MADS brown adipocytes and rescue cold-acclimated beta(3)-adrenergic receptor-knockout mice via nonshivering thermogenesis. Am J Physiol Endocrinol Metab. 2011;301(6):E1108-18.

28. Shih MF, and Taberner PV. Selective activation of brown adipocyte hormone-sensitive lipase and cAMP production in the mouse by beta 3-adrenoceptor agonists. Biochem Pharmacol. 1995;50(5):601-8.

29. Bizzi A, Codegoni AM, Lietti A, and Garattini S. Different responses of white and brown adipose tissue to drugs affecting lipolysis. Biochem Pharmacol. 1968;17(12):2407-12.

30. Bertin R, and Portet R. Effects of lipolytic and antilipolytic drugs on metabolism of adenosine 3':5'monophosphate in brown adipose tissue of cold acclimated rats. Eur J Biochem. 1976;69(1):177-83.

31. Schiffelers SL, Brouwer EM, Saris WH, and van Baak MA. Inhibition of lipolysis reduces beta1adrenoceptor-mediated thermogenesis in man. Metabolism. 1998;47(12):1462-7.

32. Sjostrom L, Schutz Y, Gudinchet F, Hegnell L, Pittet PG, and Jequier E. Epinephrine sensitivity with respect to metabolic rate and other variables in women. Am J Physiol. 1983;245(5 Pt 1):E431-42.

33. Simonsen L, Bulow J, Madsen J, and Christensen NJ. Thermogenic response to epinephrine in the forearm and abdominal subcutaneous adipose tissue. Am J Physiol. 1992;263(5 Pt 1):E850-5.

34. Astrup A, Bulow J, Madsen J, and Christensen NJ. Contribution of BAT and skeletal muscle to thermogenesis induced by ephedrine in man. Am J Physiol. 1985;248(5 Pt 1):E507-15. 
35. Wijers SL, Schrauwen P, Saris WH, and van Marken Lichtenbelt WD. Human skeletal muscle mitochondrial uncoupling is associated with cold induced adaptive thermogenesis. PLoS One. 2008;3(3):e1777.

36. Wijers SL, Saris WH, and van Marken Lichtenbelt WD. Recent advances in adaptive thermogenesis: potential implications for the treatment of obesity. Obes Rev. 2009;10(2):218-26. 


\section{Supplemental tables}

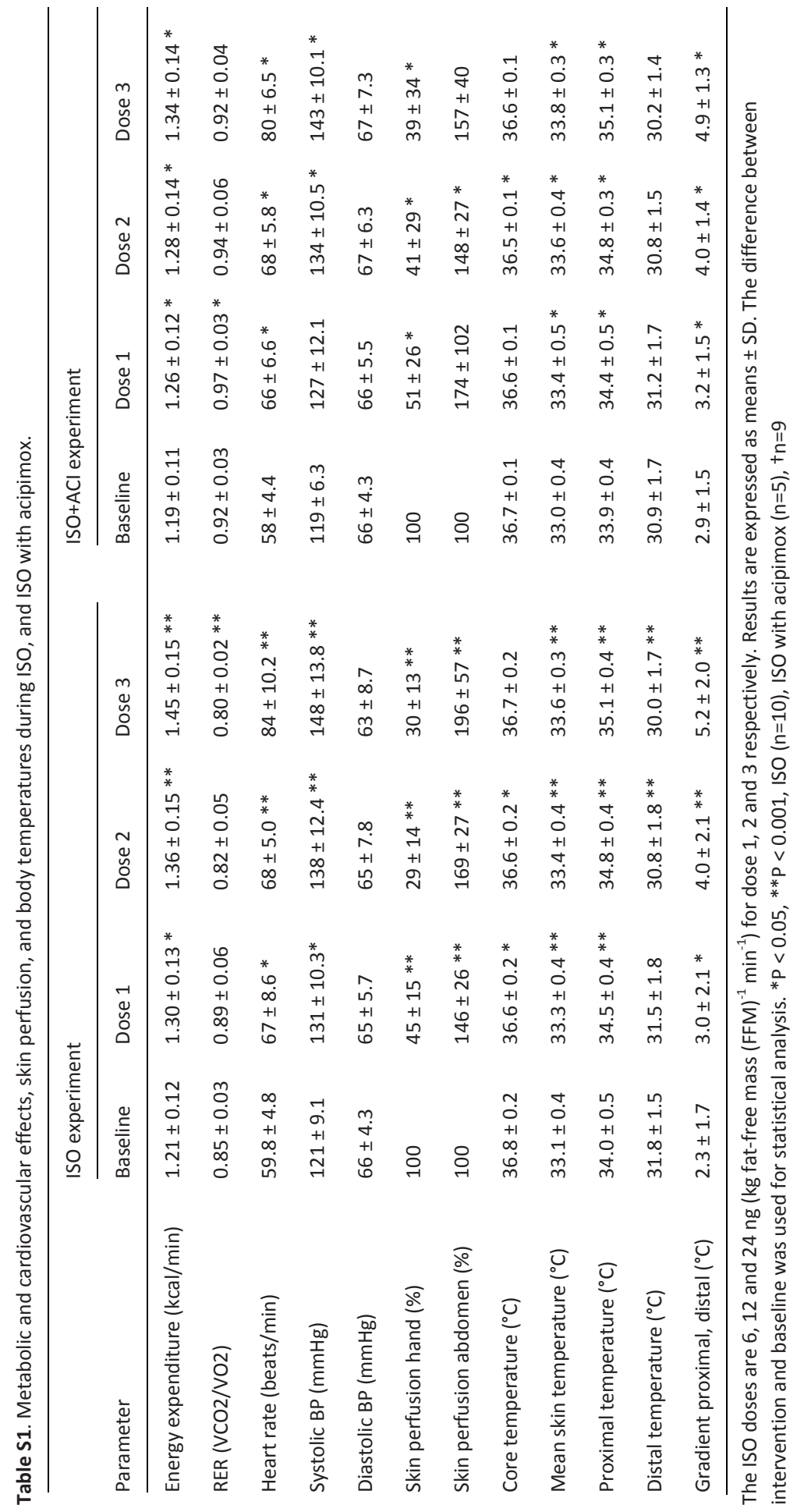


CHAPTER 4

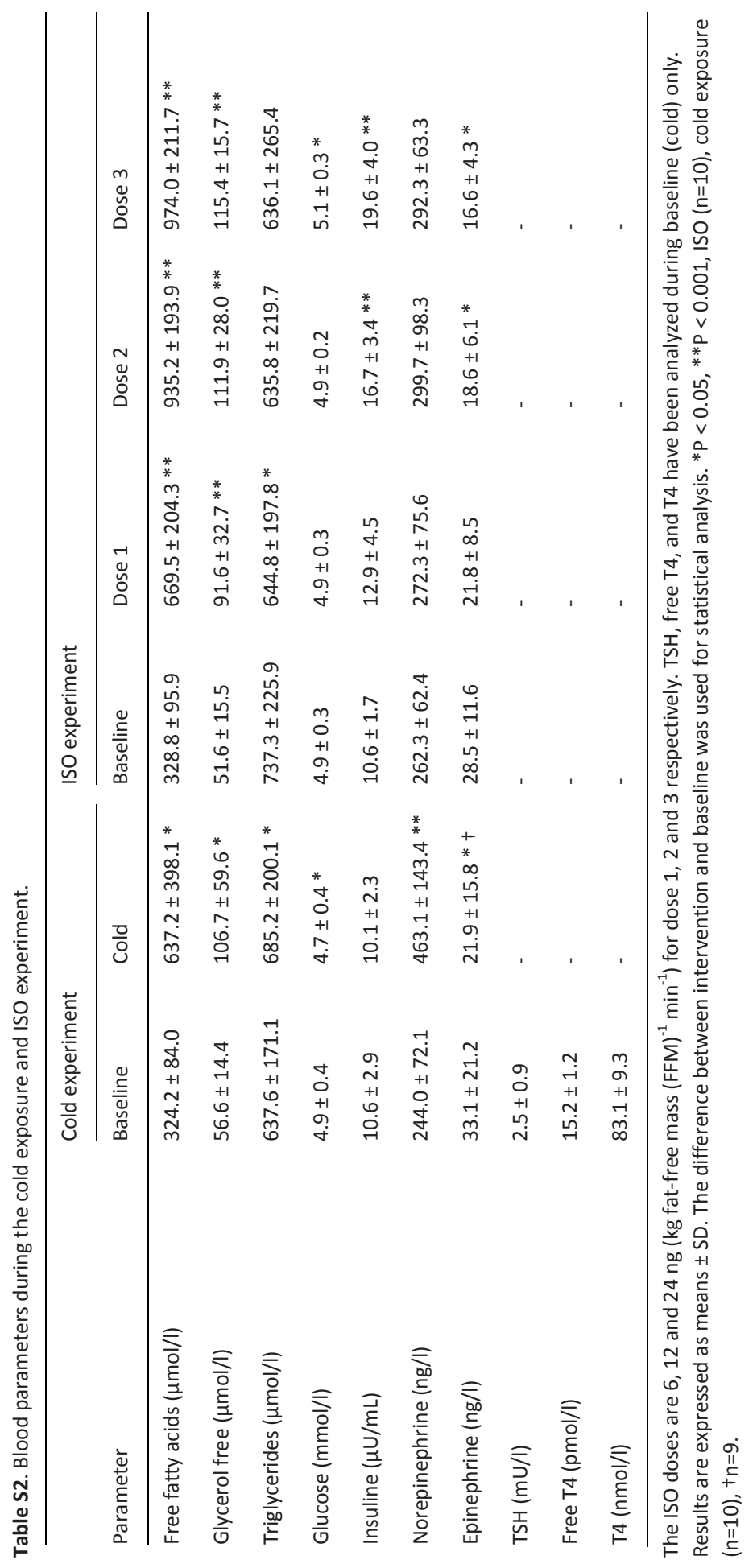


BETA-ADRENERGIC STIMULATION OF BROWN ADIPOSE TISSUE

Table S3. Blood parameters during the ISO with acipimox experiment.

\begin{tabular}{|c|c|c|c|c|}
\hline \multirow[b]{2}{*}{ Parameter } & \multicolumn{4}{|c|}{$\mathrm{ISO}+\mathrm{ACl}$ experiment } \\
\hline & Baseline & Dose 1 & Dose 2 & Dose 3 \\
\hline Free fatty acids $(\mu \mathrm{mol} / \mathrm{l})$ & $59.9 \pm 31.7$ & $80.0 \pm 28.0$ & $113.1 \pm 4.7^{*}$ & $207.4 \pm 139.7 *$ \\
\hline Glycerol free ( $\mu \mathrm{mol} / \mathrm{l})$ & $21.7 \pm 5.2$ & $22.8 \pm 4.0$ & $25.5 \pm 4.0 *$ & $32.1 \pm 14.8$ \\
\hline Triglycerides $(\mu \mathrm{mol} / \mathrm{l})$ & $635.8 \pm 280.8$ & $587.6 \pm 231.8$ & $563.2 \pm 194.9$ & $515.9 \pm 153.0$ \\
\hline Glucose $(\mu \mathrm{mol} / \mathrm{l})$ & $4.8 \pm 0.5$ & $4.7 \pm 0.3$ & $4.7 \pm 0.3$ & $5.0 \pm 0.2$ \\
\hline Insuline $(\mu \mathrm{U} / \mathrm{mL})$ & $11.6 \pm 3.5$ & $13.4 \pm 4.9$ & $15.3 \pm 7.1$ & $14.4 \pm 5.0 *$ \\
\hline Norepinephrine (ng/l) & $228.7 \pm 28.0$ & $249.9 \pm 22.1$ & $274.9 \pm 48.5$ & $289.1 \pm 77.7$ \\
\hline Epinephrine (ng/l) & $28.0 \pm 9.0$ & $24.4 \pm 6.9$ & $19.9 \pm 7.0 *$ & $17.9 \pm 5.2 *$ \\
\hline
\end{tabular}

The ISO doses are 6, 12 and $24 \mathrm{ng}\left(\mathrm{kg}\right.$ fat-free mass $(\mathrm{FFM})^{-1} \mathrm{~min}^{-1}$ ) for dose 1,2 and 3 respectively. Results are expressed as means \pm SD. The difference between intervention and baseline was used for statistical analysis. $* P<0.05$, ISO with acipmox $(n=5)$. 


\title{
CHAPTER 5
}

\author{
Reduced brown adipose tissue \\ activity in endurance trained \\ compared to lean sedentary men
}




\begin{abstract}
It has now been unequivocally demonstrated that humans possess functional brown adipose tissue (BAT) and that human BAT can be recruited upon chronic cold stimulation. Recruitment of BAT has been postulated as a potential strategy to counteract the current global obesity epidemic. Recently, it was shown in rodents that endurance exercise training could stimulate the recruitment of brown-like adipocytes within WAT via the myokine irisin, which is the cleaved circulating product of the type 1 membrane protein FNDC5. We here tested cold-stimulated BAT activity via [ ${ }^{18} \mathrm{~F}$ FDGPET-CT-imaging and browning of subcutaneous WAT by means of gene expression in twelve endurance trained athletes and twelve lean sedentary males. Indeed, mRNA expression of FNDC5 in skeletal muscle was significantly higher in endurance athletes. However, cold-induced BAT activity was significantly lower in athletes and no differences in gene expression of classical brown and beige adipocyte markers were detected between the groups. These results thus indicate that chronic endurance exercise does not lead to brown and beige adipocyte recruitment, and rather is associated with lower metabolic activity of BAT in humans.
\end{abstract}




\section{Introduction}

The presence of functional brown adipose tissue (BAT) in humans has now been unequivocally demonstrated by multiple dedicated studies (1-6) following those in 2009 (7-9). Brown adipocytes possess uncoupling protein 1 (UCP1), which uncouples respiration from ATP synthesis thereby dissipating chemical energy as heat. The thermogenic capacity of BAT makes this organ an interesting target to tackle obesity and associated diseases. In rodents, BAT has an important role in fat (10) and glucose metabolism (11), and can modulate energy balance (12). Also in adult humans, BAT activity is negatively correlated with adiposity $(7,13,14)$. Furthermore, there is strong evidence for a role of human BAT in cold-induced heat production $(1,15,16)$. Therefore, enhancing the metabolic capacity of BAT in adult humans would be a promising way to increase energy expenditure.

In addition to classical or constitutional BAT, a distinct type of thermogenic adipocytes has recently been identified within white adipose tissue (WAT), designated as beige (17) or brite (18) adipocytes. These beige adipocytes typically appear in WAT depots after stimulation (e.g. pharmacological or cold stimulation) and have comparable respiratory capacity as classical brown adipocytes (17). Beige adipocytes next to classical BAT adipocytes - may not only be present and recruited in the neck and supraclavicular area in humans (19-21), but may also be recruited in subcutaneous white adipose tissue, a process nowadays called "browning".

Recently, exercise has been hypothesized to induce browning of WAT in rodents (22). Initially, in the 1980's, it was hypothesized that exercise could stimulate BAT via increased sympathetic activity (23). However, studies in rodents generally did not show any stimulating effects of exercise on classical BAT (23-26). In the past three years however, it was demonstrated in rodents that the focus should be more on browning of typical WAT depots and less on classical BAT (22, 27-30). Interestingly, Boström et al. (2012) demonstrated in mice that exercise increases the expression of the FNDC5 gene, coding for a type 1 membrane protein that is cleaved after translation and subsequently released in the plasma as 'irisin'. In mice, this myokine stimulated browning of WAT and increased energy expenditure leading to reduced body weight and improved glucose homeostasis (22). Recently, Zhang et al. demonstrated in mice that irisin mediates browning by phosphorylation of the p38 MAPK and ERK signaling pathway (31). Boström et al. reported that endurance exercise also increased plasma irisin levels in humans and that human irisin is $100 \%$ identical to mice (22). However, recently a debate is going on whether irisin is functional in humans as it might be present in a truncated form in humans due to a mutation in the start codon of the FNDC5 gene (32). Moreover, there are concerns over the specificity of measuring irisin in humans (33), although Lee et al. (34) might have recently clarified this issue. Nevertheless, whether endurance exercise per se recruits brown and beige adipocytes in humans remains undetermined. We therefore measured cold-induced BAT activity 
by means of $\left[{ }^{18} \mathrm{~F}\right]$ fluorodeoxyglucose-positron emission tomography-computed tomography ( $\left[{ }^{18}\right.$ F]FDG-PET-CT)-scanning, and 'browning' by analyzing brown and beige markers in subcutaneous WAT in endurance trained athletes in comparison to lean sedentary controls.

\section{Results}

\section{Subject characteristics}

Both age and adiposity are known to negatively correlate with BAT activity in human adults. We therefore created comparable groups regarding age and body mass index (Table 1). As expected, fat percentage was significantly lower in the trained group (endurance athletes) compared to the untrained group (sedentary males) $(P<0.05)$, but was not related to BAT activity neither within each group, nor within the entire study population. Resting heart rate was significantly lower in the trained group $(P<$ $0.05)$, indicating the typical bradycardia found after regular endurance exercise training (35). No significant differences in baseline concentrations of thyroid hormones, FFA's, and glucose were found. Triglyceride concentration in plasma was $36 \%$ lower in the trained group, although this observation failed to reach statistical significance $(P=0.099)$. Finally, baseline insulin was significantly lower in serum of the trained group $(P<0.05)$. 
Table 1. Subject characteristics

\begin{tabular}{|c|c|c|}
\hline Characteristic & Trained & Untrained \\
\hline Age (yrs) & $25 \pm 4.4$ & $23 \pm 3.3$ \\
\hline Body mass (kg) & $72.4 \pm 7.1$ & $71.9 \pm 6.4$ \\
\hline Height (m) & $1.84 \pm 0.06$ & $1.82 \pm 0.05$ \\
\hline BMI $\left(\mathrm{kg} / \mathrm{m}^{2}\right)$ & $21.4 \pm 1.8$ & $21.8 \pm 1.9$ \\
\hline Body fat (\%) & $13.1 \pm 1.8^{B}$ & $18.1 \pm 4.3$ \\
\hline Fat free mass $(\mathrm{kg})$ & $60.2 \pm 5.7$ & $56.6 \pm 4.7$ \\
\hline VO2 $\max (\mathrm{mL} / \mathrm{min} / \mathrm{kg})$ & $59.2 \pm 3.6^{A}$ & $40.5 \pm 2.2$ \\
\hline Power output (W/kg) & $5.1 \pm 0.3^{\mathrm{A}}$ & $3.6 \pm 0.3$ \\
\hline RMR (MJ/day)* & $7.6 \pm 1.0$ & $7.0 \pm 1.0$ \\
\hline Heart rate (bpm) & $52 \pm 9^{A}$ & $61 \pm 7$ \\
\hline Systolic BP (mmHg) & $119 \pm 9$ & $119 \pm 10$ \\
\hline Diastolic BP (mmHg) & $72 \pm 7$ & $73 \pm 7$ \\
\hline $\mathrm{TSH}(\mathrm{mU} / \mathrm{L})$ & $1.98 \pm 1.53$ & $1.33 \pm 0.36$ \\
\hline Total T4 (nmol/L) & $77.1 \pm 13.6$ & $82.7 \pm 20.1$ \\
\hline Free T4 (pmol/L) & $13.7 \pm 2.2$ & $14.0 \pm 1.4$ \\
\hline $\mathrm{FFA}(\mu \mathrm{mol} / \mathrm{L})$ & $440 \pm 253$ & $567 \pm 217$ \\
\hline Glucose (mmol/L) & $4.8 \pm 0.3$ & $5.0 \pm 0.3$ \\
\hline Insuline $(\mu \mathrm{U} / \mathrm{mL})$ & $5.7 \pm 1.2^{B}$ & $9.5 \pm 5.1$ \\
\hline Triglycerides ( $\mu \mathrm{mol} / \mathrm{L})$ & $613 \pm 267$ & $960 \pm 643$ \\
\hline
\end{tabular}

Results are expressed as means \pm SD. ${ }^{A} \mathrm{P}<0.01$ trained vs. untrained, ${ }^{B} \mathrm{P}<0.05$ trained vs. untrained. Differences between the trained and untrained group were tested with independent sample t tests. * RMR was corrected for fat free mass (36). RMR = resting metabolic rate, $\mathrm{TSH}$ = thyroid stimulating hormone

\section{Lower cold-induced BAT activity in endurance athletes}

As several animal studies suggest that endurance exercise increases the metabolic capacity of BAT, we compared energy expenditure during thermoneutral conditions with two hours of mild cold exposure, and calculated the maximal nonshivering thermogenesis (NST) capacity in both groups. Indeed, energy expenditure significantly increased during cold exposure in the trained $(P<0.05)$ and untrained group $(P<$ 0.001 , Table 2). Mean NST tended to be lower in the trained group, although this was not significantly different $(8.0 \pm 8.9 \%$ versus $11.8 \pm 6.5 \%, P=0.25)$. In line with previous findings (16), cold exposure significantly increased fatty acid oxidation during cold in both groups $(P<0.05)$, whereas the oxidation of carbohydrates significantly decreased in the trained group $(P<0.05)$, and tended to decrease in the untrained group $(P=$ 0.058). 
Table 2. Thermoregulatory, cardiovascular and blood parameters in trained and untrained group during thermoneutral (baseline) and mild cold exposure.

\begin{tabular}{|c|c|c|c|c|}
\hline \multirow[b]{2}{*}{ Variable } & \multicolumn{2}{|l|}{ Trained } & \multicolumn{2}{|l|}{ Untrained } \\
\hline & Baseline & Cold & Baseline & Cold \\
\hline Energy Expenditure (kJ/min) & $5.3 \pm 0.4$ & $5.7 \pm 0.6^{B}$ & $4.9 \pm 0.4$ & $5.4 \pm 0.6^{A}$ \\
\hline Nonshivering thermogenesis (\%) & - & $8.0 \pm 8.9$ & - & $11.82 \pm 6.48$ \\
\hline $\mathrm{RQ}(\mathrm{VCO} 2 / \mathrm{VO} 2)$ & $0.85 \pm 0.04$ & $0.81 \pm 0.04^{B}$ & $0.83 \pm 0.05$ & $0.79 \pm 0.04^{B}$ \\
\hline $\mathrm{CHO}$ oxidation $(\mathrm{mg} / \mathrm{min})$ & $162 \pm 41$ & $131 \pm 41^{\mathrm{B}}$ & $134 \pm 52$ & $111 \pm 47$ \\
\hline Fat oxidation (mg/min) & $67.5 \pm 22.6$ & $90.9 \pm 23.8^{B}$ & $68.5 \pm 18.4$ & $93.4 \pm 23.6^{\mathrm{A}}$ \\
\hline Vasoconstriction toe (\%) & 0 & $83 \pm 17^{A}$ & 0 & $74 \pm 22^{A}$ \\
\hline Vasoconstriction hand (\%) & 0 & $87 \pm 13^{A}$ & 0 & $85 \pm 9^{A}$ \\
\hline Vasoconstriction underarm (\%) & 0 & $61 \pm 14^{A, C}$ & 0 & $34 \pm 21^{B}$ \\
\hline Vasoconstriction abdomen (\%) & 0 & $-16 \pm 50$ & 0 & $12 \pm 39$ \\
\hline Mean skin temperature $\left({ }^{\circ} \mathrm{C}\right)$ & $33.4 \pm 0.5$ & $29.4 \pm 0.6^{\mathrm{A}}$ & $33.2 \pm 0.4$ & $29.5 \pm 0.9^{A}$ \\
\hline Underarm temperature $\left({ }^{\circ} \mathrm{C}\right)$ & $33.4 \pm 1.0$ & $26.2 \pm 2.0^{\mathrm{A}, \mathrm{D}}$ & $33.9 \pm 0.8$ & $28.0 \pm 2.1^{\mathrm{A}}$ \\
\hline Hand temperature $\left({ }^{\circ} \mathrm{C}\right)$ & $31.5 \pm 2.1$ & $22.3 \pm 1.3^{\mathrm{A}}$ & $32.0 \pm 1.6$ & $23.3 \pm 1.6^{\mathrm{A}}$ \\
\hline Lower leg temperature $\left({ }^{\circ} \mathrm{C}\right)$ & $31.8 \pm 0.6$ & $24.6 \pm 0.9^{B, D}$ & $32.1 \pm 0.7$ & $25.8 \pm 1.5^{\mathrm{A}}$ \\
\hline Foot temperature $\left({ }^{\circ} \mathrm{C}\right)$ & $30.0 \pm 1.2$ & $21.2 \pm 1.2^{\mathrm{A}}$ & $30.1 \pm 1.3$ & $22.0 \pm 1.8^{\mathrm{A}}$ \\
\hline Core temperature $\left({ }^{\circ} \mathrm{C}\right)$ & $36.83 \pm 0.26$ & $36.72 \pm 0.42$ & $36.88 \pm 0.14$ & $36.95 \pm 0.21$ \\
\hline Systolic BP (mmHg) & $119 \pm 9$ & $134 \pm 8^{A}$ & $119 \pm 10$ & $130 \pm 11^{\mathrm{A}}$ \\
\hline Diastolic BP (mmHg) & $72 \pm 7$ & $84 \pm 7^{A}$ & $73 \pm 7$ & $84 \pm 8^{A}$ \\
\hline Heart rate (beats/min) & $52 \pm 9$ & $49 \pm 8^{B}$ & $61 \pm 7$ & $62 \pm 10$ \\
\hline Free fatty acids ( $\mu \mathrm{mol} / \mathrm{L})$ & $440 \pm 253$ & $641 \pm 366^{\mathrm{B}}$ & $567 \pm 217$ & $671 \pm 196$ \\
\hline Glycerol free $(\mu \mathrm{mol} / \mathrm{L})$ & $58.2 \pm 22.9$ & $81.6 \pm 39.9^{B}$ & $80.4 \pm 30.9$ & $86.9 \pm 20.9$ \\
\hline Triglycerides ( $\mu \mathrm{mol} / \mathrm{L})$ & $613 \pm 267$ & $651 \pm 282^{B}$ & $959 \pm 643$ & $999 \pm 525$ \\
\hline Glucose (mmol/L) & $4.8 \pm 0.3$ & $4.7 \pm 0.3$ & $5.0 \pm 0.3$ & $5.1 \pm 0.4$ \\
\hline Insulin (mU/mL) & $5.7 \pm 1.2$ & $4.6 \pm 0.6^{B}$ & $9.5 \pm 5.1$ & $12.2 \pm 6.3$ \\
\hline
\end{tabular}

Results are expressed as means $\pm \mathrm{SD}$. ${ }^{\mathrm{A}} \mathrm{P}<0.01$ baseline vs. mild cold, ${ }^{\mathrm{B}} \mathrm{P}<0.05$ baseline vs. mild cold, ${ }^{\mathrm{C}} \mathrm{P}<$ 0.01 trained vs. untrained, ${ }^{D} \mathrm{P}<0.05$ trained vs. untrained. The effect of mild cold exposure was tested with a paired samples t test. Differences between the trained and untrained group were tested with independent sample $t$ tests

After one hour of mild cold exposure the glucose analog $\left[{ }^{18}\right.$ F]FDG was injected to determine cold-induced BAT activity. The $\left[{ }^{18}\right.$ F]FDG-uptake in BAT was measured via PET imaging one hour after the injection. Interestingly, total cold-induced BAT activity was significantly lower in the trained group compared to the untrained group (622 \pm 801 versus $1837 \pm 1308 \mathrm{SUV}_{\text {total }} P<0.05$ )(Figure $\mathbf{1 A}, \mathbf{1 C}$ ), as was maximal BAT activity $\left(6.25 \pm 4.09\right.$ versus $\left.13.09 \pm 8.57 \mathrm{SUV}_{\max }, P<0.05\right)$ (Figure 1D). Furthermore, the average $\left[{ }^{18} \mathrm{~F}\right] \mathrm{FDG}$-uptake in supraclavicular BAT was significantly lower in the trained 
group (3.86 \pm 3.00 versus $8.68 \pm 6.55 \mathrm{SUV}_{\text {mean }} P<0.05$; Figure 1B). Cold-induced $\left[{ }^{18}\right.$ F]FDG-uptake in skeletal muscle $\left(0.58 \pm 0.12\right.$ versus $0.58 \pm 0.09$ SUV $\left._{\text {mean }}, P>0.05\right)$, subcutaneous WAT $\left(0.29 \pm 0.09\right.$ versus $0.24 \pm 0.07$ SUV $\left._{\text {mean }} P>0.05\right)$, visceral WAT $\left(0.89 \pm 0.43\right.$ versus $0.91 \pm 0.61$ SUV $\left._{\text {mean }}, P>0.05\right)$, liver $(1.65 \pm 0.29$ versus $2.15 \pm 1.49$ SUV $\left._{\text {mean }}, P>0.05\right)$, and brain $\left(6.50 \pm 1.44\right.$ versus $\left.6.95 \pm 0.85 \mathrm{SUV}_{\text {mean }}, P>0.05\right)$ were not significantly different between trained and untrained subjects. It thus appears that regular endurance exercise training is associated with lower cold-induced activity of BAT specifically.

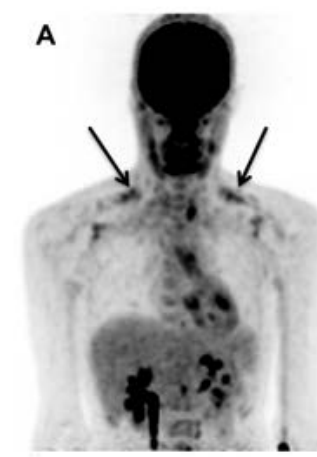

Trained

C

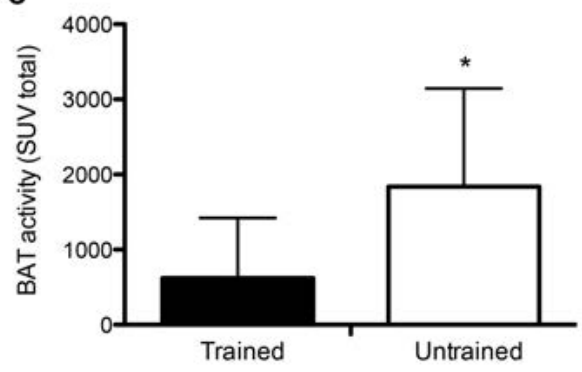

B

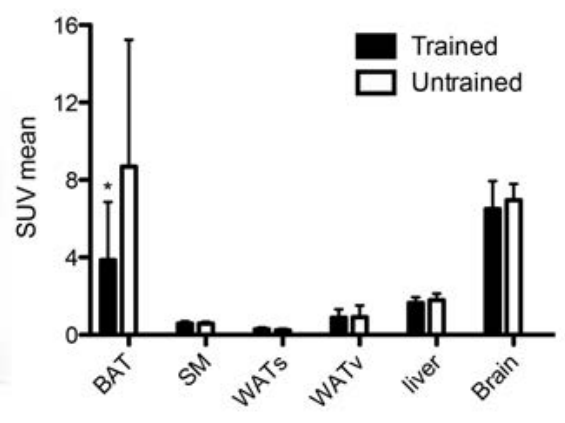

D

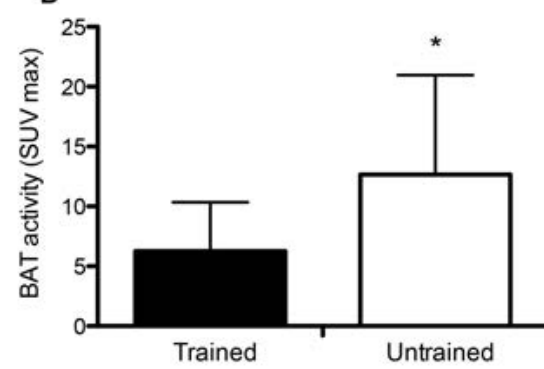

Figure 1. Decreased uptake of $\left[{ }^{18} \mathrm{~F}\right) \mathrm{FDG}$ in brown adipose tissue (BAT) during cold exposure in trained subjects. (A) Representative $\left[{ }^{18}\right.$ F)FDG-PET images demonstrating glucose uptake in trained and untrained test subjects. The supraclavicular BAT is indicated with black arrows. (B) The average $\left[{ }^{18}\right.$ F)FDG-uptake $\left(S_{\text {mean }}\right)$ measured in multiple tissues in trained and untrained subjects. (C, D) BAT activity, in SUV total and SUV max respectively, in trained and untrained subjects. Differences between groups were measured by independent sample $t$ tests. Values are expressed as mean with SD. ${ }^{*} \mathrm{P}<0.05$.

In line with our previous findings $(2,16)$, we found a relationship between BAT activity and NST in the whole study group $(r=0.67, P<0.001$; Figure $2 \mathrm{~A})$, in the trained group ( $r=0.86, P<0.001$; Figure 2B), and a trend in the untrained group ( $r 0.57, P=0.053$; Figure $\mathbf{2 C}$ ), supporting the prominent role for BAT in NST in humans. 

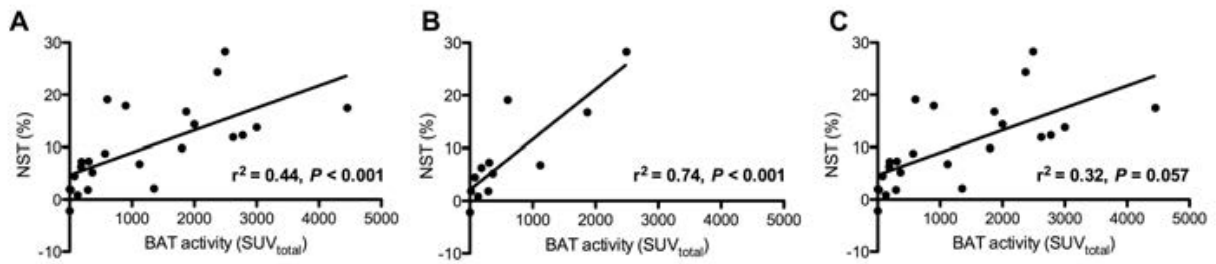

Figure 2. Correlation between BAT activity and NST. Correlation between BAT activity and NST in trained and untrained subjects together (A), only trained subjects (B) and only untrained subjects (C). BAT activity is expressed as SUV $\mathrm{V}_{\text {total }}$ and NST as percentage.

\section{Chronic endurance exercise does not induce browning of WAT}

Browning of WAT has been suggested to be due to an increase in the plasma hormone irisin, which is processed from the skeletal muscle protein FNDC5 (22). There is currently debate on whether the antibody used to measure plasma FNDC5/Irisin is valid or not $(32,33,37)$ and whether irisin in humans is functional, since a mutation in the start codon of the human FNDC5 gene might lead to the release of a truncated form of Irisin in plasma $(32,33)$. We therefore focused on mRNA expression of FNDC5 in skeletal muscle ( $\mathrm{m}$. vastus lateralis) in both groups and found that FNDC5 mRNA expression was indeed higher in the trained group (Figure $\mathbf{3 A}$ ), indicating that chronic endurance exercise stimulates FNDC5 expression. Subsequently, we examined whether chronic endurance exercise induced browning of WAT as shown by previous studies in rodents $(22,27,30)$. To this end, we analyzed gene expression of several brown and beige adipocyte cell markers in abdominal subcutaneous WAT by means of qPCR. An important marker for browning of WAT is UCP-1. However, mRNA of UCP1 was undetectable in human WAT. Another candidate reflecting an increased thermogenic gene program is PGC- $1 \alpha$, but we did not detect differences in mRNA expression between both groups $(P>0.05$; Figure 3B). Finally, we determined the mRNA expression of the brown adipocyte marker Cidea (Figure $3 C$ ), and the two beige markers: TMEM26 (Figure 3D) and CD137 (Figure 3E). Again, mRNA levels of these genes in subcutaneous WAT were similar between the trained and untrained subjects $(P>0.05)$. These findings provide evidence against browning of subcutaneous WAT depots in humans following regular endurance exercise. 

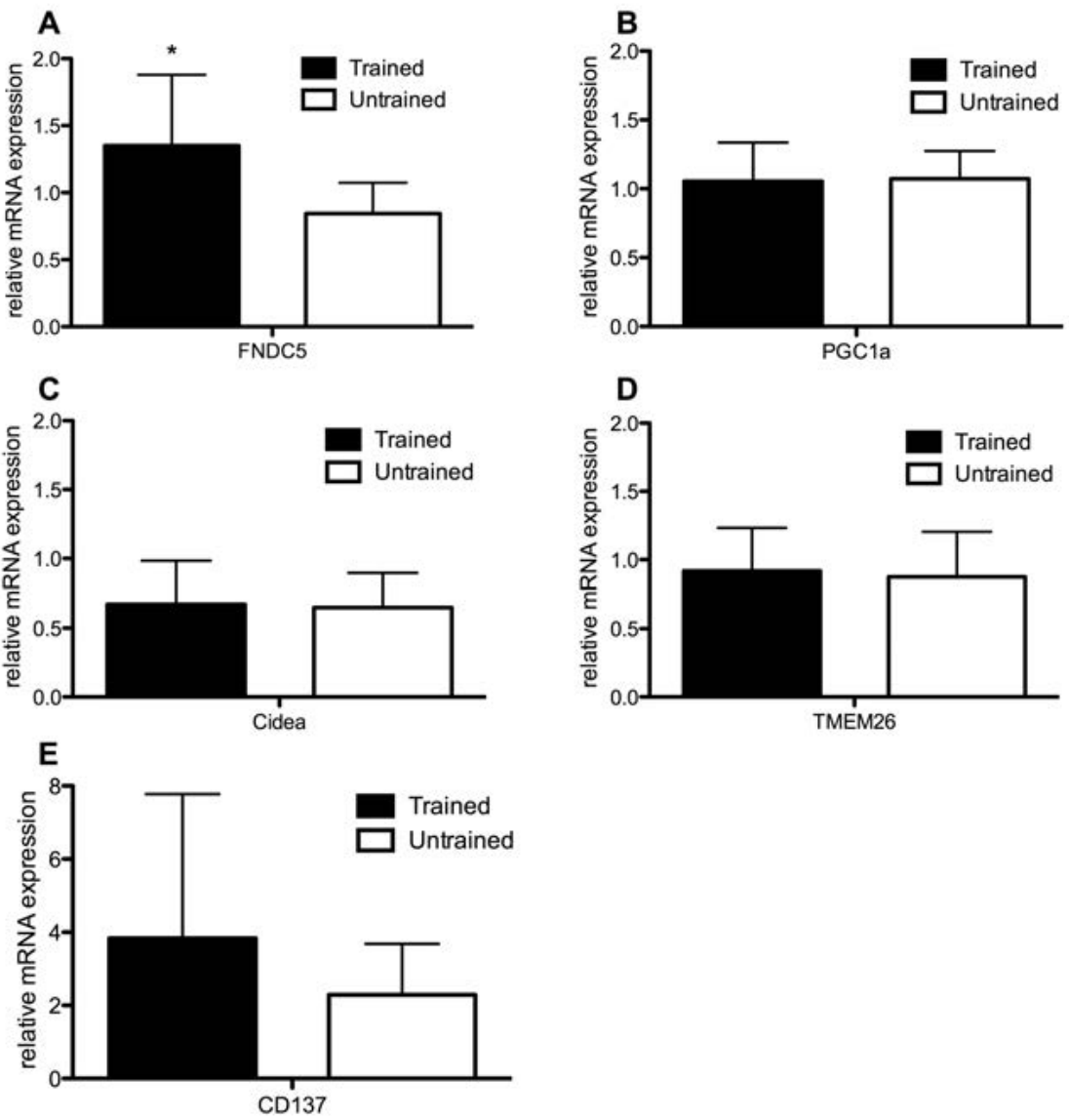

Figure 3. Effect of chronic endurance exercise on FNDC5 in muscle and browning of WAT. (A) mRNA expression of FNDC5 was determined in skeletal muscle ( $\mathrm{m}$. vastus lateralis) derived from trained and untrained subjects. In trained and untrained subjects, mRNA expression of PGC1 $\alpha$ (B), Cidea (C), TMEM26 (D), and CD137 (E) was determined in WAT. Differences between groups were measured by independent sample $t$ tests. Values are expressed as mean with $S D * P<0.05$.

\section{Vasoconstriction and body temperatures during cold exposure}

In addition to cold-induced heat production, minimizing heat loss via vasoconstriction is the other important thermoregulatory mechanism to prevent hypothermia. We determined vasoconstriction in the hand, toe, underarm, and abdomen by measuring changes in skin perfusion with Laser Doppler flowmetry. Both groups significantly increased vasoconstriction in the toe, hand, and underarm $(P<0.001$, Table 2), whereas no significant difference was observed in the abdomen during cold exposure $(P>0.05)$. Vasoconstriction in the hand, toe, and abdomen was not significantly different between groups $(P>0.05)$. Interestingly, the trained group showed a larger vasoconstriction in the underarm $(61.4 \pm 14.1 \%$ versus $34.3 \pm 21.2 \%, P<0.01)$ thereby 
minimizing heat loss in the extremities, which might decrease the need for metabolic heat production in trained individuals. Lower skin temperatures in the extremities confirmed this larger vasoconstriction. The absolute skin temperatures of the trained group were significantly lower on the lower leg $\left(24.6 \pm 0.9\right.$ versus $\left.25.8 \pm 1.5^{\circ} \mathrm{C}, P<0.05\right)$ and the underarm $\left(26.2 \pm 2.0\right.$ versus $\left.28.0 \pm 2.1^{\circ} \mathrm{C}, P<0.05\right)$. The absolute temperature on the wrist and dorsal part of the foot was slightly lower in the trained group although this difference was not significant $(P=0.09$ and $P=0.22$, respectively). Mean skin temperature was not different between both groups. Although core temperature did not significantly decrease in the trained group $\left(-0.11^{\circ} \mathrm{C}, P>0.05, \mathrm{n}=11\right)$ and in the untrained group $\left(0.08^{\circ} \mathrm{C}, P>0.05, \mathrm{n}=10\right)$, the difference between both groups tended to be statistically significant $(P=0.08)$. Taken together, it appears that the endurance athletes are less dependent on a metabolic response and rely more on vasoconstriction during cold stress.

\section{The effects of cold on thermal sensation and comfort, blood pressure, heart rate and blood values}

During the two-hour cold period we controlled ambient temperature by means of air conditioning to maximally cool subjects without inducing shivering. The average temperature in the climate tent after the injection of $\left[{ }^{18} \mathrm{~F}\right] \mathrm{FDG}$ (when shivering was absent) was not significantly different between both groups (trained: $15.95 \pm 1.41^{\circ} \mathrm{C}$ versus untrained: $17.07 \pm 2.28^{\circ} \mathrm{C}, P>0.05$ ), indicating comparable cold stress in both groups. The thermal sensation and comfort during the mild cold experiment was comparable at each time point $(P>0.05)$. Both diastolic and systolic blood pressure significantly increased $(P<0.001)$ during mild cold in both groups (Table 2 ). Heart rate decreased in the trained group $(-3 \pm 3 \mathrm{bpm}, P<0.01)$, whereas it did not change in the untrained group $(1 \pm 6 \mathrm{bpm}, P>0.05)$, with a tendency for a statistical significant difference between groups $(P=0.06)$. Blood samples were taken during baseline (thermoneutral) and after one hour in the cold. Cold exposure significantly increased plasma FFA, free glycerol, and triglycerides concentrations in the trained group $(P<$ $0.05)$, whereas no differences were found in the untrained group $(P>0.05)$, except for a tendency to an increase in plasma FFA $(P=0.06)$. Furthermore, glucose concentrations did not change during cold exposure, although a trend for a decrease was observed in the trained group $(P=0.09)$. Insulin significantly decreased during cold exposure in the trained group $(P<0.05)$, whereas it did not change in the untrained group $(P>0.05)$. However, the differences between thermoneutral and cold conditions of these blood parameters were not significantly different between the groups (Table 2). 


\section{Discussion}

Health problems associated with obesity warrant strategies to restore energy balance. Stimulating recruitment of BAT might be a plausible strategy to enhance the capacity to increase thermogenesis and induce weight loss. Endurance exercise is known for its favorable metabolic effects, and it was recently shown in rodents that one of these effects involves browning of WAT $(22,27,30)$, and possibly the stimulation of classical BAT depots (27-29). However the effects of chronic endurance exercise on BAT in humans remain unknown. We here show that chronic endurance exercise training is not associated with an increased, but rather decreased cold-induced BAT activity, and does not stimulate browning of subcutaneous abdominal WAT in young adult males.

We examined cold-induced BAT activity in twelve endurance-trained and twelve lean sedentary males, with comparable age and BMI. Both total and maximal $\left[{ }^{18} \mathrm{~F}\right]$-FDG uptake in BAT was significantly lower in athletes. With respect to browning of subcutaneous WAT, Boström et al. demonstrated that this was mediated by the exercise-induced myokine irisin (22). So far, human studies have shown conflicting results on the stimulating effects of exercise on FNDC5 and irisin $(32,34,38-42)$. We here measured mRNA expression of the precursor of irisin, FNDC5, and indeed found 1.6 fold higher mRNA levels in the trained athletes, confirming the stimulating effects of chronic endurance exercise on FNDC5. Next, browning of subcutaneous WAT was determined by measuring typical brown and beige adipocyte cell markers. We analyzed the expression of UCP-1 in biopsies from the abdominal subcutaneous adipose tissue and found that it was mostly undetectable in both groups. Furthermore, the mRNA expression of the beige markers CD137 and TMEM26 were comparable between groups, as well as PGC-1 $\alpha$ and the classical brown adipocyte marker Cidea. A recent study by Norheim et al. (39) also showed very low UCP1 expression (mean $C_{t}=$ $36.6 \pm 1.8$ ) in abdominal subcutaneous WAT before and after 12 weeks of combined endurance- and strength training in healthy and prediabetic subjects. Nevertheless, in that study UCP-1 expression significantly increased (1.82-fold) upon training when both groups were combined. In agreement with our study, no exercise effects were found on PRDM16, TBX1, TMEM26, and CD137 expression, neither in healthy nor in prediabetic subjects (39). As further evidence against an effect of exercise training on browning in humans, we found no difference in $\left[{ }^{18} \mathrm{~F}\right]$-FDG-uptake in subcutaneous WAT between trained and untrained subjects.

With respect to irisin, Raschke et al. (32) showed that incubating human subcutaneous preadipocytes with recombinant FNDC5 and irisin did not induce browning as measured by mRNA expression of PPARY, UCP1, TCF21 or ZIC1. Furthermore, Norheim et al. (39) found that neither FNDC5 mRNA expression in subcutaneous adipose tissue nor in skeletal muscle nor plasma irisin levels were related to adipose tissue UCP1 mRNA of prediabetic and healthy subjects before or after the training period. However, a cross sectional study by Moreno-Navarrete et al. 
(43) in nonobese, obese, and type 2 diabetic humans (BMI between 20 and $58 \mathrm{~kg} / \mathrm{m}^{2}$ ) did find that FNDC5 expression in muscle was associated with FNDC5 and UCP-1 gene expression in subcutaneous adipose tissue. Furthermore, they found that circulating irisin levels were negatively related with obesity and insulin resistance. More recently, Lee et al. (34) found that FNDC5/irisin was increased in young adults during submaximal exercise and during acute cold exposure (only when they shivered). Interestingly, they demonstrated that FNDC5/irisin treatment of primary human adipocytes taken from the neck stimulated only beige and not classical adipocyte gene markers. Moreover, it was shown that primary human subcutaneous adipocytes responded minimally to treatment, and primary visceral adipocytes did not respond at all. These findings thus suggest that FNDC5/irisin might stimulate browning in fat from the neck region in humans. Unfortunately, in this study, we were unable to take biopsies from these regions. Collectively, given the contradictory findings thus far, the role of irisin in humans as a therapeutic needs further investigation. We here show that exercise per se does not lead to detectable browning of subcutaneous abdominal WAT in humans.

The previous mentioned studies have solely examined the effects of exercise and irisin on adipose browning by measuring specific markers within adipose tissue. The present study also measured the effects of chronic exercise training on cold-induced BAT activity by means of FDG-PET/CT-imaging, which reflects the total amount of active BAT in each individual. Recent studies have shown that human BAT from the neck region possesses both classical brown as beige adipocytes $(17,20,21)$. Therefore, we hypothesized that if exercise - via irisin - can induce browning, it would result in enhanced BAT activity in both the neck region as in subcutaneous WAT. However, in support with the mRNA expression results on WAT browning, $\left[{ }^{18}\right.$ F]FDG-uptake was not different between athletes and sedentary subjects in both subcutaneous and visceral WAT, and was in fact significantly lower in BAT depots from the neck region in the athletes. These PET-data therefore strengthen the conclusion that chronic endurance training recruits neither brown nor beige adipocytes.

In addition to the lower observed BAT activity, average NST was also lower in the endurance athletes ( $8 \%$ versus $12 \%$ ). NST was strongly correlated with BAT activity, supporting the notion that BAT is an important mediator in cold-induced heat production $(1,3,13,16,44)$. Interestingly, the athletes showed larger vasoconstriction in the arm. It could thus be speculated that the endurance athletes rely more on insulation rather than on BAT mediated heat production during mild cold exposure. This larger 'nonfat insulation', which reflects regulated insulation by means of vasoconstriction, has been observed previously in long distance runners (45) and after 9 weeks of endurance exercise in young men (46). In the latter study, the subjects also showed a moderately lower metabolic response and lower body temperatures after the training period. The authors hypothesized that this physical conditioning may promote vascularization of muscle tissue and/or alter tissue sensitivity to circulating 
catecholamines thereby increasing the capacity for vasoconstriction. Despite increased insulation, there was a trend for lower core temperature during the cold exposure in the athletes, suggesting that athletes might tolerate lower internal body temperatures, which has been demonstrated previously in long distance runners (45). This was however not reflected by differences in thermal sensation and comfort between both groups.

Interestingly, plasma FFA, free glycerol, and triglycerides significantly increased during cold exposure in the trained group, and plasma insulin levels decreased in the endurance-trained athletes as previously observed in both lean and obese individuals (47). It has been shown in sheep that cold exposure diminishes insulin production by the pancreas likely through increased activation of $\alpha$-receptors in pancreatic $\beta$-cells by increased sympathetic activity and catecholamine release (48). It is likely that increased sympathetic stimulation by cold exposure stimulated WAT lipolysis thereby increasing plasma free FFA and glycerol to supply substrates for cold-induced thermogenesis (49). In addition, the decrease in insulin levels may result in a diminished inhibition of lipolysis, partly explaining the increase in FFA and free glycerol and may serve to fuel the increased fatty acid oxidation during cold exposure in the athletes. The increase of plasma triglycerides after cold exposure has been observed previously (50), and is in contrast to the increased triglyceride clearance observed in mice by Bartelt and coworkers (51).

In summary, endurance trained athletes had lower cold-induced BAT activity compared to lean sedentary individuals. Moreover, despite increased gene expression of FNDC5 in skeletal muscle chronic endurance exercise did not lead to browning of subcutaneous abdominal WAT. It can thus be concluded that, in contrast to rodents, chronic endurance exercise does not lead to an increased thermogenic capacity of BAT in humans.

\section{Methods}

\section{Subjects}

Twelve healthy endurance-trained and twelve lean sedentary males aged between 1835 years were studied between January and September 2013. The athletes were included in the trained group when they performed endurance exercise (long-distance running, cycling, swimming) sessions of at least one and a half hours at least three times per week during the last two years. Furthermore, they were screened for maximal oxygen consumption (VO2max), which should be above $55 \mathrm{ml} / \mathrm{min} / \mathrm{kg}$. The sedentary males were included in the untrained group if they did not perform more than one hour of sports per week during the last two years. Furthermore, a VO2 max below $45 \mathrm{ml} / \mathrm{min} / \mathrm{kg}$ was used as inclusion criterion. Due to technical problems we included one untrained individual solely based on his maximal power output, which 
was less than 4 Watt/kg General exclusion criteria were use of medication, smoking, weight gain/loss of more than $3 \mathrm{~kg}$ in the last six months, hypertension, (family history of) diabetes and diabetes related diseases, and contra indications for MRI and PET-CT. All subjects signed a written informed consent. The local medical ethical committee approved the study protocol and all subjects were treated according to the declaration of Helsinki of 1975, as revised in 1983.

\section{Study design}

Each subject underwent a mild cold experiment followed by a by $\left[{ }^{18} \mathrm{~F}\right]$ fluorodeoxyglucose-positron emission tomography-computed tomography $\left(\left[{ }^{18} \mathrm{~F}\right]\right.$ FDG-PET-CT)-scan to determine BAT activity. Within two weeks from the PET-CT scan, we took an abdominal subcutaneous adipose biopsy (needle) $6-8 \mathrm{~cm}$ lateral from the umbilicus under local anesthesia (2\% lidocaine) to determine browning of WAT. Subsequently, a muscle biopsy from $\mathrm{m}$. vastus lateralis was taken according to the technique of Bergström (52) to determine FNDC5 mRNA expression. The tissue was rinsed from blood, and directly frozen in melting isopentane. Subsequently, the biopsies were snap frozen in liquid nitrogen and stored at $-80{ }^{\circ} \mathrm{C}$ for future analysis. These measurements were conducted in the morning after an overnight fast. The mild cold experiment and biopsies were conducted within two weeks from each other. Furthermore, we paired each trained individual with an untrained subject and measured both within two weeks to preclude possible seasonal effects (acclimatization) on BAT activity and browning of WAT. Due to practical reasons, one pair was measured within 3 weeks. All subjects were asked to refrain from exercise in the three days previous to the biopsies to exclude any acute effects on skeletal muscle and adipose tissue. Body composition was determined by means of dual $x$-ray absorptiometry (type discovery A; Hologic).

\section{Mild cold experiment and PET/CT scan}

BAT activity was measured during two hours of mild cold exposure, in which we used a standardized cooling protocol (for details see (50)). All subjects arrived in the morning after an overnight fast and were asked to refrain from exercise on the previous day and consumed a standardized meal the evening before the experiment (55\% carbohydrate, $30 \%$ fat, $15 \%$ protein, $518 \mathrm{kcal}$ ). Measurements were conducted in a specially equipped air-permeable tent (Colorado altitude training, USA), in which ambient temperature could be tightly controlled. During the experiment, subjects wore standardized clothing (shorts and a t-shirt; 0.19 clo).

We measured several parameters during the mild cold experiment. Core temperature was sampled each minute via a telemetric pill (CoreTemp, HT150002, USA), which was orally ingested one hour before the start of the experiment. Mean skin temperature was measured every minute via wireless temperature sensors (iButtons, Maxim integrated, USA) at the 14 sites prescribed by ISO-standard 
9886:2004 (Ergonomics - Evaluation of thermal strain by physiological measurements, International Standards Organization, Geneva, Switzerland). Furthermore, we attached one iButton on the palmar side of the middle finger and one at the ventral site of the underarm to determine to underarm-fingertip gradient, and one iButton at the supraclavicular area to detect any differences in skin temperature at the most prominent BAT location in humans. The level of skin perfusion as a measure of vasoconstriction was determined by measuring skin perfusion by Laser Doppler Flowmetry. Probes were attached at the palmar side of the hand at the base of the thumb, at the plantar side of the hallux (Perimed PF4000, Sweden), at the ventral side of the forearm halfway between the elbow and the wrist, and at the abdomen halfway between the umbilicus and the left lateral side of the body (Perimed PF5000, Sweden). In addition, heart rate was determined each minute via a heart rate monitor across the chest (Polar T31, USA), and blood pressure each 15 minutes electronically by a blood pressure cuff on the left upper arm (Cresta, Taiwan). Shivering was determined via electromyography on the $\mathrm{m}$. vastus lateralis and $\mathrm{m}$. pectoralis major (PASAQ4.01, Maastricht Instruments BV, The Netherlands) and by the use of Visual Analog Scales (VAS). These scales were also used to measure thermal sensation and comfort each 15 minutes (53). A cannula was inserted in the antecubital vein to sample blood at the end of the baseline period and after one hour in the cold. Finally, energy expenditure was measured continuously by means of a ventilated hood system (Omnical; Jaeger).

\section{PET protocol and analysis}

We used a static PET-CT scanning protocol to determine $\left[{ }^{18} \mathrm{~F}\right] \mathrm{FDG}$-uptake in multiple tissues. The protocol started with a low-dose CT scan $(120 \mathrm{kV}, 30 \mathrm{mAs})$ immediately followed by the PET scan. The uptake of $\left[{ }^{18} \mathrm{~F}\right] \mathrm{FDG}(2 \mathrm{mCi}, 74 \mathrm{MBq})$ was determined by means of the PET scan, and the CT scan was used for attenuation and scatter correction of the PET scan and to determine the anatomical location of the $\left[{ }^{18} \mathrm{~F}\right] \mathrm{FDG}$ uptake. The upper body (pelvis to crown of the head) was scanned and 6-7 bed positions with 6 minutes per position. The voxel size of both reconstructed image sets was $4 \times 4 \times 4 \mathrm{~mm}^{3}$. The researcher (MJV) together with a nuclear-medicine physician (BB) interpreted the images using PMOD software (version 3.0; PMOD Technologies). The regions of interest (BAT) were manually outlined in the fusion image (PET and CT). Two criteria were used to classify the region as BAT. First, we classified the region of interest as adipose tissue by means of Hounsfield Units (-10 to $-180 \mathrm{HU})$. Second, we used a PET threshold of 1.5 standard uptake value (SUV), which is approximately 6 times higher than uptake in WAT, to regard the tissue as BAT. Taken all these regions together, the SUV total was calculated, which is the average SUV per volume of interest times its volume. In addition, we measured the maximal $\left[{ }^{18}\right.$ F]FDG uptake in supraclavicular BAT as an indication of maximal BAT activity. Finally, the average SUV $\left(\mathrm{SUV}_{\text {mean }}\right)$ in supraclavicular BAT, skeletal muscle, subcutaneous and visceral WAT, the 
liver, and the brain (cerebellum) by selecting cubes as volume of interests (for more details see: (16)).

\section{Blood analysis}

Blood samples $(30 \mathrm{~mL})$ were collected from the antecubital vein at the end of the baseline period and after one hour of cold exposure to determine several parameters. The concentration of plasma free fatty acids (NEFA-HR set, Wako Chemicals, Neuss, Germany), free glycerol (Glycerol kit, R-Biopharm, Darmstadt, Germany) total glycerol ( $A B X$ Triglyceriden $C P$, Radiometer, Horiba ABX, Montpellier, France) and glucose (ABX Glucose HK CP, Radiometer, Horiba ABX, Montpellier, France) were measured with a COBAS FARA centrifugal spectrophotometer (Roche Diagnostica, Basel, Switzerland). The concentrations of triglycerides in plasma were calculated by subtracting free glycerol from total glycerol concentrations. Insulin was measured in serum and analyzed on a Gamma Counter (2470 Automatic Gamma Counter Wizard ${ }^{2}$ "Wallac, Perkin Elmer, USA) with a Human Insulin specific RIA kit (Milipore, USA). Thyroid stimulating hormone (TSH) was determined in serum by means of an electrochemiluminescence immunoassay kit on a COBAS 6000 system (Roche Diagnostica). Total thyroxine (T4) was analyzed by a solid-phase, competitive chemiluminescent enzyme immunoassay on an Immulite 2000 system (Siemens). Finally, free thyroxine was measured by using a solid-phase time-resolved fluoroimmunoassay FT4 kit on an AutoDELFIA system (PerkinElmer).

\section{RNA extraction and real-time PCR analysis}

For skeletal muscle FNDC5, RNA was isolated from muscle tissue, using Trizol according to the method from Chomczynski et al. (54). RNA from WAT was extracted using Trizol reagent followed by protocol described in the RNeasy kit from Qiagen (Hildenberg, Germany). Quality and yield of RNA was assessed using a NanoDrop spectrophotometer from Thermo Fischer scientific. cDNA was created using the high capacity RNA-to-cDNA kit from Applied Biosystems (Foster City, CA). Gene expression was determined using a 7900HT Fast Real-Time PCR System from Applied Biosystems. Skeletal muscle gene expression data was normalized against RPLPO using the standard curve method. Comparison of gene expression data for WAT was accomplished using the $2^{-\Delta \Delta C t}$ method. Gene expression data was normalized against the geometric mean of TBP and RPLPO. Taqman gene expression assays were used for analysis of UCP1 (Hs00222453_m1), CIDEA (Hs00154455_m1), CD137 (Hs00155512_m1), TMEM26 (Hs00415619_m1).

\section{Statistical analysis}

We used the program SPSS 20.0 (IBM) for Macintosh for statistical analysis. To compare all parameters between baseline and mild cold we took the average of the last 30 minutes of baseline and 30 minutes after the injection of the $\left[{ }^{18} \mathrm{~F}\right] \mathrm{FDG}$-tracer. 
The effects of mild cold exposure on all variables within each group were tested by means of paired-sample $t$ tests. Note that we used non-parametric testing (Wilcoxon 's test) to measure differences in blood parameters in the untrained group $(n=7)$. There were 5 missing values due to the low amount of samples that could be drawn in this group during the cold $(n=7)$. Independent sample $t$ tests were used to compare the trained with the untrained group. Furthermore, Pearson correlation was performed to identify relations between variables on whole group level $(n=24)$, and within each group $(n=12)$.

\section{References}

1. Ouellet V, Labbe SM, Blondin DP, Phoenix S, Guerin B, Haman F, Turcotte EE, Richard D, and Carpentier AC. Brown adipose tissue oxidative metabolism contributes to energy expenditure during acute cold exposure in humans. J Clin Invest. 2012;122(2):545-52.

2. van der Lans AAJJ, J. Hoeks, B. Brans, G.H.E.J. Vijgen, M.G.W. Visser, M.J. vosselman, J. Hansen, J. A. Jörgensen, J. Wu, F. Mottaghy, P. Schrauwen, W.D. van Marken Lichtenbelt. Cold acclimation recruits brown adipose tissue and increases non-shivering thermogenesis in humans. J Clin Invest. 2013;123(8):3395-403.

3. Orava J, Nuutila P, Lidell ME, Oikonen V, Noponen T, Viljanen T, Scheinin M, Taittonen M, Niemi T, Enerback S, et al. Different metabolic responses of human brown adipose tissue to activation by cold and insulin. Cell Metab. 2011;14(2):272-9.

4. Cypess AM, Chen YC, Sze C, Wang K, English J, Chan O, Holman AR, Tal I, Palmer MR, Kolodny GM, et al. Cold but not sympathomimetics activates human brown adipose tissue in vivo. Proc Natl Acad Sci U S A. 2012;109(25):10001-5.

5. Muzik O, Mangner TJ, and Granneman JG. Assessment of oxidative metabolism in brown fat using PET imaging. Front Endocrinol (Lausanne). 2012;3:15.

6. Yoneshiro T, Aita S, Matsushita M, Kayahara T, Kameya T, Kawai Y, Iwanaga T, and Saito M. Recruited brown adipose tissue as an antiobesity agent in humans. J Clin Invest. 2013;123(8):3404-8.

7. van Marken Lichtenbelt WD, Vanhommerig JW, Smulders NM, Drossaerts JM, Kemerink GJ, Bouvy ND, Schrauwen $\mathrm{P}$, and Teule GJ. Cold-activated brown adipose tissue in healthy men. $N$ Engl J Med. 2009;360(15):1500-8.

8. Saito M, Okamatsu-Ogura $Y$, Matsushita M, Watanabe $K$, Yoneshiro $T$, Nio-Kobayashi J, Iwanaga T, Miyagawa M, Kameya T, Nakada K, et al. High incidence of metabolically active brown adipose tissue in healthy adult humans: effects of cold exposure and adiposity. Diabetes. 2009;58(7):1526-31.

9. Virtanen KA, Lidell ME, Orava J, Heglind M, Westergren R, Niemi T, Taittonen M, Laine J, Savisto NJ, Enerback S, et al. Functional brown adipose tissue in healthy adults. N Engl J Med. 2009;360(15):151825.

10. Bartelt A, Merkel $M$, and Heeren J. A new, powerful player in lipoprotein metabolism: brown adipose tissue. J Mol Med (Berl). 2012;90(8):887-93.

11. Stanford KI, Middelbeek RJ, Townsend KL, An D, Nygaard EB, Hitchcox KM, Markan KR, Nakano K, Hirshman MF, Tseng $\mathrm{YH}$, et al. Brown adipose tissue regulates glucose homeostasis and insulin sensitivity. J Clin Invest. 2013;123(1):215-23.

12. Feldmann HM, Golozoubova V, Cannon B, and Nedergaard J. UCP1 ablation induces obesity and abolishes diet-induced thermogenesis in mice exempt from thermal stress by living at thermoneutrality. Cell Metab. 2009;9(2):203-9.

13. Vijgen GH, Bouvy ND, Teule GJ, Brans B, Schrauwen P, and van Marken Lichtenbelt WD. Brown adipose tissue in morbidly obese subjects. PLoS One. 2011;6(2):e17247. 


\section{REDUCED BROWN ADIPOSE TISSUE IN ENDURANCE ATHLETES}

14. Cypess AM, Lehman S, Williams G, Tal I, Rodman D, Goldfine AB, Kuo FC, Palmer EL, Tseng YH, Doria A, et al. Identification and importance of brown adipose tissue in adult humans. $N$ Engl J Med. 2009;360(15):1509-17.

15. Chen KY, Brychta RJ, Linderman JD, Smith S, Courville A, Dieckmann W, Herscovitch P, Millo CM, Remaley $A$, Lee $P$, et al. Brown fat activation mediates cold-induced thermogenesis in adult humans in response to a mild decrease in ambient temperature. J Clin Endocrinol Metab. 2013;98(7):E1218-23.

16. Vosselman MJ, Brans B, van der Lans AA, Wierts R, van Baak MA, Mottaghy FM, Schrauwen $P$, and van Marken Lichtenbelt WD. Brown adipose tissue activity after a high-calorie meal in humans. Am J Clin Nutr. 2013;98(1):57-64.

17. Wu J, Bostrom P, Sparks LM, Ye L, Choi JH, Giang AH, Khandekar M, Virtanen KA, Nuutila P, Schaart G, et al. Beige adipocytes are a distinct type of thermogenic fat cell in mouse and human. Cell. 2012;150(2):366-76.

18. Petrovic N, Walden TB, Shabalina IG, Timmons JA, Cannon B, and Nedergaard J. Chronic peroxisome proliferator-activated receptor gamma (PPARgamma) activation of epididymally derived white adipocyte cultures reveals a population of thermogenically competent, UCP1-containing adipocytes molecularly distinct from classic brown adipocytes. J Biol Chem. 2010;285(10):7153-64.

19. Cypess AM, White AP, Vernochet C, Schulz TJ, Xue R, Sass CA, Huang TL, Roberts-Toler C, Weiner LS, Sze $C$, et al. Anatomical localization, gene expression profiling and functional characterization of adult human neck brown fat. Nat Med. 2013;19(5):635-9.

20. Lidell ME, Betz MJ, Dahlqvist Leinhard O, Heglind M, Elander L, Slawik M, Mussack T, Nilsson D, Romu T, Nuutila $P$, et al. Evidence for two types of brown adipose tissue in humans. Nat Med. 2013;19(5):631-4.

21. Jespersen NZ, Larsen TJ, Peijs L, Daugaard S, Homoe P, Loft A, de Jong J, Mathur N, Cannon B, Nedergaard J, et al. A classical brown adipose tissue mRNA signature partly overlaps with brite in the supraclavicular region of adult humans. Cell Metab. 2013;17(5):798-805.

22. Boström P, Wu J, Jedrychowski M, Korde A, Ye L, Lo J, Rasbach K, Boström E, Choi J, Long J, et al. A PGC1$\alpha$-dependent myokine that drives brown-fat-like development of white fat and thermogenesis. Nature. 2012;481(7382):463-8.

23. Wickler SJ, Stern JS, Glick Z, and Horwitz BA. Thermogenic capacity and brown fat in rats exercise-trained by running. Metabolism. 1987;36(1):76-81.

24. Scarpace PJ, Yenice S, and Tumer N. Influence of exercise training and age on uncoupling protein mRNA expression in brown adipose tissue. Pharmacol Biochem Behav. 1994;49(4):1057-9.

25. Segawa M, Oh-Ishi S, Kizaki T, Ookawara T, Sakurai T, Izawa T, Nagasawa J, Kawada T, Fushiki T, and Ohno $\mathrm{H}$. Effect of running training on brown adipose tissue activity in rats: a reevaluation. Res Commun Mol Pathol Pharmacol. 1998;100(1):77-82.

26. Shibata $\mathrm{H}$, and Nagasaka T. The effect of forced running on heat production in brown adipose tissue in rats. Physiol Behav. 1987;39(3):377-80.

27. Xu X, Ying Z, Cai M, Xu Z, Li Y, Jiang SY, Tzan K, Wang A, Parthasarathy S, He G, et al. Exercise ameliorates high-fat diet-induced metabolic and vascular dysfunction, and increases adipocyte progenitor cell population in brown adipose tissue. Am J Physiol Regul Integr Comp Physiol. 2011;300(5):R1115-25.

28. Slocum N, Durrant JR, Bailey D, Yoon L, Jordan H, Barton J, Brown RH, Clifton L, Milliken T, Harrington W, et al. Responses of brown adipose tissue to diet-induced obesity, exercise, dietary restriction and ephedrine treatment. Exp Toxicol Pathol. 2013;65(5):549-57.

29. Seebacher F, and Glanville EJ. Low levels of physical activity increase metabolic responsiveness to cold in a rat (Rattus fuscipes). PLoS One. 2010;5(9):e13022.

30. De Matteis R, Lucertini F, Guescini M, Polidori E, Zeppa S, Stocchi V, Cinti S, and Cuppini R. Exercise as a new physiological stimulus for brown adipose tissue activity. Nutr Metab Cardiovasc Dis. 2013;23(6):582-90.

31. Zhang Y, Li R, Meng Y, Li S, Donelan W, Zhao Y, Qi L, Zhang M, Wang X, Cui T, et al. Irisin Stimulates Browning of White Adipocytes through Mitogen-Activated Protein Kinase p38 MAP Kinase and ERK MAP Kinase Signaling. Diabetes. 2013. 
32. Raschke S, Elsen M, Gassenhuber H, Sommerfeld M, Schwahn U, Brockmann B, Jung R, Wisloff U, Tjonna AE, Raastad T, et al. Evidence against a beneficial effect of irisin in humans. PLoS One. 2013;8(9):e73680.

33. Erickson HP. Irisin and FNDC5 in retrospect: An exercise hormone or a transmembrane receptor? Adipocyte. 2013;2(4):289-93.

34. Lee P, Linderman J, Smith S, Brychta R, Wang J, Idelson C, Perron R, Werner C, Phan G, Kammula U, et al. Irisin and FGF21 are cold-induced endocrine activators of brown fat function in humans. Cell Metab. 2014;19(2):302-9.

35. Badeer HS. Resting bradycardia of exercise training: a concept based on currently available data. Recent Adv Stud Cardiac Struct Metab. 1975;10:553-60.

36. Wijers SL, Saris WH, and van Marken Lichtenbelt WD. Individual thermogenic responses to mild cold and overfeeding are closely related. J Clin Endocrinol Metab. 2007;92(11):4299-305.

37. Bostrom PA, Fernandez-Real JM, and Mantzoros C. Irisin in humans: recent advances and questions for future research. Metabolism. 2014;63(2):178-80.

38. Huh JY, Panagiotou G, Mougios V, Brinkoetter M, Vamvini MT, Schneider BE, and Mantzoros CS. FNDC5 and irisin in humans: I. Predictors of circulating concentrations in serum and plasma and II. mRNA expression and circulating concentrations in response to weight loss and exercise. Metabolism. 2012;61(12):1725-38.

39. Norheim F, Langleite TM, Hjorth M, Holen T, Kielland A, Stadheim HK, Gulseth HL, Birkeland KI, Jensen J, and Drevon CA. The effects of acute and chronic exercise on PGC-1alpha, irisin and browning of subcutaneous adipose tissue in humans. FEBS J. 2014; 281(3):739-49.

40. Timmons JA, Baar K, Davidsen PK, and Atherton PJ. Is irisin a human exercise gene? Nature. 2012;488(7413):E9-10; discussion E-1.

41. Pekkala S, Wiklund PK, Hulmi JJ, Ahtiainen JP, Horttanainen M, Pollanen E, Makela KA, Kainulainen $H$, Hakkinen K, Nyman K, et al. Are skeletal muscle FNDC5 gene expression and irisin release regulated by exercise and related to health? J Physiol. 2013;591(Pt 21):5393-400.

42. Hecksteden A, Wegmann M, Steffen A, Kraushaar J, Morsch A, Ruppenthal S, Kaestner L, and Meyer T. Irisin and exercise training in humans - Results from a randomized controlled training trial. BMC Med. 2013;11(1):235.

43. Moreno-Navarrete JM, Ortega F, Serrano M, Guerra E, Pardo G, Tinahones F, Ricart W, and FernandezReal JM. Irisin is expressed and produced by human muscle and adipose tissue in association with obesity and insulin resistance. J Clin Endocrinol Metab. 2013;98(4):E769-78.

44. Yoneshiro T, Aita S, Matsushita M, Kameya T, Nakada K, Kawai Y, and Saito M. Brown adipose tissue, whole-body energy expenditure, and thermogenesis in healthy adult men. Obesity (Silver Spring). 2011;19(1):13-6.

45. Dressendorfer RH, Smith RM, Baker DG, and Hong SK. Cold tolerance of long-distance runners and swimmers in Hawaii. Int J Biometeorol. 1977;21(1):51-63.

46. Kollias J, Boileau R, and Buskirk ER. Effects of physical conditioning in man on thermal responses to cold air. Int J Biometeorol. 1972;16(4):389-402.

47. Orava J, Nuutila P, Noponen T, Parkkola R, Viljanen T, Enerback S, Rissanen A, Pietilainen KH, and Virtanen KA. Blunted Metabolic Responses to Cold and Insulin Stimulation in Brown Adipose Tissue of Obese Humans. Obesity (Silver Spring). 2013;21(11):2279-87.

48. Sasaki Y, and Takahashi H. Insulin secretion in sheep exposed to cold. J Physiol. 1980;306(323-35.

49. Himms-Hagen J. Lipid metabolism during cold-exposure and during cold-acclimation. Lipids. 1972;7(5):310-23.

50. Vosselman MJ, van der Lans AA, Brans B, Wierts $R$, van Baak MA, Schrauwen $P$, and van Marken Lichtenbelt WD. Systemic beta-adrenergic stimulation of thermogenesis is not accompanied by brown adipose tissue activity in humans. Diabetes. 2012;61(12):3106-13.

51. Bartelt A, Bruns OT, Reimer R, Hohenberg H, Ittrich H, Peldschus K, Kaul MG, Tromsdorf UI, Weller H, Waurisch $C$, et al. Brown adipose tissue activity controls triglyceride clearance. Nat Med. $2011 ; 17(2): 200-5$. 


\section{REDUCED BROWN ADIPOSE TISSUE IN ENDURANCE ATHLETES}

52. Bergstrom J, Hermansen L, Hultman E, and Saltin B. Diet, muscle glycogen and physical performance. Acta Physiol Scand. 1967;71(2):140-50.

53. Kildeso J, Wyon D, Skov T, and Schneider T. Visual analogue scales for detecting changes in symptoms of the sick building syndrome in an intervention study. Scand J Work Environ Health. 1999;25(4):361-7.

54. Chomczynski $P$, and Sacchi N. Single-step method of RNA isolation by acid guanidinium thiocyanatephenol-chloroform extraction. Anal Biochem. 1987;162(1):156-9. 


\section{CHAPTER 6}

\section{Frequent extreme cold exposure and brown fat and cold-induced thermogenesis: a study in a monozygotic twin}

This content is published in Maarten J. Vosselman, Guy H.E.J. Vijgen, Boris R.M. Kingma, Boudewijn Brans, and Wouter D. van Marken Lichtenbelt. Frequent extreme cold exposure and brown fat and cold-induced thermogenesis: a study in a monozygotic twin. PLoS One. 


\section{Abstract}

\section{Introduction:}

Mild cold acclimation is known to increase brown adipose tissue (BAT) activity and cold-induced thermogenesis (CIT) in humans. We here tested the effect of a lifestyle with frequent exposure to extreme cold on BAT and CIT in a Dutch man known as 'the Iceman', who has multiple world records in withstanding extreme cold challenges. Furthermore, his monozygotic twin brother who has a 'normal' sedentary lifestyle without extreme cold exposures was measured.

\section{Methods:}

The Iceman (subject A) and his brother (subject B) were studied during mild cold $\left(13^{\circ} \mathrm{C}\right.$ ) and thermoneutral conditions $\left(31^{\circ} \mathrm{C}\right)$. Measurements included BAT activity and respiratory muscle activity by $\left[{ }^{18} \mathrm{~F}\right] \mathrm{FDG}-\mathrm{PET} / \mathrm{CT}$ imaging and energy expenditure through indirect calorimetry. In addition, body temperatures, cardiovascular parameters, skin perfusion, and thermal sensation and comfort were measured. Finally, we determined polymorphisms for uncoupling protein-1 and $\beta 3$-adrenergic receptor.

\section{Results:}

Subjects had comparable BAT activity (A: 1144 SUV $_{\text {total }}$ and B: 1325 SUV $_{\text {total }}$ ), within the range previously observed in young adult men. They were genotyped with the polymorphism for uncoupling protein-1 (G/G). CIT was relatively high (A: $40.1 \%$ and $B$ : $41.9 \%)$, but unlike during our previous cold exposure tests in young adult men, here both subjects practiced a g-Tummo like breathing technique, which involves vigorous respiratory muscle activity. This was confirmed by high $\left[{ }^{18} \mathrm{~F}\right] \mathrm{FDG}$-uptake in respiratory muscle.

\section{Conclusion:}

No significant differences were found between the two subjects, indicating that a lifestyle with frequent exposures to extreme cold does not seem to affect BAT activity and CIT. In both subjects, BAT was not higher compared to earlier observations, whereas CIT was very high, suggesting that g-Tummo like breathing during cold exposure may cause additional heat production by vigorous isometric respiratory muscle contraction. The results must be interpreted with caution given the low subject number and the fact that both participants practised the g-Tummo like breathing technique. 


\section{Introduction}

During cold exposure the human body may increase heat production by shivering and non-shivering thermogenesis (NST), and minimize heat loss by vasoconstriction [1]. A major tissue responsible for NST is brown adipose tissue (BAT). BAT produces heat via uncoupling protein-1 (UCP-1), which uncouples the respiratory chain from ATP production thereby releasing energy as heat. A lifestyle that includes frequent cold exposure might result in acclimatization and, consequently, a better-equipped thermoregulatory machinery to fight the cold. It is now well established that BAT is still present and functional in human adults during cold exposure [2-4]. Furthermore, mild cold acclimatization in humans has shown to increase NST [5,6] and BAT activity [6]. However, the effects of a lifestyle with frequent exposures to extreme cold conditions on these parameters are unknown.

It has been shown that a great variability in NST and BAT exists within the same population groups, which may be attributed to differences in lifestyle effects [7]. However, a genetic component may influence the capacity for NST as well. For instance, it has been suggested that polymorphisms in the uncoupling protein-1 gene and $\beta$-adrenergic receptor influence resting energy expenditure [8] and accelerate agerelated decrease in BAT activity in elderly [9]. It is thus likely that both nature (i.e. genetic make up) and nurture (lifestyle) influence the existence and heat generating potential of BAT. Next to BAT, also other tissues, such as skeletal muscle, might contribute to NST [10].

In this perspective, we report on the thermoregulatory responses of a monozygotic twin. One of the twins, the so-called "Iceman", has been exposed to frequent periods of extreme cold for several decades. He is world-record holder in withstanding extreme cold exposure under several disciplines, such as the fastest halfmarathon on snow and ice while barefoot, and the longest duration while fully immersed in crushed ice ( 1 hour and 50 minutes). He claims to achieve these records through a special meditation and breathing technique, which is based on g-Tummo meditation, and that he is capable to regulate his own autonomic nervous system. A recent case study demonstrated that he was capable to control the autonomic stress response during endotoxemia by using this technique [11]. His monozygotic twin brother does not experience extreme cold exposure due to a different occupation and a sedentary lifestyle, although he is aware of the techniques used by his brother. We here tested the hypothesis that the iceman has a higher cold-induced heat production and cold-induced BAT activity compared to his identical twin brother. This case study provides a unique comparison between a monozygotic twin pair, one being extremely cold-acclimated the other being not cold-acclimated at all. 


\section{Subjects and Methods}

The Medical Ethical Committee of the Maastricht University Medical Centre+ approved the protocols and both the Iceman (subject A) and his twin brother (subject B) gave written informed consent. All procedures were conducted according to the principles of the Declaration of Helsinki. The monozygotic twin brothers are both male and 52 years of age. They were screened for medical history, and were absent of any factors related to the metabolic syndrome, and had no thyroid gland dysfunction. They were not using any type of medication, which could have affected the results. Subject $A$ is well known for his capability to withstand extreme cold challenges. He is a selfemployed lifestyle educator, focusing on the capacity of the human mind to control its body by means of a special meditation and breathing technique (based on g-Tummo) [12]. He has been exposing himself to daily cold water swimming/showers and regularly visits Scandinavian and arctic regions in order to practice and train extreme cold exposure in shorts only. Subject B is employed as an international truck driver, being on the road for multiple days in a row and experiencing longer periods of inactivity. He does not practice and train extreme cold exposure. However, he is familiar with the special meditation and breathing technique used by his brother.

\section{Study design and measurements}

Subjects were measured on two separate occasions during two consecutive days in the winter season with comparable outdoor temperatures. The study protocols in both subjects were identical. In the morning of day one, BAT activity was measured during thermoneutral conditions (i.e. two hours at air temperature $31^{\circ} \mathrm{C}$ ), which served as a control-measurement (Figure 1). In the afternoon of day one, a "shivering test" was performed with the purpose to determine the air temperature associated with the onset of shivering. This information was then used for the mild cold experiment on day two to determine the ambient temperature to obtain maximal cold-induced thermogenesis (CIT) (i.e. at the lowest temperature without shivering). The mild cold experiment on day two started with a 45-minute baseline during thermoneutral conditions $(\sim 31 \stackrel{\circ}{\circ})$, followed by two and half hours of mild cold exposure (12-13 $\mathrm{O}$ ). The $\left[{ }^{18} \mathrm{~F}\right]$ fluorodeoxyglucose (FDG) tracer was injected intravenously after 90 minutes in the cold and 60 minutes later the PET-CT scan was performed. The measurements were performed in a specially equipped air-permeable tent (Colorado altitude training, USA), in which ambient temperature was tightly controlled. Subjects were measured in semi-supine position on an air-permeable stretcher (Model Campart Rome-XL) in order to lie comfortably. The subjects wore shorts only (Clo 0.06)[13]. During the experiments we measured energy expenditure via indirect calorimetry (Ventilated Hood, Omnical 2, Maastricht, the Netherlands), heart rate via a monitor on the chest (Polar T31, USA), and blood pressure via a pressure cuff on the left upper arm (Cresta, Taiwan). Mean arterial blood pressure (MAP) was calculated as MAP $=1 / 3$ Systolic 
pressure $+2 / 3$ Diastolic pressure. Skin temperatures were determined via wireless temperature sensors placed at the 14 sites prescribed by ISO-standard 9886:2004 (Ergonomics - Evaluation of thermal strain by physiological measurements, International Standards Organization, Geneva, Switzerland) (iButtons Maxim integrated, USA), and core temperature via a telemetric pill (CorTemp HT150002, USA), which was ingested one hour before the onset of the experiment. Vasoconstriction was measured by determining the change in skin perfusion via Laser Doppler at the ventral side of the hand at the base of the thumb, at the ventral side of the hallux (Perimed PF4000, Sweden), at the ventral side of the forearm halfway between the elbow and the wrist, and at the abdomen halfway between the umbilicus and the left lateral side of the body (Perimed PF5000, Sweden). Venous blood samples were taken during baseline and in the cold for analysis of hormones and metabolites, and DNA analysis via PCR to identify polymorphisms for uncoupling protein-1 (-3286 A/G polymorphism) [14] and the $\beta 3$-adrenergic receptor (Trp64Arg) [15].

During the mild cold experiment, both subjects completed visual analogue scales (VAS-scales) [16], on sensation, thermal comfort and shivering. Furthermore, BAT activity was assessed by $\left[{ }^{18} \mathrm{~F}\right]$ fluorodeoxyglucose-positron emission-tomographycomputed tomography ( $\left[{ }^{18}\right.$ F $]$ FDG-PET-CT) (Gemini TF PET-CT, Philips, The Netherlands). The protocol and analysis were comparable to our previous studies using static imaging [17]. A low-dose CT scan (120 kV, $30 \mathrm{mAs})$ preceded the PET scan, and was used for attenuation and scatter correction of the PET scan. The PET scan was used to determine $\left[{ }^{18} \mathrm{~F}\right]$ FDG-uptake. Temperature was regulated with a heater and airconditioning. Body composition was determined by means of dual $x$-ray absorptiometry (DXA, Hologic, type Discovery A, USA), and in the afternoon, a biopsy was taken from the $m$. vastus lateralis for mitochondrial respirometry measurements in permeabilized muscle fibers by means of the Oxygraph-2K (Oroboros, Austria). A part of the biopsy was placed in a preservation medium for the respiration measurements (for substrate details see [6]), and a portion of the muscle tissue was immediately frozen in melting isopentane and stored at $-80{ }^{\circ} \mathrm{C}$ for determination of mitochondrial DNA (mtDNA) copy number (ratio ND1 to LPL).

\section{Data and PET-CT analysis}

At fixed time intervals of 25 minutes duration during baseline and during cold exposure (after injection of $\left[{ }^{18} \mathrm{~F}\right] \mathrm{FDG}$ ) energy expenditure was calculated. We use the term CIT instead of classical NST for the increase in energy expenditure (as a percentage) during cold exposure, as respiratory muscle contraction was involved. These time periods were also selected for analysis of cardiovascular and body temperature parameters. Two researchers (M.V. and G.V.) and a nuclear-medicine physician (B.B.) analyzed the PET-CT scan. In order to determine BAT activity, we measured the average $\left[{ }^{18}\right.$ F]FDG-uptake, known as the mean standard uptake value $\left(\mathrm{SUV}_{\text {mean }}\right)$, and the total $\left[{ }^{18} \mathrm{~F}\right] \mathrm{FDG}$-uptake $\left(\mathrm{SUV}_{\text {total }}=\mathrm{SUV}_{\text {mean }}\right.$ multiplied by BAT volume $)$ 
in BAT by manually drawing regions of interest. We considered fat tissue as BAT when the Hounsfield Units of the CT-scan were between -10 and 180. Moreover, a minimum of 1.5 SUV was used to classify the selected fat region as BAT. Furthermore, we analyzed average $\left[{ }^{18} \mathrm{~F}\right] \mathrm{FDG}$-uptake $\left(\mathrm{SUV}_{\text {mean }}\right)$ in multiple tissues in fixed volumes of interest according to the procedure described in Vosselman et al. 2013 [18]. The blood parameters presented in the subject characteristics were compared to normal reference values presented in the assay/kit information and with respect to the thyroid parameters, references values were obtained from the department of clinical chemistry at Maastricht University Medical Centre (Maastricht, the Netherlands). Since it was impossible to study the statistical difference between the two brothers, we compared the current results with data from previous studies in young adult men. To do so, we made boxplots of the data from young adult men and determined the interquartile range and the $95^{\text {th }}$ percentile. When the results of the twin were within the interquartile range observed in young adult men, we regarded both values (subject $A$ and subject B) as comparable. When the score of one of the twin brothers was outside the interquartile range, this was regarded as different from each other. Furthermore, the score of the twins were considered as different from young adults when the score was outside of the $95^{\text {th }}$ percentile. This comparison has its limitations due to the differences in age between the young adult group and the twin brothers. Furthermore, it should be noted that the current cooling protocol lasted 30 minutes longer (2,5 hours versus 2 hours), and clothing was less (clo 0.1 versus 0.49 ). Therefore, temperature, skin perfusion, and cardiovascular data of the twin could not be compared with the young adults. However, for these measurements intra subject comparison was based on the measurement accuracy. BAT activity and CIT could be compared due to the use of the same individualized protocol in all subjects in which we cool the subjects to temperatures just above shivering, in order to obtain maximal NST and BAT activity in each subject (for more details on this protocol see [17]). The respiration values for skeletal muscle are represented as the average of two traces with standard deviation. 


\section{Day 1: Thermoneutral experiment}

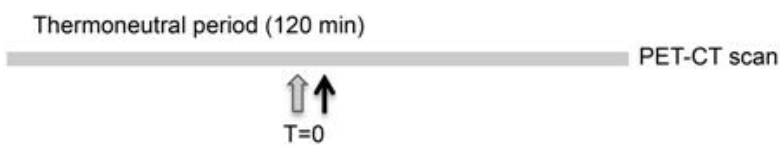

Day 1: Shivering experiment

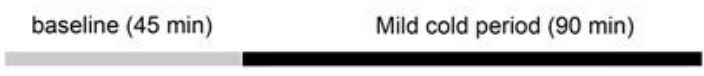

\section{Day 2: Mild cold experiment}

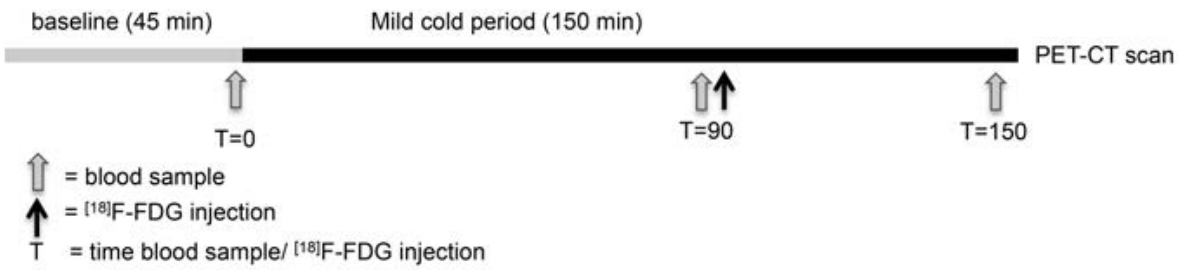

Figure 1. Study protocol. The thermoneutral experiment started in the morning on day one. After one hour a blood sample was taken and subsequently the $\left[{ }^{18} \mathrm{~F}\right] \mathrm{FDG}$ tracer was injected followed by the PET-CT scan one hour later. In the afternoon of day one, the shivering experiment was conducted, which started with a baseline period of 45 minutes during $31{ }^{\circ} \mathrm{C}$ followed by 90 minutes of mild cold exposure $\left(31{ }^{\circ} \mathrm{C}\right)$ to determine the ambient temperature at which shivering occurred. The mild cold experiment on day two consisted of 45 minutes baseline $\left(31^{\circ} \mathrm{C}\right)$ followed by 150 minutes of cold exposure. Blood samples were taken at the end of the baseline period and 90 and 150 minutes after the onset of cold exposure. The $\left[{ }^{18}\right.$ F]FDG tracer was injected 90 minutes after the onset of cold exposure, followed by the PET-CT scan one hour later.

\section{Results}

\section{Characteristics of monozygotic twin pair}

Subject $A$ had a lower fat percentage (13.7\% versus $18 \%$; normal range $11-22 \%$ ), comparable fat free mass $(69.4 \mathrm{~kg}$ versus $68.1 \mathrm{~kg}$ ) and lower fasting triglyceride levels (subject A: $698 \mu \mathrm{mol} / \mathrm{L}$ versus subject B: $1060 \mu \mathrm{mol} / \mathrm{L}$; normal range: 680-1880 $\mu \mathrm{mol} / \mathrm{L}$ ) than subject $B$ (Table 1). Fasting glucose levels were equal (both $5.7 \mathrm{mmol} / \mathrm{L}$; normal range: 3.61-6.11 $\mathrm{mmol} / \mathrm{L}$ ). Thyroid stimulating hormone levels were comparable, and within the normal range (A: $1.1 \mathrm{mU} / \mathrm{L}$ versus $\mathrm{B}: 0.9 \mathrm{mU} / \mathrm{L}$; normal range $0.4-4.3$ $\mathrm{mU} / \mathrm{L}$ ). Total T4 was slightly lower in subject $A$, and free T4 levels were comparable (total T4: A: $84 \mathrm{nmol} / \mathrm{L}$ versus B: $96 \mathrm{nmol} / \mathrm{L}$; normal range: $60-150 \mathrm{nmol} / \mathrm{L}$; free T4: A: $14.8 \mathrm{pmol} / \mathrm{L}$ versus $B 14.7 \mathrm{pmol} / \mathrm{L}$; normal range: $8-18 \mathrm{pmol} / \mathrm{L})$. Furthermore, subject $A$ had a more active lifestyle, although both were more active compared to the average found in young adults, indicated by the Baecke Questionnaire scores (total score: A: 11.4 versus $B$ : 9.7; average young adults: \pm 8.2 , derived from [19]). Interestingly, the 
monozygotic twin was genotyped with the polymorphism for uncoupling protein-1 $(G / G)$. These G-allele carriers have been associated with an attenuation of UCP-1 mediated thermogenesis [20]. No polymorphism (no Arg64 allele) was present in the $\beta 3$-adrenergic receptor.

Table 1. Subject characteristics monozygotic twin

\begin{tabular}{lll}
\hline Parameter & Subject A & Subject B \\
\hline Height $(\mathrm{cm})$ & 183 & 184 \\
Weight $(\mathrm{kg})$ & 82.2 & 87.0 \\
$\mathrm{BMI}\left(\mathrm{kg} / \mathrm{m}^{2}\right.$ ) & 24.7 & 25.8 \\
Fat percentage (\%) & 13.7 & 18 \\
Lean mass (kg) & 69.4 & 68.1 \\
Fasting glucose (mmol/L) & 5.7 & 5.7 \\
Fasting triglycerides ( $\mu$ mol/L) & 698 & 1060 \\
Thyroid stimulating hormone (mU/L) & 1.1 & 0.9 \\
Total T4 (nmol/L) & 14.8 & 14.7 \\
Free T4 (pmol/L) & 84 & 96 \\
Resting metabolic rate (MJ/day) & 8.1 & 7.8 \\
Baecke Questionnaire Score (WI/SI/LI(total)) & $3.1 / 4.3 / 4(11.4)$ & $2.4 / 3.5 / 3.8(9.7)$ \\
\hline
\end{tabular}

$\mathrm{LI}$, leisure time index; SI, sport index; WI, work index.

\section{Cold exposure effects}

Interestingly, during the "shivering experiment" on day one, both subjects did not reach the point of shivering. Normally, in such conditions with temperature drops from 31 to $13^{\circ} \mathrm{C}$, young adults and elderly start shivering [21,22]. The next day we maximally decreased ambient temperature and temperatures dropped to maximally $12^{\circ} \mathrm{C}$. Again, no shivering was observed during this cold experiment. Mean skin temperature was comparable between the subjects during baseline (A: $33.22{ }^{\circ} \mathrm{C}$ versus $\mathrm{B}: 33.40{ }^{\circ} \mathrm{C}$, Table 2), however during cold exposure mean skin temperature decreased more pronounced in subject $B$ compared to subject $A\left(A: 27.57^{\circ} \mathrm{C}\right.$ versus $B: 25.95{ }^{\circ} \mathrm{C}$ ). This decrease was predominantly seen in the proximal region $\left(A: 29.36{ }^{\circ} \mathrm{C}\right.$ versus $\mathrm{B}: 27.81$ ${ }^{\circ} \mathrm{C}$ ). Both subjects had comparable vasoconstriction in the hand (A: $91,7 \%$ versus $B$ : 91,3\%) and toe (A: $96 \%$ versus B: $96.4 \%$ ), although subject $A$ had a slightly lower distal temperature ( $A: 21.43{ }^{\circ} \mathrm{C}$ versus $\left.B: 22.34{ }^{\circ} \mathrm{C}\right)$. Subject $A$ showed more vasoconstriction in the underarm (A: $63.3 \%$ versus $B: 8.8 \%$ ) and abdomen (A: $7 \%$ versus $B:-8.8 \%$ (vasodilation)). Core temperature decreased in both subjects with a smaller decrease $\left(-0.18{ }^{\circ} \mathrm{C}\right)$ in subject $\mathrm{A}$ compared to subject $\mathrm{B}\left(-0.40{ }^{\circ} \mathrm{C}\right)$. As the accuracy of the 
measurement is $\pm 0.1^{\circ} \mathrm{C}$ and due to the small range within core temperature is held, we interpreted the difference of $-0.22{ }^{\circ} \mathrm{C}$ as physiologically different. There was a clear difference in cold sensation and comfort between both subjects. Both subjects experienced the thermal environment as neutral during baseline, however subject $A$ reported neutral to slightly cool during the mild cold period, whereas subject $B$ felt cold (Figure 2). Furthermore, subject $A$ reported that he was comfortable with these temperatures during the entire experiment, whereas subject $B$ felt between uncomfortable and very uncomfortable. Cold exposure slightly increased heart rate in subject $A$ (baseline: 46 beats/min versus cold: 52 beats/min), whereas it slightly decreased in subject B (baseline: 51 beats/min versus cold: 47 beats $/ \mathrm{min}$ ). Both subjects were bradycardic during rest conditions. Mean arterial pressure increased to a similar extent upon cold exposure in both subjects (A: from $93 \mathrm{~mm} / \mathrm{Hg}$ to $109 \mathrm{~mm} / \mathrm{Hg}$; B: from $99 \mathrm{~mm} / \mathrm{Hg}$ to $111 \mathrm{~mm} / \mathrm{Hg}$ ). After 90 minutes in the cold, plasma free fatty acids increased during cold exposure in both subjects (A: baseline $625 \mu \mathrm{mol} / \mathrm{L}$ versus cold $771 \mu \mathrm{mol} / \mathrm{L} ; \mathrm{B}$ : baseline $264 \mu \mathrm{mol} / \mathrm{L}$ versus cold $705 \mu \mathrm{mol} / \mathrm{L})$, whereas plasma glucose, insulin and epinephrine concentrations slightly decreased (Table 3). Plasma norepinephrine increased in both subjects, however, the concentration during cold was markedly higher in subject B (A: $554 \mathrm{ng} / \mathrm{L}$ versus B: $1016 \mathrm{ng} / \mathrm{L}$ ), suggesting greater sympathetic activity.

Table 2. Metabolic, cardiovascular and thermoregulatory parameters during mild cold experiment.

\begin{tabular}{|c|c|c|c|c|}
\hline & \multicolumn{2}{|l|}{ Baseline } & \multicolumn{2}{|l|}{ Cold } \\
\hline & Subject A & Subject B & Subject A & Subject B \\
\hline Energy expenditure (kJ/min) & 5.51 & 5.47 & 7.71 & 7.76 \\
\hline Respiratory quotient (VCO2/VO2) & 0.82 & 0.87 & 0.82 & 0.88 \\
\hline Heart rate (beats/min) & 46 & 51 & 52 & 47 \\
\hline Systolic blood pressure (mmHg) & 124.3 & 127.3 & 142.3 & 149.3 \\
\hline Diastolic blood pressure (mmHg) & 78.0 & 84.3 & 93.0 & 93.0 \\
\hline Mean arterial pressure (mmHg) & 93.4 & 98.7 & 109.4 & 111.0 \\
\hline Vasoconstriction hand (\%) & 0 & 0 & 92 & 91 \\
\hline Vasoconstriction toe (\%) & 0 & 0 & 96 & 96 \\
\hline Vasoconstriction arm (\%) & 0 & 0 & 63 & 9 \\
\hline Vasoconstriction abdomen (\%) & 0 & 0 & 39 & -7 \\
\hline Core temperature $\left({ }^{\circ} \mathrm{C}\right)$ & 36.57 & 36.76 & 36.39 & 36.36 \\
\hline Mean skin temperature $\left({ }^{\circ} \mathrm{C}\right)$ & 33.22 & 33.4 & 27.57 & 25.95 \\
\hline Proximal temperature $\left({ }^{\circ} \mathrm{C}\right)$ & 33.51 & 33.37 & 29.36 & 27.81 \\
\hline Distal temperature $\left({ }^{\circ} \mathrm{C}\right)$ & 32.99 & 32.65 & 21.43 & 22.34 \\
\hline Gradient proximal, distal $\left({ }^{\circ} \mathrm{C}\right)$ & 0.51 & 0.72 & 7.93 & 5.47 \\
\hline
\end{tabular}


Table 3. Blood parameters during the mild cold experiment

\begin{tabular}{lllllll}
\hline & \multicolumn{2}{l}{ Baseline } & \multicolumn{2}{l}{ Cold 90 minutes } & \multicolumn{2}{l}{ Cold 150 minutes } \\
\cline { 2 - 7 } Parameter & subject A & subject B & subject A & subject B & subject A & subject B \\
\hline Free fatty acids ( $\mu \mathrm{mol} / \mathrm{L})$ & 625 & 264 & 771 & 705 & 881 & 901 \\
Glycerol free $(\mu \mathrm{mol} / \mathrm{L})$ & 97 & 57 & 112 & 142 & 139 & 184 \\
Triglycerides $(\mu \mathrm{mol} / \mathrm{L})$ & 698 & 1060 & 766 & 1083 & 782 & 1106 \\
Glucose $(\mathrm{mmol} / \mathrm{L})$ & 5.8 & 5.3 & 5.7 & 5.0 & 5.6 & 4.9 \\
Insulin $(\mu \mathrm{U} / \mathrm{mL})$ & 10.1 & 11.0 & 8.2 & 10.1 & 8.1 & 6.0 \\
Norepinephrine $(\mathrm{ng} / \mathrm{L})$ & 389 & 284 & 439 & 751 & 554 & 1016 \\
Epinephrine $(\mathrm{ng} / \mathrm{L})$ & 32 & 21 & 21 & 10 & 16 & 7 \\
TSH $(\mathrm{mU} / \mathrm{L})$ & 1.1 & 0.9 & - & - & - & - \\
Free T4 $(\mathrm{pmol} / \mathrm{L})$ & 14.8 & 14.7 & - & - & - & - \\
T4 $(\mathrm{nmol} / \mathrm{L})$ & 84 & 96 & - & - & - & - \\
\hline
\end{tabular}
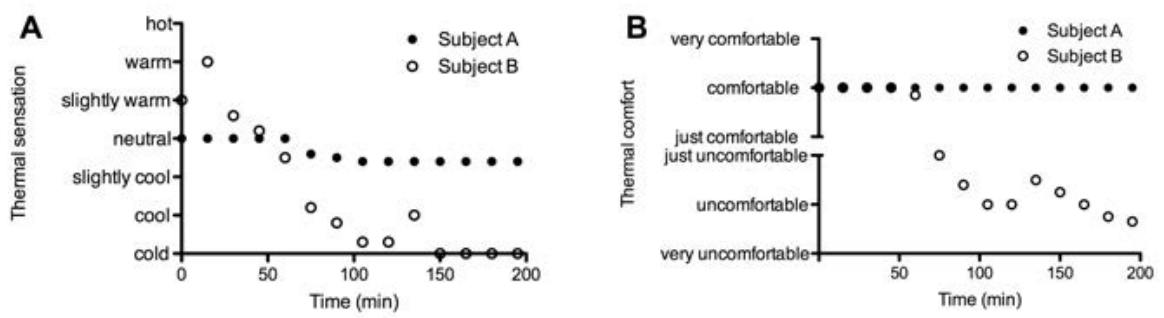

Figure 2. Visual Analog Scale (VAS) of thermal sensation and comfort during the mild cold experiment. This figure illustrates the thermal sensation (A) and comfort (B) of both subjects during the mild cold experiment.

\section{Cold-induced thermogenesis and $\left[{ }^{18}\right.$ F]FDG-uptake in BAT and skeletal muscle}

Both subjects increased energy expenditure to a similar extent in the cold (A: from $5.51 \mathrm{~kJ} / \mathrm{min}$ to $7.71 \mathrm{~kJ} / \mathrm{min}$ versus $B$ : from $5.47 \mathrm{~kJ} / \mathrm{min}$ to $7.76 \mathrm{~kJ} / \mathrm{min}$, Table 2), resulting in a CIT of $40.1 \%$ and $41.9 \%$ for subject $A$ and $B$, respectively. These values were clearly higher compared to the increase in energy expenditure we observed during mild cold experiments in young adult men (interquartile range: $7.2-18 \%$; $95^{\text {th }}$ percentile: $25.7 \%$, Figure $3 \mathbf{A}$ ). However, it should be noted that the CIT in the current experiment is not equal to classical NST, as the twin used respiratory muscle isometric contraction to generate heat as well. As expected, both subjects $A$ and $B$ showed no active BAT during the thermoneutral experiment (Figure 4A, 4D). Interestingly, cold exposure led to a comparable increase in BAT activity, although it was slightly higher in subject B (A: 1144 SUV $_{\text {total }}$ B: 1325 SUV $_{\text {total }}$ ). These values are regarded as comparable since they both fall within the interquartile range $\left(368-1930\right.$ SUV $_{\text {total }} ; 95^{\text {th }}$ percentile: 
4036 SUV $_{\text {total }}$ ) of BAT activity found in young adult men (Figure 3B) $[17,18]$. Thus, BAT activity is regarded as comparable to the values found in young adult men. Brown adipose tissue was present in the neck-, supraclavicular-, paravertebral-, and the perirenal area, which is comparable to the BAT distribution observed in young adults. We also determined $\left[{ }^{18}\right.$ F]FDG-uptake in WAT and skeletal muscle (SM) (Figure 4C, 4F). We did not observe any differences between the two subjects in glucose uptake in these tissues during both the thermoneutral (SM A: $0.7 \mathrm{SUV}_{\text {mean }}$ versus B: $0.64 \mathrm{SUV}_{\text {mean }}$; WAT A: 0.33 SUV $_{\text {mean }}$ versus B: 0.22 SUV $_{\text {mean }}$ ) and mild cold experiment (SM A: 0.75 SUV $V_{\text {mean }}$ versus B: 0.63 SUV $_{\text {mean }}$ WAT A: 0.35 SUV $_{\text {mean }}$ versus B: 0.24 SUV $_{\text {mean }}$ ).
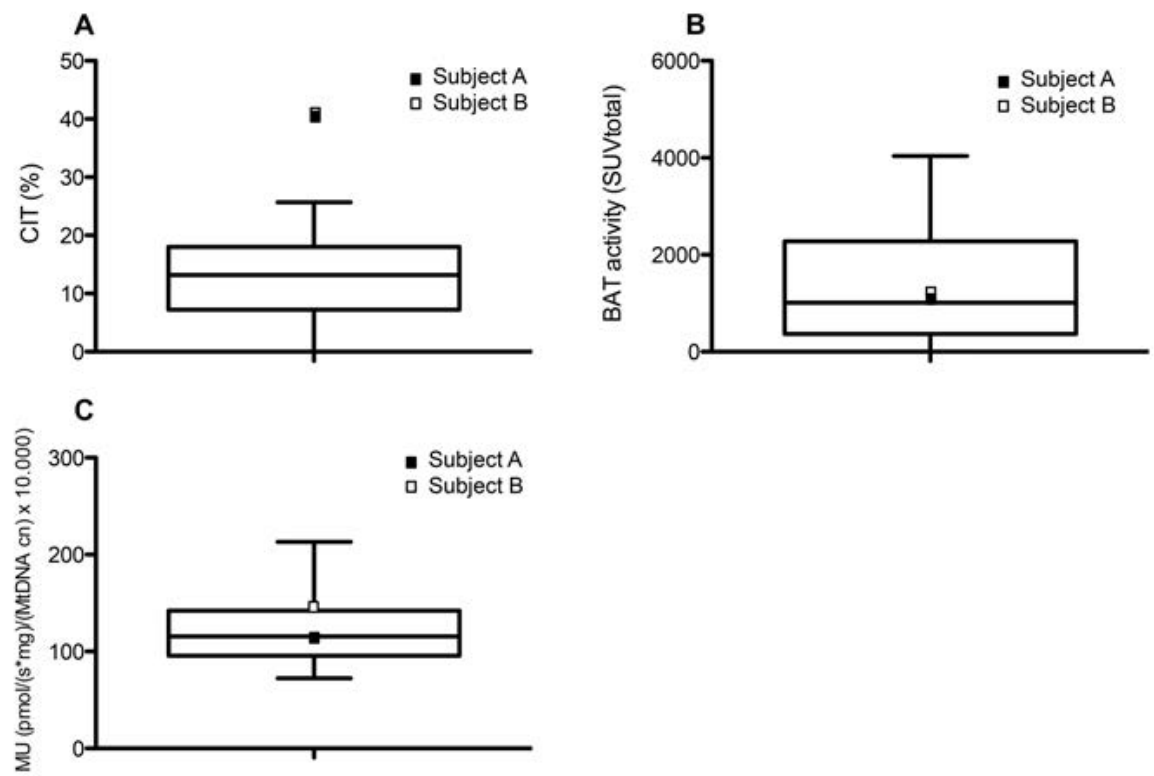

Figure 3. Comparison of $\mathrm{CIT}$, BAT activity and skeletal muscle intrinsic mitochondrial uncoupling between the monozygotic twin and young adult men. Boxplots indicating the median and interquartile range of CIT (A) and BAT activity (B) found in young adult men during previous studies $(6,17,18,29)(\mathrm{CIT} n=43$; BAT activity $n=45$ ). C) Boxplot showing the skeletal muscle mitochondrial proton leak in young adult men ( $n=30$ ) from a previous study $(n=8)$ and unpublished results $(n=22)$. In each boxplot subject $A$ is indicated as a black square and subject $B$ as an open square. The whisker bars represent the $5^{\text {th }}$ (lower) and $95^{\text {th }}$ (upper) percentile.

The cellular respiration data of the $m$. vastus lateralis fibers revealed that the state 4 respiration, reflecting mitochondrial proton leak per mitochondrion, was lower in subject A compared to subject B (A: $113.35 \pm 18.11 \mathrm{pmol} /\left(\mathrm{s}^{*} \mathrm{mg}\right) /($ MtDNA copy numbers) $x 10.000$ versus $B: 147.45 \pm 5.28 \mathrm{pmol} /(\mathrm{s} * \mathrm{mg}) /($ MtDNA copy numbers) $\mathrm{x}$ 10.000). The mitochondrial proton leak in the Iceman was within the interquartile range we observed in young adult men $(n=30)$ from a previous study and nonpublished data (interquartile range: 95.57 - $142.13 \mathrm{pmol} /\left(\mathrm{s}^{*} \mathrm{mg}\right) /(\mathrm{MtDNA}$ copy 
numbers) $\times$ 10.000; Figure $3 C$ ) [6]. Subject $B$ thus had a higher mitochondrial proton leak compared to his brother, as it was outside the interquartile range. However, it was not different from young adult males $\left(95^{\text {th }}\right.$ percentile: 213.13 $\mathrm{pmol} /\left(\mathrm{s}^{*} \mathrm{mg}\right) /($ MtDNA copy numbers) $\mathrm{x} 10.000)$.

Interestingly, both subjects immediately switched to the g-Tummo meditation/breathing technique at the onset of cold exposure, and although subject $B$ does not practice g-Tummo meditation regularly, highly similar breathing patterns were observed (visual recognition). Therefore, we decided to analyze the $\left[{ }^{18} \mathrm{~F}\right]$ FDGuptake in two important respiratory muscles (RM), the $\mathrm{mm}$. intercostales interior and exterior and the $\mathrm{m}$. scalenus. Glucose uptake increased fourfold in these muscles during the cold experiment compared to thermoneutral conditions (Figure 4C, 4F), likely explaining a part of the high CIT levels. It is known that the energy cost of breathing is around $1-2 \%$ of total oxygen consumption, and that when ventilation increases, the oxygen consumption per liter of ventilation increases [23]. It might thus be that over $10 \%$ of the CIT is explained by increased cost of breathing.

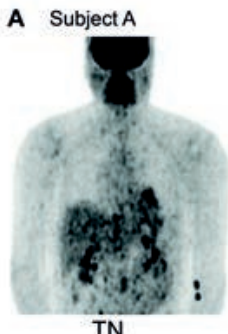

TN

C Subject B

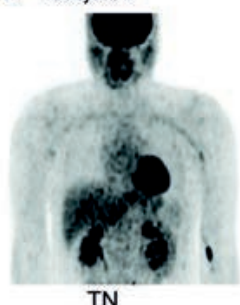

TN

E Subject A

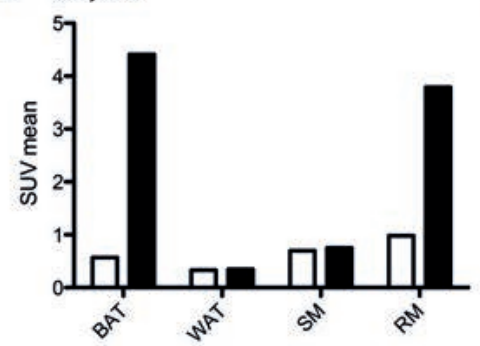

B Subject A

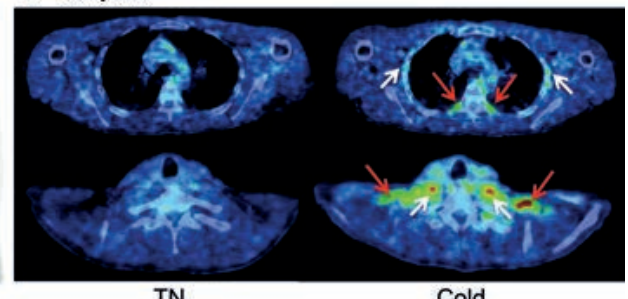

TN

Cold

D Subject B

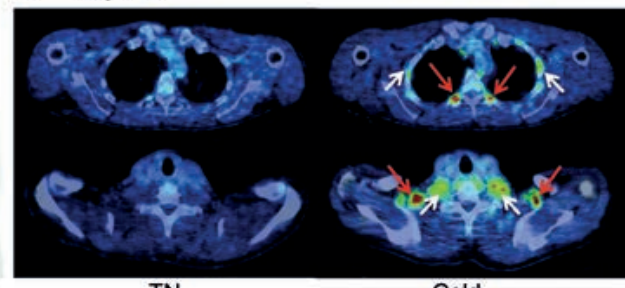

TN Cold

F Subject B

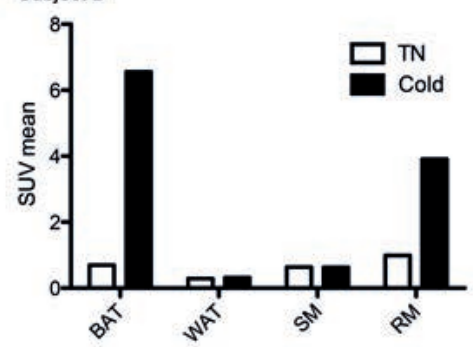


Figure 4. Brown adipose tissue and respiratory muscle activity during the thermoneutral (TN) and cold exposure experiment. A, C) PET images during thermoneutral (left) and cold (right) conditions showing $\left[{ }^{18}\right.$ F]FDG-uptake in brown adipose tissue (BAT; red arrows) and respiratory muscles (RM; white arrows). B, D) Transaxial slices of subject $A$ and $B$ (5mm thick) of thoracic area (upper) and supraclavicular area (lower) demonstrating BAT activity (red arrows) and RM activity (white arrows). E, F) $\left[{ }^{18} \mathrm{~F}\right] \mathrm{FDG}$-uptake (SUV $\left.\mathrm{V}_{\text {mean }}\right)$ in BAT, white adipose tissue (WAT), skeletal muscle (SM), and respiratory muscles (RM) during thermoneutral (TN) and cold conditions.

\section{Discussion}

The present study investigated the metabolic and insulative responses during mild cold in the so called 'Iceman', who has a lifestyle with frequent exposure to extreme cold, and in his monozygotic twin brother who is not frequently exposed to these extreme conditions. It was hypothesized that the Iceman would have a greater CIT and BAT activity. However, we found comparable CIT, BAT activity, and vasoconstriction in the extremities (hand and toe) during mild cold exposure and a slightly lower skeletal muscle mitochondrial proton leak in the Iceman compared to his twin brother.

Based on the frequent exposure of the Iceman to extreme cold, we expected to find greater BAT activity in the Iceman compared to his twin brother. It can be that these (short-term) extreme cold challenges do not recruit BAT. BAT is likely to be important during extended periods of mild cold exposure [24], and can maintain long periods of heat production. BAT thermogenesis has adaptive value because it is less exhaustive compared to shivering, due to its capacity for mitochondrial uncoupling via the specialized uncoupling protein 1 (UCP-1). We have recently shown that an extended period of mild cold exposure recruits BAT. In that study we exposed young adults to mild cold $\left(15-16^{\circ} \mathrm{C}\right)$ conditions for ten consecutive days [6], and found that both BAT activity and NST increased. It is thus likely that long periods of mild cold exposure are more effective in increasing BAT activity and CIT than single bouts of extreme cold exposure. On the other hand, an explanation for the lack of difference in BAT activity in both subjects might be that the twin had a G/G polymorphism for UCP1 , which could negatively affect the plasticity of BAT [25]. This polymorphism therefore might preclude the recruiting effects of extreme cold exposure on BAT activity. Yet, the amount of BAT activity was comparable to young adult men and is likely high for their age, as BAT is known to decrease with ageing. A study on the effect of age on BAT found active BAT in only $10 \%$ of the subjects between 50 and 60 years old [9].

With respect to the insulative response, comparable vasoconstriction was observed in the hand and toe. However, a relatively large vasoconstriction response was found on the arm in the Iceman. This indicates a better insulation in the proximal region. Furthermore, the drop in core temperature was lower in the Iceman $(-0.18$ versus $-0.4{ }^{\circ} \mathrm{C}$ ), indicating that the Iceman is better capable to maintain his body core temperature during mild cold conditions. The effects of the frequent exposure to 
extreme cold of the Iceman were well reflected by the thermal sensation and comfort. The Iceman felt slightly cool and comfortable during the entire mild cold protocol, whereas his brother experienced it as cold and uncomfortable. Thus, even though they had comparable metabolic reactions, there was a difference in subjective response to cold. Finally, plasma norepinephrine concentrations indicate that the mild cold induced a greater sympathetic stimulation in subject B. The sympathetic stimulation of BAT therefore might have been greater in subject $B$.

An interesting observation was the high heat production during cold $(>40 \%)$ in both subjects. In our studies with young adults we normally observe NST levels (without g-Tummo) between -10 and $30 \%[6,17,18]$. Given the fact that BAT activity and the intrinsic capacity for mitochondrial uncoupling in SM was comparable to young adults, other tissues and/or mechanisms must explain the high increase in CIT. Possible mechanisms that have been suggested are futile calcium cycling, protein turnover and substrate cycling [26]. However, in this special case a likely explanation for the high CIT levels is the g-Tummo like breathing technique (and possibly meditation in subject A) used by both subjects [12]. G-Tummo meditation consists of a somatic (isometric muscle contraction) and a meditative component (visualization of flames). The somatic component, which consists of deep abdominal "vase" breathing has been shown increased body core temperature, likely via increased heat production in both experienced g-Tummo meditators from Eastern Tibet and non-meditators (Western people) [12]. The meditative component exerted by the g-Tummo meditators was capable of sustaining temperature increases for longer periods. The monozygotic twin exerted this breathing technique as soon as the cooling protocols started. Metabolic activity of the respiratory muscles was clearly shown by increased $\left[{ }^{18} \mathrm{~F}\right.$ FDG-uptake in the respiratory muscles during mild cold, which was absent during the thermoneutral experiments. It is therefore likely that a great part of the increased CIT can be explained by this breathing technique and could thus be a potential mechanism to fight cold challenges. We were not able to measure the effect of meditation on CIT and BAT activity. Whether the visualization component, as found by Kozhevnikov et al. [12], is capable of increasing thermogenesis via BAT activity remains unclear.

During the cold experiments both subjects did not shiver, whereas normally young adults do. However, they were very close to shivering, because immediately after the experiment shivering occurred. This was likely due to the redistribution of cold blood leading to an after drop in core temperature (subject $A$ : 36.39 to 36.10 ㅇ $\mathrm{C}$ versus $\mathrm{B}$ 36.36 to $35.95 \stackrel{\circ}{ } \mathrm{C}$ ). Our results indicate that the delay of shivering might be due to their increased respiratory muscle contraction (because of gTummo meditation practices). This parallels the fact that exercising in the cold does not induce shivering owing to increased heat production [27]. The exact role of the meditative component on temperature perception remains unknown. Another interesting observation was the bradycardia in both subjects indicating a possible alteration in cardiac autonomic 
control. Whether this is due to their meditation/breathing technique or a certain genetic factor (e.g. [28]) cannot be answered.

It should be noted that it is not possible to perform proper statistical analysis in a case study. The present results do provide new indications and ideas, which should lead to follow-up research. However, this case study is unique due to the identical genetic background of the subjects, which makes it possible to attribute the differences in results to lifestyle characteristics. In summary, we here show that the 'Iceman', who has a lifestyle with frequent exposure to extreme cold, does not have a greater heat production and BAT activity during mild cold conditions compared to his non-acclimatized monozygotic twin brother. Hence, the lifestyle of the Iceman does not affect the metabolic response to mild cold. The Iceman did have a relatively high insulative response and his thermal sensation and comfort were less affected by cold exposure. Based on these findings, it could be hypothesized that frequent but short term extreme cold exposure is less effective in BAT recruitment compared to longer periods of mild cold exposure. Interestingly, both brothers showed a high cold-induced heat production compared to previous mild cold studies in young adults. This was likely caused by contributions of both BAT activity and high levels of respiratory muscle contraction associated with g-Tummo meditation. G-tummo like breathing may thus be responsible for heat production in the cold in addition to classical NST.

\section{References}

1. van Marken Lichtenbelt WD, and Schrauwen P. Implications of non-shivering thermogenesis for energy balance regulation in humans. Am J Physiol Regul Integr Comp Physiol. 2011;310(2):R285-96.

2. van Marken Lichtenbelt WD, Vanhommerig JW, Smulders NM, Drossaerts JM, Kemerink GJ, Bouvy ND, Schrauwen $\mathrm{P}$, and Teule GJ. Cold-activated brown adipose tissue in healthy men. $N$ Engl J Med. 2009;360(15):1500-8.

3. Virtanen KA, Lidell ME, Orava J, Heglind M, Westergren R, Niemi T, Taittonen M, Laine J, Savisto NJ, Enerback S, et al. Functional brown adipose tissue in healthy adults. N Engl J Med. 2009;360(15):151825.

4. Saito M, Okamatsu-Ogura Y, Matsushita M, Watanabe K, Yoneshiro T, Nio-Kobayashi J, Iwanaga T, Miyagawa M, Kameya T, Nakada K, et al. High incidence of metabolically active brown adipose tissue in healthy adult humans: effects of cold exposure and adiposity. Diabetes. 2009;58(7):1526-31.

5. Davis T. Chamber cold acclimatization in man. J Appl Physiol. 1961;16:1011-5.

6. van der Lans AAJJ, J. Hoeks, B. Brans, G.H.E.J. Vijgen, M.G.W. Visser, M.J. vosselman, J. Hansen, J. A. Jörgensen, J. Wu, F. Mottaghy, P. Schrauwen, W.D. van Marken Lichtenbelt. Cold acclimation recruits brown adipose tissue and increases non-shivering thermogenesis in humans. J Clin Invest. 2013;123(8):3395-403.

7. van Marken Lichtenbelt WD, Schrauwen $P$, van De Kerckhove $S$, and Westerterp-Plantenga MS. Individual variation in body temperature and energy expenditure in response to mild cold. Am J Physiol Endocrinol Metab. 2002;282(5):E1077-83.

8. Valve R, Heikkinen S, Rissanen A, Laakso M, and Uusitupa M. Synergistic effect of polymorphisms in uncoupling protein 1 and beta3-adrenergic receptor genes on basal metabolic rate in obese Finns. Diabetologia. 1998;41(3):357-61. 


\section{BROWN ADIPOSE TISSUE ACTIVITY IN THE DUTCH ICEMAN}

9. Yoneshiro T, Aita S, Matsushita M, Okamatsu-Ogura Y, Kameya T, Kawai Y, Miyagawa M, Tsujisaki M, and Saito M. Age-related decrease in cold-activated brown adipose tissue and accumulation of body fat in healthy humans. Obesity (Silver Spring). 2011;19(9):1755-60.

10. Wijers SL, Schrauwen P, Saris WH, and van Marken Lichtenbelt WD. Human skeletal muscle mitochondrial uncoupling is associated with cold induced adaptive thermogenesis. PLoS One. 2008;3(3):e1777.

11. Kox M, Stoffels M, Smeekens SP, van Alfen N, Gomes M, Eijsvogels TM, Hopman MT, van der Hoeven JG, Netea MG, and Pickkers $P$. The influence of concentration/meditation on autonomic nervous system activity and the innate immune response: a case study. Psychosom Med. 2012;74(5):489-94.

12. Kozhevnikov M, Elliott J, Shephard J, and Gramann K. Neurocognitive and somatic components of temperature increases during g-tummo meditation: legend and reality. PLoS One. 2013;8(3):e58244.

13. Bligh J, and Johnson KG. Glossary of terms for thermal physiology. J Appl Physiol. 1973;35(6):941-61.

14. Tiwari AK, Prasad P, B KT, Kumar KM, Ammini AC, Gupta A, and Gupta R. Oxidative stress pathway genes and chronic renal insufficiency in Asian Indians with Type 2 diabetes. J Diabetes Complications. 2009;23(2):102-11.

15. Widen E, Lehto M, Kanninen T, Walston J, Shuldiner AR, and Groop LC. Association of a polymorphism in the beta 3-adrenergic-receptor gene with features of the insulin resistance syndrome in Finns. $N$ Engl J Med. 1995;333(6):348-51.

16. Kildeso J, Wyon D, Skov T, and Schneider T. Visual analogue scales for detecting changes in symptoms of the sick building syndrome in an intervention study. Scand J WorkEnviron Health. 1999;25(4):361-7.

17. Vosselman MJ, van der Lans AA, Brans $B$, Wierts $R$, van Baak MA, Schrauwen $P$, and van Marken Lichtenbelt WD. Systemic beta-adrenergic stimulation of thermogenesis is not accompanied by brown adipose tissue activity in humans. Diabetes. 2012;61(12):3106-13.

18. Vosselman MJ, Brans B, van der Lans AA, Wierts R, van Baak MA, Mottaghy FM, Schrauwen $P$, and van Marken Lichtenbelt WD. Brown adipose tissue activity after a high-calorie meal in humans. Am J Clin Nutr. 2013;98(1):57-64.

19. Baecke JA, Burema J, and Frijters JE. A short questionnaire for the measurement of habitual physical activity in epidemiological studies. Am J Clin Nutr. 1982;36(5):936-42.

20. Nagai N, Sakane N, Tsuzaki K, and Moritani T. UCP1 genetic polymorphism (-3826 A/G) diminishes resting energy expenditure and thermoregulatory sympathetic nervous system activity in young females. Int J Obes (Lond). 2011;35(8):1050-5.

21. van Ooijen AM, van Marken Lichtenbelt WD, van Steenhoven AA, and Westerterp KR. Cold-induced heat production preceding shivering. Br J Nutr. 2005;93(3):387-91.

22. Kingma BR, Frijns AJ, Saris $W H$, van Steenhoven AA, and Lichtenbelt WD. Increased systolic blood pressure after mild cold and rewarming: relation to cold-induced thermogenesis and age. Acta Physiol (Oxf). 2011;203(4):419-27.

23. Peters RM. The energy cost (work) of breathing. Ann Thorac Surg. 1969;7(1):51-67.

24. Chen KY, Brychta RJ, Linderman JD, Smith S, Courville A, Dieckmann W, Herscovitch P, Millo CM, Remaley $A$, Lee $P$, et al. Brown fat activation mediates cold-induced thermogenesis in adult humans in response to a mild decrease in ambient temperature. J Clin Endocrinol Metab. 2013;98(7):E1218-23.

25. Esterbauer H, Oberkofler H, Liu YM, Breban D, Hell E, Krempler F, and Patsch W. Uncoupling protein-1 mRNA expression in obese human subjects: the role of sequence variations at the uncoupling protein-1 gene locus. J Lipid Res. 1998;39(4):834-44.

26. Wijers SL, Saris WH, and van Marken Lichtenbelt WD. Recent advances in adaptive thermogenesis: potential implications for the treatment of obesity. Obes Rev. 2009;10(2):218-26.

27. Arens EA, and Zhang H. N. Pan and P. Gibson, Woodhead Publishing Ltd; 2006:560-602.

28. Milanesi R, Baruscotti M, Gnecchi-Ruscone $T$, and DiFrancesco D. Familial sinus bradycardia associated with a mutation in the cardiac pacemaker channel. N Engl J Med. 2006;354(2):151-7. 
29. van Rooijen BD, van der Lans AA, Brans B, Wildberger JE, Mottaghy FM, Schrauwen P, Backes WH, and van Marken Lichtenbelt WD. Imaging cold-activated brown adipose tissue using dynamic T2*-weighted magnetic resonance imaging and 2-deoxy-2-[18F]fluoro-D-glucose positron emission tomography. Invest Radiol. 2013;48(10):708-14. 



\section{CHAPTER 7}

\section{General Discussion}





\section{Introduction}

The recent rediscovery of functional BAT in adult humans has revived the interest in this metabolic tissue. Regarding the current worldwide obesity problem, increasing thermogenesis via BAT might be of preventive and therapeutic value. This thesis first reviewed the literature on potential ways to activate BAT in humans (chapter 2). Next, it was investigated in young adult humans whether BAT is active upon a high calorie meal and is involved in diet-induced thermogenesis (DIT) (chapter 3). In chapter 4, BAT activity was measured during systemic $\beta$-AR stimulation of thermogenesis. Subsequently, the effects of chronic endurance exercise on BAT activity and browning of WAT were analysed (chapter 5). Finally the effects of frequent extreme cold exposure on BAT and non-shivering thermogenesis (NST) were examined in the 52 years old Dutch "Iceman" and his monozygotic twin brother. In this final chapter, the role of BAT in facultative thermogenesis will be discussed. Future perspectives will be presented on the role of BAT in DIT, and on the effects of systemic $\beta$-AR stimulation of BAT. Finally, alternative routes for BAT stimulation in humans will be addressed.

\section{The role of human BAT in facultative thermogenesis}

In rodents, it is clear that BAT is the most important heat-producing organ during NST. Furthermore, an important role for BAT in DIT has been suggested as well $(1,2)$. This facultative thermogenesis is mediated by the SNS and can be mimicked by stimulating the $\beta$-ARs present on BAT. Facultative thermogenesis has been shown to exist in humans, although the effector organs are not well known. In this thesis we studied BAT during cold exposure, after food intake, and during $\beta$-AR stimulation (Figure 1). We related BAT activity with the increases in thermogenesis. 


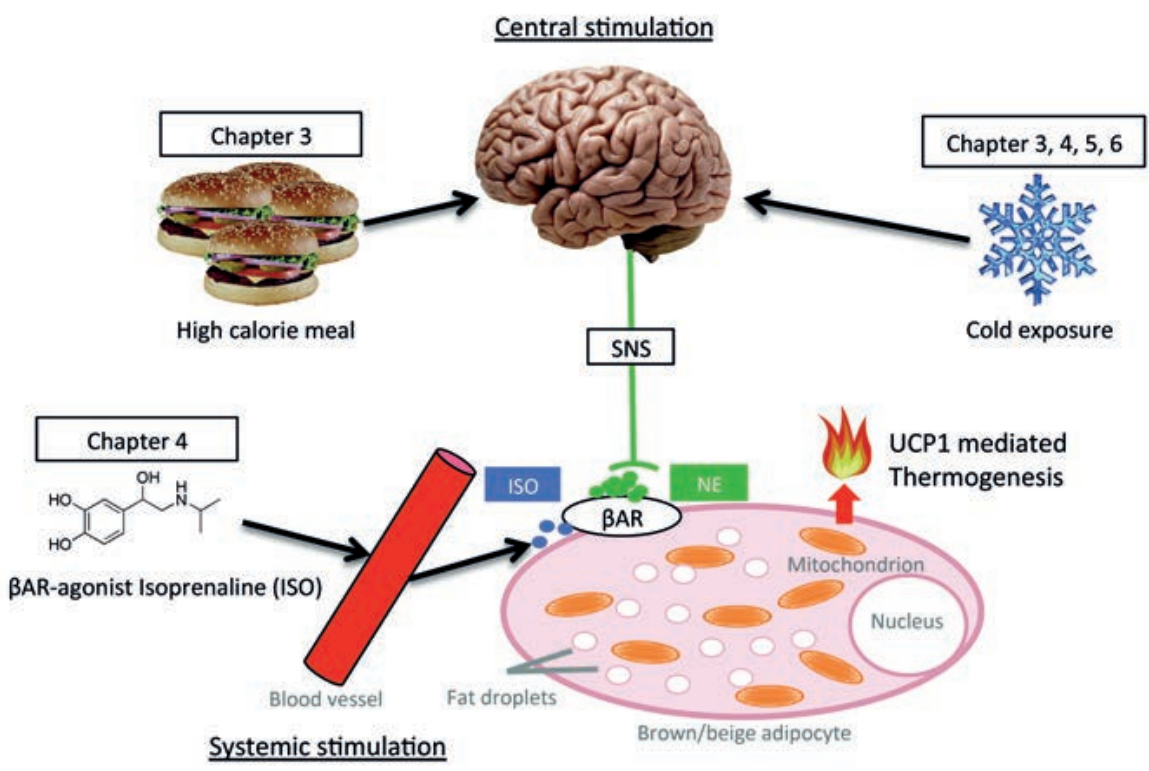

Figure 1. Schematic overview of the different forms of acute BAT stimulation in this thesis. In this thesis we examined the acute effects of both cold exposure and food intake on BAT activity. Cold exposure activates BAT via the central SNS, and it is also thought that the central SNS mediates diet-induced BAT activity. In addition, we examined the effects of systemic activation of BAT via intraveneous injection of the $\beta$-ARagonist Isoprenaline, which was injected intravenously ISO = Isoprenaline, SNS = sympathetic nervous system, UCP1 = uncoupling protein $1, \beta A R=$ beta-adrenergic receptors.

\section{Nonshivering thermogenesis}

Cold exposure is known to be the most potent activator of BAT and we have therefore used cold-induced BAT activity as a positive control for the interventions. During all cold exposure experiments energy expenditure increased without shivering, with an average NST of $12.2 \pm 7.9 \%$ when combining the cold experiments described in chapter 3-5. The extremely high cold-induced thermogenesis (40\%) observed in the case study (chapter 6) also included isometric contraction of respiratory muscle, and therefore cannot be interpreted as solely NST and was thus excluded from this calculation. There was a high interindividual variability in NST and BAT activity (chapter 3-5), which is commonly found in these types of experiments (3). Interestingly, BAT is likely involved in NST as we repeatedly observed significant relationships between NST and BAT activity in chapter $\mathbf{3}$ and $\mathbf{5}$. Combining all cold experiments also reveals a significant relationship between both parameters $\left(r^{2} 0.19 ; P<0.01\right)$. The relation of BAT with NST has also been demonstrated by other studies (4-8). A next step is quantification of the actual contribution of BAT to NST. Muzik et al. (9) calculated the contribution of BAT to 
NST by studying oxidative metabolism in BAT using ${ }^{15} \mathrm{O}_{2}$ and combining this with $\left.{ }^{18}\right]$ FDG-PET scans. They found that BAT likely contributed to less than $20 \mathrm{kcal} / \mathrm{day}$ during moderate cold stress. These findings indicate a minor role for BAT in NST. However, their 20 minutes of air-cooling $\left(15.5^{\circ} \mathrm{C}\right.$, light clothing) might not have been long enough to activate BAT. Our observations demonstrate that the time span necessary to attain maximal NST levels ranges from twenty to in rare cases 60 minutes. Therefore, we propose to use a standardized but individually attuned cooling protocol (see methods chapter 4). In this protocol, all subjects are cooled until shivering occurs in order to maximally activate BAT before measuring BAT activity, which is described in detail by van der Lans et al. (10). Thus, future research should aim at using these standardized cooling protocols in combination with various PET-tracers to more precisely quantitate the contribution of BAT to NST.

In addition to BAT, there are likely other tissues and mechanisms involved in NST as about only $19 \%$ of the variation can be explained by BAT in our experiments. Skeletal muscle might be an important tissue in NST. Astrup et al. already demonstrated that muscle contributed up to $50 \%$ during sympathetic stimulation (11). Interestingly, it was demonstrated in humans that mitochondrial uncoupling in skeletal muscle was related to NST (12), although this was not confirmed by van der Lans et al. (8). Next to mitochondrial uncoupling, futile calcium cycling via sarcolipin is proposed as another mechanism in muscle that could increase thermogenesis. Sarcolipin knockout mice developed hypothermia and were predisposed to diet-induced obesity (13). Future studies are needed to examine the role for skeletal muscle in NST.

\section{Diet-induced thermogenesis}

In chapter 3 we investigated whether human BAT is activated upon high caloric intake and is related to DIT. This form of facultative thermogenesis can be divided in an obligatory and a facultative part. The obligatory part is due to the intake and processing of the food (14), whereas the remaining part of DIT is facultative and is likely mediated by mitochondrial uncoupling, futile cycles and/or ion shuttling across membranes (15). Interestingly, it has been repeatedly demonstrated by Glick et al. that single meals activate BAT in rodents (16-19). Furthermore, DIT was greater in cold acclimated animals, who have increased BAT activity, which suggests that BAT is involved in DIT (20). Facultative DIT is likely regulated by the SNS as demonstrated by increased norepinephrine turnover in BAT after a single meal (21) and blockade of DIT by propranolol (22). In humans, multiple studies have measured (postprandial) facultative DIT during $\beta$-AR blockade and most studies found decreased levels of DIT, although this was not consistently found (23). The tissues responsible were thought to be the liver, white adipose tissue, and skeletal muscle, whereas no role for BAT was suggested (23). With respect to the macronutrient composition of the diet, several 
studies have shown that mainly carbohydrate-rich meals were capable of stimulating SNS mediated DIT (14). In our experiment (chapter 3) the effects of a high-calorie, carbohydrate-rich meal (1622 $\pm 222 \mathrm{kcal} ; 78 \%$ carbohydrate, $10 \%$ fat, $12 \%$ protein) on energy expenditure and BAT was investigated in eleven young male adults. We found that the meal significantly increased energy expenditure with an average DIT of $20 \%$. Again, a high interindividual variation was found (6.9-31.3\%). Unfortunately we were unable to distinguish between the obligatory and facultative component of DIT. Interestingly, we found higher postprandial $\left[{ }^{18}\right.$ ]FDG-uptake in supraclavicular BAT compared to thermoneutral conditions measured in a previous study (24). Furthermore, the $\left[{ }^{18}\right]$ FDG-uptake in supraclavicular BAT was greater compared to the postprandial uptake in WAT and the liver, and comparable to skeletal muscle. Compared to cold-induced BAT activity, diet-induced BAT activity was four times lower. However, true BAT activity might have been underestimated because of tracer dilution as a large part of the tracer was taken up by skeletal muscle. This high uptake in skeletal muscle diminished the availability of the tracer for BAT and other tissues as clearly illustrated in the brain (see chapter 3: Figure 3A, 3E). Thus, the increased $\left[{ }^{18}\right]$ FDG-uptake implied that BAT is actively involved in wasting excessive caloric intake and is involved in facultative DIT. However, BAT $\left[{ }^{18}\right]$ FDG-uptake was not related to DIT.

Until now, there has been one other human study trying to measure BAT activity after a meal (25). In this study BAT activity was measured during cold exposure after a high-fat meal (545 kcal; $27 \%$ carbohydrate, $56 \%$ fat, $17 \%$ protein) and during fasting in young adult males. Unexpectedly, it was demonstrated that cold-induced $\left[{ }^{18}\right]$ FDGuptake in BAT was lower after the meal compared to fasting. However, these findings are likely explained by the design of this study. First, the combination of cold exposure with dietary intake most likely obscured diet-induced BAT activity. In order to investigate the role of BAT within DIT, diet and cold exposure should not be combined. Second, the problem of tracer dilution by skeletal muscle was also present in this study, limiting the availability of the tracer for BAT. They did not take this into account in their analysis as was done in chapter 3 , and might have underestimated BAT activity during the postprandial period. Third, the caloric load was around one third of what was used in our experiment, which may not have been sufficient to trigger BAT activation.

The results from chapter 3 clearly show that BAT is activated after a carbohydraterich, energy dense meal. However, BAT activity and DIT were not related. This is likely due to the relative low facultative part compared to the obligatory part of DIT, which makes it difficult to entangle such a relationship. More specific methods to quantify the contribution of BAT to DIT are therefore warranted. On the other hand other tissues may also be involved in facultative DIT such as the liver and skeletal muscle. A large role for splanchnic tissues (50\%) and skeletal muscle $(30-35 \%)$ has been attributed to DIT in previous studies $(26,27)$. Furthermore, skeletal muscle mitochondrial uncoupling has been suggested to be involved in DIT during three days 
of overfeeding as well (28). However, no relationships between DIT and FDG-uptake and these tissues were found in our study.

\section{Perspectives on BAT in relation to DIT}

The findings presented in chapter 3 provide the first evidence that BAT is active after a high-calorie meal rich in carbohydrates. Whether this is also true for meals with a different macronutrient composition remains to be studied. In rats, a high-fat meal was less effective in activating BAT than a high-carbohydrate meal (29). Interestingly, long term overfeeding of unbalanced meals in protein content (both low- and high protein content) results in lower metabolic efficiency, which can be explained by increased DIT (30). However, the effects of a single low/high-protein meal are not well known. This topic thus requires further research.

In order to determine the contribution of BAT to facultative DIT, it is necessary to investigate whether in BAT, apart from glucose uptake as measured by $\left[{ }^{18}\right]$ FDG-PET/CT, the actual oxygen metabolism is increased in the postprandial situation. This lack of information on BAT metabolism is a limitation of $\left[{ }^{18}\right]$ FDG-PET that applies to all types of interventions in this thesis. Uptake of $\left[{ }^{18}\right]$ FDG does not reflect mitochondrial uncoupling but more the indirect capacity of the tissue to take up glucose, as directed by the expression of GLUT, and a number of internal (e.g. UCP1 activity) and external factors (e.g. insulin) (31). One could argue that the postprandial tracer uptake solely reflected postprandial glucose uptake for storage as glycogen or for other cellular purposes apart from mitochondrial uncoupling. To examine this one could measure oxygen consumption and blood perfusion by using oxygen labelled tracers, as has been done previously during cold exposure $(4,9)$. Alternatively the use of the tracer ${ }^{11} \mathrm{C}$ acetate could shed light on whether oxidative metabolism in BAT is involved (5).

In addition to single meals, the role of BAT during longer periods of overfeeding needs to be studied. In rodents, Rothwell \& Stock demonstrated that BAT is involved in DIT during overfeeding (32), and Stock suggested the same mechanism to occur in humans (30). Moreover, Feldmann et al. showed in 2009 that knocking out BAT abolishes DIT and induces obesity in mice (33). A recent study by Schlögl et al. (34) investigated whether 24 hours of $200 \%$ overfeeding (60\% fat, $20 \%$ carbohydrate, $20 \%$ protein) would lead to an extended activation of BAT in humans. DIT was doubled (280 $\pm 164 \mathrm{kcal})$ during overfeeding compared to DIT when subjects were in energy balance. However, no glucose (FDG) uptake in BAT was found 4 and 12 hours after the 24-hour overfeeding period. In our study, BAT glucose uptake was increased 75 minutes after the meal. The different experimental set-up likely explains these different results. We measured acute postprandial effects, while in Schlögl et al. BAT activation was studied over a more extended period of time. Thus far, it is unknown if BAT is activated each time after a meal or that it adjusts its activity via an energy 
sensing mechanism such as leptin, which is thought to occur during overfeeding in rodents (35). When the former would be the case, 4 hours after the meal may be too late, and if the latter would be true, 24 hours of overfeeding would be too short. To study whether BAT is activated during overfeeding therefore requires longitudinal study designs with longer periods of overfeeding. One possible study set-up would be to expose humans to an overfeeding diet for minimally one week. One could use indirect calorimetry in respiration chamber setting to measure DIT continuously and use PET-CT-scanning during to measure cold-induced BAT activity before, halfway, and after the overfeeding period. This would provide valuable information on whether BAT adapts to overfeeding and if this is associated with increased DIT. On the contrary, caloric restriction is known to reduce energy expenditure and DIT, and it would be interesting to study whether this is reflected by adaptations BAT activity as well. Finally it would be worth studying whether interventions that lead to increased BAT recruitment, such as cold acclimation, are also associated with increased DIT upon a single meal challenge.

\section{Beta-adrenergic stimulation of thermogenesis}

The SNS is known to regulate NST and likely DIT in rodents. The same role for the SNS likely applies to humans as well (28). The SNS stimulates facultative thermogenesis by acting on (mainly) the $\beta$-adrenergic receptors present in the cell membranes of effector tissues. Sympathomimetics or $\beta$-AR-agonists can mimic this sympathetically induced thermogenesis by targeting these adrenergic receptors. In rodents, adrenergic thermogenesis primarily originates from BAT (36). In chapter 4 we investigated whether BAT is also involved in $\beta$-AR stimulation of thermogenesis in humans. We therefore measured both energy expenditure and BAT activity during systemic stimulation of the $\beta$-ARs by infusion of the non-selective agonist isoprenaline (ISO). Thermogenesis increased in correspondence with the dosage used (chapter 4: Figure 1A) up to a maximum of $19.7 \pm 7.2 \%$ during the final dose of $24 \mathrm{ng} / \mathrm{kg}$ fat-free mass ${ }^{-1}$ $\mathrm{min}^{-1}$. These levels are in line with previous human studies using similar doses of ISO (37-39). Unexpectedly, even though ISO stimulated thermogenesis to a similar level as during cold exposure $(16.9 \pm 7.8 \%)$, this was not associated with increased BAT activity. Cypess et al. (40), who studied the effects of ephedrine (sympathomimetic) on energy expenditure and BAT activity in lean human adults, observed comparable findings. During intramuscular injection of $1 \mathrm{mg} / \mathrm{kg}$ ephedrine, energy expenditure increased with $9 \%$ without concomitant BAT activity. Carey et al. (41) did find increased BAT activity in lean (not in obese) human adults when administering $2.5 \mathrm{mg} / \mathrm{kg}$ orally. However, BAT activity was considerably lower than during cold exposure. Energy expenditure increased with $18 \%$ in lean and $13 \%$ in obese young adults. Given that the obese did not show BAT activity, it could be hypothesized that a part of this $5 \%$ 
difference was explained by BAT activity. The authors concluded that the amount of BAT activity found likely contributed less than $1 \%$ to the ephedrine-induced thermogenesis, which was based on the previous calculations of the contribution of cold-induced BAT to NST by Muzik et al. (9). However, as explained previously, methodological issues might have underestimated these calculations of BAT's contribution to NST. Moreover, no relationship was found between ephedrine-induced BAT activity and energy expenditure.

Based on these findings, it can thus be concluded that other tissues than BAT play a role during systemic $\beta A R$-stimulation of thermogenesis. Given the widespread distribution of adrenergic receptors in the body (e.g. white adipose tissue, liver, skeletal muscle, heart, lungs), multiple tissues likely contribute to this broad systemic adrenergic stimulation of thermogenesis. It was suggested that a small part $(<5 \%)$ of adrenergic thermogenesis could be explained by the energy cost of cardiac and respiratory work (42). As during NST and facultative DIT, skeletal muscle likely plays an important role here as well. It was already suggested by Astrup et al. in 1985 that skeletal muscle most likely explains $50 \%$ of the ephedrine-induced thermogenesis (11). Furthermore, infusion of epinephrine demonstrated that $40 \%$ of the induced thermogenesis originates from skeletal muscle and 5\% from adipose tissue (43).

These findings thus indicate that systemic adrenergic stimulation is not a promising route to stimulate BAT thermogenesis. The lack of BAT activity observed during ISO infusion might be explained by too low concentrations of the agonist at receptor level. During central stimulation (e.g. cold exposure), sympathetic nerves release high concentrations of NE at receptor level, which cannot be reached by agonists via the plasma (44). The reason why ephedrine did activate BAT slightly during high doses is likely due to its indirect effect on stimulating NE release at the sympathetic nerve endings (40). Dulloo et al. (45) demonstrated in mice that the effects of ephedrine on BAT are fully dependent on functional sympathetic innervation and thus on postsynaptic NE release. This release of NE during ephedrine stimulation was indeed reflected by increased plasma spill over of NE ( 370 ng/L) (41). That ISO does not stimulate the SNS centrally was confirmed by the fact that plasma NE concentrations were not changed (chapter 4). Thus, stimulating the release of NE at the postsynaptic sympathetic nerves in BAT is more effective than broad systemic $\beta$ AR-stimulation.

A second explanation for the lack of BAT activation might be the low specificity of ISO for the $\beta_{3}-A R$. Indeed, the sensitivity of the $\beta_{1}$ - and $\beta_{2}-A R$ to ISO is very high, whereas it is a 100 times lower for the $\beta_{3} A R(46)$. In rodents, the $\beta_{3}-A R$ is the most important receptor type regarding acute thermogenic stimulation of BAT and browning of WAT in rodents (36). In humans, the presence of $\beta_{3}-A R$ mRNA in supraclavicular BAT has been demonstrated in adults (47) and from peritumoral BAT in a patient with pheochromocytoma (48). Interestingly, in the latter study it was demonstrated that $80 \%$ of the $\beta$-AR subtypes were $\beta_{3}$-ARs. Furthermore, Krief et al. 
(49) found that mRNA of the $\beta_{3}$-AR receptor correlated with UCP1 mRNA. These findings thus suggest that specifically targeting the $\beta_{3}$-AR might be an effective way to stimulate BAT thermogenesis. In rodents, $\beta_{3}-A R$ agonists have shown to induce acute thermogenic responses $(50,51)$. Furthermore, long-term administration of $\beta_{3}-A R$ agonists stimulated weight loss and had antidiabetic effects $(50,52)$. There has been a long search for specific $\beta_{3}$-AR agonists to stimulate thermogenesis and induce weight loss in humans (53). Thus far, only the agonist L-796568 had acute effects on energy expenditure (54), although this effect was lost during 28-day treatment (55). Another indication for the role of the $\beta_{3}-A R$ in stimulating thermogenesis comes from a recent study by Wijers et al. (56). In this study, administration of $160 \mathrm{mg}$ propranolol (BARblocker) was not capable to block cold-induced thermogenesis in humans (56). It is known that the $\beta_{3} A R$ has 100-1000 times lower sensitivity for propranolol (36), requiring dosages not suitable for human use. These findings thus suggest that $\mathrm{CIT}$, and possibly BAT activation, is mediated via the $\beta_{3} A R$. The development of a more specific $\beta_{3} A R$-agonist for humans could therefore clarify if this receptor is indeed the most important of the $\beta A R$ family to stimulate human BAT. Nevertheless, the finding that propranolol reduces $\left[{ }^{18}\right]$ FDG-uptake in BAT still suggests that other $\beta$-ARs are involved $(57,58)$.

\section{Perspectives on adrenergic stimulation of BAT thermogenesis}

Thus, systemic adrenergic stimulation, as shown by ephedrine and ISO, in humans increases thermogenesis up to $20 \%$, with only a minor role for BAT. Future studies should examine the role of skeletal muscle in this type of facultative thermogenesis, and which mechanisms are behind the muscle-induced adrenergic thermogenesis. One possible way to measure whether skeletal muscle mitochondrial uncoupling is involved would be to use magnetic resonance spectroscopy (MRS). With this technique it has been demonstrated to measure mitochondrial uncoupling in skeletal muscle in vivo (59). Measuring mitochondrial uncoupling via MRS in skeletal muscle during administration of adrenergic agonists would therefore be interesting.

With respect to targeting BAT via the adrenergic receptors, more research is required to examine the exact role for each receptor. Although, the $\beta_{3}-A R$ is suggested to be the most important receptor in stimulating BAT thermogenesis, a role for the other receptors cannot be excluded thus far. To examine this, future in vivo studies could use more specific $\beta$-AR agonists or combine less specific agonists with specific antagonists. While setting up these types of experiments, it should be realized that adrenergic stimulation goes along with cardiovascular side effects. This is predominantly caused by stimulation of the $\beta_{1}$-ARs on the heart. In our experiment (chapter 3), heart rate increased from $60 \pm 5$ to $84 \pm 10$ beats/min and systolic blood pressure from $121 \pm 9$ to $148 \pm 14 \mathrm{mmHg}$. The studies using ephedrine also 
demonstrated these side effects. Thus, to investigate the role of the $\beta_{1}$-AR in BAT activation, a specific $\beta_{1}-A R$ antagonist, such as atenolol, could be combined with cold exposure. To date, there is no clear evidence for a role for the $\beta_{2}$-ARs in mediating BAT activity. Nevertheless, this receptor type has been found in the immortalized PAZ6 cell line derived from the stromal vascular fraction of a human infant (48). It might thus be interesting to test whether a $\beta_{2}$-AR-agonist (e.g. salbutamol) could stimulate BAT. Salbutamol has been tested in humans before and was known to induce energy expenditure, lipid oxidation, and lipolysis (60). Interestingly, in this study it was also shown that obese people demonstrated a blunted effect on these parameters with salbutamol administration. It might thus be that this reduced thermogenesis partly originates from lower BAT activity observed in obese subjects. However, again, Salbutamol is not specific enough as it targets $\beta_{1} A R s$ as well, leading to tachycardia. With respect to BAT recruitment, it should be kept in mind that the $\beta_{1}$-AR likely plays an important role given its presence in brown preadipocytes (36). Regarding browning of WAT, the $\beta_{3}-A R$ is important given that $\beta_{3}-A R$ agonists stimulate this process.

\section{Alternative strategies for stimulating BAT in man}

The previous sections have demonstrated that both cold exposure and diet stimulate BAT thermogenesis most likely via the SNS. Targeting the SNS to stimulate BAT can be achieved systemically, such as by adrenergic agonists. Another route to stimulate BAT is to manipulate the SNS centrally. Indeed, cold acclimation, which acts via central SNS pathways, has now been demonstrated to increase the metabolic capacity of BAT in humans $(8,61,62)$. The case study from chapter 6 indicates that frequent exposure to extreme cold is less effective, although other intermittent cold exposure regimes and more systematic studies are needed before definite conclusions can be drawn. Another route to stimulate the sympathetic outflow to BAT is by using certain type of food ingredients that target the transient receptor potential (TRP) channels, which are the temperature receptors involved in signalling cold and heat sensation to the brain (63). Both capsaicin (capsaicin-like compounds found in non-pungent red pepper) and grains of paradise (Guinea pepper or Alligator pepper) induced acute and chronic thermogenic responses in BAT positive subjects whereas no effect was found in BAT negative subjects (63-65). Other bioactive food ingredients (e.g. caffeine, polyphenols), and drugs (e.g. sibutramine) might be capable to stimulate BAT as well, and remain to be investigated. Interestingly, a recent study by Lopez et al. (66) demonstrated that the thyroid stimulates BAT likely via the hypothalamus as well (66), as opposed to the previous thought that the thyroid hormone only stimulates BAT peripherally and not via central mechanisms. Interestingly, centrally acting drugs (such as antipsychotics, SSRIs, sympathomimetics) are known to affect energy balance. Gaining information on the mechanisms involved might provide crucial information on how to target BAT 
centrally (67). The same holds for the central pathways involved in regulation of adaptive DIT. Manipulating these pathways could be very potent and target BAT in a specific way. This might overcome the cardiovascular side effects that are associated with peripheral SNS activation. However, whether these central types of therapies might be applicable and are not associated with side effects remain to be found out.

Besides central sympathetic stimulation, animal studies have demonstrated alternative routes that stimulate BAT and browning of WAT, such as the endogenous hormones natriuretic peptides and irisin (see chapter 2), fibroblast growth factor 21, bile acids, and bone morphogenic proteins (as reviewed in (68)). In chapter $\mathbf{5}$, we have examined the effects of frequent endurance exercise on BAT and browning of WAT as an alternative route. In rodents, it has been shown that endurance exercise stimulated BAT activity and, more convincingly, browning of WAT via the myokine irisin. To study this, we compared BAT activity and browning of WAT in endurance trained athletes with sedentary lean males (chapter 5 ). In contrast to findings in rodents, we found that endurance trained athletes had lower BAT activity compared to the sedentary males and no browning of WAT was found. This thus suggests that endurance exercise is not an effective alternative route to stimulate BAT in humans. However, whether irisin might be relevant as a therapeutic needs further investigation.

In general, to what extent BAT can be recruited on the long term and actually contributes to whole body energy expenditure are issues that need to be addressed before the potential of BAT in preventing and treating obesity can be assessed. Furthermore, it is important to find out to what degree sustained BAT thermogenesis is compensated by increased energy intake.

\section{Concluding remarks}

BAT in adult humans is back on the scientific agenda as a potential contributor to NST and may therefore play a role in the prevention of obesity. In this thesis we investigated several ways to stimulate BAT in humans. It can be concluded that cold exposure is the most effective BAT stimulator in humans, and there is substantial evidence from literature that BAT can be recruited upon cold acclimation. Systemic $\beta$ adrenergic stimulation appeared to be less effective, although more specific activation of the $\beta_{3} A R$ might be a viable way to stimulate BAT. In addition, we provided evidence for diet-induced BAT activity. Future studies need to investigate to what extent BAT is involved in facultative DIT, and if BAT is thus involved in energy balance regulation by wasting excessive caloric intake. The results from this thesis provide important information on ways to stimulate BAT in humans that opens new avenues to develop optimal (long-term) strategies to stimulate the thermogenic capacity of BAT and its link to health. 


\section{References}

1. Cannon B, and Nedergaard J. Metabolic consequences of the presence or absence of the thermogenic capacity of brown adipose tissue in mice (and probably in humans). Int J Obes (Lond). 2010;34(Suppl 1):S7-16.

2. Chechi K, Nedergaard J, and Richard D. Brown adipose tissue as an anti-obesity tissue in humans. Obes Rev. 2014;15(2):92-106.

3. van Marken Lichtenbelt WD, and Schrauwen P. Implications of nonshivering thermogenesis for energy balance regulation in humans. Am J Physiol Regul Integr Comp Physiol. 2011;301(2):R285-96.

4. Orava J, Nuutila P, Lidell ME, Oikonen V, Noponen T, Viljanen T, Scheinin M, Taittonen M, Niemi T, Enerback $S$, et al. Different metabolic responses of human brown adipose tissue to activation by cold and insulin. Cell Metab. 2011;14(2):272-9.

5. Ouellet V, Labbe SM, Blondin DP, Phoenix S, Guerin B, Haman F, Turcotte EE, Richard D, and Carpentier AC. Brown adipose tissue oxidative metabolism contributes to energy expenditure during acute cold exposure in humans. J Clin Invest. 2012;122(2):545-52.

6. Vijgen GH, Bouvy ND, Teule GJ, Brans B, Schrauwen P, and van Marken Lichtenbelt WD. Brown adipose tissue in morbidly obese subjects. PLoS One. 2011;6(2):e17247.

7. Yoneshiro T, Aita S, Matsushita M, Kameya T, Nakada K, Kawai Y, and Saito M. Brown adipose tissue, whole-body energy expenditure, and thermogenesis in healthy adult men. Obesity (Silver Spring). 2011;19(1):13-6.

8. van der Lans AAJJ, J. Hoeks, B. Brans, G.H.E.J. Vijgen, M.G.W. Visser, M.J. vosselman, J. Hansen, J. A. Jörgensen, J. Wu, F. Mottaghy, P. Schrauwen, W.D. van Marken Lichtenbelt. Cold acclimation recruits brown adipose tissue and increases non-shivering thermogenesis in humans. J Clin Invest. 2013;123(8):3395-403.

9. Muzik O, Mangner TJ, and Granneman JG. Assessment of oxidative metabolism in brown fat using PET imaging. Front Endocrinol (Lausanne). 2012;3:15.

10. van der Lans AA, Wierts R, Vosselman MJ, Schrauwen P, Brans B, and van Marken Lichtenbelt WD. ColdActivated Brown Adipose Tissue in Human Adults - Methodological Issues. Am J Physiol Regul Integr Comp Physiol. 2014.

11. Astrup A, Bulow J, Madsen J, and Christensen NJ. Contribution of BAT and skeletal muscle to thermogenesis induced by ephedrine in man. Am J Physiol. 1985;248(5 Pt 1):E507-15.

12. Wijers SL, Schrauwen $P$, Saris $W H$, and van Marken Lichtenbelt WD. Human skeletal muscle mitochondrial uncoupling is associated with cold induced adaptive thermogenesis. PLoS One. 2008;3(3):e1777.

13. Bal NC, Maurya SK, Sopariwala DH, Sahoo SK, Gupta SC, Shaikh SA, Pant M, Rowland LA, Bombardier E, Goonasekera SA, et al. Sarcolipin is a newly identified regulator of muscle-based thermogenesis in mammals. Nat Med. 2012;18(10):1575-9.

14. van Baak MA. Meal-induced activation of the sympathetic nervous system and its cardiovascular and thermogenic effects in man. Physiol Behav. 2008;94(2):178-86.

15. Sims EA, and Danforth E, Jr. Expenditure and storage of energy in man. J Clin Invest. 1987;79(4):1019-25.

16. Glick Z, Teague RJ, and Bray GA. Brown adipose tissue: thermic response increased by a single low protein, high carbohydrate meal. Science. 1981;213(4512):1125-7.

17. Glick Z, Teague RJ, Bray GA, and Lee M. Compositional and metabolic changes in brown adipose tissue following a single test meal. Metabolism. 1983;32(12):1146-50.

18. Glick Z, Bray GA, and Teague RJ. Effect of prandial glucose on brown fat thermogenesis in rats: possible implications for dietary obesity. J Nutr. 1984;114(2):286-91.

19. Glick Z, Wickler SJ, Stern JS, and Horwitz BA. Regional blood flow in rats after a single low-protein, highcarbohydrate test meal. Am J Physiol. 1984;247(1 Pt 2):R160-6.

20. Allard $\mathrm{M}$, and Leblanc J. Effects of cold acclimation, cold exposure, and palatability on postprandial thermogenesis in rats. Int J Obes. 1988;12(2):169-78. 


\section{GENERAL DISCUSSION}

21. Glick Z, and Raum WJ. Norepinephrine turnover in brown adipose tissue is stimulated by a single meal. Am J Physiol. 1986;251(1 Pt 2):R13-7.

22. Glick Z, Uncyk A, Lupien J, and Schmidt L. Meal associated changes in brown fat thermogenesis and glycogen. Physiol Behav. 1989;45(2):243-8.

23. Astrup AV, Christensen NJ, Simonsen L, and Bulow J. Effects of nutrient intake on sympathoadrenal activity and thermogenic mechanisms. J Neurosci Methods. 1990;34(1-3):187-92.

24. van Marken Lichtenbelt WD, Vanhommerig JW, Smulders NM, Drossaerts JM, Kemerink GJ, Bouvy ND, Schrauwen $\mathrm{P}$, and Teule GJ. Cold-activated brown adipose tissue in healthy men. $N$ Engl J Med. 2009;360(15):1500-8.

25. Vrieze A, Schopman JE, Admiraal WM, Soeters MR, Nieuwdorp M, Verberne HJ, and Holleman F. Fasting and postprandial activity of brown adipose tissue in healthy men. $J$ Nucl Med. 2012;53(9):1407-10.

26. Jensen MD, Johnson $\mathrm{CM}$, Cryer PE, and Murray MJ. Thermogenesis after a mixed meal: role of leg and splanchnic tissues in men and women. Am J Physiol. 1995;268(3 Pt 1):E433-8.

27. Brundin $T$, and Wahren J. Influence of a mixed meal on splanchnic and interscapular energy expenditure in humans. Am J Physiol. 1991;260(2 Pt 1):7.

28. Wijers SL, Saris WH, and van Marken Lichtenbelt WD. Individual thermogenic responses to mild cold and overfeeding are closely related. J Clin Endocrinol Metab. 2007;92(11):4299-305.

29. Lupien JR, Glick Z, Saito M, and Bray GA. Guanosine diphosphate binding to brown adipose tissue mitochondria is increased after single meal. Am J Physiol. 1985;249(6 Pt 2):R694-8.

30. Stock MJ. Gluttony and thermogenesis revisited. Int J Obes Relat Metab Disord. 1999;23(11):1105-17.

31. Bauwens M, Wierts R, van Royen B, Bucerius J, Backes W, Mottaghy F, and Brans B. Molecular imaging of brown adipose tissue in health and disease. Eur J Nucl Med Mol Imaging. 2014.

32. Rothwell NJ, and Stock MJ. A role for brown adipose tissue in diet-induced thermogenesis. Nature. 1979;281(5726):31-5.

33. Feldmann HM, Golozoubova V, Cannon B, and Nedergaard J. UCP1 ablation induces obesity and abolishes diet-induced thermogenesis in mice exempt from thermal stress by living at thermoneutrality. Cell Metab. 2009;9(2):203-9.

34. SchlogI M, Piaggi P, Thiyyagura P, Reiman EM, Chen K, Lutrin C, Krakoff J, and Thearle MS. Overfeeding over 24 hours does not activate brown adipose tissue in humans. J Clin Endocrinol Metab. 2013;98(12):E1956-60.

35. Nedergaard J, Bengtsson T, and Cannon B. Three years with adult human brown adipose tissue. Ann N $Y$ Acad Sci. 2010;1212:E20-36.

36. Cannon B, and Nedergaard J. Brown adipose tissue: function and physiological significance. Physiol Rev. 2004;84(1):277-359.

37. Bell C, Stob NR, and Seals DR. Thermogenic responsiveness to beta-adrenergic stimulation is augmented in exercising versus sedentary adults: role of oxidative stress. J Physiol. 2006;570(Pt 3):629-35.

38. Stob NR, Seals DR, Jorgen J, van Baak MA, Steig AJ, Lindstrom RC, Bikman BT, and Bell C. Increased thermogenic responsiveness to intravenous beta-adrenergic stimulation in habitually exercising humans is not related to skeletal muscle beta2-adrenergic receptor density. Exp Physiol. 2007;92(5):823-30.

39. Schiffelers SL, Blaak EE, Baarends EM, Van Baak MA, Saris WH, Wouters EF, and Schols AM. betaAdrenoceptor-mediated thermogenesis and lipolysis in patients with chronic obstructive pulmonary disease. Am J Physiol Endocrinol Metab. 2001;280(2):E357-64.

40. Cypess AM, Chen YC, Sze C, Wang K, English J, Chan O, Holman AR, Tal I, Palmer MR, Kolodny GM, et al. Cold but not sympathomimetics activates human brown adipose tissue in vivo. Proc Natl Acad Sci U S A. 2012;109(25):10001-5.

41. Carey AL, Formosa MF, Van Every B, Bertovic D, Eikelis N, Lambert GW, Kalff V, Duffy SJ, Cherk MH, and Kingwell BA. Ephedrine activates brown adipose tissue in lean but not obese humans. Diabetologia. 2013;56(1):147-55.

42. Sjostrom L, Schutz Y, Gudinchet F, Hegnell L, Pittet PG, and Jequier E. Epinephrine sensitivity with respect to metabolic rate and other variables in women. Am J Physiol. 1983;245(5 Pt 1):E431-42. 
43. Simonsen L, Bulow J, Madsen J, and Christensen NJ. Thermogenic response to epinephrine in the forearm and abdominal subcutaneous adipose tissue. Am J Physiol. 1992;263(5 Pt 1):E850-5.

44. Atgie C, D'Allaire F, and Bukowiecki LJ. Role of beta1- and beta3-adrenoceptors in the regulation of lipolysis and thermogenesis in rat brown adipocytes. Am J Physiol. 1997;273(4 Pt 1):C1136-42.

45. Dulloo A, Seydoux J, and Girardier L. Peripheral mechanisms of thermogenesis induced by ephedrine and caffeine in brown adipose tissue. Int J Obes (Lond). 1991;15(5):317-26.

46. Shimizu M, Blaak EE, Lonnqvist F, Gafvels ME, and Arner P. Agonist and antagonist properties of beta 3adrenoceptors in human omental and mouse 3T3-L1 adipocytes. Pharmacol Toxicol. 1996;78(4):254-63.

47. Virtanen KA, Lidell ME, Orava J, Heglind M, Westergren R, Niemi T, Taittonen M, Laine J, Savisto NJ, Enerback S, et al. Functional brown adipose tissue in healthy adults. N Engl J Med. 2009;360(15):151825.

48. Jockers R, Issad T, Zilberfarb V, de Coppet $P$, Marullo S, and Strosberg AD. Desensitization of the betaadrenergic response in human brown adipocytes. Endocrinology. 1998;139(6):2676-84.

49. Krief S, Lönnqvist F, Raimbault S, Baude B, Van Spronsen A, Arner P, Strosberg A, Ricquier D, and Emorine L. Tissue distribution of beta 3-adrenergic receptor mRNA in man. J Clin Invest. 1993;91(1):3449.

50. Yoshida T, Sakane N, Wakabayashi Y, Umekawa T, and Kondo M. Anti-obesity and anti-diabetic effects of CL 316,243, a highly specific beta 3-adrenoceptor agonist, in yellow KK mice. Life Sci. 1994;54(7):491-8.

51. Himms-Hagen J, Cui J, Danforth E, Jr., Taatjes DJ, Lang SS, Waters BL, and Claus TH. Effect of CL-316,243, a thermogenic beta 3-agonist, on energy balance and brown and white adipose tissues in rats. Am J Physiol. 1994;266(4 Pt 2):R1371-82.

52. Arbeeny CM, Meyers DS, Hillyer DE, and Bergquist KE. Metabolic alterations associated with the antidiabetic effect of beta 3-adrenergic receptor agonists in obese mice. Am J Physiol. 1995;268(4 Pt 1):E678-84.

53. Arch JR. The discovery of drugs for obesity, the metabolic effects of leptin and variable receptor pharmacology: perspectives from beta3-adrenoceptor agonists. Naunyn Schmiedebergs Arch Pharmacol. 2008;378(2):225-40.

54. van Baak MA, Hul GB, Toubro S, Astrup A, Gottesdiener KM, DeSmet M, and Saris WH. Acute effect of L796568, a novel beta 3-adrenergic receptor agonist, on energy expenditure in obese men. Clin Pharmacol Ther. 2002;71(4):272-9.

55. Larsen TM, Toubro S, van Baak MA, Gottesdiener KM, Larson P, Saris WH, and Astrup A. Effect of a 28-d treatment with L-796568, a novel beta(3)-adrenergic receptor agonist, on energy expenditure and body composition in obese men. Am J Clin Nutr. 2002;76(4):780-8.

56. Wijers SL, Schrauwen P, van Baak MA, Saris WH, and van Marken Lichtenbelt WD. Beta-adrenergic receptor blockade does not inhibit cold-induced thermogenesis in humans: possible involvement of brown adipose tissue. J Clin Endocrinol Metab. 2011;96(4):E598-605.

57. Soderlund V, Larsson SA, and Jacobsson H. Reduction of FDG uptake in brown adipose tissue in clinical patients by a single dose of propranolol. Eur J Nucl Med Mol Imaging. 2007;34(7):1018-22.

58. Parysow O, Mollerach AM, Jager V, Racioppi S, San Roman J, and Gerbaudo VH. Low-dose oral propranolol could reduce brown adipose tissue F-18 FDG uptake in patients undergoing PET scans. Clin Nucl Med. 2007;32(5):351-7.

59. Befroy DE, Petersen KF, Dufour S, Mason GF, Rothman DL, and Shulman GI. Increased substrate oxidation and mitochondrial uncoupling in skeletal muscle of endurance-trained individuals. Proc Natl Acad Sci U S A. 2008;105(43):16701-6.

60. Schiffelers SL, Saris WH, Boomsma F, and van Baak MA. beta(1)- and beta(2)-Adrenoceptor-mediated thermogenesis and lipid utilization in obese and lean men. J Clin Endocrinol Metab. 2001;86(5):2191-9.

61. Yoneshiro T, Aita S, Matsushita M, Kayahara T, Kameya T, Kawai Y, Iwanaga T, and Saito M. Recruited brown adipose tissue as an antiobesity agent in humans. J Clin Invest. 2013;123(8):3404-8.

62. Blondin DP, Labbe SM, Christian Tingelstad H, Noll C, Kunach M, Phoenix S, Guerin B, Turcotte EE, Carpentier AC, Richard D, et al. Increased brown adipose tissue oxidative capacity in cold-acclimated humans. J Clin Endocrinol Metab. 2014;99(3):E438-46. 


\section{GENERAL DISCUSSION}

63. Yoneshiro T, and Saito M. Transient receptor potential activated brown fat thermogenesis as a target of food ingredients for obesity management. Curr Opin Clin Nutr Metab Care. 2013;16(6):625-31.

64. Yoneshiro T, Aita S, Kawai Y, Iwanaga T, and Saito M. Nonpungent capsaicin analogs (capsinoids) increase energy expenditure through the activation of brown adipose tissue in humans. Am J Clin Nutr. 2012;95(4):845-50.

65. Sugita J, Yoneshiro T, Hatano T, Aita S, Ikemoto T, Uchiwa H, Iwanaga T, Kameya T, Kawai Y, and Saito M. Grains of paradise (Aframomum melegueta) extract activates brown adipose tissue and increases wholebody energy expenditure in men. Brit J Nutr. 2013;110(4):733-8.

66. López M, Varela L, Vázquez M, Rodríguez-Cuenca S, González C, Velagapudi V, Morgan D, Schoenmakers E, Agassandian K, Lage R, et al. Hypothalamic AMPK and fatty acid metabolism mediate thyroid regulation of energy balance. Nat Med. 2010;16(9):1001-8.

67. Whittle A, Relat-Pardo J, and Vidal-Puig A. Pharmacological strategies for targeting BAT thermogenesis. Trends Pharmacol Sci. 2013;34(6):347-55.

68. Broeders E, Bouvy N, and van Marken Lichtenbelt W. Endogenous ways to stimulate brown adipose tissue in humans. Ann Med. 2014. 
Summary

Samenvatting 


\section{Summary}

The number of people with overweight and obesity has dramatically increased in the last decennia. Obesity is a high risk factor for developing diseases such as type 2 diabetes, cardiovascular diseases, and certain forms of cancer. Obesity develops from an imbalance between energy intake and energy expenditure. Stimulating energy expenditure is thus a strategy to induce weight loss and to prevent and/or treat obesity. Brown adipose tissue (BAT) is known for its high capacity to increase energy expenditure upon cold, known as nonshivering thermogenesis (NST), making it an attractive target for weight reduction, or at least weight maintenance.

Until recently it was thought that only human neonates and babies had significant amounts of BAT. However, several studies in 2009 demonstrated that human adults still have functional BAT. By means of $\left[{ }^{18} \mathrm{~F}\right]$ fluorodeoxyglucose (FDG)-positron emission tomography (PET)/computed tomography (CT)-scanning it has been shown that BAT can be activated upon cold exposure and is positively associated with non-shivering thermogenesis (NST). Furthermore, it appears that overweight and obese people have lower BAT activity. BAT is also associated with increased thermogenesis after single meals and periods of overfeeding, known as diet-induced thermogenesis (DIT). Both NST and DIT are under control of the sympathetic nervous system (SNS). Stimulating the SNS and adrenergic receptors indeed increases BAT thermogenesis in rodents and is regarded as a possible route to induce weight loss. In this thesis we studied BAT during cold exposure, after feeding, and during $\beta$-AR stimulation. We related BAT activity with the increases in thermogenesis. Finally we examined the role of endurance training and extreme cold exposure on BAT in humans.

Much research on BAT has been conducted in rodents and little is known about human BAT. Therefore we compared the anatomy and morphology of rodent BAT with human BAT in chapter 2. Human BAT is found on different anatomical locations and is not present in distinct dense BAT depots as found in rodents, but more in islands of brown adipocytes residing within WAT. In addition to brown adipocytes, beige adipocytes are found in rodents as well. These beige fat cells are important in the recruitment of BAT. Recent studies have demonstrated the presence of beige adipocytes in adult humans as well. Next, chapter $\mathbf{2}$ summarizes the current human BAT activators and addresses the most promising routes to stimulate BAT in man, based on the latest rodent studies. At this moment, cold exposure is the most effective BAT stimulator, and high doses of the ephedrine (sympathomimetic drug) have been shown to moderately activate BAT in humans. Indirect evidence exists that activators of the transient receptor potential channels, such as capsaicin, might stimulate BAT thermogenesis. In the last part of chapter $\mathbf{2}$ it is explained that endurance exercise might be a way to stimulate BAT and browning of WAT in humans via the hormone irisin, as shown in rodents. Furthermore, natriuretic peptides induce browning in WAT from rodents and human multipotent adipose-derived stem cells. In humans, these 
peptides have been associated with stimulation of fatty acid oxidation and energy expenditure. Future human studies should therefore investigate their potential in stimulating BAT.

Animal studies have demonstrated that BAT is involved in regulating energy balance by burning excessive caloric intake, known as facultative DIT. Therefore we studied the role of BAT after a high calorie meal in eleven young adult male subjects (chapter 3). Both energy expenditure and BAT activity were measured after the intake of high calorie, carbohydrate-rich meal and cold exposure was used a positive control. It was shown that the postprandial uptake of $\left[{ }^{18} \mathrm{~F}\right] \mathrm{FDG}$ in supraclavicular BAT was higher than in WAT and the liver. Furthermore the uptake in BAT was also higher during thermoneutral fasting conditions. This provided a first indication that BAT is involved in burning excessive caloric intake in humans. However, we did not find a correlation between BAT and DIT, and BAT activity after the meal was still significantly lower than during cold exposure. The latter might be explained by the high $\left[{ }^{18} \mathrm{~F}\right] \mathrm{FDG}$ uptake in skeletal muscle leading to tracer dilution. The results legitimate additional research to the contribution of BAT to DIT upon overfeeding in humans.

Cold exposure and food intake activate the SNS, which in turn stimulates BAT thermogenesis in rodents. Upon sympathetic stimulation norepinephrine is released and acts on the adrenergic receptors on brown adipocytes. Whether human BAT can be stimulated via the adrenergic receptors has been studied in chapter 4 . We measured both energy expenditure and BAT activity during systemic infusion of the non-selective $\beta$-AR agonist isoprenaline and compared this to cold exposure in ten male subjects. Surprisingly, it was shown that isoprenaline did not activate BAT in nine out of ten subjects, whereas energy expenditure increased with $20 \%$. These results indicate that other tissues are likely involved in the $\beta$-AR-induced thermogenesis, such as skeletal muscle. It might be that ISO was not given in sufficient concentrations to activate the $\beta$-ARs. However, we were unable to give higher dosages due to the associated cardiovascular stress. Future studies should therefore investigate the possibilities to target BAT via central SNS stimulation and via more specific $\beta-A R$ agonists.

In addition to cold and $\beta$-adrenergic stimulation, other routes to stimulate BAT are proposed in literature such as endurance exercise (chapter 2). It has been demonstrated in rodents that endurance exercise stimulates classical BAT, although this has not been consistently found. The stimulating effects of endurance exercise are more pronounced on typical WAT depots. It has been demonstrated in mice that endurance exercise stimulates the release of the myokine irisin in plasma that leads to browning of WAT. In chapter $\mathbf{5}$, we investigated whether regular endurance exercise is associated with higher BAT activity and more browning of subcutaneous WAT. Twelve endurance-trained and sedentary lean males were included in the study and BAT activity was measured during cold exposure. In addition, a muscle and WAT biopsy were taken to analyse gene expression for FNDC5 in muscle, and several brown and 
beige adipocyte markers in adipose tissue. In muscle, we found that FNDC5 mRNA (precursor of irisin) was significantly higher in the endurance athletes. This thus demonstrates the stimulating effects of exercise on FNDC5 and likely irisin production by skeletal muscle in humans. Surprisingly, it was found that the endurance athletes had lower cold-induced BAT activity compared to the sedentary subjects, and no differences were found in mRNA expression for all brown and beige adipocyte markers in WAT. These findings thus indicate that regular endurance exercise does not stimulate BAT and browning in humans.

Finally, we investigated the effects of frequent extreme cold exposure on BAT activity by measuring the so-called 'Iceman' and his non-acclimated monozygotic twin brother (52 years old) in chapter 6. The Iceman holds multiple world records in withstanding extreme cold exposure, such as the longest duration while fully immersed in crushed ice (1 hour and 50 minutes). In this case study, it was demonstrated that both subjects had comparable BAT activity during mild cold, comparable to young adults, but rather high for their age, given that BAT activity decreases with age. Moreover, we did not find differences in cold-induced thermogenesis between the twin, but both had a very high thermogenesis compared to young adults. This high cold-induced thermogenesis was likely caused - in addition to BAT - by the g-Tummo like breathing technique used by both subjects involving isometric respiratory muscle contraction. Indeed, high FDG-uptake was found in these muscles. Thus in addition to heat production by BAT (NST), isometric contraction of skeletal muscle contributed to the very high cold-induced energy expenditure. Interestingly, there was a clear difference in the subjective response to cold exposure, as the Iceman reported the cold exposure as neutral and comfortable, whereas his twin brother found it relatively cold and uncomfortable. Given their comparable BAT activity, it might be that short exposures to extreme cold, as practiced by the Iceman, are less effective in BAT stimulation than mild longer periods of mild cold exposures. However, longitudinal studies with larger groups are needed to confirm this observation.

This thesis shows that cold exposure is the most effective BAT activator. Moreover, we found a positive relationship between BAT activity and NST. An important next step will be to quantify the capacity of BAT to increase thermogenesis. The finding that BAT is activated after a high-calorie meal is promising. Whether BAT is actively involved in wasting excessive caloric intake needs to be studied. Finally, the results from studies on BAT activators in animals are promising. These findings provide starting points in the search for BAT stimulating strategies in humans that might help to prevent and treat obesity. 


\section{Samenvatting}

Het aantal mensen met overgewicht en obesitas is sterk toegenomen in de laatste decennia. Obesitas vormt een risicofactor voor ziektes zoals type 2 diabetes, cardiovasculaire ziektes, en sommige vormen van kanker. Obesitas ontstaat door een verstoring in de energiebalans waarbij de inname van energie hoger is dan het gebruik. Het stimuleren van het energiegebruik is daarom een strategie om gewicht te verliezen en zou kunnen bijdragen aan het voorkomen en behandelen van obesitas. Een manier om het energiegebruik te stimuleren is via bruin vet. Bruin vet is in staat om warmte te produceren tijdens koude omstandigheden, de zogenaamde 'nonshivering thermogenesis' (NST) oftewel niet-rillende thermogenese. Deze capaciteit om warmte te produceren - door het verbranden van calorieën - maakt bruin vet een interessante kandidaat om gewicht te verliezen en/of gewichtsverlies te behouden.

Tot voor kort werd aangenomen dat bij de mens alleen baby's significante hoeveelheden bruin hebben. Echter, in 2009 is aangetoond dat ook volwassenen over functioneel bruin vet beschikken. Met behulp van $\left[{ }^{18} \mathrm{~F}\right]$ fluorodeoxyglucose positron emissie tomografie/computed tomografie (FDG-PET/CT)-scanning is aangetoond dat bruin vet geactiveerd kan worden wanneer mensen worden blootgesteld aan koude. Ook blijkt dat de mate van bruin vet activiteit is gerelateerd aan de stijging van warmteproductie in het lichaam tijdens koude. Daarnaast laten de resultaten zien dat proefpersonen met overgewicht minder bruin vet hebben dan slanke proefpersonen. Tijdens het onderzoekstraject, beschreven in deze thesis, hebben we gekeken naar de rol en activatie van bruin vet bij de mens. We hebben bruin vet activiteit gemeten na inname van voeding, en gedurende stimulatie van de $\beta$-adrenerge $(\beta-A R)$ receptoren. Beide condities hebben we vergeleken met bruin vet activiteit bij blootstelling aan milde koude (ongeveer $15^{\circ} \mathrm{C}$ ). Ook hebben we gekeken of mensen met meer bruin vet ook een hogere warmteproductie hebben. Daarnaast hebben we onderzocht of personen die aan duursport doen meer bruin vet hebben dan ongetrainde personen en hebben we gekeken wat het effect is van extreme koude blootstelling op bruin vet en warmteproductie in 'de Iceman'.

Tot nu toe is verreweg het meeste onderzoek naar bruin vet uitgevoerd bij dieren. Daarom hebben we in hoofdstuk 2 de anatomie en morfologie van bruin vet in knaagdieren vergeleken met dat in de mens. Bruin vet in de mens bevindt zich op andere anatomische locaties en heeft een andere structuur en dichtheid. Bij de mens komt bruin vet voor als eilandjes van bruin vetcellen tussen het witte vetweefsel. In knaagdieren kunnen naast bruine vetcellen, beige vetcellen worden onderscheiden. Deze laatste vetcellen zijn van belang bij vermeerdering van bruin vet. Recente studies hebben aangetoond dat ook de mens over zowel bruin als beige vet beschikt. Vervolgens wordt in hoofdstuk 2 een overzicht gegeven van de potentiele varianten om bruin vet te activeren in de mens, gebaseerd op recente studies in knaagdieren. Op dit moment is koude de meest succesvolle bruin vet activator. Daarnaast kan een hoge 
dosering efedrine (sympathicomimeticum) bruin vet activeren in de mens. Bovendien bestaat er indirect bewijs dat activators van transient receptor potential channels, zoals capsaïcine, thermogenese stimuleren door middel van bruin vet activatie. In het laatste deel van hoofdstuk 2 wordt uitgelegd dat duurtraining een mogelijke manier kan zijn om bruin vet en 'browning' (aanmaak van beige vet cellen in wit vet) te stimuleren in de mens via het hormoon irisine. Tenslotte wordt het stimulerende effect van natriuretische hormonen (ANP en BNP) op browning bij knaagdieren en op humane stamcellen verkregen uit vet (human multipotent adipose-derived stem cells) samengevat. Uit onderzoek in de mens blijkt dat deze hormonen gerelateerd zijn aan stimulatie van vetzuur oxidatie en energiegebruik. Toekomstige studies zouden daarom moeten onderzoeken wat de potentie van deze hormonen is in het stimuleren van bruin vet in de mens.

Dierstudies hebben aangetoond dat bruin vet betrokken is bij het reguleren van de energiebalans door middel van het verbranden van overtollige calorie inname. Dit proces staat bekend als dieet-geïnduceerde thermogenese. Om dit in de mens te onderzoeken hebben we bruin vet activiteit gemeten na inname van een calorierijke maaltijd in elf jongvolwassen mannen (hoofdstuk 3). Zowel het energiegebruik als bruin vet activiteit hebben we gemeten na inname van een calorierijke maaltijd met een hoog percentage aan koolhydraten, en tijdens blootstelling aan milde koude in gevaste toestand (positieve controle). De resultaten lieten zien dat na de maaltijd de opname van $\left[{ }^{18}\right.$ F]FDG in supraclaviculair bruin vet significant hoger was dan in wit vet en in de lever. Daarnaast bleek de opname in bruin vet ook significant hoger te zijn in vergelijking met de gevaste, thermoneutrale conditie. Deze studie geeft een eerste aanwijzing dat bruin vet betrokken is bij het verbranden van overtollige energie inname. Echter, we hebben geen relatie tussen de hoeveelheid bruin vet activiteit en de mate van dieet-geïnduceerde thermogenese gevonden. Daarnaast bleek de activiteit na voeding ook lager te zijn dan tijdens koude blootstelling. Dit laatste zou kunnen worden verklaard door de hoge opname van $\left[{ }^{18} \mathrm{~F}\right] \mathrm{FDG}$ in de skeletspier wat leidde tot verdunning van de tracer waardoor minder beschikbaar was voor het bruin vet (hoofdstuk 3). Deze resultaten geven aanknopingspunten tot vervolgonderzoek naar de bijdrage van bruin vet aan dieet-geïnduceerde thermogenese na overvoeding in de mens.

Bruin vet wordt geactiveerd via het sympathisch zenuwstelsel. Na sympathische stimulatie wordt noradrenaline vrijgemaakt door de zenuwuiteinden dat vervolgens de adrenerge receptoren op de bruin vet cellen prikkelt. In hoofdstuk $\mathbf{4}$ is gekeken of de stimulatie van de bèta-adrenerge receptoren ( $\beta-A R$ ) leidt tot activering van bruin vet in de mens. We hebben het energiegebruik en bruin vet activiteit gemeten tijdens de infusie van de non-selectieve $\beta$-AR-agonist isoprenaline, en tijdens koude blootstelling (positieve controle) in tien jongvolwassen mannen. Opvallend was dat isoprenaline bruin vet niet activeerde in 9 van de 10 proefpersonen terwijl het energiegebruik wel met $20 \%$ toenam. Deze resultaten tonen aan dat andere weefsels verantwoordelijk zijn 
voor deze toename, zoals bijvoorbeeld de skeletspier. Het is mogelijk dat de toegediende concentratie isoprenaline niet hoog genoeg was om de $\beta$-AR op bruin vet te activeren. Hogere concentraties zijn echter niet mogelijk vanwege het stimulerende effect op de hartslag. Toekomstige studies zouden daarom moeten kijken naar de mogelijkheden om BAT te activeren via het centrale zenuwstelsel of via meer specifieke $\beta$-AR agonisten.

Naast koude en $\beta$-AR stimulatie zijn er ook alternatieve routes om bruin vet te stimuleren, zoals beschreven in hoofdstuk 2 . In knaagdieren is aangetoond dat duurtraining (klassiek) bruin vet stimuleert, dit is echter niet in alle studies gevonden. De stimulerende effecten van duurtraining op bruin vet waren voornamelijk zichtbaar in de vorm van browning van de typische wit vet depots. Een studie in muizen heeft laten zien dat duurtraining de aanmaak van beige vet stimuleerde via het hormoon irisine. In hoofdstuk $\mathbf{5}$ hebben we onderzocht of regelmatige duurtraining is geassocieerd met een hogere bruin vet activiteit en meer 'browning' van onderhuids wit vetweefsel in de mens. In deze studie hebben we bruin vet gemeten in twaalf getrainde en twaalf ongetrainde jongvolwassenen tijdens blootstelling aan kou. Daarnaast hebben we zowel een stukje spier als wit vet afgenomen. In de spier hebben we de genexpressie bepaald voor FNDC5, wat de voorloper (precursor) van het hormoon irisine is. In het wit vetweefsel hebben we gekeken naar de genexpressie van verschillende markers die de mate van browning aantonen. De resultaten lieten zien dat de atleten inderdaad een verhoogde FNDC5 mRNA expressie hadden in de spier en dus mogelijk een verhoogde aanmaak van irisine. Verassend genoeg was de hoeveelheid koude-geïnduceerd bruin vet in de atleten significant lager ten opzichte van de ongetrainde mannen. Bovendien was er geen verschil in de genexpressie van de onderzochte markers voor browning in het witte vetweefsel. Deze resultaten laten indirect zien dat regelmatige duurtraining bruin vet en browning niet stimuleren.

Ten slotte hebben we in hoofdstuk 6 gekeken naar de effecten van frequente blootstelling aan extreme koude bij de zogenaamde 'Iceman' en zijn eeneiige tweelingbroer (52 jaar). De Iceman heeft verschillende wereldrecords in het doorstaan van extreem koude omstandigheden, zoals een verblijf van 1 uur en 50 minuten in een bak met schaafijs ('crushed'-ice). Zijn tweelingbroer ondergaat deze extreme koude blootstelling niet. Uit de case studie bleek dat de tweelingbroers eenzelfde hoeveelheid actief bruin vet hadden tijdens milde koude en dat er geen verschil in warmteproductie was tussen hen. Ze hadden een vergelijkbare hoeveelheid bruin vet als jongvolwassenen, wat hoog is voor hun leeftijd, aangezien bruin vet activiteit afneemt met de leeftijd. Opvallend was hun zeer hoge stijging in warmteproductie, welke hoger was dan in jongvolwassenen. Deze zeer hoge warmteproductie werd hoogstwaarschijnlijk bereikt door - naast bruin vet activiteit - een g-Tummo-achtige ademhaling door beiden. Deze manier van ademhaling bestaat uit krachtige isometrische contractie van de ademhalingsspieren. De bijdrage van de ademhalingsspieren aan de warmteproductie werd bevestigd door de verhoogde 
$\left[{ }^{18}\right.$ F]FDG opname in deze spieren. Er bleek wel een duidelijk verschil in perceptie van koude tussen de tweeling. De Iceman ervoer de koude als neutraal en comfortabel terwijl zijn tweelingbroer het koud en oncomfortabel vond. Gezien de gelijke hoeveelheid bruin vet in de tweelingbroers, is het mogelijk dat frequente, kortere periodes van blootstelling aan extreme koude minder effectief zijn in de stimulatie van bruin vet dan blootstelling aan langere periodes van milde koude. Echter, longitudinale studies met grotere groepen zijn nodig om dit te kunnen bevestigen.

De resultaten uit deze thesis bevestigen dat koude de meest effectieve strategie is om bruin vet te activeren. Daarnaast bestaat er een positieve relatie tussen bruin vet en warmteproductie in de mens. Een zeer interessante bevinding van deze thesis is dat bruin vet actief is na inname van een calorierijke maaltijd. Of bruin vet daadwerkelijk een belangrijke rol speelt in de verbranding van overtollige calorie-inname is een belangrijke vraag voor toekomstig onderzoek. Tenslotte bieden de verschillende bruin vet activators in knaagdieren veel perspectief in de zoektocht naar strategieën om bruin vet in de mens te stimuleren en mogelijk overgewicht en obesitas te kunnen voorkomen en te behandelen. 


\section{Valorisation}




\section{Social relevance - obesity epidemic}

Currently, the world is facing an alarming increase of obesity prevalence, which extents to developing countries and obesity is thus not longer regarded as a typical Western disease. Obesity prevalence has nearly doubled since 1980, and in 2008 more than 1.4 billion adults were overweight of whom 200 million men and 300 million women were obese. Strikingly, more than 40 million children under the age of five are obese. In the Netherlands, $48.5 \%$ of the people (19 years and older) are overweight and $12.7 \%$ are obese. The future perspectives on the development of obesity are disturbing since it is predicted that obesity prevalence will increase with $33 \%$ (in the United States) in the next two decades. This is an alarming trend as obesity is related to metabolic diseases such as type 2 diabetes, cardiovascular diseases, and certain forms of cancer. Furthermore, this will further hinder efforts for healthcare cost containment. Therefore, strategies are warranted to counteract this global obesity epidemic. The overall aim of brown adipose tissue (BAT) research is to explore its role in the development, prevention, and treatment of obesity. This thesis investigated possible strategies to activate BAT in humans and examine its role in energy expenditure.

\section{Scientific background - development of obesity}

Obesity develops as a consequence of a positive energy balance in which energy intake exceeds energy expenditure. To restore and/or maintain a healthy energy balance, one could reduce energy intake or increase energy expenditure. Reduction of energy intake by diet is one of the most studied interventions, however this type of intervention has a high relapse rate and people thus often cannot maintain their initial weight loss. On the other hand, stimulating energy expenditure could be a plausible alternative to restore a healthy energy balance. Physical activity or exercise is one of the most used strategies to induce weight loss by increasing energy expenditure. Again, even though exercise promotes healthier outcomes in relation to the metabolic syndrome, people often have difficulties maintaining regular exercise regimes and its role on weight loss is therefore limited. Moreover, in certain circumstances people are not able to perform physical exercise. Finding alternative strategies to increase energy expenditure are therefore important. Notably, even slight increases in energy expenditure can have effects on energy balance in the long run. One way to increase energy expenditure is cold exposure. Slight reductions in ambient temperature can already increase energy expenditure with 5-30\% in humans without inducing shivering. An important tissue in mediating this is BAT.

In small mammals, BAT is the most important organ to maintain body temperature, and moreover, it has been suggested that it is directly involved in energy balance regulation. Interestingly, mice without BAT tend to become obese. The recent 
observations that BAT is still present in considerable amounts in humans, has driven human BAT research in the last 5 years. Findings thus far demonstrate that there is a negative relationship between BAT and adiposity, indicating overweight and obese people to have less active BAT. Thus BAT might play a role in weight regulation in humans as well. In this thesis we explored whether human BAT is involved in burning excessive caloric intake. The other goal was to find ways to activate BAT in humans and explore its relationship with energy expenditure. There is now strong evidence that BAT contributes to cold-induced energy expenditure, as confirmed in the present thesis. Therefore, BAT might have potential in targeting the current obesity problem, and therefore more research in humans is required.

\section{Target groups}

Finding strategies to prevent and treat obesity are crucial given the development of associated metabolic diseases affecting millions of people worldwide leading to exploding healthcare costs. Therefore, the search for novel strategies to counteract obesity is important for the general public, especially for people that have an increased risk in developing overweight and obesity. Stimulating energy expenditure by activating and recruitment of BAT could be one such strategy.

In order to tackle overweight and obesity, health institutions, health care professionals, and general society need to be informed about possible strategies. Translation of scientific knowledge to society is therefore essential. In this thesis we clearly demonstrate that cold exposure increases energy expenditure and BAT activity. This activation of BAT thermogenesis occurs at relatively low temperatures when shivering is absent. Recent research demonstrates that mild reductions in temperature can already activate BAT. This means that lowering ambient temperature in houses and offices might be one way to burn calories. Clearly, more research is needed to generate conclusive results about the potential of this intervention in stimulating weight loss. Nevertheless, in order to stimulate the translation of science to society and obtain awareness and support from the general public, communicating these observations outside science is important.

Next to this behavioural intervention to target overweight and obesity, pharmaceutical interventions stimulating energy expenditure and BAT activity are important. Targeting BAT via pharmaceutical agents requires a good understanding of BAT physiology and the molecular pathways that lead to BAT stimulation. Human BAT research is therefore essential, as well as a good collaboration between universities and the pharmaceutical industry. This thesis contributes to a better understanding of human BAT physiology and strategies to pharmaceutically target human BAT. 


\section{Activities and products}

All research described in this thesis has been conducted at the department of Human Biology in collaboration with Nuclear Medicine of Maastricht University Medical Center+. This collaboration between the University and a hospital is a good example of how basic science can be performed in a hospital setting, combining knowledge of scientists and medical specialists. This collaboration is essential given that the current technique to measure human BAT requires the knowledge of nuclear medical specialists. BAT is currently measured by means of $\left[{ }^{18} \mathrm{~F}\right]$ fluorodeoxyglucose-positron emission tomography-computed tomography ([ $\left.{ }^{18} \mathrm{~F}\right]$ FDG-PET-CT)-scanning. In order to increase the knowledge on human BAT, good collaboration between hospital and university setting is essential.

In order to use BAT as a possible treatment for overweight and obesity, more extensive knowledge is required. The present findings do indicate that the most effective way to activate BAT in humans is by exposure to mild cold. As explained previously, reduction of ambient temperature in houses and offices is therefore a strategy to increase energy expenditure via BAT. With respect to the pharmaceutical approach, this thesis clearly demonstrated that systemic, non-selective adrenergic stimulation of BAT is ineffective in humans. Furthermore, the associated cardiovascular stress (i.e. increased heart rate and systolic blood pressure) is problematic using these types of stimulants. Therefore, future studies should investigate more selective $B-A R$ agonists that could target BAT, such as the $\beta_{3}-A R$, without causing these side effects. Moreover, non-adrenergic agents and agents that are able to stimulate BAT centrally (i.e. via the brain) instead of systemically (i.e. via the blood) might be more effective. Recent studies in rodents indicate the potential ways to stimulate this tissue and should be investigated in humans.

The results described in this thesis are written in original articles that have been published or submitted to scientific journals in the field of obesity and diabetes. Moreover, these articles can be found online and are accessible to scientists who are interested in this topic. In addition to this, results have been presented on international conferences and some have been published in a national newspaper. The present results help to understand BAT physiology in humans and can be used for future studies on exploring strategies to stimulate BAT in humans.

\section{Innovation}

The work described in this thesis is mostly new in the field of BAT research. Prof. dr. W.D. van Marken Lichtenbelt was among the first researchers to rediscover BAT in human adults in 2009, and more BAT researchers joined his group from then onwards. 
This thesis confirms the experiments in 2009 showing that cold exposure is an effective strategy to activate human BAT. The innovative part of this thesis was to explore other strategies to activate human BAT. The experiment on B-AR stimulation of BAT in humans was the first to investigate a possible role for BAT in the well-known adrenergic stimulation of thermogenesis. Furthermore, it was the first to explore the role of the sympathetic nervous system and the adrenergic receptors in stimulating human BAT in vivo.

Moreover, in this thesis we explored whether human BAT is involved in weight regulation by burning excessive caloric intake. That BAT could play a role in weight regulation has been demonstrated in animals. In this thesis it appeared that BAT was indeed activated upon a single high calorie meal, although no direct relationship between postprandial BAT activity and diet-induced thermogenesis was found. These findings suggest that BAT might be activated after excessive food intake, but whether it actively burns calories and to what extent remains to be found out. Clearly, more evidence is needed to confirm whether BAT can burn excessive caloric intake.

Animal studies have provided several strategies to recruit BAT in white adipose tissue, as explained in chapter 2 . We here tested one of these promising strategies in humans, namely endurance exercise. The finding in mice that endurance exercise can recruit BAT via the hormone irisin was not confirmed in human adults. Regular endurance training was not associated with increased browning of white adipose tissue and seems to result in even less BAT activity.

\section{Planning and realization}

In this thesis we measured BAT activity in humans during several interventions by means of $\left[{ }^{18} \mathrm{~F}\right]$ FDG-PET-CT-scanning. We have clearly demonstrated that cold exposure is the most effective way to activate BAT in humans. Recently our lab has demonstrated that BAT can also be recruited upon longer periods of cold exposure in healthy human adults with a concomitant increase in the capacity for nonshivering thermogenesis. This effect of cold acclimatization on BAT and nonshivering thermogenesis is now being explored in obese and type 2 diabetic people by the research team of Prof. dr. W.D. van Marken Lichtenbelt. As explained before, finding alternative ways to activate and recruit human BAT are important. Currently the effects of bile acids on human BAT are being conducted at the department of Human Biology and Nuclear Medicine. Another important step will be to further explore the role of BAT during situations of overfeeding.

From a methodological point of view, it will be important to find alternatives to $\left[{ }^{18}\right.$ F]FDG-PET-CT-scanning for BAT measurement in the future. First, because it is a very expensive technique, and second, it is associated with a radioactive burden for the study participants, which also limits the amount of scans that can be used per subject. 


\section{VALORISATION}

For longitudinal studies on human BAT, it will be important to find less invasive methods. Another important aspect is that $\left[{ }^{18}\right.$ F]FDG-PET-CT solely measures glucose uptake and not oxidative metabolism in BAT. An important future step is to gain more knowledge about the heat producing capacity of BAT during several conditions of stimulation. Therefore measuring oxidative metabolism in BAT will be important. Such a measurement provides more information to what extent full BAT activation can contribute to total daily metabolism and ultimately weight loss.

Finally, future research should also examine the effects of long term BAT stimulation on energy balance and measure whether or not the human body adapts to this continuous stimulation of energy expenditure, for instance by increase energy intake. 
Dankwoord 
Het is september 2014 en ik realiseer me dat ik nu echt ga promoveren. Dr. Vosselman, wie had dat gedacht. In ieder geval tijdens mijn middelbare school niemand, inclusief mijzelf, maar goed, een mens kan veranderen. Toen ik in 2009 aan mijn PhD begon zat ik geregeld met de handen in het haar tijdens het lezen van die moleculaire bruin vet artikelen. "Hoe gaat mij dit in hemelsnaam lukken?" Gedurende de vier jaar kwam ik er wel achter dat er een flinke leercurve in een PhD traject zit. Gelukkig maar... In deze vier jaar heb ik ontzettend veel geleerd van mijn collega's. Uiteindelijk schrijf je zelf het proefschrift, maar al het werk dat is verzet tijdens de afgelopen vier jaar is onmogelijk in je eentje te volbrengen. Het is dan ook de samenwerking binnen onze onderzoeksgroep die ik zo heb gewaardeerd. Bedankt daarvoor!

Wouter, ik had me geen betere supervisor kunnen wensen. Jouw passie, betrokkenheid en humor hebben de vier jaar echt glans gegeven. De deur stond altijd open en je gaf bovendien veel ruimte voor zelfstandigheid. Zo af en toe gaf je weer een zetje in de goede richting als ik wat aan het zwemmen was. Naast het creëren van een goede werksfeer zorgde je ook voor genoeg sociaal vertier. De vele zeiltochtjes over de maas verkleed in piraten outfit en de aansluitende etentjes bij jou, Anne, en Merel thuis waren altijd fantastisch. Voor deze hartelijke ontvangst en heerlijke etentjes wil ik Anne natuurlijk ook hartelijk bedanken! Het weekendje London met onze Thermugroep in een hok van $12 \mathrm{~m}^{2}$ liet wel blijken dat we allemaal goed door één deur konden. Ik vind het geweldig dat je nu professor bent geworden, want dat heb je zeker verdiend. Ga vooral zo door als begeleider en ik hoop dat er nog vele mooie bruin vet onderzoeken zullen plaatsvinden!

Patrick, ook met jou was het prettig samenwerken. Jouw gedrevenheid en daadkracht werkte zeer aanstekelijk. Bedankt voor de hulp bij het schrijven van de manuscripten. Ik verbaasde mij iedere keer weer hoe ontzettend snel je een heel manuscript had verbeterd. Heb daar veel van geleerd, met name ook dat je af en toe gewoon moet doorpakken en niet te lang moet blijven treuzelen over een paar zinnen. Sorry nog dat de jonge garde de HB tourpool wat heeft laten verwateren. Ik geloof dat de uitreiking nog steeds moet plaatsvinden van het jaar 2013. Dacht dat jij ook net toevallig winnaar was dat jaar ;-)

Marleen, bedankt voor de hulp tijdens het uitvoeren van mijn meest spannende experiment. Het monitoren van het hart met een ECG, na het toedienen van een stofje dat het hart op hol doet slaan was wel even wat anders dan iemand twee uur in de kou zetten. Fijn dat jij in de gaten hield of ik niet een nanomolletje teveel gaf!

Kamer 2.318! Wat een tijd. Eén om nooit te vergeten, want Boris, Erik, wat waren we een top team. Boris, tja, waar moet ik beginnen. Denk dat we teveel hebben mee- 
gemaakt om hier te beschrijven, maar kort samengevat: brand, balletje-balletje, bier, honden, London-baby, Iceman, fietsraces, bubbelbad, ongeluk-met-bril, kerstboom, champagne, risk, borsjt, 16, Valkenburg, Oktoberfest-proost-tand-uit-de-mond, SBF, het 'nieuwe werken', Mappista, Intimate... waarschijnlijk vergeet ik nu nog de helft. Papa Boris, we blijven elkaar sowieso nog zien, maar veel geluk met Eva en Lisa, en op naar prof. Kingma! Erik, Knaller, hetzelfde geldt voor jou, teveel gebeurtenissen om op te schrijven: balletje-balletje, SBF, geluidsoverlast, handstand-push-up, stikstofbom(metje), google-translate, Istanbul, A-A-A-Afrika, Qlimax, zzzzzzzzz, where is it?, eueueue, dialect, mossels, vrijgezellenfeest, boomstammen slepen, bruiloft, Tabatalangs-de-drukke-autobaan-in-Istanbul... Ook jij bent inmiddels Papa! Ik zie een trend met één outlier in 2.318. Ook wij zien elkaar nog geregeld, maar wil je ook bedanken voor de gave tijd en wens je veel geluk met Anna en Emilie en succes met het afronden van het proefschrift!

Guy, jij bent eigenlijk degene die me heeft overtuigd om bruin vet onderzoek te doen. Nadat jij me had laten zien hoe zo'n bruin vet experiment er aan toe ging kon ik geen nee meer zeggen ;-). Ook met jou heb ik geweldige dingen meegemaakt. Om maar in dezelfde stijl door te gaan: the Butcher, bluf, Oroboros-tripje, Londen, roltrap, Stockholm, dr. Muzaffer Kushan a.k.a. dr. Death, I'm with blue, living the life, schoenen, alles-is-mogelijk, 150m, party-on, Groningen-net-doen-alsof-we-niet-tebrak-waren-voor-de-Iceman-presentatie, lantaarnpaaltje Ceramique, dat-kanmakkelijk! Naast deze dolle pret, wil ik je ook bedanken voor de hulp tijdens de experimenten en biopten die je hebt uitgevoerd. Dat je een top-chirurg gaat worden staat vast. Blijf vooral wie je bent en we zullen elkaar nog vaak genoeg ontmoeten en deze herinneringen ophalen. Veel geluk met Maartje in Rotterdam!

Anouk, wij hebben denk ik de helft van mijn experimenten samen uitgevoerd en ik kan me niet anders herinneren dan dat we een top combi waren! Het voelde soms ook alsof we samen deze PhD aan het doen waren. Als ik wat vergeten was, zorgde jouw planning kwaliteiten ervoor dat het alsnog goed kwam. Wij hebben ook ontzettend veel beleefd samen en zijn alle congressen samen afgegaan. Kers op de taart was natuurlijk onze Kopenhagen trip! Wat een luxe als PhD studentjes;-). Om New York niet te vergeten.. dat was eigenlijk nog gekker! Ik waardeer je collegialiteit enorm en hoop dat je een leuke vervolgstap kan maken in je carrière. Daarnaast ook veel geluk samen met Pieter-Jan, want o wat een vrolijkheid sinds je hem leerde kennen $(\dot{)}$.

Mark, het was ook zeer fijn om samen met jou te werken. Je bent de relaxedheid zelve, en was nooit te beroerd om een collega te helpen. Super! Als je die relaxedheid nou ook eens toepaste op de potjes Ruzzle, dan kan ik ook eens winnen! Veel succes nog met het afronden van de laatste experimenten! Christel, ook jij bedankt voor de collegialiteit en heel veel succes bij het CTCM! Evie, jij zorgde voor een beetje power in 
onze groep en bent een echte aanpakker. Je hebt een mooi doel voor ogen en met jouw gedrevenheid gaat dat zeker lukken! Het laatste jaar op 2.318 was heel gezellig met jou erbij. Je hebt je kranig geweerd tussen die bommen testosteron. Lisje, ook jij bracht wat extra pit in de groep! Je bent een aardige flap-uit en ik heb me goed vermaakt het laatste half jaar met jou op de kamer. Van de onzinnige roddels tot de moeilijkere en serieuze gesprekken des levens, ze waren altijd prettig. Hannah, jij hebt de kneepjes van het bruin vet vak geleerd bij me en blijkbaar vond je het zo boeiend dat je besloot om een PhD te doen ;-). Je was een fijne collega! Sorry nog voor die keren dat ik chagrijnig was's morgens om 7 uur en dat ik je verjaardag was vergeten. Veel succes nog en maak er wat moois van! Reni, ook jij bedankt voor de hulp tijdens mijn laatste experimenten! Je was ook zeer behulpzaam en hebt me het nodige werk uit handen genomen. Ook al mijn mannelijke proefpersonen waren onder de indruk van jullie ;-). Marije, ik heb je maar eventjes meegemaakt als collega, maar ik wil je ook veel succes wensen met je PhD. Je zult het vast goed kunnen vinden in de groep. Joris, dank je wel voor de prettige samenwerking tijdens ons onderzoek bij de duuratleten! Hebben we toch mooi volbracht met die topsporters.

Bram, met jou heb ik ook veel beleefd. Al die avonden brainstormen met Boris over hoe we de wereld van appjes konden veroveren waren geweldig. Daarnaast hebben we de nodige HB stapavonden samen afgesloten. Een hoop gekkigheid meegemaakt, wat soms iets doorsloeg door dat laatste biertje;-). We zullen zeker en vast nog wel wat stapavondjes meemaken in de toekomst. Jij succes met de laatste loodjes! Masper, Guy, jullie ook bedankt Duitse en Belgische gezelligheid! Misschien is het Oktoberfest 2015 een goed moment om een reünie te houden. Jos, de sociale gangmaker van $\mathrm{HB}$, dank voor het organiseren van de leuke activiteiten! Ook al heb ik (te) vaak gepast door mijn voetbal-ambitie, het was zeker gezellig! Goed dat jij begrijpt dat je pas een goed team hebt als je ook naast werktijd met elkaar kan opschieten. Silvie, Esther, Lena, bedankt voor het verhogen van het "partygehalte" op de HB feesten! Verder wil ik alle andere collega's van HB bedanken voor de leuke tijd!

Wat betreft het uitvoeren van mijn experimenten was de hulp van Nucleaire Geneeskunde ontzettend belangrijk. Professor Mottaghy bedankt hiervoor. Boudewijn, bedankt voor de tips en hulp bij het uitvoeren van mijn studies. Het was prettig om jou als arts te hebben, want er kan altijd iets gebeuren bij humaan onderzoek! We hebben aardig wat uurtjes samen doorgebracht achter de PMOD computer en naast de serieuze bruin vet discussies was een lolletje ook zeer gebruikelijk. Veel succes nog en ik hoop dat de samenwerking met Wouter nog vele jaren zo door mag gaan. Roel, bedankt voor de technische tips! Als PMOD weer eens niet deed wat ik wilde, had jij de oplossing. Bedankt. Mariëlle, Emiel, dank voor alle moeite die jullie hebben gestoken om mijn onderzoek goed te laten verlopen! Matthias en Jan bedankt voor de ideeën tijdens Thernu! Ivo, dank je wel voor het afdraaien van die bloedbuizen! Daarnaast wil 
ik graag Christian, Kyra, Cristel, Denise, Renée, Lotte, Roy, Serve, Florence bedanken voor de Dexa-scans, PET-CT scans, en infuusjes. Het was altijd prettig met jullie samenwerken! Cindy, Martine, en Marie-Louise, dank voor het inplannen van die tientallen scans en de vrolijke ontvangst bij de balie!

Verder wil ik Wendy, Hasibe, Esther, Gert en Johanna bedanken voor de hulp bij het analyseren van de vele samples en biopten. Loek, Paul, Laurens, bedankt voor alle technische assistentie.

Desirée, Claudia, Yolanda, dank voor de altijd vrolijke ontvangst op het secretariaat. Als ik het even niet zag zitten tussen de papers en data, dan kon ik altijd even komen buurten en een paaseitje of pepernootje komen eten... Daarnaast is jullie behulpzaamheid echt fantastisch!

Defence committee: Thank you for reviewing my thesis and for your presence at my official dissertation.

Het allerbelangrijkste van het onderzoek blijft natuurlijk de proefpersonen. ledereen die heeft meegedaan aan mijn experimenten, waaronder ook veel vrienden, hartelijk dank! Ik hoop dat jullie nog een beetje koude training blijven doen om het bruin vet te stimuleren.

$\mathrm{Pa}, \mathrm{Ma}$, Frank, bedankt dat ik mijn carrière bij jullie mag voortzetten in het prachtige bedrijf. Ondanks dat deze doctorsgraad niet helemaal noodzakelijk was voor de sollicitatie hoop ik toch dat mijn onderzoekservaring nog wat extra's kan brengen (-).

Sanne, lief, jij hebt natuurlijk alle stress van mij moeten doorstaan de afgelopen jaren. Dank voor je begrip. Denk dat het alleen nog maar erger zal worden in het ondernemers-vak, dus ik hoop dat je het tot nog toe een eitje vond ;-). 



\section{Curriculum Vitae}



Maarten Vosselman was born on the $6^{\text {th }}$ of December in Epe, the Netherlands. He finished his secondary school at de RSG Springborn in Epe in 2002, and moved to Maastricht to study Health Sciences in 2003. After he received his Bachelor degree in 2007, he continued with the Master Physical Activity \& Health at Maastricht University. During this year he completed an internship focusing on human thermoregulation at Wollongong University in Australia. After he obtained his Masters degree in 2009, he started a PhD under supervision of prof. dr. W.D. van Marken Lichtenbelt and prof. dr. L.P.A.Y. Schrauwen at the department of Human Biology in Maastricht. During his PhD he focused on human brown adipose tissue and studied several strategies to activate brown adipose tissue in humans as demonstrated in the present dissertation and the numerous publications in scientific journals. In 2014, he decided to join the family company De Bolster B.V. in Epe, which is a seed company specialized in organic seed production and breeding. 



\section{List of publications}




\section{Published papers}

Machado-Moreira CA, Barry RJ, Vosselman MJ, Ruest RM, Taylor NA. Temporal and thermal variations in site-specific thermoregulatory sudomotor thresholds: Precursor versus discharged sweat production. Psychophysiology. 2014; epub ahead of print.

Vosselman MJ, Vijgen GEHJ, Kingma BRM, van Marken Lichtenbelt WD. The effect of frequent extreme cold exposures on brown fat and cold-induced thermogenesis: a study in a monozygotic twin. PLOS One. 2014;9:e101653.

van der Lans AAJJ, Wierts R, Vosselman MJ, Schrauwen P, Brans B, van Marken Lichtenbelt WD. Cold-activated brown adipose tissue in human adults methodological issues. Am J Physiol Regul Integr Comp Physiol. 2014; epub ahead of print.

van der Lans AAJJ, Hoeks J, B Brans, Vijgen GH, Visser MG, Vosselman MJ, Hansen J, Jorgensen JA, Wu J, Mottaghy FM, Schrauwen P, van Marken Lichtenebelt WD. Cold acclimation recruits human brown fat and increase nonshivering thermogenesis. $J$ Clin Invest. 2013;123:3395-3403.

Vosselman MJ, Brans B, van der Lans AAJJ, Wierts R, Mottaghy, F, van Baak MA, Schrauwen $P$, Lichtenbelt WD. Brown adipose tissue activity after a high-caloric meal in humans. Am J Clin Nutr. 2013;98:57-64

Vosselman MJ, van Marken Lichtenbelt WD, Schrauwen P. Energy dissipation in brown adipose tissue: from mice to men. Mol Cell Endocrinol. 2013;379:43-50.

Kingma BR, Vosselman MJ, Frijns AJ, van Steenhoven AA, van Marken Lichtenbelt WD. Incorporating neurophysiological concepts in mathematical thermoregulation models. Int J Biometeorol. 2013;58:87-99.

Vosselman MJ, van der Lans AAJJ, Brans B, Wierts R, van Baak MA, Schrauwen $P$, van Marken Lichtenbelt WD. Systemic $\beta$-Adrenergic Stimulation of Thermogenesis Is Not Accompanied by Brown Adipose Tissue Activity in Humans. Diabetes 2012; Dec;61:3106-13. 


\section{Submitted papers}

Schrauwen P, Broeders, EPM, van der Lans, AAJJ, Hansen M, Vosselman MJ, van Marken Lichtenbelt WD. Serum FGF21 levels are associated with brown adipose tissue activity in humans. Submitted.

Vosselman MJ, Hoeks J, Brans B, Pallubinsky H, Nascimento EBM, van der Lans AAJJ, Broeders EPM, Mottaghy FM, Schrauwen P, van Marken Lichtenbelt WD. Reduced brown adipose tissue activity in endurance trained compared to lean sedentary men. Submitted. 


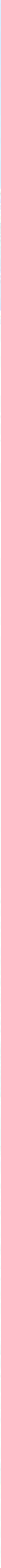

